\title{
THE PURCHASE DECISION-MAKING PROCESS FOR RENEWABLE HEATING TECHNOLOGIES: \\ A CONSUMER PERSPECTIVE
}

\author{
MARIO REICHLER \\ A thesis submitted to The University of Gloucestershire \\ in accordance with the requirements of the degree of \\ Doctor of Business Administration \\ in the School of Business and Technology
}

October 2019 


\begin{abstract}
The discussion about energy has become an important topic in recent years. For end users, issues, such as price increases for oil and gas, limited resources, and alternative energy sources, have become increasingly important, attracting the attention of scholars and politicians alike. Political discussions on energy issues form part of the daily news. For example, pollution of the environment with carbon dioxide $\left(\mathrm{CO}_{2}\right)$ and global warming due to the greenhouse effect have become hot topics for debate. Considering the growing importance of renewable energy for households, this investigation focuses on the factors that drive homeowners to purchase renewable energy technologies, as well as on the implications of these factors on the design of future business-to-consumer (B2C) marketing models that can contribute towards an increase in the use of renewable energy. Contextually, the research is based on heating consumption in German households.
\end{abstract}

This thesis examines the potential purchase of existing renewable energy technologies by end users in the German housing market. The increased use of renewable energy is not studied with a view towards future technologies, but rather in terms of the decisionmaking process of end users to possibly invest in already available renewable heating technologies. Decision-making processes are seen as discrete activities which involve individuals over a period of time. These processes include selection and implementation, and have an end point (Wilson, 2004).

Based on a grounded research methodology, a series of interviews have been carried out with homeowners as decision-makers for the purchase of existing renewable energy heating systems. The interviewees are homeowners who live in old houses with bad insulation and heating technology standards, still constituting a high proportion of homeowners in Germany. The understanding of their decision-making process can help managers of renewable energy companies, politicians, and local authorities develop viable strategies for increasing the purchase of renewable heating technologies.

This research indicates the importance of not only rational decision-making factors as strongly economical related issues affecting the purchase of renewable heating technologies, but also of bounded rational factors influenced by the personal insights of homeowners and their relationship to involved stakeholders within the market for renewable heating technologies. 


\section{DECLARATION}

I declare that the work in this thesis was carried out in accordance with the regulations of the University of Gloucestershire and is original except where indicated by specific reference in the text. No part of the thesis has been submitted as part of any other academic award. The thesis has not been presented to any other education institution in the United Kingdom or overseas.

Any views expressed in the thesis are those of the author and in no way represent those of the University.

Signed:

Date: 28 October 2019 


\section{ACKNOWLEDGEMENT}

I would like to express my gratitude to all those who supported me in finalising my thesis.

I give special thanks to Professor Dr. Svetla Marinova, who supported and inspired me, as first supervisor throughout the dissertation process. I would also like to thank Professor Dr. Christoph Brake for his additional support as second supervisor.

I am grateful to Mr. Guenter B. Goedde, my employer, for granting me the time to conduct my research, despite my busy professional daily routine.

Furthermore, I appreciate the support I received from Mrs. Katharina Koßmann, Mr. Hans-Josef Schulte and all the interview partners during my data collection period with end users and experts.

Finally, I thank my family, who respected the time I spent on my research. 


\section{TABLE OF CONTENTS}

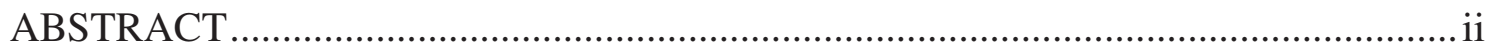

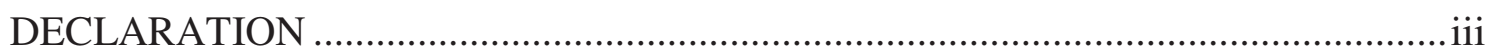

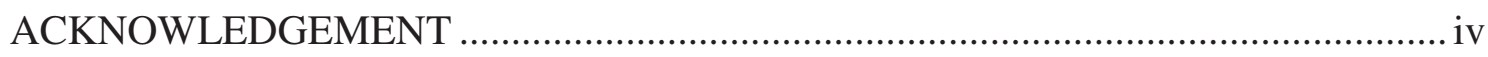

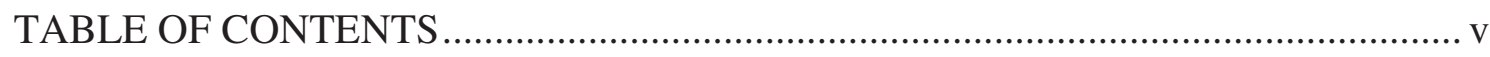

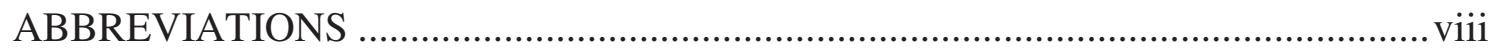

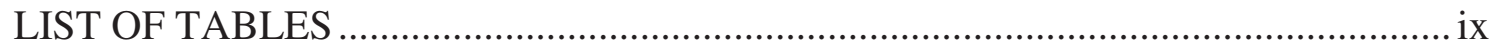

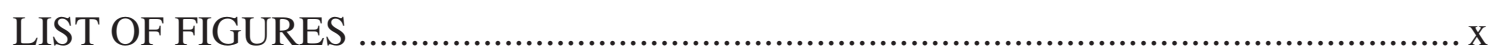

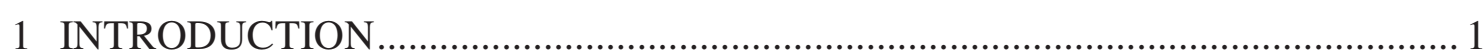

1.1 CONTRIBUTION TO KNOWLEDGE AND PROFESSIONAL PRACTICE.... 6

1.2 THESIS STRUCTURE ..............................................................................

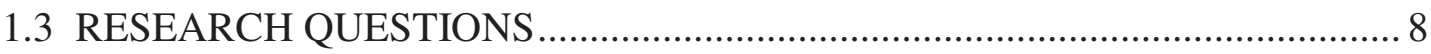

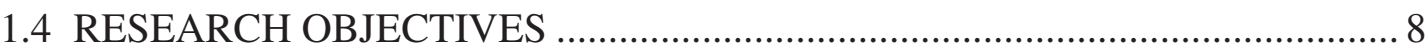

1.5 LIMITATIONS AND DEFINITION OF THE RESEARCH FIELD.................... 9

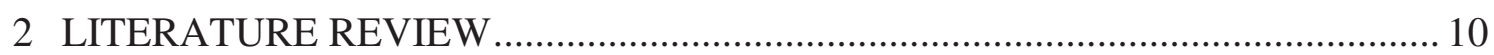

2.1 DECISION-MAKING PROCESS: REMARKS AND RESTRICTIONS........... 10

2.2 DECISION-MAKING MODELS AND DECISION OUTCOMES......................13

2.2.1 RATIONAL DECISION-MAKING MODELS........................................ 13

2.2.2 PROCESSUAL DECISION-MAKING MODELS..................................15

2.2.3 BOUNDED RATIONAL RELATED DECISION-MAKING

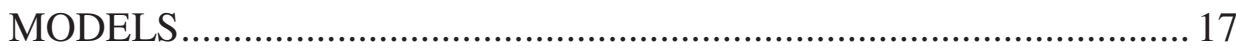

2.2.4 ACTION AND BEHAVIOURAL DECISION-MAKING MODELS ...19

2.2.5 INTUITION-BASED DECISION-MAKING AND SENSE-MAKING.23

2.3 STAKEHOLDER RELATED ASPECTS OF DECISION-MAKING

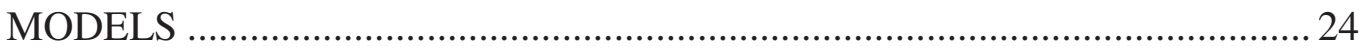

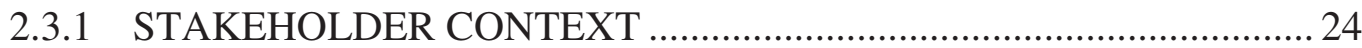

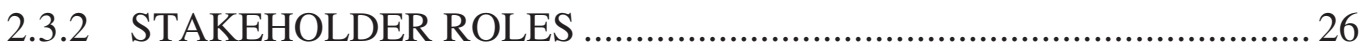

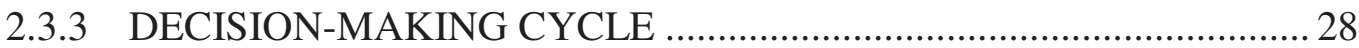

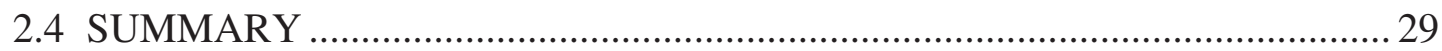

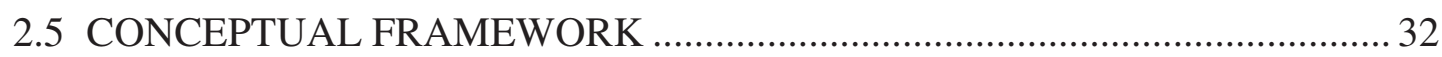

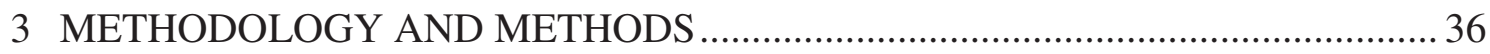

3.1 GENERAL COMPARISON OF DIFFERENT RESEARCH APPROACHES.. 36

3.2 QUANTITATIVE RESEARCH APPROACH.................................................... 38

3.3 QUALITATIVE RESEARCH APPROACH..................................................... 41 
3.4 CRITICAL REFLECTION ON MY METHODOLOGICAL CONVICTION...45

3.5 GROUNDED RESEARCH AS FURTHER RESEARCH APPROACH........... 48

3.6 SEMINAL GROUNDED THEORY OF GLASER \& STRAUSS..................... 48

3.6.1 STRAUSSIAN VS. GLASERIAN SCHOOL..................................... 49

3.6.2 FURTHER CRITICAL REFLECTION ON AND BOUNDARIES OF GROUNDED RESEARCH APPROACH .................................... 55

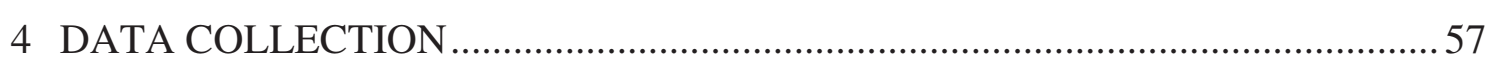

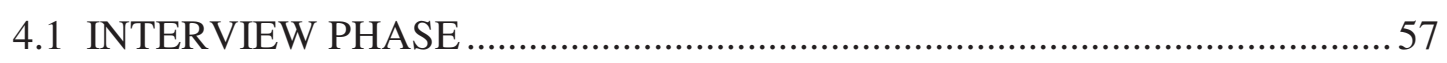

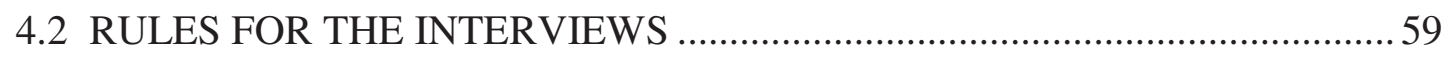

4.3 ETHICAL ISSUES AND ACCESS TO RESEARCH PARTICIPANTS ...........60

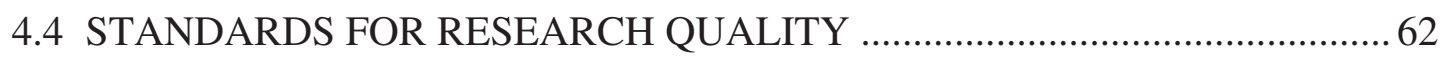

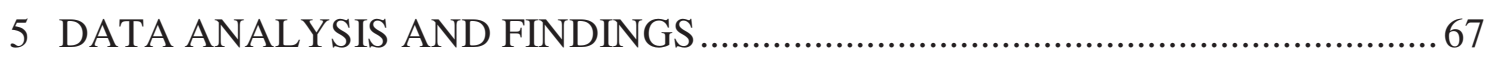

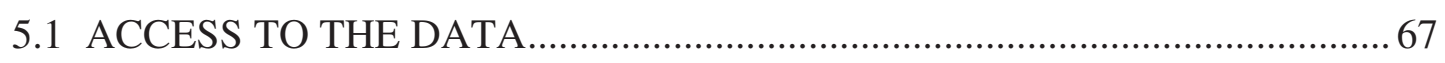

5.2 METHODICAL APPROACH TO THE DATA STRUCTURE.........................67

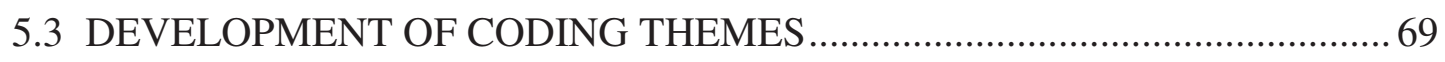

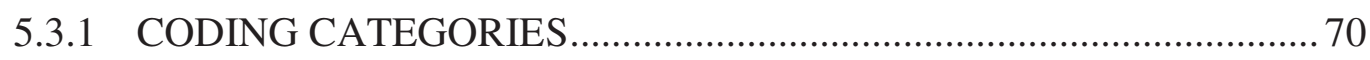

5.3.2 RATIONAL VS. BOUNDED RATIONAL DECISION-MAKING

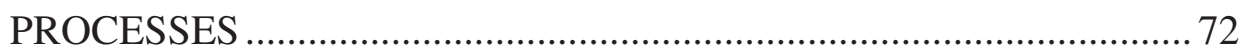

5.4 THEORETICAL INSIGHTS AND STORIES WITHIN THE AXIAL

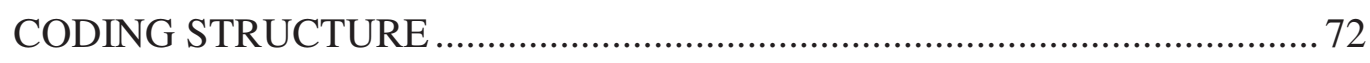

5.4.1 SPECIFICS OF THE TECHNOLOGY.............................................. 73

5.4.2 MOTIVATION FOR THE PURCHASE ............................................. 86

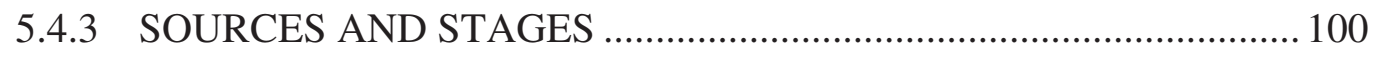

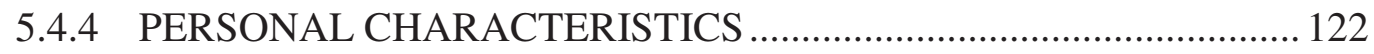

5.4.5 AFFECTING FACTOR: TECHNICAL ISSUES .............................. 155

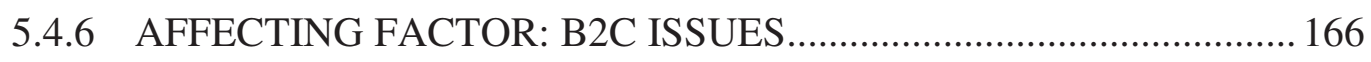

5.4.7 AFFECTING FACTOR: POLITICS............................................... 177

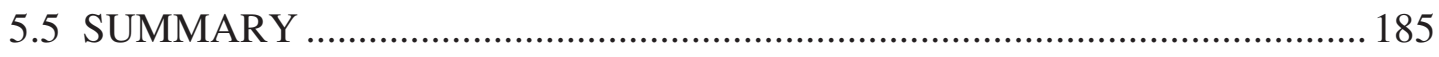

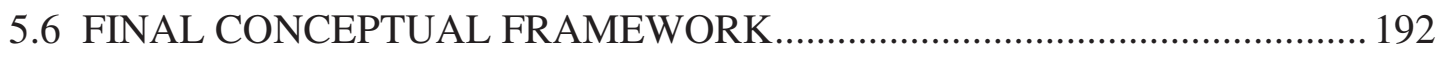

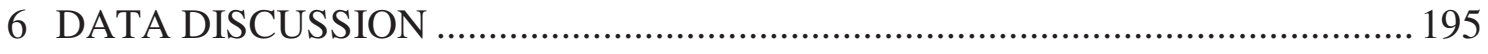

6.1 RATIONAL VS. BOUNDED RATIONAL DECISION-MAKING

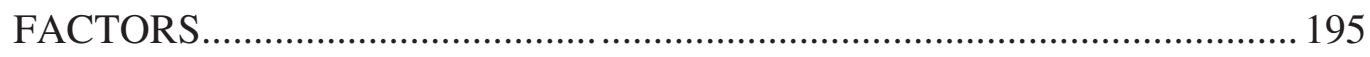

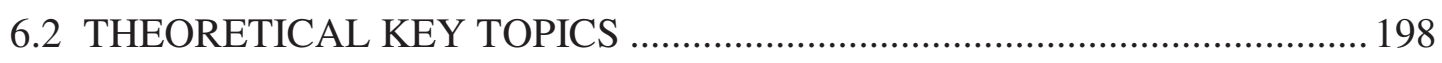

6.3 RESPONSE ON RESEARCH QUESTIONS ............................................. 211 
7 CONTRIBUTIONS, LIMITATIONS AND CONCLUSION

7.1 REFLECTION ON CONTRIBUTION TO KNOWLEDGE AND

PROFESSIONAL PRACTICE 219

7.2 LIMITATION AND IMPLICATION FOR FURTHER RESEARCH. 222

7.3 CONCLUSION 222

APPENDIX I: LITERATURE REVIEW: DECISION-MAKING MODELS 225 APPENDIX II: OVERVIEW OF RENEWABLE HEATING TECHNOLOGIES ..... 231 APPENDIX III: QUESTIONNAIRE FOR SEMI-STRUCTURED INTERVIEWS ... 232 APPENDIX IV: LIST OF INTERVIEWEES. 235

APPENDIX V: CONFIDENTIALITY AGREEMENT FOR

SEMI-STRUCTURED INTERVIEWS 236

REFERENCES 238 


\section{ABREVIATIONS}

AEE Agentur für Erneuerbare Energien (Agency for Renewable Energies)

AR Action Research

B2C Business to Consumer

BMVBS Bundesministerium für Verkehr, Bau und Stadtentwicklung (Federal Ministry of Transport, Building and Urban Development)

BMWI Bundesministerium für Wirtschaft und Technologie (Federal Ministry of Economics and Energy)

CHP Combined Heat and Power

$\mathrm{CO}_{2} \quad$ Carbon Dioxide

DM Decision-Maker

DMP Decision-Making Process

EEG Erneuerbare-Energien-Gesetz (Renewable Energy Law)

EEWärmeG Erneuerbare-Energien-Wärmegesetz (Renewable Energy Heating Law)

ENEV Energieeinsparverordnung (Energy Saving Regulation)

e.g. for example

EU European Union

i.e. that is

GWh Gigawatt hours

KfW Kreditanstalt für Wiederaufbau

(Credit Institute for Reconstruction)

kW Kilowatt

kWh Kilowatt hours

p. $\quad$ page

pp. $\quad$ pages

RQ Research Question

SDMP Strategic Decision-Making Process

SPSS Statistical Package for Social Sciences

vs. versus

\& and 


\section{LIST OF TABLES}

TABLE 1: RATIONAL VS. BOUNDED RATIONAL DECISION-MAKING APPROACHES 25

TABLE 2: LITERATURE REVIEW: DECISION-MAKING MODELS AND INFLUENCING FACTORS 225

TABLE 3: COMPARISON OF QUANTITATIVE AND QUALITATIVE RESEARCH APPROACHES 40

TABLE 4: PROS AND CONS OF GROUNDED RESEARCH AS A QUALITATIVE RESEARCH APPROACH 43

TABLE 5: COMPARISON OF DIFFERENT RESEARCH APPROACHES 45

TABLE 6: GROUNDED RESEARCH: STRAUSSIAN VS.

GLASERIAN SCHOOL 52

TABLE 7: ETHICAL ISSUES IN RESEARCH 61

TABLE 8: CRITERIA FOR QUALITY OF RESEARCH .64

TABLE 9: OVERVIEW OF RENEWABLE HEATING TECHNOLOGIES 231

TABLE 10: INFLUENCING FACTORS ON NEW HEATING TECHNOLOGIES.. 199

TABLE 11: ECONOMIC VS. ECOLOGICAL DATA ON DECISION-MAKING PROCESSES 201

TABLE 12: INFLUENCING FACTORS ON THE PURCHASE OF RENEWABLE HEATING TECHNOLOGIES 218 


\section{LIST OF FIGURES}

FIGURE 1: CONCEPTUAL FRAMEWORK: DECISION-MAKING PROCESS OF DECISION-MAKERS .................................................................... 34

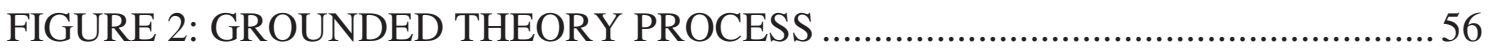

FIGURE 3: QUESTIONNAIRE FOR SEMI-STRUCTURED INTERVIEWS........... 232

FIGURE 4: LIST OF INTERVIEWEES …..................................................... 235

FIGURE 5: CONFIDENTIALITY AGREEMENT FOR STRUCTURED INTERVIEWS

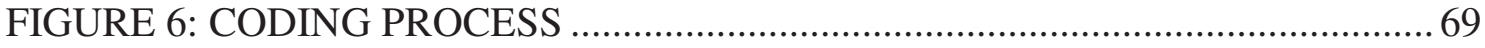

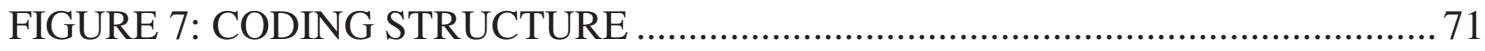

FIGURE 8: FINAL CONCEPTUAL FRAMEWORK: DECISION-MAKING PROCESS OF END USERS.

FIGURE 9: INFLUENCING RATIONAL AND BOUNDED RATIONAL DECISION-MAKING FACTORS

FIGURE 10: INFLUENCING STAGES ON THE DECISION-MAKING PROCESS 204

FIGURE 11: ACCELERATING DECISION-MAKING FACTORS FOR END USERS 207

FIGURE 12: MEANING OF INVOLVED DECISION-MAKING FACTORS 210 


\section{INTRODUCTION}

The topic of renewable energy has been dominating social, political and environmental debates in recent years. On one hand, some of the issues attracting attention, such as price increases for oil and gas, limited resources and, therefore the need for research in the field of renewable energy technologies, among other factors, concern end consumers. On the other hand, political and environmental discussions in our society on issues, such as environmental pollution by carbon dioxide $\left(\mathrm{CO}_{2}\right)$ and the heating of our planet caused by greenhouse gases, form part of the daily news.

One dominating topic in Germany, reflecting on the energy revolution, is 'Power Grids'intelligent networks connect the generation of power, its storage and distribution, and its consumption (BMWI, 2017). The move away from fewer central power plants is characterised by the installation of smaller and many de-centralised renewable energy plants. To realise such demand-side management, interactive data processing technologies between producers and consumers is required. Another key topic revolves around the erection of wind energy plants and the necessary laying of trails for power supply distribution, mainly from the northern parts of Germany to the southern parts.

Aside from these topics, which focus on the generation of electricity, debates about renewable heating technologies are dominating the daily news. Available studies are often related to scientific capacity scenarios which consider a $100 \%$ coverage of the heating demand in Germany with existing and foreseeable renewable heating technologies. 'Power-to-gas', using wind energy for the generation of hydrogen, is only one of various concepts being developed to improve economic feasibility (AEE, 2017). Energy research studies, mainly based on scientific studies of specialised institutes, are often motivated or instructed by the government or governmental authorities.

The focus of this qualitative investigation shall be the design of future $\mathrm{B} 2 \mathrm{C}$ models in the context of the further increase of renewable heating technologies; only already existing technologies for end users on the market will be considered. The increase of renewable energy usage in the context of future technologies will not be examined. The decisionmaking process of homeowners as decision-makers will be at the centre of the research, concerning investments in renewable and already available heating technologies. Focus shall be placed on the purchase of renewable heating technologies for old houses, rather than new ones, as they are usually constructed with poor or no insulation standards and 
non-renewable heating technologies. Therefore, they have a high-energy demand, and thus greater potential for the purchase of renewable heating technologies.

The research shall consider the decision-making process of end users, their insights and the involved human beings and organisations within the heating market. A more detailed exploration of key factors will be carried out in order to fully evaluate in detail the heating consumption in Germany and the demands on B2C factors.

\section{Contextualising the term 'renewable'}

The greater question to be answered is: what is understood by the term renewable, and what is the boundary to sustainable, as commonly used terms in the context of energy distribution concepts, not based on carbonised solutions of coal, oil and gas.

Regarding relevant production and distribution concepts, Armstrong \& Ryan (2009) define renewable energy, using six sustainable criteria for renewable energy: (1) technical criteria to provide a technical solution; (2) economic criteria from economic aspects including pay back and contribution to the asset value of households; (3) environmental criteria with issues from the environmental impact of the technology, and existing life cycle assessment (LCA) information; (4) social criteria with social related issues of the technology; (5) cultural impacts with cultural aspects related to the research area (here: New Zealand); and (6) general and regulatory criteria with issues of location dependency, territorial authorities, and regulatory impacts.

Brohmann et al. (2009) relate three factors to the term sustainable (as do Armstrong \& Ryan, 2009, not to be confused with 'renewable'). (1) The individual area which consists again of the individual area of action as demand-side area and the informal area with informal activities undertaken by consumers. (2) The supply-side and structural area of action, which includes the activities of companies and governmental bodies to provide sustainable products, services, and information. (3) The socio-political area of action, which contains the activities of governmental bodies but also of organisations and associations to form the framework for governance. These three areas are regarded as interrelated: consumer behaviour, based on individual decisions, and individual behaviour.

Consequently, both Armstrong \& Ryan (2009) and Brohmann et al. (2009) relate the term sustainable, in a broader context, to issues related to technical aspects, individual factors (household/individual), and environmental criteria in a social and political 
context. Brohmann et al. (2009) refer to the Brundtland Report (Brundtland, 1987). The report puts together the results of a meeting of the General Assembly of the United Nations, which was addressed to a global agenda for change with reference to the protection of our environment. Therefore, in relation to my research area regarding renewable heating technologies, the report covers a more advanced, but related topic.

The greenhouse effect is connected to the burning of fossil fuels and the cutting and burning of forests, releasing carbon dioxide $\left(\mathrm{CO}_{2}\right)$. The accumulation in the atmosphere of $\mathrm{CO}_{2}$ and certain other gases traps solar radiation near the Earth's surface, causing global warming. This could cause sea level rises over the next forty-five years, large enough to inundate many low lying coastal cities and river deltas. It could also drastically upset national and international agricultural production and trade systems.

Renewable resources, such as forests and fish stocks, need not be depleted provided that the rate of use is within the limits of regeneration and natural growth. However, most renewable resources are part of a complex and interlinked ecosystem, and maximum sustainable yield must be defined after taking into account system-wide effects of exploitation

Sustainable development requires that the rate of depletion of non-renewable resources should foreclose as a few future options become available. So-called free goods like air and water are also resources. The raw materials and energy of production processes are only partly converted to useful products; the rest comes out as waste. Sustainable development requires that the adverse impacts on the quality of air, water, and other natural elements are minimised so as to sustain the ecosystem's overall integrity. In essence, sustainable development is a process of change in which the exploitation of resources, the direction of investments, the orientation of technological development, and institutional change are all in harmony and enhance both current and future potential to meet human needs and aspirations.

A closer focus on the technical issues of the term renewable energy is made in the glossary of the Federal Ministry of Economics and Energy (BMWI, 2016/1, p. 43):

'Renewable Energies are energy sources which stay endless at disposal of human beings according to a time scale. Almost all renewable energies are finally fed by the sun. The 
sun will consume and is, therefore, no renewable energy in a stronger context. Based upon the existing stand of science the foreseeable time life of the sun will, however, be more than 1 milliard years and is from the human perspective almost unlimited. The three originary sources are solar radiation, geothermal heat and tidal power. They can either be used directly or indirectly in forms of bio mass, wind, water power, environmental heat as well as wave energy.'

On the other hand, reference is also made to non-renewable fossil energy sources, with specific mention of coal, gas and oil (BMVBS, 2011).

As a concluding remark, I relate 'renewable' to a cycle of renewing energy sources and 'sustainable' to making these sources last on earth, in contrast to non-renewable energy sources, which are limited.

\section{European Energy Transition}

Apart from national goals, the EU has decided upon a transnational climate and energy framework in 2018 (Agora, 2019). The European energy transition shall be based on solidarity, security, competitiveness, and innovation, which contains a set of objectives for and interdependency between all Member States. Up to 2030, greenhouse gas emissions are to fall by at least $40 \%$ below 1990 levels, and renewables are to deliver $32 \%$ of our energy. Wind and solar shall shape Europe's power system. In the building sector, as some of the various megatrends shaping tomorrow's energy system, smart home systems are considered to optimise the use of rooftop solar installations, heating systems and battery storages. Renewable heating supply shall be expanded for buildings and district heating networks, including solar thermal, geothermal energy, ambient energy via heat pumps, and wood-based biomass from waste.

\section{Governmental goals in Germany}

The energy transition is a national long-term strategy for the development of a federal low-carbon energy system based on renewable energy sources (Kuittinen \& Velte, 2018).

In order to replace all fossil fuels for final energy consumption in the areas of electricity, heat and transport, renewable electricity must be harnessed (AEE, 2019). Such an intelligent interaction of electricity, heat and transport is being discussed under the term sector coupling by actors from politics, business and research. In the heating sector, the 
operation of heat pumps using electricity generated from renewable sources has a significant role to play.

To form a better picture of the nationwide goals in Germany, some general targets are presented, first introduced by some statistical data (BMWI, 2018). In Germany, based on the figures for 2017 , renewable heating energy consumption is equal to $13.2 \%$ of the total heating energy consumption, compared to $4.4 \%$ in 2000 . Therefore, the consumption of renewable heating energy corresponds to a high share of the total consumption and still reflects on a high potential towards $100 \%$. The majority of houses (66\%) were built before 1978, without any requirements in terms of insulation standards (BMVBS, 2013) and commonly cannot be assumed to contain the latest requirements on heating technologies (regulations according to 'ENEV'). They are, therefore, potentially of interest in research related to the replacement of old technologies with new and renewable heating technologies.

The Public Agency for Renewable Energy (AEE, 2015) summarises different reports of organisations with statements that around $70 \%$ or nearly 21 million heating systems still do not correspond to the latest conditions. Thus, there is a high potential for the purchase of renewable heating technologies, especially in older houses. For the future, a stronger interplay is expected between the utilisation of electricity and heat (AEE, 2017). Applications are seen in a stronger use of electricity as auxiliary power for heating pumps in combination with other energy carriers, such as gas or wood (bivalent or hybrid heating systems).

Different governmental initiatives in the form of laws, regulations and incentive programmes have been implemented in order to increase the purchase of renewable heating technologies in Germany. Three important cornerstones are pointed out (BMWI, 2016/2; AEE, 2015), which reflect on domestic homes, mainly detached and semidetached:

\section{Renewable Heating Energy Law 'EEWärmeG':}

Realisation of a share of $14 \%$ for renewable heating energies on the total consumption for heating and cooling has been identified as a long-term goal for 2020. For new buildings, from 2009 onwards, a certain minimum percentage of the total energy consumption has to be covered with renewable energy sources: solar heat (15\%), biogas 
(30\%), geothermal or environmental heat, such as with heating pumps or biomass/wood pellets $(50 \%)$.

Renewable Energy Regulation 'EnEV':

Requirements on heat insulation for new buildings and reconstruction of old buildings.

\section{Market Incentive Program 'MAP':}

National promotional programme for old buildings (loans and benefits for purchase of renewable heating technologies).

\section{Renewable heating technologies}

A short overview shall be given about the most common heating technologies in use. The data are based on different secondary data (BMWI, 2016/2; AEE, 2015; BMVBS, 2013) and various expert interviews (Figure 4). The descriptions with advantages and disadvantages are qualitative without any evaluation, which would have to be related to technical data and individual aspects on-site (Table 9). The evaluation of the technologies will later be taken up by the interviewees in Chapter 5.4:

Solar heat, bio mass, thermal heating pumps and micro CHP are the selected technologies that are limited to on-site solutions, which can be chosen independently of homeowners. Therefore, heating solutions based on district heating with a necessary infrastructure are not considered.

\subsection{CONTRIBUTION TO KNOWLEDGE AND PROFESSIONAL PRACTICE}

This DBA thesis' contribution to knowledge and professional practice in the respective field shall be related to the following research results:

\section{Contribution to decision-making theory}

Outcomes will identify whether, how, and why homeowners of old houses decide to adopt renewable heating technologies. This means that the study will find out what are the driving factors for homeowners in their assessment and choice of a specific type of renewable heating technology, and in their decision on whether or not to purchase a renewable heating technology. Thus, the study aims to outline influencing factors related to the perception, experiences, technology awareness, and related behaviour of 
homeowners as decision-makers in the purchase of renewable heating technologies. Moreover, the implications of these factors will be identified in relation to other stakeholders in the renewable heating technology market, such as manufacturers and distributors of renewable heating technologies, friends or consultants.

\section{Managerial and policy implications in the use of renewable heating technologies}

Managerial implications could be associated with new business models in promoting such technologies aimed at accommodating consumer requirements for information and consumer consultation. Additionally, politicians may be inspired to design more attractive public incentives to push renewable heating energy concepts.

\section{Social implications}

The research may help various suppliers and distributors of renewable heating technologies improve their approach towards informing consumers about renewable heating technologies, which they offer, in order to influence their decision-making process. An increase in the application of renewable heating technologies should result in the reduction of carbon dioxide, which should, in turn, have a limiting influence on the greenhouse effect.

\subsection{THESIS STRUCTURE}

The thesis starts with a discussion informing the choice of the research problem and the follow up research questions. This is followed by an in-depth literature review about consumer decision-making, explored in relation to the conceptual framework for the study.

Next, the research methodology and specific research methods for data collection and analysis are discussed.

Based on this, data analysis emerges using secondary data and interviews with end users and experts, who are external to the market, but deal with these technologies. This is followed by primary data from semi-structured interviews, which have been chosen as a means to enter into interactive communication with end users and experts.

The data are systematised, coded and analysed, and the results inform the theoretical deductions, managerial and policy implications of the research. 


\subsection{RESEARCH QUESTIONS}

The research focus is the decision-making process of homeowners as decision-makers in the $\mathrm{B} 2 \mathrm{C}$ context of renewable heating technologies. The following research questions (RQ) will be investigated:

RQ 1: What are the specifics of existing renewable heating technologies and their usage from the perspective of consumers?

RQ 2: What are the motives of consumers for the purchase of existing renewable heating technologies?

RQ 3: How do the specifics of existing renewable heating technologies affect consumer choice of a specific technology?

RQ 4: What stages do consumers go through in the process of reaching a final decision on the purchase of an existing form of renewable heating technology?

RQ 5: How do consumer-related, technology-related, and provider-related factors affect consumers in the various stages of the decision-making process for the purchase of an existing form of renewable heating technology?

\subsection{RESEARCH OBJECTIVES}

The research aims to explore how consumers decide to purchase or not to purchase renewable heating technologies, with particular focus on their motives, available choices, and related factors.

Related to the research questions, the research objectives are as follows:

First, to understand and compare the specifics of existing renewable heating technologies and their usage from the perspective of consumers.

Second, to identify and analyse the motives of consumers for the purchase of existing renewable heating technologies.

Third, to explore how the specifics of existing renewable heating technologies affect consumer choice of a technology. 
Fourth, to define and explore the decision-making stages of consumers in the process of reaching a final decision on the purchase of an existing form of renewable heating technology.

Fifth, to find out how and to what extent various factors (consumer-related, technologyrelated, and provider-related) affect consumers in the different stages of the decisionmaking process for the purchase of an existing form of renewable heating technology.

\subsection{LIMITATIONS AND DEFINITION OF THE RESEARCH FIELD}

The research context is Germany. More specifically, the research is focused on homeowners of old houses. The majority of German houses $(66 \%)$ were built before 1978, without any requirements in terms of insulation standards (BMVBS, 2013).

Two groups of interviewees are considered in the process of data collection. One group constitutes homeowners that have bought renewable heating technologies, while the other comprises homeowners who are still using non-renewable heating technologies and have not (as yet) bought renewable heating technologies.

Thus, the research explores only first-time purchases of renewable heating technologies and does not investigate why consumers may re-purchase or switch from one type of renewable heating technology to another.

The research focuses on detached and semi-detached family houses only. Existing renewable heating technologies relate to room heating and heating of service water, as these are considered essential heating demands of end users. Renewable heating technologies for residential and industrial buildings and heating technologies for thermal processes in industrial sectors will not be considered.

The exploration is founded on qualitative research approaches, based on the analysis of socially constructed meanings of the interviewed end users. 


\subsection{DECISION-MAKING PROCESS: REMARKS AND RESTRICTIONS}

With respect to the research content, consumers as homeowners are decision-makers who can decide which renewable heating technology they use or would use in their home. Thus, in the process of choosing a possible renewable heating technology, they go through a specific decision-making process that is driven by certain motives and impacted by consumer-related, technology-related, and provider-related factors.

The key questions that arise are: How do end consumers as homeowners make these decisions and what is their decision-making process related to? How and when does their decision-making process begin? How and when is it considered to be finished, interrupted, continued, or even cancelled?

\section{Decision-making process}

The decision-making process in relation to organisational context and involved human beings has been subject to various investigations. In their seminal work, Mintzberg, Raisinghani \& Theoret (1976) define the decision-making process as a set of actions and dynamic factors that begins with the identification of a stimulus for action and ends with specific commitment to action. Franz \& Kramer (2010) suggest that any decision-making process consists of decision characteristics and personal and organisational characteristics as input influences, which lead to decision outcomes. Wilson (2004) reflects that discrete activities involving individuals over a period of time comprise the decision-making process. These activities, which have an end-point, include selection and implementation processes with activities over a certain period of time.

The decision-making processes in this thesis are analysed as a social construction of decision-makers. Al-Tarawneh (2012) defines decision-making as the process of identifying and selecting an option from among possible solutions to a problem, according to the demands of the situation. Thus, the research focuses on people's behaviour, opinion of and decision-making with respect to heating technologies. The investigation does not consider quantitative studies about the probability of choosing between high-risk options. Instead, it reflects on engaged decision-makers and their social construction of the purchase of renewable heating technologies. 
Müller-Hansen et al. (2017) consider modelling assumptions about actors, their goals and behavioural options as necessary for decision rules regarding human social interactions and the aggregation of individuals' behaviour.

An important aspect will be to answer the question about which characteristics of decision-making processes and strategic decision-making processes should be combined or separated. Extant literature contains research with both terms, 'non-strategic' and 'strategic'.

According to Bigby \& Douglas (2015) more comprehensive decisions are expressed as bigger decisions which endure things in a person's life, ranging from their home to where they live or what support they receive.

Nutt \& Wilson (2010) characterise strategy as a pattern that emerges from a stream of decisions and may not be an attribute or descriptor of a single decision. They relate this statement to decision-making processes in organisations where decision-makers do not always have access to the necessary knowledge to start with a clear planned purpose.

Mintzberg, Raisinghani \& Theoret (1976) relate long time periods to decisions characterised as strategic. Their research results in organisational structures, such as firms, thereby identifying a minimum period of one year. Consequently, when faced with complex situations, decision-makers see a door opener to reduce these decisions into various smaller scale decisions. They relate strategic decisions to a commitment for future action; put simply word, they only view strategic decisions as important in terms of the action taken, the resources committed, or the precedents set.

Nutt \& Wilson (2010) argue that strategic decision-making is often used for important decisions and refer again to organisations of all types. In this context, they define the term organisation as any collective social, economic or political activity with a plurality of human effort. Strategic decisions are carried out among and between individuals within the organisation.

Morris, Greenwood \& Fairclough (2010) identify significant differences between strategic and non-strategic decisions. In the context of professional firms and organisational resources, they refer to strategic decisions as those which are comparatively new compared to non-strategic ones, such as routines. Erasmus, Boshoff \& Rousseau (2001) refer especially to consumer related decision-making models. In their literature review, they reflect very critically on the limited theoretical background of 
research studies and mention that formerly developed decision models, which are still in use, constitute research undertaken by marketers, rather than academics. They argue that decision-making needs to be viewed as a more complex phenomenon. In their opinion, behavioural aspects during the decision-making process should be considered more in the research phase, instead of acting as a reflection on interrelation concepts and flow of activities. This process should be context specific and product specific to provide new insights and to contribute to theory building in the domain of consumer science. They look to qualitative research methods to examine the meaning of human actions.

The literature review will show that the characteristics of strategic decision-making models contain comprehensive aspects about the structure, content and process of these models. Before entering into a certain research direction the question of whether considering exclusively strategic related models is problematic or whether they ought to be excluded will have to be answered. Two terms seem to be noticeable - organisation and long-term.

Although some details remain to be examined in the course of this research, end users can be seen in an organisational and structural context, alongside other participants of the renewable heating market. Further details about actors in the renewable heating market still have to be investigated, but manufacturers and distributors of the relevant technologies or even family members of the end user are already mentioned. As Nutt \& Wilson (2010) state, organisations can be of all types with a plurality of human effort.

Renewable heating technologies are large investments and, therefore, they require a longer planning period. Issues, such as financing, influence the cash-flow budget of end users and the reliability of the chosen solution has to be evaluated carefully. Therefore, strategic decisions are expected to be complex. Nutt \& Wilson (2010) refer to strategic decisions as a stream of decisions; whereas Mintzberg, Raisinghani \& Theoret (1976) focus on smaller sub-decisions within the decision-making process.

Elbanna (2011) considers strategic and non-strategic decision-making characteristics, although he reflects on the managerial context of firms. The author characterises the following four contextual perspectives for strategic decision-making: (1) characteristics of top management, (2) decision-specific characteristics, (3) environmental determinism, and (4) firm characteristics. The first three perspectives, reflecting on the involved human beings as decision-makers, are particularly interesting. Decisions are considered 
in relation to other organisations, such as companies, and are associated with the decision-maker's personal characteristics, like age and experience. The decision-specific characteristics refer to the importance, motive and uncertainty of decisions. The environmental aspects are viewed in the context of relationships with customers, suppliers and competitors, which emphasises that decision-making takes place under certain conditions; it is determined by one's motives and is influenced by context and relationships with others.

\subsection{DECISION-MAKING MODELS AND DECISION OUTCOMES}

This part of the literature review is focused on theoretical investigations about how and which kind of decisions are made.

\subsubsection{RATIONAL DECISION-MAKING MODELS}

Turpin \& Marais (2004) relate the view of a rational decision-making model to a manager as a rational and completely informed decision-maker.

Simon (1977) suggests that four steps are essential: (1) intelligence, to find occasions for making decisions; (2) design to develop and analyse possible courses of action; (3) choice, to select a course from those available; and (4) review, to assess past choices. The rational managers know all alternatives, and the consequences of implementing these; have the ability to compare consequences and determine the preferred alternative.

Weick, Sutcliffe \& Obstfeld (2005) relate rational decision-making models to perceptual accuracy. Problems have to be evaluated in order to identify goals, possible solutions and the course of action, which is chosen from a set of alternatives. The importance of accurate information is essential in his model. However, many organisations cannot use this method as information accuracy is somewhat limited. Rather, experience, critical evaluation, interpretations, and choices complement available information. One of the key questions is associated with the meaning of rationality when rational models are explored.

Anderson (2002) summarises three aspects: rationality, creativity, and balanced judgement. He describes rationality as a direction in thoughts. These thoughts begin with 
the consideration of facts, followed by value premises, and proceed to a logical conclusion in preference of a given alternative.

Eisenhardt \& Zbaracki (1992) follow the definition of Mintzberg, Raisinghani \& Theoret (1976) who differentiate between rationality and bounded rationality in decision-making. Rationality can be seen with actors who gather appropriate information, develop alternatives and then select the optimal one. While there are cognitive limits to the rational model, decisions follow the basic phases of problem identification, development, and selection; the decision cycle repeats itself or goes more in-depth throughout the process.

According to Simon (1978), the classical theory of omniscient rationality is simple. In the context of business organisations, he argues that environment, combined with assumptions of perfect rationality, fully determines behaviour. The process of reflecting on observations in greater detail does not assume that rational behaviour is caused by correct predictions, but that it demands knowledge and abilities to identify options and make choices.

Mori (2010) states that rationality describes actions with desirable outcomes and emphasises the Strategic Decision-making Process (SDMP), which is limited by cognitive and political realities. This leads to the issue of subjectivity and objectivity in rational decision-making.

Daellenbach \& McNickle (2005) define objectivity as the expression or interpretation of facts or conditions independent of the observer's mind. They consider full independence as illusionary, as individuals have perceptions of an unknown constructed reality about which they can gain more insights. They argue that our mind can only capture personal perceptions which are in line with our world view.

Lunenberg's (2010) indicates that a rational model, in the context of decision-making, is rational insofar as decisions are made under certainty. These decisions consist of different steps as a logical sequence of activities, beginning with the identification of the problem and ending with the evaluation of decision effectiveness; again, a stepwise approach.

Therefore, rational models assume that all necessary information for making a decision and choosing a certain outcome is available and that decisions are consequently based on a chronological, analytical, and stepwise approach. 


\subsubsection{PROCESSUAL DECISION-MAKING MODELS}

Aside from rational decision-making models, process models also focus on facts, and more specifically, on procedures of how to evaluate information. They exclude emotional aspects, as do rational models. Anderson (2002) identifies steps in the decision-making process that include problem structuring and evaluation. Problem structuring is defined as involving identifications of alternatives, values that distinguish the alternatives, and uncertain events, which can affect the values within the alternatives. Franz \& Kramer (2010) refer to rational decisions as based on classical decision-making theories instead of behavioural ones. Anderson considers that rational is a matter of direction in thought and evaluation is a matter of weighing the relative desirability of various outcomes and the likely impact of various uncertain events in deciding which alternative is, on balance, preferable. Process orientation is then a particular way to reduce uncertainty, focusing more on the decision-making process rather than the outcomes of it. In other words, process orientation focuses on making a good decision, rather than reaching a good outcome.

Papadakis, Thanos \& Barwise (2010) view the decision-making process as a link between formulation, decision content, and implementation. They conclude that processrelated procedures consider: (1) context, (2) process, and (3) outcome. They identify decisions associated with a process, dealing with the how of research strategy, as well as content decisions, dealing with the what.

Poole \& Van de Veen (2010) argue that decision-making is a multilevel process, with smaller decisions forming part of larger ones. They differentiate between a process and variance theory. The process theory explains a chronological process of problem definition, problem analysis, solution generation, solution evaluation, and decision, like rational models do. Explanations are needed about which mechanism drives the process; for example, norms in group interactions. These mechanisms are seen as processual worldviews (ontology) and processual approaches (epistemology). The process study narrates social constructions related to qualitative process studies. The variance theory is viewed as changing relationships between independent and dependent variables. They relate this theory to probabilistic relationships, as they can be influenced by factors or events which are different from those hypothesized. Therefore, they have to be expressed in terms of functional laws. According to Poole \& Van de Veen's argumentation, a process theory explains how a sequence of events leads to an outcome. Conversely, the 
variance approach is consistent with a decision based on efficient causality, related to problem analysis, number of options, and task complexity.

Depending on the mode of change (prescribed or constructive) and the unit of change (single or multiple entities), Poole \& Van de Veen define four theoretical groups in their conclusion.

(1) Teleological theory is focused on a cycle of goal driven formulation, implementation, evaluation, and modification of actions or goals. (2) Dialectical theory considers emerging conflicts between people or positions. The end point is not clear in the beginning. Conflicts ensue in the process. (3) Evolutionary theory considers emergence of variation, selection, and retention events. Multiple ideas exist in competitive or cooperative relationships. Certain ideas shall gain approval from the group. (4) Multiple motor processes consider several major stages in the decision-making process. For 'intermotor relationships' several interdependent stages have been identified: different types of relationships with reinforcing (positive), damping (negative), and complex (non-linear) factors. Finally, they note temporary relationships with different durations of the decision-making process.

With respect to the research topic and limitations of this thesis mentioned in Chapter 7 , the processual approach of sequence, as a stepwise approach, is of interest in forming an a priori conceptual framework, in contrast to the variance approach, which is based on mathematical and probabilistic relationships.

Daellenbach \& McNickle (2005) explain process approaches in decision-making in a way that no assumptions are made about a possible system structure. Rather, the observed processes and relationships of interest between the various components of the system are used for discovering a good structure. The worldview dictates the system through which performance evaluators are to be observed. In contrast, structural approaches are regarded as the preferred method when the situation is well-understood, and when the worldview implied by the system performance evaluators of the chosen structure fits the one identified in the problem situation.

Nutt \& Wilson (2004) suggest that the cognitive make up of decision-makers might influence their choices. Hence, processual decision-making models assume that all necessary information to make decisions and choose a certain direction to reach an outcome is available; decisions are then based on a chronological and stepwise approach. 


\subsubsection{BOUNDED RATIONAL RELATED DECISION-MAKING MODELS}

Turpin \& Marais (2004) characterise bounded rationality as activities of 'searching and satisfying': if an alternative satisfies, the search is terminated. The political view is seen as a personalised bargaining process, driven by agendas of participants, rather than rational processes. As goals, values and relevance of information differ between the people involved, the decision process never ends.

Lunenberg's (2010) suggests that the decision-maker is either not aware of problems, or they have limited time to search for all possible solutions. Decision-makers, therefore, decide based on their intuition, experience, advice from others and, perhaps, some creative thoughts.

Wilson (2010) argues that decisions can become framed and bounded. There are different connections between the rational or classic decision-making model (sequences of problem identification, alternative generation, selection of best alternative, implementation) and other factors. One aspect that evidences connections are political conflicts. They can fragment the decision-making focus. Political activity reflects the interests for implementation and, therefore, results in a lack of support for issues to be dealt with. Thus, this approach does not legitimise the view of 'being', as objects within decision-making can be studied in their own right and based on their own characteristics. While independent activity has no absolute meaning beyond its social construction, being bounded shows evidence of connections between different aspects. Wilson concludes that there is a rich agenda for ontological questions, related to what a decision is, and epistemological questions, regarding how to conceptually approach the topic of decision-making.

Bennet \& Bennet (2008) add to the understanding of the decision-making processes as being informed by experience, education, relational networks, knowledge of past success and historic individual preferences, multiple frames of reference, cognitive insights, wellness (mental, emotional and physical), and knowledge of related external and internal environmental pressures. The ontology of the decision is determined via a set of characteristics and conditions, which may have an important influence on the desired outcome. In a managerial context, boundary management is a technique to control and influence situations and their boundaries. Further, bounded related issues retain simplicity to reduce uncertainty as it makes decisions easier, more focused, and efficient. 
In order to follow up the most effective decision strategy, the core question is whether the decision is about a problem or a symptom of a problem. Decision-making cycles and their causal links may also be relevant.

Mark \& Henry (2004) explore mechanisms through which evaluation may have an effect on (decision) outcome. Four kinds of processes related to social and behavioural sciences are classified: (1) general influences can occur on individual, interpersonal and collective levels, e.g. how much time an individual spends on thinking about their response; (2) cognitive and affective processes refer to shifts in thoughts and feelings; (3) motivational processes refer to goals and inspirations; (4) changes in action - thus as decision outcomes - are finally mentioned as behavioural processes.

Christie (2007) focuses on the what influences decision-making and identifies: (1) individual attitudes and behaviours; (2) interpersonal behaviours, such as justification, persuasion, social norms and minorities - opinion influence; (3) collective action in public and private organisations.

Daellenbach \& McNickle (2005) reflect on rational and bounded rational choices through 'critical system thinking'. They see humans as interpreting a real world through their perceptions. They are affected by interests, values, and world views. Associated boundary choices involve subjectivity, which they express with the adage: 'we only see what we want to see'.

Simon (1978) views rationality as bounded when its failures of omniscience are those of knowing all the alternatives, uncertainty about relevant events, and inability to calculate consequences.

Thus, bounded rational decision-making processes ignore idealised circumstances in contrast to rational-related decision-making processes. Personalised aspects, like values, political views and cognitive-related personal characteristics, have to be taken into account and considered individually for each decision-maker.

\section{'Garbage can' as a particular bounded rational decision-making process}

Eisenhardt \& Zbaracki (1992) describe the garbage can model as the accidental or random confluence of 4 streams: (1) choice opportunities, (2) solutions as answers looking for problems, (3) participants with schedules to which they may need to pay attention, and (4) problem concerns of people inside or outside the organisation. Politics 
are mentioned as actions by which people enhance their power to influence decisions. The model calls attention to the importance of chance. Intuition is deemed to provide a more realistic view of the decision-making processes; with intuition, decision-makers refer to more incremental adaptations, based on deep, intimate knowledge of the situation.

Eisenhardt \& Zbaracki deduce a loose understanding of means and ends as one characteristic; organisational participants, learn on the basis of trial and error, without a clear understanding of underlying causes. In their opinion decisions are not the result of analytical approaches of individuals using bounded rational, but rather random, related events.

Rainey, Ronquillo \& Avellaneda (2010) suggest that participation, preferences and technologies are ambiguous, uncertain, and rapidly changing. Decision-making occurs where a problem arises and the decision-makers come together in a choice opportunity, receptive to an available solution.

Similarly, Cohen, March \& Olsen (1972) define a garbage can simply as no standard program of action. Preferences are unclear and sometimes impossible to express. People do not always know what they want to do and have to re-interpret preferences. The garbage can model describes decision-making in an organised anarchy. Decisions are outcomes or interpretations in the organisation. Garbage can is compared to a choice opportunity when solutions and problems are dumped when they are generated. They contain streams of problems and choices of the different participants, hence, the garbage can does not resolve problems but it enables choices.

\subsubsection{ACTION AND BEHAVIOURAL DECISION-MAKING MODELS}

The process of attaining information or looking for and evaluating the best alternatives is viewed as an action or set of actions. In close relation to the research topic of this work, the final action - independent of the preceding evaluation process - is the behaviour, i.e. the buying of or investing in renewable heating technologies, or the postponement or even cancellation of this decision step as final decision outcome.

Mintzberg \& Westley (2001) argue that there is much more to decision-making than conscious thoughts and the process is not just black and white. They reflect on the 
rational decision-making process as a clearly identified process: define, diagnose, design and decide. In contrast, they classify three related approaches to decisions: (1) 'doing first' stands for spontaneous decisions, simple relationships may help people move forward; (2) 'seeing-first' are emotional decisions with required creative solutions; (3) 'thinking first' are problem-focused decisions, such as in structured processes.

Tsoukas (2010) relates the Heideggerian approach to the deep structuring of reality under consideration of practical consciousness and the conscious process of making commitments to actions for various purposes, such as problem solving, motivation, or legitimation. He mentions decisions aimed at addressing problems, which emerge to the actor and depend on two factors: (1) the engagement with the world of the decisionmaker, expressed in the type of rationality and knowledge, and (2) the appearance of consciousness to the decision-maker, immersed in or detached from, a practical context. Tsoukas mentions decisions occurring prior to action, where outcomes are related to the decision-maker's intentions. Often, the decisions are not calculative or abductive, but rather spontaneous responses to the present circumstances. In contrast, action, as a decision outcome, may be interrupted by the decision-maker, who can generate reflective knowledge for further action. Reflective knowledge is developed with the upcoming situation in mind, through questioning the means and tactics for decision-making.

Mark \& Henry (2004) focus on behaviour in terms of its influence on outcomes. They define changes in action as behavioural processes, which often comprise long-term outcomes of interest.

March (1991) observes that decision-making behaviour is related to rational processes, which may follow routines, but he also defines decision-making in terms of experimental learning, where outcomes may have to be interpreted and solutions may be found, which may differ from the generally accepted optimum. He argues that the process of decisionmaking is ultimately more significant than the outcome; and the process is related to behavioural and ethical influencing factors.

For the purposes of this research paper, these factors are viewed as informing decision outcomes, in other words, showing how decisions are made.

Ajzen (1991) explores behaviour under the term of planned behaviour by focusing on the individual's intention to act. Behavioural achievement depends jointly on motivation (intention) and ability (behavioural control). The subjective factor as a subjective norm 
refers to the perceived social pressure to perform or not to perform a particular behaviour.

The Department of Energy \& Climate Change (2012) relates driving factors for influencing energy behaviour of decision-makers in an individual, group and material context. The environment as an outer cycle represents the material context, as there are schedules, objects, infrastructure, institutions, technologies, and frameworks. Social aspects are mentioned as inner cycles, and individual factors are in the centre. The following social or group factors are also identified: influencers, identity, norms, roles meanings and networks. Individual issues constitute habits, agency, emotions, values, beliefs and attitudes, and costs and benefits.

Rosenkranz et al (2013) express norms in relation to action associated with unwanted emotions, such as guilt, embarrassment, shame, which an individual feels when he/she is not complying with them. Observing others can, therefore, affect individuals' action through perception, by influencing behaviour of households impacted by social norms when deciding whether to improve energy efficiency in private households.

Heuristics are mentioned in the decision-making context by Lunenberg (2010). He considers a set of heuristics to guide decisions. Heuristics constitute a rule of thumb; for example, controlling the centre of the board when playing chess. In terms of social and behaviour related sciences, this translates into general rules of thumb, such as 'the customer is always right'. Heuristics, therefore, help simplify complex decision-making situations. However, this approach, as with judgment and intuition, may oversimplify complex problems. Beresford \& Sloper (2008) argue that heuristic models describe the actual process of decision-making. Choice is the outcome of a process, which involves assessment and judgment, and, finally, the evaluation of different options. Heuristic models specify a process rule. The basis of their argument is that although the optimal solution to problems is unclear, heuristics can be used to find a good enough solution. Heuristics, based on reasons, often focus on a search for cues or reasons for action.

Müller-Hansen et al. (2017) define actions as intentional and subjectively meaningful activities and behaviour as a broader concept that included unconscious and automatic activities, such as habits or reflexes. Decision-making is a cognitive process choosing between alternative actions, which may include analytic and intuitive modes of thinking. 


\section{Political decision-making}

In a behavioural context, political decision-making models are part of the literature about decision-making processes:

Mori (2010) relates political behaviour to different power and conflicts of interests of decision-makers. Conflicts diminish when efforts are made to ensure shared visions between different stakeholders. An integrative framework in microfinance organisations reflects especially on the strategic decision-making processes of stakeholders. Customers in the B2C context in the renewable heating market are one stakeholder group. These stakeholders are related to the human beings behind the organisation and focus on three criteria: (1) rationality, expressed as a focus on information, use of analysis and use of techniques, which refer to the rational decision-making process' different stages; (2) political behaviour, expressed as use of power, coalition formation, individual interests and negotiation; (3) intuition, expressed as personal judgment, gut feeling, and past experience.

Political behaviour is hereby contextualised as behaviour by individuals or groups, when using power or exercising influence (Child, Elbanna \& Rodrigues (2010)). Political behaviour comprises actions to serve decision-makers' self-interests. For strategic decisions, it is seen as relevant for the interaction between people. Transparency is considered essential for good corporate governance and political studies can inform corporate governance policies. Political behaviour as behaviour of individuals or groups involves the use of power or exercise of influence.

Eisenhardt \& Zbaracki (1992) differentiate between bounded rational and political decision-making models. Bounded related models are seen as a reaction to cognitive assumptions about individuals; political models are expressed as a reaction to groups and their social assumptions - they are individually rational, but not collectively so. They argue that organisations are coalitions, comprised of people and competing interests, in which conflicts may arise.

Miller (2010) also relates politics strongly to an organisational context based around a division of labour, allocating different tasks, authorities, and power to groups or interests, which do not always share the same goals. This may lead to conflicts and contention.

To sum up, action-based and behavioural decision-making models are focused on decision outcomes. Unlike rational decision-making processes, they do not relate to a 
clear structural evaluation process. Decisions can be spontaneous and may be influenced by personal, social, or environmental issues related to the decision-maker. Political decision-making mainly focuses on strategic and structural approaches and competing interests of groups and coalitions may lead to conflicts. In the end, the most powerful group and their goals may give rise to the final decision. Corresponding decision-making models cannot be seen entirely as rational or bounded rational decision-making models.

\subsubsection{INTUITION-BASED DECISION-MAKING AND SENSE-MAKING}

A question related to perception in decision-making is: why does something make sense to the decision-maker? It is, therefore, related to the decision-making process as insight and a sequence before activities or action take place as the decision outcome.

Mori (2010) relates intuition to strategic decisions based on deep and intimate knowledge of the situation in which the decision-makers reach their decision. Personal judgment, gut feeling, and past experience form the basis of the decision.

Eisenhardt \& Zbaracki (1992) define intuition as incremental adaptations and explain that it is an assumption from which decisions emerge, or an assumption on which different perspectives of decision-makers are based at a particular time.

Khatri \& $\mathrm{Ng}$ (2000) propose three indicators to describe the role of intuition in strategic decision-making: (1) reliance on judgment, rather than computational routines for work, which cannot be analysed, required, when the decision needs to be made quickly, in the absence of adequate information and without precedent; (2) reliance related to experience as knowledge of a specific problem and its solution; (3) gut feeling as a strong feeling about the decision, lacking rational reasoning. Intuition constitutes deep and intimate knowledge based on experience of the situation, which is faced by decision-makers. Overall, the authors argue that strategic decision-making is a process, involving both rationality and intuition.

With respect to presumption and its interpretations, Weick, Sutcliffe \& Obstfeld (2005) see sense-making as the development of plausible images that rationalise what people do. Organisational sense-making asks the people involved, 'What's the story here?', when they are confronted with something unintelligible. Answers emerge from dialogue and connections with past experiences. Finally, decision outcome is about action and 
communication as an ongoing process; it is viewed as a meaningful exchange between actors and their environment. Sense-making is considered in relation to interdependent people who search for meaning, settle for plausibility, and move on. Taken together, these properties can be perceived as micro-level actions with large consequences. Wright (2004) considers sense-making a social process. The sense made by individuals of certain situations is linked to their experience and mind-set.

To conclude, issues, such as experience, feelings, and intimate knowledge, indicate personalised characteristics, related to decision-makers and their bounded awareness. The decision-making process is therefore related to the personal insights of decision-makers and to questions about how and why decisions emerge. In other words, it is connected to rational and/or bounded rational factors on the one hand (why), and the assessment and outcome on the other hand (how and what). Main criteria are indicated in Table 1.

\subsection{STAKEHOLDER RELATED ASPECT OF DECISION-MAKING MODELS}

\subsubsection{STAKEHOLDER CONTEXT}

Freeman (1984) defines a stakeholder as any group or individual that can affect or is affected by the achievement of the corporation's purpose.

Mitchell, Agle \& Wood (1997) qualify persons, groups, neighbourhoods, organisations, institutions, societies, and even the natural environment as actual or potential stakeholders. They define stake as an area of argument, since it is on the basis of the stake that a decision as to what counts is ultimately reached. Stakeholder attributes are variable and unstable; they are socially constructed and do not contain an objective reality. Consciousness and wilful exercise may or may not be present.

In relation to the interacting, human related context, Daellenbach \& McNickle (2005) mention a very abstract way of operating within systems, referring to firms as an organisational unit. They define the crucial ingredients of a system: components, their relationships, the behaviour, or activities of the system. They refer to the relevant environment, its input, outputs, and the interest of the observer. The separation between the system and its environment means that there is a boundary. It deals with the question: what part of the system should be included? The advantage of seeing systems in a 


\begin{tabular}{|c|c|c|}
\hline Rational related aspects & Bounded rational related aspects & Differences \\
\hline Completely informed DM & $\begin{array}{l}\text { Activities of searching and satisfying } \\
\text { as a personalised bargaining process } \\
\text { DM interpret 'real world' through } \\
\text { their perceptions and subjectivity }\end{array}$ & $\begin{array}{l}\text { Character driven } \\
\text { influences at the } \\
\text { beginning or during } \\
\text { the decision-making } \\
\text { process }\end{array}$ \\
\hline $\begin{array}{l}\text { Attempt optimising clear goals } \\
\text { Observation based on } \\
\text { worldviews of DM }\end{array}$ & $\begin{array}{l}\text { DM decide on their intuition, } \\
\text { experience, advice from other people } \\
\text { or creative thoughts }\end{array}$ & $\begin{array}{l}\text { Influences of others } \\
\text { and their role on the } \\
\text { DM }\end{array}$ \\
\hline $\begin{array}{l}\text { Procedural orientation reduces } \\
\text { uncertainty, focusing rather on } \\
\text { processes than outcomes }\end{array}$ & $\begin{array}{l}\text { Political conflicts may fragment the } \\
\text { decision-making focus and result in a } \\
\text { lack of support for issues to be dealt } \\
\text { with, being bounded shows evidence } \\
\text { of connections between different } \\
\text { aspects }\end{array}$ & $\begin{array}{l}\text { Procedure of } \\
\text { emerging approach to } \\
\text { decisions }\end{array}$ \\
\hline $\begin{array}{l}\text { Gathering information, } \\
\text { developing alternatives and } \\
\text { selecting the optimal one }\end{array}$ & $\begin{array}{l}\text { Failures of omniscience of knowing } \\
\text { all alternatives, uncertainty about } \\
\text { relevant events and inability to } \\
\text { calculate consequences }\end{array}$ & $\begin{array}{l}\text { Foundation on certain } \\
\text { or uncertain aspects } \\
\text { by DM }\end{array}$ \\
\hline $\begin{array}{l}\text { Assumption of perfect } \\
\text { rationality fully determines } \\
\text { behaviour } \\
\text { Decisions under certainty } \\
\text { Direction in thoughts which } \\
\text { begin with facts, then value } \\
\text { premises and proceed to a } \\
\text { logical conclusion to prefer a } \\
\text { certain alternative }\end{array}$ & $\begin{array}{l}\text { DM not aware to all problems and } \\
\text { limited in time, decisions are taken } \\
\text { based on intuition, experience, } \\
\text { advice from others and some creative } \\
\text { thoughts }\end{array}$ & $\begin{array}{l}\text { Availability of time } \\
\text { and volume of } \\
\text { information to DM }\end{array}$ \\
\hline
\end{tabular}

Table 1: Rational vs. bounded rational decision-making processes

Source: The Author, based on Anderson (2002), Bennet \& Bennet (2008), Daellenbach \& McNickle (2005), Eisenhardt \& Zbaracki (1992), Franz \& Kramer (2010), Lunenberg (2010), March (1994), Mintzberg, Raisinghani \& Theoret (1976, ), Simon (1978), Turpin \& Marais (2004), Wilson (2010)

hierarchy is that relationships are shown in their context. Complex relationships may cause conflicts, due to the people involved, their worldviews, goals, aims, physical relationships, structures and processes, behaviour, and the control of action. They classify six elements of problems in the context of conflict: (1) the decision-maker; (2) their objectives; (3) the associated decision criterion; (4) the performance measure; (5) the control inputs or alternative courses of action; and (6) the context in which the 
problem occurs. Stakeholders are then seen as the people involved in systems. They assume various roles defining their position, inputs, interests and outcomes sought.

Yosie \& Herbst (1998) identify four categories of decisions involving stakeholders: (1) right-based decisions (e.g. legal and civil rights); (2) value-based decisions (e.g. the debate over abortion, school choice); (3) interest-based decisions (e.g. land use issues, economic development; (4) power-based decisions (e.g. voting, declarations of war). Transparency is important in stakeholder processes to ensure openness and accountability of all participants. Core and expansive factors can shape the future of stakeholder processes with reference to the core transparency and interactive decisionmaking.

Harrison et al. (2015) relate stakeholder theory to creating more value among stakeholders. Perspectives vary as to who should share in the created value.

Stakeholders in this research are any group or individual, which may affect the decisionmaking process and participate in stakeholder processes that are socially constructed (Mitchell, Agle \& Wood, 1997). Engaged parties extend to other individuals, firms, groups or regulators involved in the decision-making process.

\subsubsection{STAKEHOLDER ROLES}

Daellenbach \& McNickle (2005) define the characteristics of people involved in the stakeholder context: problem owners are persons who exercise control over the choice of course of action. Normally, they are also the decision-maker. Problem users use the solution and execute the decision approved by the problem owners or decision-makers. They have no authority to change the decision. Problem customers are the beneficiaries or victims of the consequences of using the solution. Finally, problem analysts or solvers analyse the problem and develop a solution for approval by the problem owners.

Based upon research conducted by the European Environmental Agency (1999), Castellani, Piazzalungs \& Sala (2013) identify different influences, which can be used for the assessment and management of environmental problems, related to positive and negative effects of wood burning. Bi-directional relationships are regarded as important for the exchange of understandable information about science and policy, for example. 
Different roles of influencers are also identified; those related to individuals constitute drivers and pressures in a wider political and environmental context.

Gachet \& Brézillon (2002) note four possible roles in decision-making with social networks, enterprises, communities, and task forces playing a role. (1) Sensors mainly detect a change in context. An actor can be a sensor at the beginning of the decisionmaking process. New information as an external event may lead to a change in the problem definition and possibly in the decision-making structure. (2) Processors are able to proceduralise the contextual knowledge according to the problem to be fixed, and to turn it into some meaningful knowledge. Proceduralised knowledge can lead to a change in context. (3) Decision-makers use the knowledge in the proceduralised context to formulate the requirements to solve the problem of what has to be done. (4) Satisfiers fulfil an abstract requirement. They can lead to change in context. As an example in a firm context, they mention machine tool diagnostics, where a maintenance expert might be the sensor who diagnoses the problem. The production manager then generates a new production plan as processor. The director chooses the final plan to implement as decision-maker. The machine operator will finally benefit as satisfier.

Ackermann \& Eden (2011) relate stakeholders to the demands they can make in organisations. They classify stakeholders on power-interest grids. Players have significant power and interests and are, therefore, significant stakeholders. Subjects have notable interest but little power. They could be encouraged, in coalitions, to increase their power and to convert to players. Context setters have significant power, but little interest; they can influence the overall future context. Finally, the crowd consists of stakeholders with little interest and little power; they are seen as potential rather than existing stakeholders. Often, discovering the networks can often reveal new stakeholders or may indicate the demand for further disaggregation.

Bryson (2004) reflects on the work of Ackermann \& Eden (2011), adding a problemframe stakeholder map. To find winning coalitions, differences are identified between weak and strong supporters, as well as between weak and strong opponents.

To sum up, influences of the stakeholders on the decision-making process and the decision-maker depend on their role, which reflects the structure of the decision-making process. Bryson (2004) puts pushing or damping influences together in a simple 
classification, which consists of four terms: weak and strong supporters, as well as weak and strong opponents.

\subsubsection{DECISION-MAKING CYCLE}

Daellenbach \& McNickle (2005) relate the achievement of goals to efficiency and effectiveness. Efficiency is viewed from the perspective of how well resources are used in a given activity. Effectiveness is considered as how well the goals or objectives of the entity or activity are achieved. True efficiency also considers the overriding objectives as this enhances the effectiveness of decisions taken by the decision-maker. Effectiveness deals with doing the right thing, efficiency with doing things right. System thinking considers decision-making within a system context. Reductionist cause-and-effect thinking, which studies individual parts of the system, may not be sufficient to evaluate effective action. In order to get a complete picture, it is essential to study the systematic role in the system. With respect to management aspects, situations have to be viewed from an observer perspective, since people viewing the same situation with the same purpose in mind may form different conceptualisations. Conceptualisations are dependent upon the individuals' personal factors, of which they may not even be aware.

Bennet \& Bennet (2008) explore the complexity of decision-making processes, differentiating between diverse connections as part of the relationships during the decision-making process. Emergence is a global or local property of a complex system that results from interactions and relationships between its people. These characteristics represent stable or quasi-stable patterns, like culture, trust, and attitudes. Decisionmakers must increasingly rely on their intuition and judgment at the point of action. Organisational learning requires individuals to work together and to combine their knowledge through interactions.

The butterfly effect occurs when small changes in a complex system result in significant disruptions. A tipping point occurs when complex systems change slowly until a threshold is suddenly reached, which creates large changes in the system (crash). Feedback loops can be self-reinforcing or damping, improving a situation or making it worse.

Dynamic factors also influence the decision-making process in a number of ways. Mintzberg, Raisinghani \& Theoret (1976) define six dynamic factors in the managerial 
context: (1) interruptions (may cycle back or bargain until blocking forces disappear), scheduling (time) delays; (2) timing delays; (3) speedups; (4) feedback delays (decisionmaker waiting for result); (5) comprehension cycles (cycling back to earlier phases to recognise the issue or to understand consequences and alternatives); and (6) failure recycles (waiting for an acceptable solution as a new path).

Tucker et al. (2005) especially explore double-loop learning processes in organisations, which consider interaction based on cause-effect chains for strategic decision-making and learning from experience of engaged participants. In a managerial context, differences are made between single-loop learning and double-loop learning processes. Single-loop learning is considered difficult when mechanisms guiding the decisionmaking process are not questioned or modified to meet changing environmental conditions. Double-loop learning re-evaluates the governing mechanisms. The process then often leads to new decision strategies. Positive or reinforcing feedback loops amplify the behaviour of a system, negative or self-correcting feedback loops counteract changes by working to offset or balance the declination of a system.

To conclude, the decision-making cycle or, in other words, processual approach, may influence the time to reach a decision. Feedback loops or other dynamic factors, such as interruptions, delays, or more general damping and accelerating impacts are some of these influences (Bennet \& Bennet, 2008; Mintzberg, Raisinghani \& Theoret, 1976; Tucker et al., 2005).

\subsection{SUMMARY}

With respect to the literature review and the design of an a priori conceptual framework, rational and bounded rational approaches to the decision-making process are to be considered as essential. The context is the purchase of renewable heating technologies and the role of decision-makers is performed by homeowners. Qualitative decisionmaking models will be considered as part of a qualitative research approach to strongly consider the social contribution during the decision-making processes of end users. Essential extracts from the literature review are presented in Table 2.

The seminal work of Mintzberg, Raisinghani \& Theoret (1976) defines decisions as commitments to action and the decision process as a set of actions and dynamic factors. Their research indicates that decision-makers reduce complex decisions to sub-decisions 
to which they apply interchangeable procedures or routines. Decisions have been analysed as related to an organisational context with connections between the decisionmakers and their (market) environment. In the context of the research topic, purchasing of renewable heating technologies is a long-term decision and involves end users in a greater B2C context for investment products, therefore, connected with other stakeholders. Moreover, there are no pre-established routines for the decision-making process (Morris, Greenwood \& Fairclough, 2010).

Rational models assume that decisions are reached under complete information (e.g. Turpin \& Marais, 2004). Rational choice relates to the overall term of rationality assumptions about the future consequences of current actions and about future sentiments with respect to their consequences (March, 1991). The models, therefore, consider different stages until the decision-maker has gathered appropriate information to develop alternatives in order to select the preferred product in a final decision (Eisenhardt \& Zbaracki, 1992). However, rational decision-making, with respect to more complex strategic decision-making, is considered limited by the cognitive and political realities of the decision-maker (Mori, 2010). Rational decision-making models relate to objective decision-making aspects. Objectivity may be expressed as an interpretation of facts or conditions independent of the observer's mind (Daellenbach \& McNickle, 2005). This leads to the question of whether there can be objectivity or whether the decision-making process is bounded to influencing factors.

In contrast, bounded rational models argue that these rational related circumstances are idealised conditions. The decision-maker is not aware of all problems to be considered and is limited by time and creative thoughts (Lunenberg, 2010). The evaluation of decisions may be affected by interpersonal influences, cognitive and affective processes, motivational aspects, and, finally, changes in outcomes (Mark \& Henry, 2004). Decisionmaking processes bounded to certain circumstances involve the consideration of individual frame conditions. Garbage can models relate to rather randomly related and not analytical decision-making approaches (Eisenhardt \& Zbaracki, 1992). Decisionmaking may then consider rapid changes between preferences when problems arise (Rainey, Ronquillo \& Avellaneda, 2010). Intuition is a very strongly related characteristic, which is based on a deep and intimate knowledge of the situation in which the decision-maker reaches a decision (Mori, 2010). Criteria consist of personal judgment, gut feeling, and past experience. 
Overall, the literature review and further interviews reflect on decision-making processes, regarding how and why decision-making processes take place. Questions about what decisions will be part of the data collection in this thesis. More profound questions have to be answered about presumptions and their socially related interpretations, theorised as sense-making (Weick, Sutcliffe \& Obstfeld, 2005). These questions will be addressed to end users as homeowners and decision-makers for the purchase of renewable heating technologies. Their relationships with experts, their personal environment, and overall political outlook will be considered. The evaluation and identification of stakeholders will, therefore, form part of the further research and data collection in the research field.

Freeman's (1984) proposes that stakeholders are any group or individual that can affect or is affected by the achievement of corporation's purpose, as mentioned above. The explorations about stakeholder aspects, thus, are not only of relevance in the extensively analysed organisational context of firms, but also with respect to all engaged human beings, with their relationships and influences. As Mitchell, Agle \& Wood (1997) conclude, the stake as an area of argument is what counts. Stakeholder attributes are variable and not steady, they are socially constructed. Stakeholder roles, in the structural context of relationships of engaged stakeholders, are related to powers or weaknesses on their decision-making approach and their active or passive role in relation to the decision-maker. With respect to the research context and the purchase of renewable heating technologies, the essential point is whether stakeholders play a major role or not. Bryson (2004) reflects on four classifying criteria, as there are weak and strong supporters as well as weak and strong opponents. Transparency is considered to enable interactive decision-making (Yosie \& Herbst, 1998). Processual or chronological cycles constitute the best way to study the systematic role in the system (Daellenbach \& McNickle (2005). Contextualised to the role in the renewable heating market, the system and its connections stand for end users in the B2C context with involved stakeholders. Feedback loops may be self-reinforcing or damping factors, improving a situation or making it worse (Bennet \& Bennet, 2008). Other dynamic factors can be interruptions, delays or speedups (Mintzberg, Raisinghani \& Theoret, 1976). Positive or reinforcing feedback loops may amplify the behaviour of a system; negative or self-correcting feedback loops can counteract changes by working to offset or balance the declination of a system (Tucker et. al, 2005). 


\subsection{CONCEPTUAL FRAMEWORK}

Based on the literature review, an a priori conceptual framework has been developed to explore the decision-making process of end consumers, regarding the purchase of renewable heating technologies. The framework below consists of three elements; (1) decision-making stages; (2) influencing factors on the decision-maker; and (3) decisionmaking procedures (Figure 1).

\section{(1) Decision-making stages}

With respect to the research content, consumers as homeowners are decision-makers who can decide which renewable heating technology they use or would use in their house. Thus, in order to purchase a possible renewable heating technology, they go through a specific decision-making process that is related to consumer-related, technology-related, and provider-related factors. According to rational decision-making models (March, 2001; Turpin \& Marais, 2004; Eisenhardt \& Zbaracki, 1992; Lunenberg, 2002; Weick, Sutcliff \& Obstfeld, 2005) the decision-making process will be divided into four sequential stages: (1) gaining information; (2) selection of alternatives; (3) evaluation of the technical solution; and (4) choice. The study will explore the content and factors affecting each stage and the progression of the decision-maker from one stage to another.

\section{(2) Influencing factors on the decision-maker}

In a structural context, influencing factors are related to stakeholders who may be manufacturers and distributors of renewable heating technologies, friends, consultants, or organisations. More generally, they are seen as organisations or any group or individual who can affect or are affected by the achievement of the organisation's objectives (Freeman, 1984). In the research context, the objective shall be to explore the motives of the decision-maker to purchase or possibly purchase available renewable heating technologies.

The individual roles of various stakeholders who might affect consumer choice shall be classified into five roles: strong and weak supporters $(1+2)$ and strong and weak opponents (3+4), all according to Bryson (2004), and further observers (5) who do not affect the choice.

The characteristics are as follows: 
Supporters, who support the motivation of decision-makers to invest in renewable heating technologies, e.g. manufacturers.

Opponents, who restrain the motivation of decision-makers to invest in renewable heating technologies, e.g. family members or authorities responsible for final approvals of new installations.

Further, the categorisation of supporters and opponents identifies two positions:

Active position: being a necessary part in the chain for installing or cancelling a possible renewable heating concept, e.g., without a suitable heating concept from a manufacturer, the project will not be terminated.

Passive position: being an optional part in the chain for installing or cancelling a possible renewable heating concept, e.g., a consultant might influence the decision, but is not required for the implementation of renewable heating concepts.

Observers: viewing the decision without taking a clear position. They are either neutral or do not have any power to affect the decision. In order to finalise the decision-making process without delay, they should be avoided as their involvement takes time without contributing to the progression of the decision action.

\section{(3) Decision-making procedure}

The third element of the framework is linked to the interaction of the previously discussed elements as a processual context. Further, insights of decision-makers shall be investigated, which are the reasons to interact in a certain way. They primarily concern how decision-makers reach decisions and how these are related to boundaries.

The procedure takes place with different sequences. There may be damping or improving (accelerating) factors, feedback loops, delays or interruptions (Mintzberg, Raisinghani \& Theoret, 1976; Bennet \& Bennet, 2008; Tucker et. al, 2005). The number of factors involved and their influence will affect the decision-making time and choice.

The approach to decisions is seen as a process that is related to choice and the involvement of assessment and judgment (Beresford \& Sloper, 2008); they reflect decision-makers' boundaries. In contrast to rational decision-making models, not all alternatives may be known (March, 2001) and accurate information is not available (Weick Sutcliff \& Obstfeld, 2005). Boundaries can be political views or political 


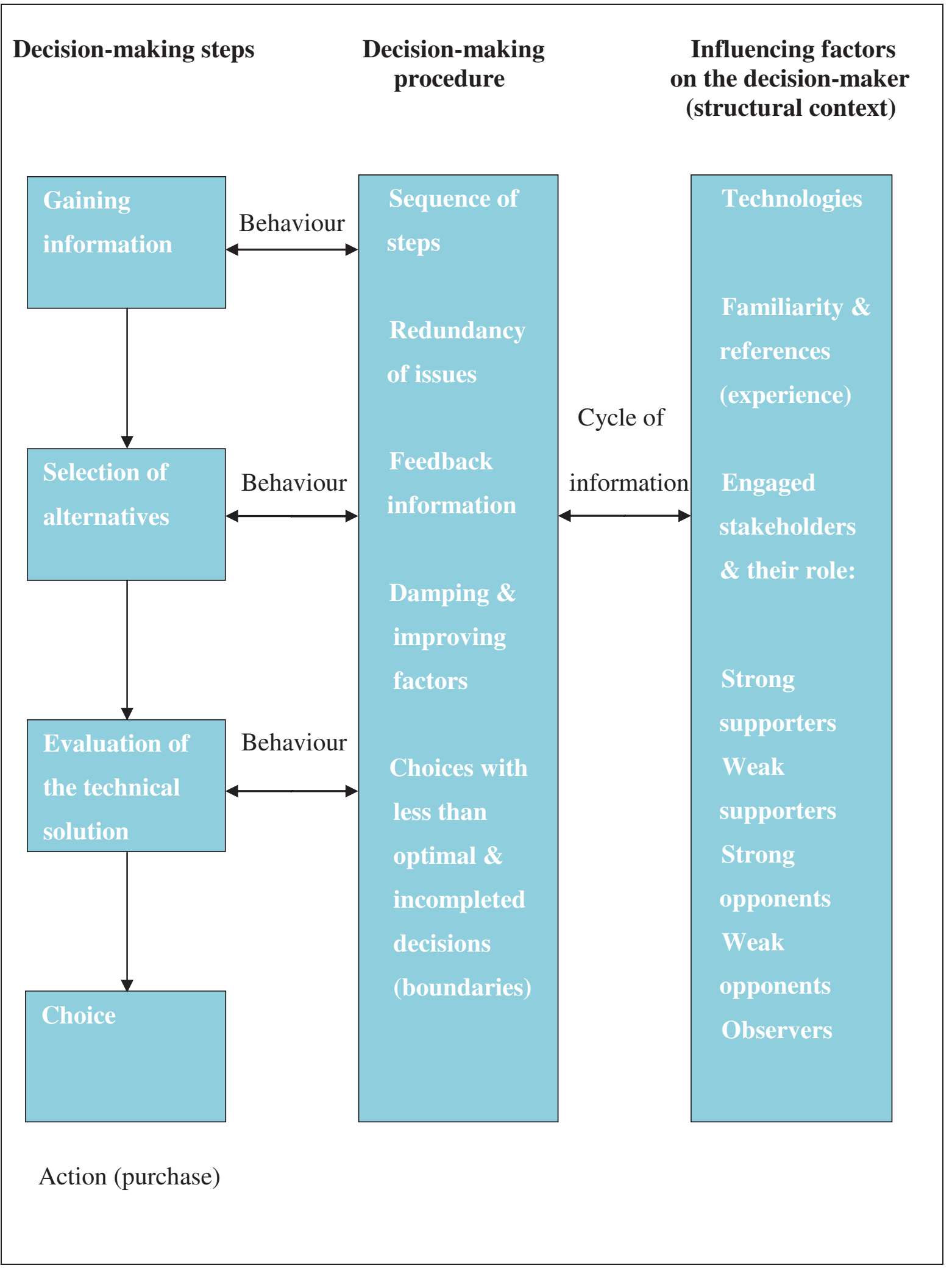

Figure 1: Conceptual framework: decision-making process of decision-makers

Source: The Author, based on Bennet \& Bennet (2008), Beresford \& Sloper (2008), Bryson (2004), Daellenbach \& McNickle (2005). Eisenhardt \& Zbaracki (1992), Freeman (1984), Lunenberg (2002), March (2001), Mintzberg, Raisinghani \& Theoret (1976), Tucker et al. (2005), Turpin \& Marais (2004), Weick, Sutcliff \& Obstfeld (2005), Wilson (2010). 
conflicts (Turpin \& Marais, 2004; Wilson, 2010). Associated boundary choices involve subjectivity of decision-makers through their perceptions (Daellenbach \& McNickle, 2005). As they cannot be aware of all problems due to their time limitations, bounded rationality problems are assumed to be solved by decision-makers based on intuition, experience, advice from others, or some creative thoughts (Lunenberg, 2010). 


\subsection{GENERAL COMPARISON OF DIFFERENT RESEARCH APPROACHES}

As part of the further methodological research approach, it is significant to consider fundamental assumptions and beliefs, which undergird research, because they influence the methods, data, and evidence used in the research process and the way in which they will be interpreted (Daymon \& Holloway, 2011). The principles on which the research is founded constitute the philosophical orientation towards the research and the generated form of knowledge.

Research involves different steps, which belong to philosophical debates and result in different quantitative and qualitative research approaches:

First, philosophical debate about ontology: Easterby-Smith, Thorpe \& Jackson (2012) define ontology as views about the nature of reality and existence. Further debates go in different directions and fuel other discussions. One of two extreme positions represents the realist point of view, emphasising that the world is concrete and external. Typically, this is a debate held by philosophers of natural science. The other position contains several varieties of relativism aspects. It suggests that there are not only scientific laws to be discovered, but that they are created by people.

Daymon \& Holloway (2011) associate this philosophical debate with the study of being and involved ideas, related to human existence. It engages the nature of being and social reality.

In their early and fundamental research study, Burrel \& Morgan (1979) use ontology, to address the question of whether reality has an objective nature and is a given, or whether it is the product of individual cognition.

Second, philosophical debate about epistemology:

Easterby-Smith, Thorpe and Jackson (2012) relate epistemology to a general set of assumptions, which describe ways of inquiring into the nature of the world. Two contrasting views have been pinpointed as fundamental philosophical positions: positivism and social constructivism. Strong positivist positions of realists will normally express data in a quantitative form. Constructivist positions of relativists assume no preexisting reality and there are multiple qualitative and quantitative methods through which views may be gathered. 
Greener (2008) relates the approach of positivists to empirical testing and the approach of interpretivists to subjective thoughts and ideas. Therefore, positivism focuses on a single reality, while interpretivism adopts a multiple reality perspective, observing the world through the eyes of the people being studied.

Daymon \& Holloway (2011) characterise ontology as a philosophical study or theory of knowledge. They consider that it investigates what amounts to valid knowledge, while examining the question: how does the researcher know the world?

Burrell \& Morgan (1979) connect assumptions about the grounds of knowledge with the philosophical discussion about ontology. They claim that ontology is focused on the question of whether the researcher's experience and personal nature affect the categorisation of knowledge as hard and real, or softer and more subjective.

Wayuni (2012) subscribes constructivism as a belief that reality is constructed by social actors and by people's perceptions. Due to the subjective human perspectives, social reality may have multiple perspectives and can change. Therefore, based on constructivist approaches, researchers tend to interact and have a dialogue with the research participants, as they do not see a single truth in the way that positivists do.

Another often-mentioned paradigm located between the outer positions of positivism and constructivism is referred to in the literature as post-positivism.

According to Guba \& Lincoln (1994), post-positivism stands for a reality, which is assumed to exist, but is imperfectly apprehensible due to human intellectual mechanisms and the intractable nature of phenomena. Wahyuni (2012) mentions post-positivist approaches and refers to generalisation as positivists do, but admits knowledge is a result of social conditioning. In order to understand social realities, they have to be framed in a context of relevant laws or social structures of the observed phenomena.

To summarise, the different research approaches are related to the following research questions and remarks (Daymon \& Holloway, 2011; Greener, 2008; Burrel \& Morgan, 1979):

Ontology: 'What can be said to exist?', 'Is reality objective in nature or is it the product of one's mind?'. It influences the epistemology and methodology of a research study.

Epistemology: the next research step will then be to explore: 'How do I know the world?', 'What is the relationship between the inquirer and the known?'. Other related 
questions are: to what extent can we know something is true? What is regarded as true or false and should it be regarded in a hard and real form, or in a more subjective way, respectively? This theory of knowledge determines for the researcher what counts as valid knowledge, such as knowledge of constructivists or positivists.

Guba \& Lincoln (1994) talk about paradigms as basic belief systems, which are based on ontological, epistemological and methodological assumptions. They represent a worldview and define the individual place in it.

\section{These steps ultimately then lead to different methodology approaches:}

Research methodology: this term is concerned with questions such as: 'How do we know?'. It refers to the ways in which knowledge is acquired. Methodological issues are the concepts themselves, their measurement and the identification of underlying themes. In other words, it includes a range of methods that can be used in order to achieve research goals.

Methods: they consist of step-by-step techniques that researchers adopt as part of a systematic process; for example, quantitative or qualitative approaches. They include the procedures and tools required to realise the research. Questionnaires, observations or interviews can be mentioned as method-based techniques.

\subsection{QUANTITATIVE RESEARCH APPROACH}

A quantitative approach is normally associated with a so-called deductive approach to testing theory (Greener, 2008). Often, numbers and facts (therefore, a positivist model and an objectivist view of the objects) are studied. The deductive approach begins with a look at theory, and produces hypotheses related to the focus of the research and used to test a theory. This approach will hereby be referred to as impersonal objective research to prove or disprove a hypothesis for the purposes of this research paper.

Daymon \& Holloway (2011) associate quantitative methods with numbers and detachment and are, therefore, not well-suited to description. These methods point to research through testing, rather than that which emerges from meanings derived from participants. With reference to research in the field of public relations and marketing, quantitative research is considered to be grounded in positivism in order to explain phenomena based on what is already known. This is regarded as one relevant aspect, 
which examines questions about cause and effect. Contrastingly, the authors consider the quantitative approach to be less suited to investigating the complexity and transformability of contemporary communication relationships.

One important aspect considers how the research may be influenced due to significant consequences, such as evidence, which arises from the construction of the sampling design. A high response rate in a survey is important to make the sample representative (Easterby-Smith, Thorpe \& Jackson, 2012).

If the sampling is wrong, accuracy in calculating the results is of no consequence because the results will not be generalised. If a summary measure does not alter significantly, it will be treated as robust. The greatest part of data analysis is seen in hypothesis testing, when it is appropriate to generalise beyond a specific sample. Sampling data has to be identified in order to draw conclusions from that pattern.

Analysis and testing of quantitative data from social sciences has to be of statistical significance. Variables as relations between the different answers must be identified. The collected data can then be put into a matrix or put directly into statistical package software, such as SPSS (Statistical Package for Social Sciences). Their statistical significance must be evaluated in order to test the hypotheses and to confirm or reject the theory.

Quantitative research, with regard to positivist research approaches, can be summarised as a view on causal explanations, focusing on describing and explaining behaviour, rather than describing meanings of social phenomena (Kura, 2012).

\section{Evaluating thoughts}

With respect to the research topic, the exploration of decision-making processes indicates a complex interaction of information, behaviours and feelings of end users. It also indicates the necessary interpretation of their feedback; in other words, what end users already know and how they form their interpretation of the topic. Answering and analysing a high volume of questionnaires to obtain reliable data for statistical analysis without personal interaction is supposed to lead to different conclusions. These deductions may be applied not only to the research participants, but also to the researcher. 
As Greener (2008) argues, human behaviour is difficult to grasp and isolate, since it changes constantly and can offer different dimensions to different audiences. Greener says that it rarely makes sense to look only at numerically measured evidence when trying to understand what is going on in groups of people.

Against this background, following the standpoint of Easterby-Smith, Thorpe \& Jackson (2012), it is contended that the validity of sufficient knowledge of the research participants during the data collection may cause incorrect sampling, but might be of no consequence to the outcome, based on a statistical analysis.

Some relevant comparison issues between quantitative and qualitative research are indicated in Table 3.

\begin{tabular}{|l|l|l|}
\hline Aspects & Quantitative approach & Qualitative approach \\
\hline Research path & Rather deductive & Rather inductive \\
\hline Approach start & $\begin{array}{l}\text { Looking at theory and } \\
\text { producing hypotheses }\end{array}$ & $\begin{array}{l}\text { Generation of theory from } \\
\text { data as description of } \\
\text { participants' experiences }\end{array}$ \\
\hline Data volume & $\begin{array}{l}\text { Large sample sizes to } \\
\text { model interaction effects }\end{array}$ & $\begin{array}{l}\text { Small but comprehensive } \\
\text { sample sizes, such as } \\
\text { - in-depth interviews } \\
\text { - observation }\end{array}$ \\
\hline Base & $\begin{array}{l}\text { Explanation of already } \\
\text { known phenomena }\end{array}$ & $\begin{array}{l}\text { Explanation of } \\
\text { contemporary } \\
\text { communication } \\
\text { relationships }\end{array}$ \\
\hline Critics & $\begin{array}{l}\text { Accuracy in calculation of } \\
\text { no consequence with } \\
\text { wrong sampling }\end{array}$ & $\begin{array}{l}\text { Examination of questions to } \\
\text { cause and effects, } \\
\text { high subjectivity due to } \\
\text { communication with } \\
\text { stakeholder research groups }\end{array}$ \\
\hline
\end{tabular}

Table 3: Comparison of quantitative and qualitative research approaches

Source: The Author, based on Greener (2008), Easterby-Smith, Thorpe \& Jackson (2012) 


\subsection{QUALITATIVE RESEARCH APPROACH}

Qualitative researchers seek to uncover the views and meanings of research participants in order to understand the world in their terms (Daymon \& Holloway, 2011). One aspect that must be taken into account is the way in which their understanding changes when communicating as a member of a stakeholder group. However, some critics consider qualitative research too subjective.

Greener (2008) argues for qualitative approaches by claiming that behaviour is difficult to grasp as it changes. It rarely makes sense to look only at the numerical measured evidence of data. The focus will not only be on trying to estimate things about a population. The data shall be understood and related to theory or ideas.

Views and meanings are to be sought by the researcher (Daymon \& Holloway, 2011). Qualitative research methods represent a powerful means of gaining an in-depth and holistic understanding of relationships.

There are various approaches that can be used in qualitative data collection (EasterbySmith, Thorpe \& Jackson, 2012): interviews are one way to use so-called language data. Another method is observations. In-depth interviews provide an opportunity to probe deeply and to enter into new dimensions and insights with the interviewee. The authors refer to constructivists and strong constructivist positions. In both cases, they assume that there may be different realities in their position, which require gathering views through different research methods. In the former case, they may be qualitative and quantitative. In the second case for strong positions, they may pay even more attention to the use of language and conversations as no pre-existing reality is assumed; thus, there is no absolute truth.

After collecting the data, framing the data indicates ways to make sense of qualitative data and to observe links between the data that can be developed (Easterby-Smith, Thorpe \& Jackson, 2012).

\section{Grounded research}

The method of natural language analysis focuses on the detailed analysis of scripts, rather than other aspects such as physical or symbolic artefacts. Otherwise, incorrect interpretations could arise, since their interpretation requires the researcher to have more training for interviews. Two methods of natural language analysis are mentioned 
First, content analysis approaches: the researcher considers the data for constructs and ideas that have been decided in advance. Content analysis indicates a deductive method.

Second, grounded analysis: the research data is linked in a more holistic way. Researchers let the data speak for itself and leave room for the use of more intuition in understanding the data.

The grounded theory approach represents the idea that research can be developed from the collected data (Daymon \& Holloway, 2011). The inductive approach requires the researcher to begin without a hypothesis. However, it is worth developing a research question.

In their fundamental work, Glaser \& Strauss (1967) consider grounded theory as a research approach, which derives from data, illustrated by characteristic data. They argue against deductive concepts which derive from certain relevant concepts and hypotheses. In contrast, a systematic discovery of the theory from the data is necessary to form theoretical concepts.

The grounded theory approach represents the idea that research can be developed in a more suitable way from the collected data (Daymon \& Holloway, 2011). The starting point of research adopting a grounded theory approach lacks a hypothesis or theory; instead theory is developed throughout the course of the research both inductively and deductively.

Therefore, it is contended that this approach provides an exciting method for the creation of theoretical ideas, in a stepwise manner, by means of a processual approach. This approach also obtains reliable data in response to the criticism that it is too subjective. Glaser \& Strauss (1967) argue that this approach should be embarked upon with an open mind and without pre-research assumptions. The goal is generating ideas by comparing where facts are similar or different to generate properties of categories in order to increase their generality.

Timonen et al. (2018) consider grounded theory study as explanations of a process or phenomenon to seek theories.

A sufficient number of users as interviewees have to be considered for a first sample. Compared to quantitative studies, the comprehensive single data collection process, which consists of in-depth interviews, can thus be limited. In-depth interviews will be a 
way to evaluate meanings and interpretations (Easterby-Smith, Thorpe \& Jackson, 2012). The number of interviewees will be reviewed as necessary with each interview by means of constant comparisons and increase of knowledge (Glaser \& Strauss, 1967).

In-depth interviews can reflect on certain issues such as the technical background of the interviewees, which gives the researcher (interviewer) more comprehensive answers due to greater awareness of context. Some main issues are indicated in Table 4.

For the purposes of this research paper, the grounded research approach is considered as a worthwhile and exciting research approach. It will be constructed, grounded in the data, which develops with each single interview into a theoretical concept. This approach allows for more open research, where the structure of the data analysis derives from the data, rather than being imposed on the external data as with quantitative or more concrete positivist approaches (Easterby-Smith, Thorpe \& Jackson, 2012). Whilst using provisional hypotheses, statements regarding the way in which the concepts are related may arise by a line-by-line analysis of the data (Strauss \& Corbin, 1992).

\begin{tabular}{|c|c|c|}
\hline Aspects & Critics & Advantages \\
\hline Approach & $\begin{array}{l}\text { High subjectivity, } \\
\text { data interpretation requires } \\
\text { training }\end{array}$ & $\begin{array}{l}\text { Involving and } \\
\text { communicating with } \\
\text { research participants, } \\
\text { communication is seen as } \\
\text { formative process to create } \\
\text { individual worldviews }\end{array}$ \\
\hline Hypotheses & $\begin{array}{l}\text { Too substantive, theory has } \\
\text { lower generality }\end{array}$ & $\begin{array}{l}\text { No hypothesis allows } \\
\text { guiding the conceptual } \\
\text { framework by data and } \\
\text { theoretical sampling }\end{array}$ \\
\hline Generalisation & Low and too weighty & $\begin{array}{l}\text { Quality of more importance } \\
\text { than the sampling size, } \\
\text { research 'let the data speak' }\end{array}$ \\
\hline Validity & $\begin{array}{l}\text { Grounded theory is } \\
\text { complex and shall not } \\
\text { follow a simplified version, } \\
\text { stages of categorisation or } \\
\text { coding may be condensed }\end{array}$ & $\begin{array}{l}\text { In-depth and holistic } \\
\text { understanding of } \\
\text { relationships in their } \\
\text { context }\end{array}$ \\
\hline
\end{tabular}

Table 4: Pros and cons of grounded research as a qualitative research approach

Source: The Author, based on Easterby-Smith, Thorpe \& Jackson (2012), Daymon \& Holloway (2011),

Glaser \& Strauss (1967), Strauss \& Corbin (1992) 


\section{Other Research Approaches}

The nature of case study research is bounded in place and time (Daymon \& Holloway, 2011). It requires intensive examinations often over a long period. Although, the findings will not be universal to all cases, some conclusions may resonate to apply findings to other situations. Case studies usually aim to capture features of contemporary events, so you can never have the final say. Case studies often require long examination periods.

The case study approach has a specific in-depth focus on a phenomenon (Daymon \& Holloway, 2011), which this thesis relates to a very close consideration on the investigation already in the beginning of the research.

With respect to the research question, my research will focus on the exciting question: to what extent are end users prepared to adopt certain technologies, rather than examining the reasons why end users decide for or against the purchase of renewable heating technologies. Yin (2012) contextualises this closer consideration with boundaries of cases; for example, a boundary based on a behavioural condition or event. Daymon \& Holloway (2011) even relate boundaries to place and time.

Action research is an action-based form of research where research participants reflect on an issue or problem (Daymon \& Holloway, 2011). Commonly, action researchers are part of the organisation they study. One goal is to produce practical knowledge on the way in which people live their everyday lives. Herr \& Andersen (2005) define action research as an inquiry, which is carried out by or with insiders of an organisation, but never to or on them. It is a spontaneous but also systematically undertaken process. Koshy (2005) argues for action research as a research methodology, developing the act of knowing through observation and questioning and, therefore, being involved in constructing one's own knowledge - situation based.

Despite my constructivist viewpoint, work with action research as a methodological approach is something I consider possible. However, I prefer a stepwise approach, where analyses of the transcribed data prove more interesting. As with the pieces of a puzzle, my research paper aims to create a picture to reflect more strongly on the grounded research approach. Further, my thesis is not constructed as a member of the research member group. Instead, I will reflect on the interviewees' information from a greater distance, on the basis of individual semi-structured interviews. 


\subsection{CRITICAL REFLECTION ON MY METHODOLOGICAL CONVICTION}

In Chapter 3.3, the reasoning for following a grounded research approach with respect to the academic outcomes of the research question was presented. Nonetheless, differences between the evaluated methodologies are indicated in Table 5.

\begin{tabular}{|l|l|l|l|}
\hline Criteria & $\begin{array}{l}\text { Quantitative } \\
\text { approach }\end{array}$ & $\begin{array}{l}\text { Qualitative non } \\
\text { AR approach } \\
\text { (for example: } \\
\text { grounded theory) }\end{array}$ & AR approach \\
\hline Data & $\begin{array}{l}\text { Using quantitative } \\
\text { data }\end{array}$ & $\begin{array}{l}\text { Mainly qualitative } \\
\text { data, but can also be } \\
\text { quantitative data to } \\
\text { gather views } \\
\text { (triangulation) }\end{array}$ & $\begin{array}{l}\text { Quantitative and } \\
\text { qualitative data, } \\
\text { triangulation }\end{array}$ \\
\hline Epistemology & $\begin{array}{l}\text { Mainly positivist } \\
\text { position, based on } \\
\text { facts and scientific } \\
\text { laws }\end{array}$ & $\begin{array}{l}\text { Different sets of } \\
\text { beliefs, truth and } \\
\text { laws created by } \\
\text { people }\end{array}$ & $\begin{array}{l}\text { Reflection on issues } \\
\text { by research members, } \\
\text { creating knowledge as } \\
\text { pragmatic theory }\end{array}$ \\
\hline $\begin{array}{l}\text { Methods } \\
\text { (samples) }\end{array}$ & $\begin{array}{l}\text { - Questionnaires } \\
- \text { Surveys } \\
\text { - Statistics }\end{array}$ & $\begin{array}{l}\text { - In depth-interviews } \\
\text { (grounded research) }\end{array}$ & $\begin{array}{l}\text { - Observation } \\
\text { - Questionnaires } \\
\text { - Interviews }\end{array}$ \\
\hline $\begin{array}{l}\text { Involvement of } \\
\text { the researcher }\end{array}$ & $\begin{array}{l}\text { Low, mainly } \\
\text { statistical analysis of } \\
\text { data }\end{array}$ & $\begin{array}{l}\text { High, due to direct } \\
\text { and in-depth } \\
\text { communication with } \\
\text { research objects }\end{array}$ & $\begin{array}{l}\text { Very high, due to } \\
\text { direct communication } \\
\text { and observation, close } \\
\text { involvement in the } \\
\text { research process }\end{array}$ \\
\hline
\end{tabular}

Table 5: Comparison of different research approaches

Source: The Author, based on Easterby-Smith, Thorpe \& Jackson (2012), Greener (2008), Daymon \& Holloway (2011)

Aside from this immediate reference to the chosen research path, I have become aware that there is much more underpinning my chosen approach and my insights, which finally resulted in this decision. Differences regarding this process have to be deducted between reflection and critical reflection or reflexivity as a deeper consideration: According to Smith (2009), knowledge outcomes are based on reflection as a means of learning about practice and exploring practice through structured or critical thinking, to consider a particular professional event or theme in the context of meanings. Reflection is, consequently, seen as a focus on professional practice. In contrast, reflexivity is 
considered to be used in research to conceptualise, analyse, and indicate to others the researcher's relationship with the research.

\section{Theoretical thoughts about reflection, critical reflection, reflexivity}

Finlay (2008) points out that the terms of reflection, critical reflection, and reflexivity are often confused and wrongly assumed to be interchangeable. Reflection, on one end of the spectrum, consists of thinking about something; reflexivity, on the other end of the spectrum, consists of a more immediate and dynamic process. Critical reflection sits inbetween the two.

Moon (2006) summarises these distinctions by stating that different levels of reflection seem to agree with different terminologies. Reflexivity and critical reflection are viewed as the deepest level of reflection. In terms of learning, this yields better quality outcomes.

Therefore, my research considers both - critical reflection and reflectivity - as a further and more critical approach to the research questions. A distinction is only made with respect to the less critical term, reflection, and its interpretation in the literature.

Reynolds (1998) distinguishes between reflection and critical reflection in the following manner:

Reflection is regarded as a management learning concept and is primarily expressed as a key element of problem solving. It is, further, seen as a focus on the presenting details of a task problem.

Critical reflection is considered by Reynolds to be a cornerstone of emancipator approaches to education. The purpose is to examine social processes, which have the status of unnoticed or unquestioned certainty. The fundamental task of critical reflection is to identify, question, and possibly change, the assumptions of the view of unquestioned common sense.

In summary, as argued by Moon (2006) the different debates surrounding reflection and deeper insights of critical reflection and reflectivity can be expressed in a two-stage approach of reflective writing and thinking.

In a first step, reflection is presented, as giving examples, generation of discussions, enabling practice and opportunities for feedback, giving a starting exercise, setting up ideas for learner and demonstrating samples. In a second and more comprehensive step, 
deeper reflection has to be facilitated. The introduction of a framework with description of levels of reflection is mentioned, introducing further exercises.

\section{My own findings as researcher}

At the end of this research approach, it will be important to reach new theoretical outcomes with respect to the research questions. Therefore, I have to look back over individual experiences, skills, knowledge or expertise of the involved research members. A changing process during the research may emerge. Reflective thinking and writing is a transformative process during which meaning is given to learning and modifying. Communication and discussion with other people is important to reflect on views and beliefs to generate theoretical interpretations on a doctoral level.

The following are concluding thoughts on my critical reflective thinking, which encouraged me to think about my ontological standpoint and influenced me to follow a constructivist approach.

At the beginning of my research, my aim was to use mainly quantitative, alongside some qualitative, key factors relating to the purchase of renewable heating technologies by homeowners as end consumers. More precisely, I intended to explore a 100\% supply of end consumers by designing B2C concepts with long-term issues until the year 2050. The topic and time period was established from different quantitative research studies based on calculations and assumptions regarding energy consumption. As quantitative analysis with calculations makes certain assumptions, such as price increases, the available capacity of non-renewable energy resources, or population development, these research parameters were finally considered to be over idealised assumptions.

Therefore, I decided to adopt the constructivist approach and inductive approach grounded in the statements of the involved end users. The reason and conviction for this decision was to investigate aspects in the direction of an increase in renewable energy distribution, rather than defining issues using a particular date. So far, this has required meanings, positions and existing knowledge of the market participants to be considered.

With respect to the core research question about the decision-making process of end users, I am convinced that a direct dialogue with end users as homeowners, and the meaning of this dialogue is deemed necessary. The interaction between end users and stakeholders, such as manufacturers and distributors of existing renewable heating technologies for detached and semi-detached family houses, has to be considered. 
Further, the personal environment, like family relations and character of end users, will have to be investigated.

\subsection{GROUNDED RESEARCH AS ADOPTED RESEARCH APPROACH}

I continue with the qualitative research approach and grounded theory research. Compared to deductive related approaches, I see the challenges and tensions related to building up a theory step-by-step, based on the interplay between data collection and theory construction.

Strauss \& Corbin (1992) mention the open coding, the first step of the coding process, as working on a puzzle to build up a picture.

This qualitative and mainly inductive research approach constructs the theory grounded in the data without a hypotheses; I consider this methodology an interesting way to build up a theory, based on a stepwise and creative approach. My reasoning is that this research path allows for an open and exciting start to the research, which requires deep involvement and dialogue with the involved research participants.

The sample for the grounded research approach comprises homeowners of old houses, which fall into different age groups. They will either have already purchased renewable heating technology or not. The sample will include male and female respondents. It will also consist of homeowners who live alone, with a partner, or have a family. The homeowners either have a detached or semi-detached property. A combination of various perspectives will form a more complete picture of renewable heating technology purchases.

\subsection{SEMINAL GROUNDED THEORY OF GLASER \& STRAUSS}

Grounded theory is mainly based on Barney Glaser and Anselm Strauss' early publication in the late 1960s (Glaser \& Strauss, 1967). The work is based on the interpretation of qualitative data, which observes hospital care and management of terminally ill patients.

The inductive approach to theory has been analysed in a vast number of academic publications, represented originally by first generation researchers, such as Glaser and 
Strauss, and subsequent researchers, such as Charmaz. Each of them has shifted their position at certain points and added other positions in later publications.

At the beginning of the further research approach, some background information about the leading literature from Glaser \& Strauss (1967) will be presented. This research later formed the basis for the further development of other grounded theory schools.

Glaser \& Strauss (1967) mention, in their book, conviction as a means to successfully close the gap between theory and empirical research and to improve methods for testing theory. They relate their work to studying social phenomena, especially based on qualitative data, such as data related to political, educational, economic, or industrial studies.

They refer the term grounded theory to the discovery of theory from data. Theory shall provide clear enough categories to explain behaviour in social related studies. Theory is generated by comparing large-scale units (comparative analysis).

\subsubsection{STRAUSSIAN VS. GLASSERIAN SCHOOL}

In their further research work, Glaser and Strauss went in two different directions with respect to the grounded theory approach. Both of them wrote several publications. Glaser (1992) believes that researchers should start their research without pre-suppositions. Contrastingly, Strauss (1987), later with Corbin (Strauss \& Corbin, 1992) recommends prior research using structured processes to make sense of data.

Strauss' School (later Strauss \& Corbin, 1992)

Grounded theory is seen to offer insights, enhance understanding and provide a meaningful action to them. Coding procedures build on, rather than test, theory. They help analysts consider alternative phenomena. Theory is viewed as a set of welldeveloped categories, forming a theoretical framework that explains some social, psychological, or other phenomena. The value of a framework deemed to be its facilitation in providing insights on perspectives and phenomena and to generate theoretical questions.

Data should be systematically gathered through the research process. Hypotheses derive from the data, which must be continuously compared to incoming data. The interplay of 
inductive and deductive approaches is considered the heart of theorising in order to create hypotheses about their relationships. Theorising is mentioned as the act of constructing a scheme to systematically integrate concepts through statements or relationships. The central category shall then be the main topic of the research.

Strauss \& Glaser point out that the theoretical perspective of a researcher will influence the stance the researcher takes towards the study. At the beginning, provisional hypotheses are also seen as possibilities which may arise during line-by-line analysis as microanalysis to generate initial categories. In their opinion, it is like working on a puzzle; the researcher has to analyse and sort the pieces.

Categories help to complete explanations about phenomena. They have to be validated through further data collection and analysis. Open coding is defined as the process for identification of concepts as building blocks of theory with these categories and subordinated properties. Theoretical comparisons bring out properties, which in turn can be used to examine the incident in the data. If the properties are evident within the data, the researcher does not rely on these tools.

Hypotheses refer to statements of relationships by axial and selective coding. Axial coding is viewed as the process of relating categories to their subcategories as concepts that pertain to a category to give it further clarification and specification. Axial coding stands for coding around the axis of a category. Subcategories answer questions like when, why, who, how and with what consequences to answer phenomena. Selective coding is the process of integrating and refining the theory. Thus, the relevance of the data for the theory will be examined. Memoing may help illustrate the analytical process and develop ideas; this is an important reflection. Theoretical sampling is the gathering of data, such as written records, driven by concepts. Data derives from the evolving theory and comparison of concepts by the researcher until each category is saturated. These concepts contain the researcher's thoughts for further theorisation.

\section{Glaser's school}

In the title of his work, Glaser (1992) already reflects very critically on the Straussian approach by saying emergence vs. forcing. As he explains in detail in his book, he is convinced that theory for properties emerges out of the data, and that these properties should not be structured before the data collection. He refers to this kind of forcing as 
preconceived conceptual description. In this context, he mentions the fear of biased perspective. Glaser understands the Straussian approach as an overload of procedures.

Memos are referred to as a theorising write-up of ideas that emerge during the coding process. He points out that problems emerge during the study and questions regarding the problem then guide theoretical sampling. Therefore, no preconception should take place in advance of the emergence.

Glaser, as Strauss does, mentions categories and properties to integrate variables out of the data. Categories are a type of concept and properties are a conceptual characteristic of a category. Coding is then referred to as conceptualising data by constant comparison of incidents, again (as Strauss does) to discern more categories and their properties. Analytical tools, used to create a theoretical concept, are preconceiving questions: who, when, why, where, what, how, how much, with what results.

Three levels of coding are defined: open coding is the initial stage, with no preconceived codes. Theoretical coding yields the conceptual relationships between categories and their properties. Finally, constant comparative coding is the fundamental operation. Glaser (1992) reflects on his former work (Glaser, 1978) where he mentions greater ' 6 Cs' as categories of 18 coding families for theoretical coding: causes, context, contingencies, consequences, co-variances and conditions. Main differences between the schools of Strauss and Glaser are indicated in Table 6.

Comparisons are very often made between Glaser's, and Strauss' and Corbin's research. Heath \& Cowley (2003) summarise that Strauss and Corbin follow the deductiveinductive approach under the control of a specified framework. Coding is seen to produce a linear model of causes, intervening conditions, and consequences to procedualize the open, axial, and selective coding process. In contrast, Glaser adopts the inductive method.

According to Locke (2003), the definition of concepts in grounded theory models starts from empirical observation. This is in opposition to hypothetical-deductive research models, where the investigative action begins with theory. Grounded theory is associated with micro-level processes, which reflect action and interaction. The conceptualisation of the grounded theory is invented through aspects of the social world, created by the researcher (p. 37): 


\begin{tabular}{|c|c|}
\hline STRAUSSIAN & GLASERIAN \\
\hline Data should be systematically gathered & Data unstructured before data collection \\
\hline $\begin{array}{l}\text { Hypotheses to be continuously checked } \\
\text { against incoming data }\end{array}$ & Theory emerge out of the data \\
\hline Having a general idea of where to begin & $\begin{array}{l}\text { Beginning with general wonderment (an } \\
\text { empty mind) }\end{array}$ \\
\hline Interplay of inductive and deductive data & Data emerging through inductive approach \\
\hline $\begin{array}{l}\text { Forcing the theory, with structured } \\
\text { questions }\end{array}$ & Emerging theory, with neutral questions \\
\hline $\begin{array}{l}\text { Conceptual description (description of } \\
\text { situations) }\end{array}$ & Development of a conceptual theory \\
\hline $\begin{array}{l}\text { Theoretical sensitivity comes from } \\
\text { methods and tools }\end{array}$ & $\begin{array}{l}\text { Theoretical sensitivity (the ability to } \\
\text { perceive variables and relationships) } \\
\text { comes from immersion in the data }\end{array}$ \\
\hline The theory is interpreted by an observer & The theory is grounded in the data \\
\hline $\begin{array}{l}\text { The credibility of the theory comes from } \\
\text { the rigor of the method }\end{array}$ & $\begin{array}{l}\text { The credibility of the theory, or } \\
\text { verification, is derived from grounding in } \\
\text { the data }\end{array}$ \\
\hline $\begin{array}{l}\text { Basic social processes need not be } \\
\text { identified }\end{array}$ & A basic social process should be identified \\
\hline The researcher is active & $\begin{array}{l}\text { The researcher is passive, exhibiting } \\
\text { disciplined restraint }\end{array}$ \\
\hline Data is structured to reveal the theory & Data reveals the theory \\
\hline $\begin{array}{l}\text { Coding is more rigorous and defined by } \\
\text { technique. The nature of making } \\
\text { comparisons varies with the coding } \\
\text { technique. Labels are carefully crafted at } \\
\text { the time. Codes are derived from 'micro- } \\
\text { analysis' which consists of analysis data } \\
\text { word-by-word }\end{array}$ & $\begin{array}{l}\text { Coding is less rigorous, a constant } \\
\text { comparison of incident to incident, with } \\
\text { neutral questions and categories and } \\
\text { properties evolving. Take care not to over- } \\
\text { conceptualise, identify key points }\end{array}$ \\
\hline $\begin{array}{l}\text { Three types of coding, open (identifying, } \\
\text { naming, categorising and describing } \\
\text { phenomena), axial (the process of relating } \\
\text { codes to each other) and selective } \\
\text { (choosing a core category and relating } \\
\text { other categories to that) }\end{array}$ & $\begin{array}{l}\text { Two coding phases or types, simple } \\
\text { (fracture the data then conceptually group } \\
\text { it) and substantive (open or selective, to } \\
\text { produce categories and properties) }\end{array}$ \\
\hline
\end{tabular}

Table 6: Grounded research: Straussian vs. Glaserian School

Source: The Author, based on Jones \& Alony (2011)

'The conceptualized element then becomes a lens for bringing into focus the patterning perceived in the social situation they studied.'

As a representative of the subsequent generation of grounded researchers, after Glaser and Strauss, Charmaz (2006) does not only compare Glaser and Strauss, but also reflects on her own research experiences and research output with samples, and interestingly 
considers both research approaches in her own style. Some more details will be explored in this respect.

In terms of qualitative approaches, she points out that researchers who focus on qualitative methods have one great advantage over their quantitative colleagues. They can add new pieces to the research puzzle or conjure entire new puzzles while they gather data, which is beneficial since new data may emerge late in the analysis. In her opinion, objectivist grounded theory resides in the positivist tradition, dealing with data as real in and of itself, instead of dealing with the processes of its production.

At the beginning of her work, Charmaz reflects on the Straussian research approach. She mentions that a focus on ideas may take place at the beginning of the research to finish a paper or project based on these ideas. However, by continuing her research approach, she first follows the less structured grounded approach of Glaser. She refers to initial openended coding to acknowledge researchers' prior ideas and skills through a concentrated active involvement in the process, followed by a more directed focused coding, using the most significant codes. Therefore, this takes place before the analytic work has been done (p. 48):

"I agree with Glaser's approach of keeping initial coding open-ended yet acknowledge that researchers hold prior ideas and skills."

Then, she continues with the conceptualising approach of Strauss. A main focus of her argumentation is the discussion of coding as an attachment, from labels to data segments to compare them with other data segments. Therefore, she connects grounded theory methods to systematic guidelines to collect and analyse qualitative data in order to construct theories grounded in the data themselves. She characterises axial coding, in the same way as Strauss, as a relation of categories to subcategories; in other words, in their interrelation and interaction. 'Axial coding' questions are: when, where, why, who, how, and with what consequences.

She relates Strauss (and Corbin's) version to new technical procedures, rather than emphasizing the comparative methods. In her opinion, passive non-structured interviews hold constructivism to a minimum. She also relates to the inductive and deductive research process when contending that other researchers, who might have seen things from different perspectives, may be able to re-enter scenes as observers. Interviewees can only seek access to stories that might illuminate the category. 
Theoretical sampling then becomes a means of gaining access to specific experiments, depicted as seeking pertinent data to develop emerging theory. It provides direction in cases where the researcher goes with his ideas.

By going back and exploring further questions, the fragments of experience take form. This helps to identify boundaries and to identify relations between categories.

Charmaz also reflects on coding families, as Strauss does, because theoretical sampling should not take place randomly. The literature review and theoretical frameworks are seen as ideological sites in which the researcher claims, locates, evaluates, and defends his position. As qualitative researchers, they have the advantage of being able to add new pieces to the research puzzle. Hypotheses are specified as relationships in between codes to be integrated into a theory.

Charmaz relates theoretical coding to possible relationships between categories: the '6 Cs' of Glaser (1978) are quoted as coding families, along with degree, dimension, interactive theoretical, and type that derive from major concepts - identity-self, meansgoals, cultural, consensus, unit group. For example, the unit group family may include the issues organisational, aggregate, territorial, societal status, and role units as subcategories. Theoretical coding includes situations and their conceptualisation by asking how, why, and where situations occur.

As coding may be too general or identifying topics instead of actions and processes, memo-writing then provides space to become actively engaged in material. It is an intermediate step between data collection and writing drafts.

Jones \& Alony (2011) describe the research approach of Glaser as beginning with general wonderment, whereas the approach of Strauss is defined as already having a general idea from the beginning. They mention the Glaserian and the Straussian schools (Glaser, 1992; Strauss \& Corbin, 1990). The Glaserian school is related to an empty mind, while Strauss' school permits a general idea of the area under study. Glaser is related to emerging theory, whereas Strauss uses structured questions. Strauss' coding process is also considered more rigorous and defined by technique. In opposition, Glaser (1992) is presented as a researcher who does not over-conceptualise. 


\subsubsection{FURTHER CRITICAL REFLECTION ON AND BOUNDARIES OF GROUNDED RESEARCH APPROACH}

With respect to my personal and managerial characteristics, mentioned in Chapter 3.4 as reflective outcomes, I prefer structured approaches to reach results. However, I look for the involvement of others to develop suitable solutions and to fill in gaps in my knowledge to create social consensus.

Therefore, I will follow the Straussian approach in my further research (Strauss \& Corbin, 1998). Structured processes will be used to make sense of the data, instead of unstructured ones without pre-suppositions as Glaser recommends (Glaser, 1992).

Further, I agree with Strauss \& Corbin with respect to coding procedures, forming welldeveloped categories as a basic work for a theoretical framework. I am also convinced that a previous hypothesis helps in the beginning of the research and data collection. Data should be systematically gathered through the research process. A hypothesis then derives from the data, which must be continuously checked in relation to the research questions; in an inductive and deductive way. This will finally identify relationships between the coded data and create hypotheses. The main issues of the grounded research approach to be followed up by Strauss are indicated in Figure 2. In contrast, I consider that creating properties by means of coding families, as argued by Glaser (1992), and Charmaz (2006) in the first part of her research approach, is far too broad; I fear that relevant data may not have been filtered and channelled in an essential manner as part of the interview phase. However, as Charmaz (2006, p. 148) argues, when following the more structured approach of Corbin \& Strauss, within her theorising stage:

'Interviewees can only seek access to stories that might illuminate the category. Then, theoretical sampling becomes a means of gaining access to specific experiments.'

Prior to data collection, the literature review and theoretical frameworks are ideological, as Charmaz argues, in which the researcher claims, locates, evaluates and defends their position. Breuer (2010) follows this approach (Strauss \& Corbin's) by referring to it as a methodological, flexible stance. He also defines his approach as a process of awareness: Coding is seen as a conceptualisation and relates to phenomena, which expresses terms out of the data as a useful relationship. The goal is to create a conceptual centre theory around a central concept for theoretical satisfaction. 


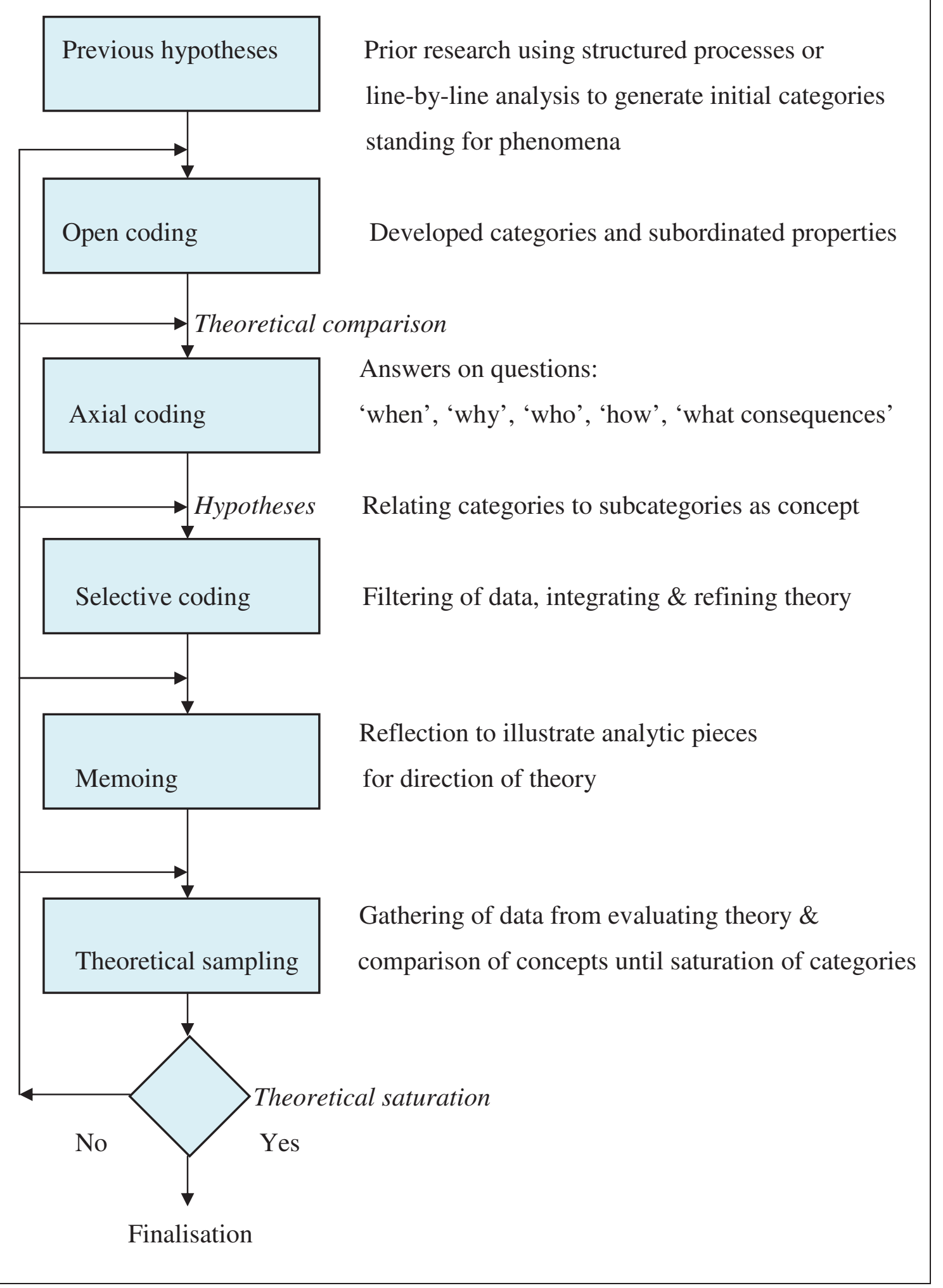

Figure 2: Grounded theory process

Source: Strauss \& Corbin (1992), own illustration of author 


\section{DATA COLLECTION}

The data collection with end users took place by means of interviews. Easterby-Smith, Thorpe \& Jackson (2012) relate this language data to qualitative research as main approaches to get insights into social and organisational realities. They discover views, perceptions and opinions of individuals and groups.

\subsection{INTERVIEW PHASE}

Semi-structured interviews offer the possibility to work more confidentially with interviewees as their replies are expected to be more personal (Easterby-Smith, Thorpe \& Jackson, 2012; Greener, Daymon \& Holloway, 2008). Therefore, uncertainties seeking clarification can be tested out. Instead of statements about descriptive amounts, the dialogue can move to individuals' value-based replies.

Bias of the interviewees can be identified and the interview can then be guided in different directions. For example, silent probes require slow or reluctant questions, breaks in the answers require pauses to allow the interviewees to develop ideas. Reflective expressing allows questioning in own words to get a further understanding and clarification of responses, such as "what do you mean by saying...". Explanatory probes may be answered by 'what' questions. Therefore, I considered semi-structured in-depth interviews as a main instrument for exploring the decision-making process. The purpose of the in-depth interviews was to understand the motives, the stages during the decisionmaking process, the factors affecting consumer choice, and the meanings that interviewees attach to issues and situations.

Further, in-depth interviews indicate bias to other qualitative research methods (Easterby-Smith, Thorpe \& Jackson, 2012). The data analysis can be focused on the transcribing of the spoken language into text. In contrast to other approaches, such as discourse analysis, observation (e.g. ethnography) or interaction (e.g. AR), no examination and understanding of body movement, symbols, settings and observations is required to consider a broader social context. Leech (2002) concludes techniques for semi-structured interviews in a way so as to allow respondents to be the experts and to inform the research. 
With respect to the topic of this thesis, the interviews were aimed at understanding the way in which homeowners reach a decision on the purchase of renewable heating technology. The structure of the questionnaire provided an overall frame of thirty-seven questions for collecting the information and organising it in themes, universally accepted in the decision-making literature (Figure 3).

Twelve end users were interviewed, and a further six experts were queried with questions about the renewable heating market and relevant technologies (Figure 4). The information of the experts was not transcribed, but in certain contexts was used as memos. The data of the end users was recorded and transcribed in German, then translated into English for sampling and coding, and analysed with computer-based software, NVivo. It helped structure the comprehensive text data for higher accessibility (Easterby-Smith, Thorpe \& Jackson, 2012).

Based on the research framework, the introduction of questions about motivational aspects on the purchase of renewable heating technologies, about the information sources and choices, their evaluation, the process to take action, and about personal data to assign key questions and influencing factors to possible personal characteristics, was considered.

The interviews should last between forty-five minutes and one and a half hours. Interviewees were allowed to talk about each issue that would form the structure of the semi-structured questions. This considered subjective human perspectives and shared the perspectives of interviewees on particular social phenomena by the researcher (Wahyuni, 2012). The number of interviews was reviewed as necessary, by means of constant comparison, to the point where no new knowledge was obtained (Glaser \& Strauss, 1967).

\section{Sampling strategy}

For the selection of homeowners as decision-makers, it was a prerequisite that the houses they lived in and owned were of older construction, i.e. without legal requirements for thermal insulation measures or the use of renewable heating technologies. The interviews with the first homeowners came via contacts in my homeland. In the course of further networks in the context of the research work, contacts developed to energy representatives of two municipalities. In one of the two cases contacts to citizens from a working group to regenerative energy concepts were obtained. In the second case a 
mailing action was addressed by the mayor to the citizens. These homeowners participated already in a thermography campaign for their houses by means of thermal image camera for the evaluation of the insulation characteristics. Further contact references I obtained by means of the involved energy consultant as part of my expert interviews.

The selection of the experts took place against the background of describing the key data on the various renewable heating technologies in order to obtain a comprehensive picture based on the different professional orientations of these experts.

\subsection{RULES FOR THE INTERVIEWS}

Several principles had to be considered for the designed structured questions (EasterbySmith, Thorpe \& Jackson, 2012; Daymon \& Holloway, 2011, Greener, 2012):

The questionnaire followed the framework from which different key settings are pointed out:

- Attention: questions asking more than one thing may reduce the possibility to know what people are thinking about and should, therefore, be avoided.

- Jargons and colloquialism should be avoided. Informal and insider questions in the form of open questions have to be applied ('what', 'why', 'how', 'when', 'where', 'in what way'...).

- Use of simple expressions.

- Avoidance of negatives.

- Reflexivity of the researcher in the conversation with the interviewee is necessary and can be achieved through a self-critical approach. 'Pipeline transmitting' should be avoided.

- Trustfulness and spending time on the process will ensure confidential communication. Absurd comments on replies of the interviewees are prevented.

- The use of the participants' language will be without academic terms.

- The interview shall begin with rather open questions about the topic in general and then be followed by more detailed questions about certain issues.

- The researcher has to show interest in the interviewee's perspective by asking flexible questions to follow new questions. 
Attention: semi-structured interviews are not the same every time but ensure collected material with similar types.

Reflection on the interview phase and conceptualisation of pre-tests:

The realisation of the interviews in a familiar context in the house of the end users was a great personal experience: the duration of twelve interviews took between twenty-seven and seventy minutes; nine interviews took forty-five minutes or longer.

The first interview was the second shortest of all. Thereafter, no more questionnaires were sent to the interviewees before the meeting, only general information was given to prevent pre-prepared answers. After the second interview, two introducing questions were included, which the interviewees answered most comprehensively in comparison to the other questions answered. These answers were important for the coding and theorising procedure of the grounded research. Therefore, the first two interviews have to be considered as pre-tests, the final questionnaire (Figure 3) remained unchanged for the following 10 interviews with end users.

\subsection{ETHICAL ISSUES AND ACCESS TO RESEARCH PARTICIPANTS}

Ethical issues are important in order to guarantee trustworthy, confidential and reliable research with the involved research members. Smith (2009, p. 144) says:

'Ethics could be described as a set of rules or guidelines which influence behavior on a societal and individual basis. They underpin notions of what is right or wrong, and are derived from the norms and values shared with societies.'

Greener (2008, p. 40) refers to ethics in relation to moral choices affecting decisions, standards, and behaviour. The ethical issues observe the protection of the interests of the research subjects. A code of practice has to be considered as part of the research (Easterby-Smith, Thorpe \& Jackson, 2012; Daymon \& Holloway, 2011; University of Gloucestershire, 2008). A summary is given in Table 7.

After providing a general introduction of the research project at the beginning of the interviews, I handed out a confidentiality agreement (Figure 5). Then, I started asking the 


\begin{tabular}{|l|l|}
\hline Key principles & $\begin{array}{l}\text { Practical behaviour of the researcher towards } \\
\text { the interviewee }\end{array}$ \\
\hline Respecting interviewees' comfort & $\begin{array}{l}\text { Putting no pressure on participants } \\
\text { Interview at a familiar place to help the } \\
\text { interviewee feel at ease } \\
\text { One-on-one interviews without other observers } \\
\text { No harm by any action or omission of the } \\
\text { research study } \\
\text { Right to refuse participation or switch off the } \\
\text { tape recorder at any time }\end{array}$ \\
\hline Ensuring fully informed consent & $\begin{array}{l}\text { Full information about the research topic and } \\
\text { research procedure (interview duration and } \\
\text { further steps) } \\
\text { Supply of written information }\end{array}$ \\
\hline Eorrect citations of information & $\begin{array}{l}\text { Participation in the research was voluntary and } \\
\text { the interviewee could withdraw at any time from } \\
\text { the research process }\end{array}$ \\
\hline Ensuring confidentiality & $\begin{array}{l}\text { No indiscreet questions } \\
\text { research path } \\
\text { Proposal to get reply on research results }\end{array}$ \\
\hline Application of anonymised citing \\
\hline
\end{tabular}

Table 7: Ethical issues in research

Source: The Author, based on Easterby-Smith, Thorpe \& Jackson (2012), Greener (2008), Daymon \& Halloway, 2011

questions identified in the semi-structured questionnaire and prompting questions when necessary.

If interviewees wished to speak on related issues, they had the freedom to do so. In that sense, the semi-structured questionnaire was not restrictive. Recording was important for the documentation and its transcription for the design of the coding process. 
Interviewees were able to refuse participation or switch off the tape recorder at any time. Confidentiality was guaranteed by applying anonymised citing. As part of the dialogue with the interviewees, information was given by the researcher about the research procedure (duration and steps). The interviewees were informed that participation in the research was voluntary and that they could withdraw at any time from the research process. No indiscreet questions were to be asked. Names of interviewees would not be published and only citied as initials. The interviewees were informed that they could get full information about the research goals and the research path and that they had the option to receive feedback on the research results after the termination of the research study.

\subsection{STANDARDS FOR RESEARCH QUALITY}

In their early work, Glaser \& Strauss (1965) refer to qualitative research as a preliminary, exploratory effort to quantitative research. They mention quantitative approaches as over-emphasizing testing of hypotheses and de-emphasizing the discovering of relevant conceptual aspects for the substantive area being researched.

\section{Credibility}

In relation to qualitative research, Glaser \& Strauss argue, in their work, for the collection and analysis of the credibility of the data by using comparison groups. In their opinion, the researcher's study of other qualitative data (e.g. interviews, adding field note, events of persons) can enable them to make a judgment about their theory as a framework and realise the discovery of substantive theory (hypotheses out of concepts for a substantive research area, such as patient care or gang behaviour). Their arguments already reflect on the coding process they would publish in their later work (Glaser \& Strauss, 1967).

Charmaz (2006) relates quality and 'credibility' of a research study to the collection of enough background data about persons, processes, and settings. She points out the interpretive positions, which bring grounded theorists into the research process (p. 180):

'We stand within the research process rather than above, before, or outside it.' 
Locke (2003) links credibility with theoretical sampling in order to extend general applicability, which Locke also expresses as the analytical generalizability of the theory. In his opinion, comparison groups as analytic procedures have greater analytic generalisability.

The term generality emerges from the analytic process instead of being a prescribed goal, as Charmaz (2006) notes. She argues that even minimizing the significance of data that do not fit their emerging categories can emphasise grounded theory.

\section{Triangulation}

Locke (2003) mentions going to other sources for guidance and relates data gathering practices in Glaser \& Strauss' ground work (1967) to what is nowadays referred to as triangulation. The term stands for data collection from multiple sources, such as semistructured interviews, field-observations, as well as from archival sources. Strauss \& Corbin (1998) view triangulation as an interplay of different methods and field notes as an observational part of the data analyses. They do not relate triangulation to different research sources in the traditional sense. They reflect on the coding procedure.

Bitsch (2005) argues for grounded theory as the methodology of developing inductive theories, which are grounded in gathered and analysed data in a systematic way. Sampling (drawing) decisions are grounded in the emerging concepts, thus, they evolve during the research process.

\section{Confirmability by objectivity}

Confirmability is deemed to be the qualitative aspect, which allows for greater objectivity. Bitsch (2005) mentions objectivity through tools such as member checks to ensure that replies are obtained from the interviewees. Audit trail should allow the tracking of data to its sources through the description of research design collection and methods.

Strauss \& Corbin (1998) stay related to an objective stance: comparing incidents in the data to better stay grounded in them. This does not entirely remove the potential for biased interpretations. Thus, the researcher should turn to literature or experience to find examples of similar phenomena and to think of properties of dimensions. Therefore, the greater the number of persons interviewed or observed, the more the researcher will be able to check interpretations against alternative explanations. 
Indicators representing research quality are considered in Table 8.

\begin{tabular}{|c|c|c|}
\hline Criteria & Critics & Solution \\
\hline Reliability & $\begin{array}{l}\text { Replicability, using more } \\
\text { than one questionnaire as an } \\
\text { instrument will not reproduce } \\
\text { the same results or answers, } \\
\text { due to own characteristics } \\
\text { and background influence in } \\
\text { qualitative research }\end{array}$ & $\begin{array}{l}\text { Generation of audit trail as } \\
\text { sequential steps in the } \\
\text { research, similar observations } \\
\text { should be reached by other } \\
\text { observers }\end{array}$ \\
\hline $\begin{array}{l}\text { Validity } \\
\text { approach) }\end{array}$ & $\begin{array}{l}\text { Not measurable, unlike } \\
\text { quantitative research }\end{array}$ & $\begin{array}{l}\text { Accurate reflection on the } \\
\text { research, member checking } \\
\text { by showing results and } \\
\text { asking research members for } \\
\text { their comments (remark: } \\
\text { Daymon \& Holloway (2011) } \\
\text { call this internal validity; } \\
\text { Wahyuni, (2012) mentions } \\
\text { this as parallels to } \\
\text { credibility), consideration of } \\
\text { a sufficient number of } \\
\text { perspectives (remark: Glaser } \\
\text { \& Strauss, (1965) relate this } \\
\text { to using comparative groups; } \\
\text { later, (1967) regarded as } \\
\text { coding process) }\end{array}$ \\
\hline $\begin{array}{l}\text { Sampling (relating to } \\
\text { grounded research as } \\
\text { theoretical sampling) }\end{array}$ & $\begin{array}{l}\text { Not wholly determined prior } \\
\text { to the research, but proceeds } \\
\text { throughout }\end{array}$ & $\begin{array}{l}\text { Different perspectives about } \\
\text { the data to be collected have } \\
\text { to be included, a theoretical } \\
\text { sampling strategy (coding) } \\
\text { provides a clear justification } \\
\text { for included sampling units, } \\
\text { sampling stops at the point of } \\
\text { data saturation with no } \\
\text { arising ideas }\end{array}$ \\
\hline Generalisability & $\begin{array}{l}\text { Findings and conclusions not } \\
\text { fixed as in law-like pattern of } \\
\text { quantitative research, due to } \\
\text { interpretive worldview }\end{array}$ & $\begin{array}{l}\text { Formulating of rules or } \\
\text { propositions for circum- } \\
\text { stances, to be related to } \\
\text { (Daymon \& Holloway (2011) } \\
\text { call this also external } \\
\text { validity), theory-based gener- } \\
\text { alisation by transferring } \\
\text { verified original data to other } \\
\text { sites sample, should be } \\
\text { sufficiently diverse to allow } \\
\text { interferences to other } \\
\text { contexts }\end{array}$ \\
\hline
\end{tabular}




\begin{tabular}{|c|c|c|}
\hline Objectivity & $\begin{array}{l}\text { Human biases cannot be } \\
\text { removed in qualitative } \\
\text { research }\end{array}$ & $\begin{array}{l}\text { Reflection on and acknowl- } \\
\text { edgment of standpoints in the } \\
\text { research to be taken into } \\
\text { account by readers for } \\
\text { their own interpretations } \\
\text { (Wahyuni, (2012)) mentions } \\
\text { this with parallels to } \\
\text { confirmability, Strauss \& } \\
\text { Corbin (1998) argue for } \\
\text { finding similar phenomena as } \\
\text { properties and dimensions, } \\
\text { equal to the grounded } \\
\text { research approach) }\end{array}$ \\
\hline Triangulation & $\begin{array}{l}\text { Contexts may not be crucial } \\
\text { in determining how people } \\
\text { express themselves }\end{array}$ & $\begin{array}{l}\text { Combination of more than } \\
\text { one perspective to provide a } \\
\text { more complete picture, this } \\
\text { can be multiple sources, } \\
\text { theoretical interpretations or } \\
\text { methods as interviews, } \\
\text { documents and question- } \\
\text { naires (Strauss \& Corbin } \\
\text { (1998) reflect on the coding } \\
\text { procedure) }\end{array}$ \\
\hline Reflexivity & $\begin{array}{l}\text { Self-critical stance of author } \\
\text { is important, excessive navel } \\
\text { gazing has to be avoided }\end{array}$ & $\begin{array}{l}\text { Focus on participants, own } \\
\text { reflective chapter with } \\
\text { assumptions and preconcep- } \\
\text { tions and information on the } \\
\text { way in which values and } \\
\text { knowledge have been } \\
\text { influenced often added to } \\
\text { increase research reliability }\end{array}$ \\
\hline
\end{tabular}

Table 8: Criteria for quality of research

Source: The author, based on Daymon \& Holloway (2011), Easterby-Smith, Thorpe \& Jackson (2012), Glaser \& Strauss (1965), Glaser \& Strauss (1967), Strauss \& Corbin (1998), Wahyuni (2012)

\section{Brief summary}

Some expressions from the field of research quality are used alternatively in academic literature: In Wahyuni's literature review (2012), credibility is referred to as a parallel to internal validity and confirmability as a parallel to objectivity. Locke (2003) relates credibility to theoretical sampling, and thus to the early work of Glaser \& Strauss (1967). With respect to qualitative research, Glaser \& Strauss (1965) argue for comparative groups in their earlier work. A concluding overall expression is presented by Daymon \& 
Holloway (2011) in their summary about ensuring qualitative research; they require qualitative aspects to be rigorous in the procedures, showing how research can be trusted. 


\subsection{ACCESS TO THE DATA}

The collection of the data and its analysis took place through interviews. Easterby-Smith, Thorpe \& Jackson (2012) refer to this kind of data collection in connection with insights into social and organisational realities, in order to discover views, perceptions and opinions of individuals and groups. Semi-structured and open guided interviews, especially, offer the possibility to work more confidentially with interviewees, as their replies tend to be more personal in nature. In addition, expert interviews and secondary data were considered as memos. The data collected during the research was related to the research questions via a coding scheme.

\subsection{METHODICAL APPROACH TO THE DATA STRUCTURE}

Charmaz (2006) relates quality and credibility of a research study to contextualised grounded theory that can start with sensitising concepts, which end with an inductive analysis. Therefore, generality about the research result emerges from the analytic process rather than a prescribed goal. The consideration of sufficient data quality is an important aspect of any research and, therefore, also part of qualitative research approaches. Qualitative research studies are characterised by fewer interviewees in contrast to quantitative research studies, which commonly use questionnaires. In contrast, qualitative research methods, and the grounded research as one methodological approach, consider their data with huge or, as Charmaz (2006) says, rich data, taken out of the involved and close contact with the interviewees. In this context, Strauss \& Corbin (1998) evaluate interpretations against the more alternative explanations offered by interviewing more persons as part of an objective stance. Gentles et al. (2015) argue for smaller samples compared to quantitative estimates with representing populations to acquire useful information for understanding the complexity, depth, variation, or context surrounding a phenomenon.

Glaser \& Strauss (1967) refer to the coding process in their earlier work (Glaser \& Strauss, 1965) to provide clear categories to explain behaviour in social related studies. Theoretical sampling is then the process for generating theory out of the data collection. Instead of huge figures, they point out theoretical saturation. Data, for example, from interviews, has to be collected until an essential degree is reached. 
In my research, I interviewed twelve end users as homeowners, and decision-makers with respect to detached or semi-detached houses for the purchase of heating technologies in their property. I first structured the data in close relation to the five research questions, but then noticed, as part of a critical reflective approach, that the data was too comprehensive just for five main categories. At the end of the process, there were seven categories. I followed Strauss \& Corbin (1992) and their coding procedure:

Well-developed categories shall form a theoretical framework, already present in my research questions, from my a priori conceptual framework. Based on the interplay of inductive and deductive data collection, out of the consolidation of my first eight end user interviews and expert interviews, I then created a first logical and hierarchical structure. Strauss \& Corbin (1992) mention this as open coding to identify concepts as building blocks of theory with categories and subordinated properties. The data is used to examine the incident of the data and to create properties by theoretical comparisons.

Axial coding is then the process of relating categories to their subcategories.

Thereafter, selective coding is the process of integrating and refining the theory. The relevance of the data to the theory will be examined.

Hypothesis is accordingly the statement of relationships between the axial and selective coding. This step is followed by the theoretical sampling as the gathering step and process of the data driven by concepts for involving theory and comparing concepts by the researcher until each category is satisfied.

Memoing may help to illustrate the analytical process to develop ideas. In the context of my research, secondary data and expert interviews enlarge the data analysis of the end user interviews.

Coding is referred to as conceptualisation to develop more categories and properties.

Critical reflection on the remaining three interviews did not give rise to new insights on the theoretical concept and coding structure. Therefore, I did not continue with further interviews and treated the data collection as essential or, in other words, with respect to the ground work of Glaser \& Strauss (1967), the theoretical saturation as confirmed. 


\subsection{DEVELOPMENT OF CODING THEMES}

The result of the coding structure was developed by the following chronological steps as part of a creative inductive and deductive comparative process of the interview data (Figure 6):

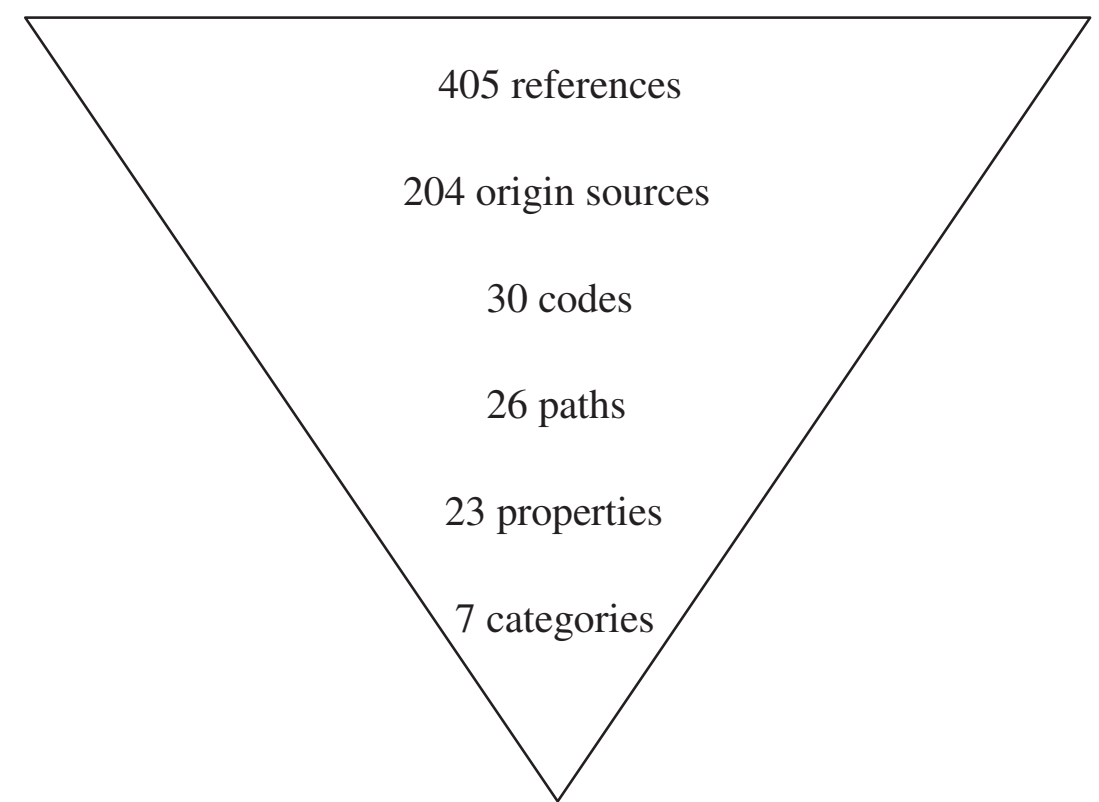

Figure 6: Coding process (own study)

First: data structuring the five research questions below, RQ1 to RQ5, based on the $a$ priori conceptual framework in Chapter 2.5.

Second: refining the data and relating it to the five research questions in terms of categories and subordinated properties.

Third: enlarging the five research questions to seven categories out of thirty codes in total; therefore, twenty-three subordinated properties.

The categories in close relation to the research questions RQ1, 2 and 4 are originally taken from Chapter 1.4, whereas research questions RQ3 and 5 have been modified. Research question RQ3 has been removed and the content on the effect of renewable heating technologies on consumers' choice of a specific technology is now integrated in the coding category 'Affecting factor: character'.

Finally, as part of research question RQ 5, the consumer-related, technology-related, and provider-related factors are finally designed as three separate categories about influencing factors during the decision-making process under technological, political, $\mathrm{B} 2 \mathrm{C}$ related, and personal factors (Figure 7). 
The chronology has been changed. Due to the chronological process of decisions, the existing situation of the technology used on-site is considered first, followed by the motivation whether to be interested in new technologies, and finally, the stages of decision-making.

Categories and subordinated properties are the codes, which are related, in a hierarchical structure, to the categories within the 'Axial coding'.

Fourth: as a result of the selective coding, mentioned in other exemplary grounded researches as overarching theoretical dimensions (Patvardhan, Gioia and Hamilton, 2015) or aggregate dimensions (Mantere, Schildt \& Sillince, 2012), two main categories have been defined:

(1) Rational related decision-making factors;

(2) Bounded rational related decision-making factors.

They shall form the main chapters within the data discussion and theorising to tell a research story, as a central theme for developing theoretical insights - the stage before theoretical sampling. The question will be: which factors during the research process are rational related and which ones are not, or, in other words, which are bounded rational related. At least one of the two aspects, if not both, are linked to each property. I identified twenty-six paths from the different properties to the overall dimensions of rational or bounded rational decision-making factors.

\subsubsection{CODING CATEGORIES}

As a result of the methodological approach, the collection, interpretation and consolidation of the relevant data and the consideration of the original research questions, seven (A to $\mathrm{G}$ ) main categories are formed within the axial coding structure, or, as Patvardhan, Gioia, and Hamilton (2015) say, second order themes:

- Specifics of the technology;

- Motivation for the purchase;

- Sources and stages;

- Personal characteristics;

- Affecting factor: technical issues; 
- Affecting factor: B2C aspects;

- Affecting factor: politics.

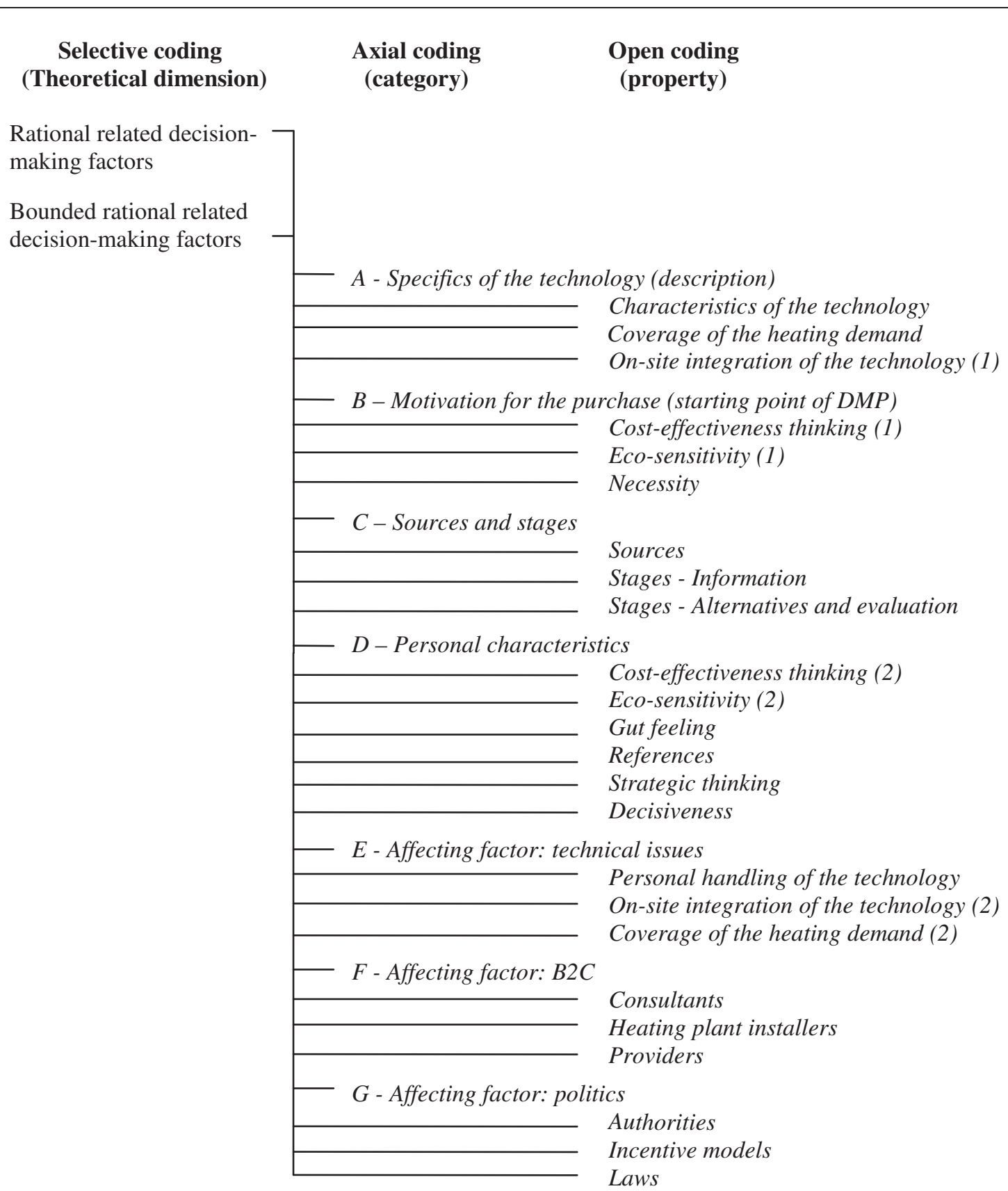

Figure 7: Coding structure (own study) 


\subsubsection{RATIONAL VS. BOUNDED RATIONAL DECISION-MAKING PROCESSES}

The characteristics of rational and bounded rational decision-making processes as the two coding themes of the selective coding are summarised as follows with relevant data from the literature review in Chapter 2 (Table 1).

\section{Evaluating thoughts}

The rational decision-making process may be influenced, interrupted, accelerated or stopped by bounded rational related factors when the decision-maker reaches their decision based on personal background, including experiences, interpretations, or emotional aspects. Compared to rational decision-making processes, personal agendas of the decision-makers, therefore, may indicate, why certain decisions were taken or not. With respect to the purchase of renewable heating technologies by end users, it will be essential to identify relevant factors and to explore how they may be amplified or weakened.

\subsection{THEORETICAL INSIGHTS AND STORIES WITHIN THE AXIAL CODING STRUCTURE}

Within this Chapter, theoretical insights will be considered in conjunction with interview data.

The following explanation will be considered in the text data:

(1) Interview partners are related to initials. 'M.R.' stands for me, as researcher.

(2) End users are cited in frames and, in parts, reference is made to their statements outside of these frames.

(3) References to experts are only quoted outside of the frames and referred to as being from experts.

(4) Remarks of the researcher are mentioned as further background in brackets.

(5) Directly related expressions to the categories are pointed out in bold characters.

(6) Sentences of no relevance are left out and indicated with dotted lines. 


\subsubsection{SPECIFICS OF THE TECHNOLOGY}

In order to evaluate or deduce decision-making processes in the context of renewable heating technologies, their application on-site has to be analysed. In Chapter 4.5.3, the different non-renewable and renewable heating technologies in use are already presented. Each technology has its characteristics with respect to performance, function, feed-in material, and coverage share in detached or semi-detached houses where they come into power.

The following data analysis is limited to a description of categorising technologies and how they are used in households of end users. The descriptive analysis is not a reflective and immediate part of the greater evaluation of rational or bounded rational decisionmaking processes. These issues will be explored in the following Chapters: 5.4.2 to 5.4.7. However, the use and technical related limits of the applied technologies will affect decisions, and how far certain technologies can be or have already been purchased from their technical evaluation on-site, based on the available knowledge of each end user.

Three codes are considered relevant for data selection and analysis. With respect to meanings and knowledge of end users, the selected interviews do not consider whether renewable heating technologies have already been adopted or not. The relationship between renewable heating technologies and end users is relevant in this Chapter. Further research and the contextualisation between the codes and the related statements will be part of the data discussion in Chapter 6:

\section{a. Characteristics of the technology:}

The interviews with end users are considered independently of the usage, decline, or increase of renewable heating technologies, which may also be used in combination with non-renewable technologies, such as oil or gas driven boilers. The focus is on statements about the way in which the technology in use is evaluated with respect to its technical application. The different technologies are considered as first-order change for the different heating technologies.

\section{Micro combined heat and power plants (Micro CHP)}

The following answer was related to the question about the meaning of micro combined heat and power plants and fuel cells from the interviewee's point of view: 
Interview_r_b

R.B.: Well, I think that I would then be autonomous in all areas. That is an aspect. Or I can imagine that there will be social aspects where you share such a micro combined heating system with some neighbours, not only one, but more. That might be a direction in which it will develop.

M.R.: Do you also know fuel cells?

R.B.: Well, there I would have to ask, first.

The terms 'can imagine' and 'might be a direction' indicate in this case that micro combined heat and power plants and fuel cells are still less known heating technologies in older buildings. The statement 'share' in this case indicates that the technology is seen as 'oversized' for detached and semi-detached buildings.

Only limited knowledge about these technologies and more concrete fuel cells is also represented by the following interviewee:

\section{Interview_k_v}

M.R.: You mentioned micro combined heating power units. Do you also know fuel cells? K.V.: Well, I have heard about them, but I think they are still a dream of the future. I have not looked into the subject.

Another meaning is again related to the 'oversized' performance for smaller houses and, therefore, the lower expected profitability:

Interview_m_I

M.L.: Well, a micro combined heat and power plant seems quite good, but it causes much exhaust. Exactly the fuel cell, it produces exhaust as well. And, it does not calculate in one's household. Such a micro combined heat and power plant creates 5 $\mathrm{kW}$ in electrical performance and $7,8,9,10 \mathrm{~kW}$ in thermal performance. It creates too little energy to be profitable. 
Finally, in the below-mentioned fourth interview, with A.H., the 'oversized' performance related to economic aspects, and the lacking publicity of fuel cells are again pointed out:

Interview_a_h

A.H.: Well, it is a very interesting technology [pause]. However, in my opinion, it is only worthwhile for a semi-detached house.

M.R.: Why only for a semi-detached house?

A.H.: Well, first, it is a question of efficiency rate. Moreover, the bigger the house, the more economically the combined heat and power plant will work. It depends then on the price-performance ratio. They exist also for detached houses, but all the people I spoke to told me that it rather is not economical.

M.R.: Have you also formed a picture about fuel cells?

A.H.: Yes. I think they are an interesting thing. However, the technology is still not sophisticated, in my opinion.

The statements about 'oversized' heating performance of micro combined heat and power plants, and still not established fuel cells as 'young technologies', at least in older houses, are confirmed by the expert interviews (namely T.R. as heating installer, S.F. as sales director of a public service and M.A. as energy consultant, Figure 4).

\section{Thermal heating pumps}

In the following interview, thermal heating pumps, as another heating technology, are especially related to electrical energy demand, which is one necessary aspect of their heating performance:

Interview_a_h

A.H.: Electricity is not cheap. Very often, they mention interesting factors, but [pause]. Let me tell you another example. $1 \mathrm{kWh}$ gas is $5 \mathrm{Cent}, 1 \mathrm{kWh}$ electricity is 30 Cent. You have to consider the efficiency factor. A lot of people work with very big factors. But, whether it will work at a constant level at the end, that is the question. Further, electricity is not a clean energy, when they now run down the nuclear power 
stations. Well, brown coal, a brown coal power station may have an efficiency factor of $40 \%$, it really does not make that much sense.

The above-mentioned evaluation is focused on electricity as power supply for thermal heating pumps. The wider context of how the necessary electricity is generated and how it influences pollution is considered from an economic and ecological perspective.

The ecological rather than economic aspect is also the focal point of the next statement:

Interview_m_I

M.L.: Yes. It is the only system, through which I can feed the heating pump with photovoltaic energy. Using wind electricity I can feed the heating pump with sufficient electricity. Through waterpower and so on as well. There are already providers of electricity who sell eco electricity.

The argumentation considers a combined heating distribution solution when producing electricity with photovoltaic cells and using it for own consumption and electricity supply of thermal pumps.

The next two interview sections are strongly focused on the application of heating pumps in houses and, therefore, technical aspects, rather than economic issues:

Interview_m_I

M.L.: Normally, a heating pump is designed for a low temperature heating system. Therefore, I need low temperature radiators or a surface system, like a floor, wall or roof heating system.

Interview_g_g

G.G.: Within private households I still know the principle of geothermal heating [pause]. In my opinion, it is a really interesting thing when you have the right building stock for it. You must have, as far as I understand, a passive house because the heating source is very slow. You cannot go in a cold room and just turn on the radiator, because it is not that hot. You must make sure that a certain heating level is 
continuously maintained [pause]. For certain buildings it is suitable and works fine, as far as I am informed. Our house, which was constructed at the end of the 70s, does not satisfy these requirements.

The evaluation of these interviews confirm common technical reports and the statements of experts (namely, T.R. as heating plant installer and M.A. as energy consultant, Figure 4) about the low flow temperature of thermal heating pumps, which is commonly not sufficient in old and badly insulated houses when the equipment (e.g. radiators with better flow rates, better insulation) is not adapted.

\section{Wood pellet ovens}

This technology is especially suitable as a replacement for oil boiler systems as the tank room can be used as necessary storage for the wood pellets as highlighted in the following statement:

Interview_k_v

K.V.: No, actually, it was very convenient. Due to the fact that we removed the tanks, we gained additional room in our cellar.

Additionally, the following answer is related to the question, how could the purchase of renewable heating technologies be increased:

Interview_t_a

T.A.: I do not know how it works with new buildings, what kind of heating system they build in. Pellet heating is excellently suited to after-market expansion for fuel heating; with respect to space, it is quite good.

However, A.H. who still used a gas boiler system, criticised the transport of pellet systems, based on information from others. He also denied the system as these people have obviously been influenced by price increases for the purchase of this technology. His perception of wood pellet systems can be seen in the following excerpt: 
Interview_a_h

A.H.: Negative, very negative.

M.R.: Why?

A.H.: First, the technology. The screw breaks down very often. A relative has such a system. The cost has increased substantially [pause]. In my opinion, it is not a good technology [pause]. And I know that the repair of the screws can be a problem.

\section{Solar and photovoltaic systems}

These two renewable heating technologies are well-known, as demonstrated by the interviews. One reason may be that these technologies are 'present' in our society as they are positioned and visible on house rooftops.

Very often, decisions and discussions are related to the option to either choose one system or the other. Concluding thoughts about the economic factors are mentioned below:

\section{Interview_d_v}

M.R.: And was it desirable for you to use photovoltaic systems for the generation of electricity?

D.V.: Well, at that time I asked for some quotations. The advantage of solar technology was then much greater, but so was the investment. That is what I still have in mind.

As already noted with respect to the application of thermal pumps, the energy distribution concept with photovoltaics is highlighted as a central theme, using electricity to supply power to thermal heating pumps: 
Interview_r_z

R.Z.: My heating plant installer told me: "Leave it. What you earn with your photovoltaic plant will be much more compared to another pump, a buffer storage to make your tap water. And if, after twenty years the guaranteed buyback price is no longer available, you can use your own electricity to run your heating pump to produce your warm water."

The own consumption of electricity in combination with photovoltaic, instead of solar heating systems, is reflecting in the increasing electricity tariffs in Germany. Nowadays, they are caused by the Renewable Energy Law (EEG). Electricity supply companies have to charge their customers a, so-called, EEG contribution. The distributors of electricity are obliged to feed in electricity of plant operators, as there are private households with photovoltaic systems. One reflection on this issue, therefore, may be to use photovoltaic cells to cover own electricity demand, as indicated in the following interview:

Interview_m_I

M.L.: Well, me, I prefer to cover my own needs. That means I need 5, maximum $8 \mathrm{~kW}$.

M.R.: Just own needs, as the compensation is not that high anymore?

M.L.: The compensation is not that high anymore, the feed in compensation is not that high anymore. The whole thing is also charged with taxes. I can only earn real money when I save electricity.

\section{b. Coverage of the heating demand:}

Consequences of the adoption of renewable heating technologies are also seen in relation to the extent to which end users are covering or are prepared to cover their heating consumption with renewable heating technologies. Again, the different technologies are considered as first-order change to the different statements. 


\section{Thermal heating pumps}

The below-mentioned statements point out that thermal heating pumps are not $100 \%$ reliable throughout the year, especially during winter, due to their low flow temperature. Therefore, they have to be used in conjunction with other technologies:

\section{Interview_m_}

M.L.: A so-called bivalent plant.

M.R.: What is the meaning of bivalent?

M.L.: Bivalent means that you have two systems. When it gets very cold and the heating pump cannot keep up its performance anymore, the oil heating, gas heating, or a second heating generator acts as a supporting mechanism. Depending on what you have, it can also be a wood boiler or something like that. In other words, a second heating generator supports the heating pump. An air, water, thermal heating pump will never be designed for $100 \%$ performance, it would be much too big.

Additional systems to thermal heating pumps can, therefore, be renewable methods, such as wood pellet systems, or non-renewable systems, such as classical gas or oil heating systems.

The second interviewee considers renewable heating systems as an additional option. However, he does not accept a wood pellet oven due to his views on the insufficient eco balance:

\section{Interview_r_z}

\section{R.Z.: I do not know of any technology, which will deliver $100 \%$ guaranteed output} based on renewable energy. It is always a combination of heat, wind, solar power. I have to combine different renewable technologies. The only exception is when I use a heating pump as renewable technology. However, to start it running, I have to use primary energy, I need electricity. 


\section{Wood pellet ovens and wood stoves}

Wood fired systems, e.g. pellet ovens and wood stoves, are technically considered the only systems which can run throughout the year as a stand-alone solution or additional heating support for solar systems. However, they are not mentioned by all interviewees.

In the interview below, wood pellet systems are regarded in the context of solar heating systems to balance heating consumption on a completely renewable heating basis during winter:

Interview_c_w

M.R.: How far could you imagine covering $100 \%$ of your heating consumption by means of renewable heating technologies?

C.W.: Well, going back to pellets [pause]. Okay, I assume that I can cover my complete heat consumption. That is how I imagine it: I must have enough pellets and then I heat and have warm water. As I mentioned, I do not think that you can cover all heating demands only with solar heat. Therefore, I have already had the idea that the combination of solar and pellets could be an interesting thing.

In the next interview, the homeowner covers additional heating demand with another non-renewable gas heating system, in addition to the wood stove:

Interview_m_r.2

M.R.: So you have built in now a gas heating system, a wood stove. Heat, you will then use later on and you will combine it. Is there a reason that you want to use it that way, the wood stove and the gas heating system in parallel?

M.R.2: Yes, we will have them parallel.

$\cdots$

M.R.2: No, above all we want it warm upstairs in Fabien's [son] room, so it will be heated with the oven. Through the water pipe, the heating works with water. 


\section{Solar and photovoltaic systems with other technologies}

Solar or indirectly photovoltaic systems as a form of power supply for other heating technologies (e.g. thermal heating pumps) are further concepts for renewable technologies. They are commonly well-known and visible due to their positioning on roofs. Photovoltaic cells may hereby also be used to cover only own electricity demand. In this case, therefore, no renewable heating systems come to the point of use:

R.B. was asked whether he uses photovoltaic cells to cover his own electricity consumption:

\section{Interview_r_b}

R.B.: Exactly, to cover my own consumption of electricity, as for big consumers, such as the washing machine or the dryer.

Other aspects require different heating sources to avoid dependence on only one technology:

Interview_r_b

R.B.: Well, I want to have a security of supply. I do not want to have a gap in my supply. M.R.: So, your decision would not be to just take one solution you can use completely throughout the year as renewable heating technology?

R.B.: Not at all, maybe I would use solar technology in combination with other concepts like oil, gas, electricity, pellets, or something else. At the moment, solar must become more sophisticated with respect to roof installation.

Another interviewee, still thinking about his future heating concepts, is aware of these options, but is still looking for more information: 
Interview_d_v

M.R.: Do you think it is technically possible to work with $100 \%$ renewable heating technologies?

D.V.: Yes.

M.R.: By means of which technologies?

D.V.: A lot of people work simultaneously with solar, photovoltaic cells and these warm water storages [pause]. Which other technologies are also available?

\section{c. On-site integration of the technology:}

The above-mentioned factors consider the limitations or performance characteristics of the various technologies in use or to be purchased in the future. Another point of view is to relate the purchase to the existing situation on-site, and to the extent to which a new renewable heating system can then be integrated into or replace a former system. These issues relate to the technical influencing factor in the decision-making process too.

Local benefits of end users at home, who work with wood pellets systems are strongly considered. Interviewees who are aware of these systems answered in a similar way to the response presented below with respect to questions about their meaning:

Interview_k_v

K.V.: We thought about it. However, in my opinion, the heating pump was more desirable, as I do not need a storeroom as for oil. So, we gained this additional cellar.

Thus, a pellet heating system is, above all, interesting for people who previously used an oil heating system as the tank room can be used for pellet storage, as already indicated in the previous chapter about characteristics of heating technologies. 
In contrast, solar and photovoltaic systems have the common characteristic of being installed on the roof. In several cases, this was viewed critically, and even prevented end users from adopting these technologies.

A.H. reflects on this point, when asked about the problems with roof installation:

Interview_a_h

A.H.: Well, the roofing tiles. Nobody wanted to deal with it.

M.R.: Due to static aspects?

A.H.: No, no. It is due to the foam. They cannot remove the roofing tiles. Well, other aspects about renewable heating technologies [pause]. Some years ago, we also wanted to build a new house and then wanted to install a ventilation system. Yet, with such an old house, it does not make any sense.

Another answer mentions the involvement of a carpenter against the same background:

Interview_k_v

K.V.: Surely, I have thought about photovoltaic or other heat exchangers on the roof. However, I spoke to the carpenter who told me that my roof was not designed for it. Additional weight is problematic and the roof tiles have to be drilled to install the piping system. I am frightened to get problems with the tightness and do not want to create issues with it. Therefore, I do not want to deal with it.

The influences of high investments are also noted independently from running cost, in the context of thermal heating pumps, due to a higher electricity demand in older and commonly badly insulated houses. The running and investment costs are high for socalled water heating pumps, where a hole has to be drilled in the garden to use ground water: 
Interview_r_z

R.Z.: Yes, and then the next step came up. What kind of heating system will we put behind. We quickly decided on an air heating pump. We then informed ourselves on the subject of water heating pumps, with a hole. However, for the hole, I would have had to invest 10,000 EUR. I have calculated how long I can heat with the air heating pump, and I will never have the problem that the ground breaks down, but I use the air which is simply there.

\section{Findings - Specifics of the technology:}

Descriptive issues have been considered for the above-mentioned coding category and properties without evaluating rational and bounded rational decision-making factors to point out technical and commercial characteristics of renewable heating technologies. The background may help to form a more comprehensive picture about the technologies in the following chapters, which are related very often to certain heating technologies in the interviews. The assignment to rational or bounded rational related approaches will then be taken into consideration in the chapters regarding the decision-making process.

However, the statements about the technical and commercial factors of the technologies may differ substantially between participants due to their different on-site situation, and their availability and interpretation of information. Therefore, in a broader context, they are expected to be bounded on personal insights in a 'second stage' with respect to the interpretation of information. However, above all, they are bounded by means of external influencing factors in a pre-selecting 'first stage', such as the technical situation on-site, and the volume and content of given information.

In order to express it by means of the exclusion principle, renewable heating technologies are not related to one specific technology in the end user context (related commercial and technical statements). Already, the limited number of interviews examined so far indicate that each case has to be examined on its own merits.

End users are most familiar with wood pellet systems and solar systems. Further, they recognise thermal pump systems, mainly combined with photovoltaic systems to feed the 
electricity from the photovoltaic panel system into the public network and/or to cover the electricity demand of the heating pump.

Although representative statements about the share of technologies in use require quantitative explorations with an enlarged sample of end users, certain technical aspects mentioned from end users are confirmed by expert interviews and through secondary data (Chapter 4.5.3):

- Micro CHP units are related to high heating supply capacities and thus multiple end users, such as multi-family houses or residential buildings.

- Thermal heating pumps require large investments for their installation and are deemed to have limited efficiency in old houses with poor insulation, due to their higher electricity demand caused by higher heat performance.

- The usage of photovoltaic cells is considered to not only cover the electricity demand of thermal heating pumps, but also to cover the own electricity demand, depending on the electricity tariffs (EEG contribution).

- Wood fired heating systems require enlarged space to store fuel and are appreciated by end users with former oil heating systems (tank room).

A general possible $100 \%$ year-round heating demand with only one heating technology is not confirmed or known by all participants, though this would be possible with a wood fired heating system. It is often considered that renewable technologies need to be combined with other renewable heating technologies (solar and photovoltaic systems), and/or non-renewable heating technologies, such as gas and oil fired systems.

The different examinations of the technologies are limited due to the available information. Thus, they assume rational matters, which are interpreted within bounded constraints. They may be different in case of other interpretations by end users. One solid renewable technology is, therefore, not foreseeable and may be influenced by bounded rational related decision-making factors.

\subsubsection{MOTIVATION FOR THE PURCHASE}

In my a priori conceptual framework I did not claim to consider motivational aspects as part of the decision-making process. The steps of the decision-making process in the a priori framework are based on a stepwise rational decision-making approach related to 
gaining or gathering information, knowledge of alternatives, or systematic collection of information at the beginning of the process. Reference in the literature review is made to Mintzberg, Raisinghani \& Theoret (1976), Eisenhardt \& Zbaracki (1992), March (1991), Al-Tarawneh (2012), Anderson (2002), Simon (1977), Poole \& Van de Ven (2010), Weick, Sutcliffe \& Obstfeld (2005), Wilson (2010) and Franz \& Kramer (2010) as some academics conducting research in the field of rational decision-making processes.

Although the topic is touched upon by some authors of my literature review, I mainly considered personalised influencing factors of decision-makers or influencing factors of other stakeholders for bounded rational decision-making approaches. The agendas of stakeholders as part of their bargaining process, the intuition of homeowners as decisionmakers, their experience and education, advice from others, interests, values and world views of decision-makers, the social construction of conflicts by decision-makers as end users with other involved stakeholders, their emotions, beliefs and attitudes are mentioned. In particular, these factors are referred to by Turpin \& Marais (2004), Lunenberg (2010), Wilson (2010), Bennet \& Bennet (2008), Daellenbach \& McNickle (2005) and The Department of Energy \& Climate Change (2012).

In the course of research during the coding process, I became more and more aware that motivational aspects are closely related to the behaviour of consumers and influenced by their needs. They play an additional part in purchasing renewable heating technologies.

\section{Motivation vs. motive}

Bernard et al. (2006) define motives in the context of wider motivation. In contrast, motivation is a powerful behaviour directed towards the fundamental goal of inclusive fitness. Motivation refers to why certain behaviour persists as opposed to others. It is related to human beings initiation, choice, and persistence in particular behaviours and environments. Motives then guide behaviours and interests in social domains which direct motivation. They are purposes, which a person has taken and follows; thus, they are personalised.

Edelmann (2003) mentions motivation as activating processes. Individual drives or interests on issues or their attraction can lead human beings to certain activities. Motives are related to inborn needs. Other motivation processes are stimulating as sensitive importance of issues and cognitive processes like decisions, expectations or plans. Edelmann differentiates between intrinsic motivation, coming from insight, and extrinsic 
motivation, which is external. Intrinsic factors can be curiosity and incentives, whereas external factors are focused on awards and force. Her report is strongly related to learning issues at school, however, she reflects on a further differentiation between motivation and human beings' internal and external motives, which are part of the scientific literature about psychology.

Heckhausen \& Heckhausen (2010) point out two important characteristics of motivational behaviour in a rather general and abstract way. They mention the pursuit of activity and the organisation of acting with aim engagement or aim alienation. Motivational influences, related to individual persons, are contrasted with universal needs, individual motive dispositions (implicit), and aim (explicit).

With respect to this research, therefore, motivation is considered as overall drive, whereas motives are related to certain and more strongly personal goals. Relevant expressions of the interviewees have to be identified, analysed, and assigned within the data analysis. Deeper psychological aspects are not considered as they do not form part of this work. In contrast, as motives are more concretely related to behaviour and outcome in certain contexts, they are part of the coding structure of this work. They relate to behaviour regarding issues surrounding the extent to which renewable heating technologies have been or may be purchased by end users.

As Heckhausen \& Heckhausen (2010) argue, motives pursue behaviour to activity in an individual and personal context.

Some motivational aspects are considered within the literature, however, they are not a separate part of my a priori framework:

Mark \& Henry (2004) explore mechanisms on decision outcomes. Motivational processes refer to goals, inspirations and finally changes in action as decision outcomes and part of behavioural processes. Ajzen (1991) explores behaviour under the term of planned behaviour by focusing on the individual's intention to act. He argues that behavioural achievement depends jointly on motivation (intention) and ability (behavioural control). The subjective factor as a subjective norm refers to the perceived social pressure to perform or not to perform a particular behaviour. Elbanna (2011) characterises strategic decision-making in the context of relationships with customers, suppliers and competitors. They are determined by one's motives. Tsoukas (2010) relates the Heideggerian approach as deep structuring of reality under consideration of practical 
consciousness and the conscious process of making commitments to actions for various purposes, such as motivation.

Therefore, the final framework is broadened by contextualising motivational factors to the decision-making process. More concrete, personalised motives will be the starting point of the stepwise decision-making approach for the purchase of renewable heating technologies.

\section{a. Cost-effectiveness thinking:}

Cost-effectiveness thinking, with respect to the research context, is interpreted with figures and terms like profitability and efficiency; in other words, strict goals. Finally, it reflects on the question of whether the investment in renewable heating technologies will be economically sound or not.

This factor is, therefore, not focused on emotional aspects, which are related to bounded rational processes. Turpin \& Marais (2004) relate these bounded rational processes to personal insights as personalised bargaining processes and values, or according to Lunenberg (2010) to different statements with intuition, advice from others, and creative thoughts.

In contrast, rational and processual decision-making processes are focused on different steps to find the best solutions. Eisenhardt \& Zbaracki (1992) relate rationality to actors who gather appropriate information, develop alternatives, and then select the optimal one.

The optimal alternative with respect to figures will be the one which will cost the least or save the most compared to other alternatives.

The code 'Cost-effectiveness thinking' is also considered with the same name within axial coding around the category of personal characteristics on the decision. There, the code is regarded as a step to determine whether a certain concept is an action or outcome within the (stepwise) decision-making process.

To foreclose, all statements made during the interviews related to economic aspects were very clear, explicit, and based on monetary views, independent from their heating system, which was already in use, or planned. Some statements are listed below.

The following interviewees were asked why they changed their old system: 
Interview_a_h

A.H.: Yes, because it was old and due to economic reasons.

M.R.: So, you talk about the efficiency rate?

A.H.: Yes, the efficiency rate.

Interview_e_s\&w_s

M.R.: Well, which information do you require and which do you leave out to form an overall picture? Are you focused on emotions, are you figure-orientated, do you pay attention on economics?

E.S.: Well, economics, of course.

interview_c_w

C.W.: A top priority would definitely be the profitability. As I told you, I have the feeling that oil heating is expensive with respect to the running cost. Well, yes, that is the most important thing.

The above-mentioned interviewees reflected on future decisions to be taken, or on decisions they have already taken to go for a new purchase on a non-specified but single heating technology (concept).

Another point which came up was the likelihood of an economically motivated decision to prevail, when the decision-maker was faced with different options. The question was why they chose a solar system and not a thermal heating pump or something else:

Interview_e_s\&w_s

E.S.: Photovoltaic, but it was too expensive.

W.S.: Due to the roof. It does not have the right position. 
M.R.: But then you get compensation when you do not use it for your own purposes.

W.S.: Yeah, yeah.

$\cdots$

M.R.: Well, which information do you require and which do you leave out to form a picture? Are you focused on emotions, are you figure-orientated, do you pay attention on economics?

E.S.: Well, economics, of course.

M.R.: Well, so you also check the calculations, whether it works or not at the end...

E.S.: Yes.

A further interesting aspect is that economic issues are not only entirely related to the purchase. Instead, they form an integrative part of the decision, alongside other aspects. The following issues, conviction and comfort of certain heating technologies, are demonstrating samples of such additional factors:

Interview_m_I

M.L.: Well, I thought about it for a while. Will I renew the oil heating or will I invest into the heating pump. Finally, I decided to use the heating pump.

M.R.: And what was the reason?

M.L.: The reason [pause], the reason was that the heating pump was cheaper, based on a cost effectiveness calculation, compared to the oil heating.

$\cdots$

M.R.: What kind of information do you require in detail to form a picture? Are these rather commercial aspects or...?

M.L.: Well, on the one hand, I must be convinced by the technology and then of course the commercial side. 
A second statement in this context was in reference to the question about whether the interviewee was more focused on getting away from oil or gas or whether a certain feeling, such as comfort, was the reason. The interviewee had already bought a split log oven:

Interview_d_v

D.V.: Well, comfort, but also cheap energy.

Based on the above, it is evident that the code 'Cost-effectiveness thinking' is strongly related to rational decision-making aspects. If the technology does not 'count', it will not be purchased. Personalised and bounded related aspects, like convenience and comfort, may play a role, but do not replace economic considerations.

\section{b. Eco-sensitivity:}

Aside from the 'hard fact' of figures, the code 'Eco-sensitivity' is considered for soft decisions expressed with 'sensitivity' and in the context of sustainable thinking, represented as eco (short-form) or ecological and, therefore, stands for a bounded related decision-making issue.

As theoretical background for the further approach, it is necessary to learn more about the issue of eco-sensitivity and the ecological background with reference to renewable heating technologies:

The governmental BMVBS report (2011) identifies renewable energies, on one hand, as those generated through wind power, photovoltaic or solar plants, biomass and geothermal heating stored in the ground and used for heating, and non-renewable resources, on the other hand, such as coal, gas or oil.

Regarding relevant production and distribution concepts, Armstrong \& Ryan (2009) consider renewable energy based on its sustainable criteria. The matter of economic criteria considers economic aspects including pay-back and contribution to the asset value of households, environmental criteria relate to issues from the environmental impact of the technology. 
Brohmann et al. (2009) relate covering sustainable (not renewable) to the individual area of end users and individuals. It consists of action as a demand-side area with informal activities undertaken by consumers. The area thus considers consumer behaviour.

Reference in their study is made to the Brundtland Report (Brundtland, 1987), a summary of a meeting of the General Assembly of the United Nations, which was addressed to a global agenda for change for the protection of our environment. Sustainable development requires that the adverse impacts on the quality of air, water, and other natural elements are minimised so as to sustain the ecosystem's overall integrity.

Compared to economic factors, decisions exclusively motivated by ecological considerations were only mentioned by a minority of interviewees and only when combined with other factors, such as economic aspects.

The interviewee below was asked about his thoughts and attitudes when he heard the term 'renewable energies', also in comparison to classical energy distribution concepts with oil, gas or coal:

Interview_t_a

T.A.: Well, I try not to use fossil fuels, I am pro renewable energy.

$\cdots$

M.R.: Are there personal characteristics or behaviours you could describe, which lead to your decision? Are you more focused on figures or visions, your attitudes to the complete subject?

T.A.: Yes, attitude plays a major role. Of course, figures, too. It must be payable. But it is, yes, also the attitude. And the investment, the solution, a lot of leisure time activities are included there. Therefore, green thought.

Another interesting point of view was that some answers were less motivated, in a narrow sense, by the different technologies, but more motivated, in a broader sense, by the political context: 
Interview_m_I

M.L.: Well, we have to get away from oil, gas and coal. The main goal must be to get away from these fossil fuels. I am no friend of wood. Because for wood, the carbon dioxide, the circulation, the carbon dioxide circulation will be certainly balanced. The carbon footprint will be balanced, because wood is a renewable raw material.

Social and global issues are related to this statement, in a wider context, associated with the term sustainable and the discussion about minimising the greenhouse effect.

The next interviewee reflected on this thought, too, when ignoring wood pellet systems as renewable technologies due to the necessary clearing and forestation of wood:

Interview_r_z

R.Z.: I do not know any technology, which will deliver $100 \%$ guaranteed out of renewable energy. So-called peaks then, too. It is always heat, wind, solar power, when it is there. Different renewable technologies have to be combined. The only exception is, when I have a heating pump as renewable technology. But at the beginning I have to input primary energy to use this thing, I need electricity.

Interesting aspects were brought up by C.W. in evaluating renewable heating concepts, restrained due to eco-balance of products; therefore, their influence during their complete life cycle from production to waste disposal.

The question in the following interview was about which renewable heating technologies C.W. knew and which opinion he related to them:

Interview_c_w

C.W.: I am still not sure, whether it [solar heat] will be profitable with respect to the point of eco balance. On the one hand, you save renewable energy, on the other hand you have panels which might have to be depolluted expansively, sometimes. 
Therefore, I am a little bit sceptical with photovoltaic and solar heat, because I do not know how to handle them when they do not work anymore. Does anybody know how to do it?

The statements, in a broader context in contrast to the daily involvement point out that no economic or figure related issues are founded in their motivation for the purchase of renewable heating technologies in the future. Attitude regarding the matter of renewable energies plays a greater role.

The interviews indicate, with respect to the already presented explorations on hard facts and soft facts that the statements about 'Eco-sensitivity' are bounded rational related decision matters, contextualised with influencing personalised factors, such as feelings and attitudes. Therefore, they reflect on personal insights and positions.

It has to be pointed out that not all interviewees reflected additionally on ecological sensitivity, instead some only focused on economic issues.

\section{c. Necessity:}

This code shall consider how urgent decision-makers consider strategic decision-making in the purchase of new heating or renewable heating technologies in their property.

Papadakis \& Barwise (1998) relate strategic aspects to major long-term consequences and regard them as hard to reverse. They see strategic decisions also as decisions, which involve the commitment of significant resources. Mintzberg, Raisinghani \& Theoret (1976) expand on both terms - long-term and strategic - in their considerations. They call decisions strategic if they have long-term effects. Further, they associate the demand of considerable resources and setting of precedents with strategic decisions. Consequently, they see it as a door opener to various smaller scale decisions. They define a strategic decision as a commitment to a future action. Such decisions are important in terms of the action taken, the resources committed, or the precedents set.

Nutt \& Wilson (2010) argue that strategic decision-making is often used for important decisions in organisations. In this context, they define organisation as any collective social, economic, or political activity with a plurality of human effort. 
Therefore, organisation stands for the structure and, finally, the process of decisionmaking, the involvement of different aspects and the necessary time to reflect on these inputs until it comes to action.

Against this background, contextualised organisational aspects about reasons to take or not to take a decision on the purchase of renewable heating technologies are of interest for decision-making processes of end users. They are related and addressed to involved individuals or groups, such as relations, manufacturers, or distributors of heating energy and heating products, and other external influencing factors. The following statements are deduced from reasons either to deal with the purchase of renewable heating energy or to leave it at present.

\section{Statements "to do something"}

Aside from technical breakdowns, which require action from all interviewees, the belowmentioned interviewee is focused on oil prices and, therefore, economic reasons to keep himself busy with regards to a possible new renewable heating system:

Interview_c_w

C.W.: Well [pause]. It would be accelerated in case of a breakdown [laughing]. It would probably also be accelerated when the oil prices rise again. Then you certainly would have to think about it. Because, I think what we have to pay already is at the pain barrier. Well, at the moment, it works. But when it was around 1 EUR, it was at the pain barrier.

D.V. argued for the purchase of a split log oven as he could run it with lower temperatures and split logs [for free from relations]. Therefore, in the end, he argued economic reasons for the purchase of this renewable heating technology, which would come out cheaper than his oil boiler system [still required for warm water]: 
Interview_d_v

D.V.: Exactly, I was not satisfied with the old technology. Well, when I come from work, I normally have fourteen or fifteen degrees in my living room. Then, I load the oven and it gets warm.

E.S. also mentioned economic factors, expressed in the context of effectiveness, as a reason to purchase solar panels:

Interview_e_s\&w_s

E.S.: ... it was just old, not that effective anymore and, therefore, we took the decision to undertake something [laughing].

The same motivation, founded in effectiveness, was mentioned by the next couple. In this case, they invested in a new oil heating system and argued that energy saving was not only a result of the purchase of renewable heating technologies, but also due to lower consumption and better environmental protection with the replacement:

\section{Interview_c I\&e_ I}

M.R.: The old system was broken down. You had to do something?

E.L.: Yes.

C.L.: Yes, but it would not have been necessary, immediately. With respect to the huge background, we decided to go for something else. Of course, there is the financial aspect, the financial saving. At the beginning, you must finance the new heating plant. But there was also the thought of environment protection, energy saving. This was also in the foreground. Well, only the [pause]. Well, it is linked to other aspects. But at the beginning, it is a big investment which you cannot immediately amortise just through energy saving. 
T.A. again reflects on economic reasons, instead of urgent issues, such as technical breakdown, for keeping his chosen heating distribution and for the purchase of a wood pellet system:

Interview_t_a

T.A.: Yes. In the beginning, there was already the oil heating. We already renewed the burner, in the meanwhile. Even twice. And it was not broken, the oil heating. Well, then the oil price increased and, well, we had the money.

\section{Statements "not to do or postpone something"}

In contrast to the above statements, the below-mentioned interviewees also do not dismiss the purchase of renewable energy completely, but focus on future purchase, and are very strongly motivated by available financial resources.

K.V. was asked how far house insulation was part of his investment and which priorities were there compared to the heating system:

Interview_k_v

K.V.: I thought about it already. But I will be seventy-five soon and I do not want to be bound by additional cost, which only will only lead to profitability in twenty years' time [pause]. You can do a lot, but it should work in a foreseeable time. Otherwise, I have to notice that the running cost of my existing heating system is more expensive in order to change something very fast.

E.L. expressed very clearly that money must be available and that the financial benefits of a promotion campaign will only be accepted as a subordinated part: 
E.L.: Of course, it is a financial question in general then. Even, if a promotion came up, however, it will be a substantial investment [laughing], won't it? And as we have worked so far to the order principle, we have not considered it so far. Considering it would have come at a later point in time. We cannot do everything at once.

C.W. again related investments to financial resources, in the context of other household costs:

Interview_c_w

M.R.: Is there a reason that you did not work on it?

C.W.: Well, also due to financial reasons, because it is not possible to do everything at the same time [laughing]

All the interviews point in the same direction. In cases where the purchase is of interest, it is prioritized, along with other aspects, due to the availability of money.

From an academic point of view, extracted from extant literature, the purchase of heating technologies (renewable or non-renewable) is a strategic decision. The interviews show that end users behave in accordance with rational decision-making aspects, and are not driven by spontaneous emotional aspects. Instead, they are driven by strategic, long-term and sequential stages, reflecting on other investments, their financial resources, and an economic evaluation of the investments.

\section{Findings - Motivation for the purchase:}

'Cost-effectiveness thinking' is always an essential motive for the investment decision. Whether it is a stand-alone aspect, or whether it is considered in the context of other issues. 'Eco-sensitivity' is an additional decision-making factor, but it is interesting to know the extent to which eco-sensitivity is linked to economic factors. Attitudes differ between individual aspects with respect to single purchase or, in a greater political 
context, with respect to political views on a macro-economic or political level, such as climate change. The 'necessity' of purchasing renewable heating technologies represents a comprehensive decision-making process, long-term and rather 'complex'. Different aspects, like prioritising other investments or observing the development of fuel prices for non-renewable technologies, are part of the decision. The availability of sufficient financial resources is very important in reaching a decision.

\subsubsection{SOURCES AND STAGES}

The sources of information and their involvement in the rational part of the stepwise decision-making process require better understanding. The stages leading up to the act of purchase involve gathering of information, search for alternatives, and their evaluation (Mintzberg, Raisinghani \& Theoret, 1976; March, 1991; Lunenberg, 2010; Turpin \& Marais, 2004). The final stage of action is the purchasing or installation process, which is not part of this coding structure. The main process of decision-making, which constitutes the core of this investigation, has then already taken place. The relevant factors for evaluation of options are considered in the categories: 'Motivation for the purchase' and 'Affecting factor: personal character'.

\section{a. Sources:}

This code considers exclusively what kind of sources are available and where decisionmakers have access to relevant information, independent of whether decision-makers are passive or active in acquiring this information. This aspect, therefore, constitutes the information channels of the end users to their environment to form a picture or to enter into a decision-making process. With respect to personal insights and bounded rational aspects, which will be analysed in Chapter 6 of the data discussion, this code does not consider how decision-makers have formed their personal world views; instead it looks at which information has been considered and evaluated.

The interviews show that mainly electronic, Internet sources have influenced most end users, independent of their age. Plant manufacturers, print media, and information onsite, such as exhibitions or referencing plants, are additional or alternative sources.

The following interviewees reflected-on various sources: 
Interview_a_h

M.R.: Where do you get your information from?

A.H.: Well, the Internet, expert magazines. Well, I inform myself very comprehensively.

$\cdots$

M.R.: Do you also consider references?

A.H.: Yes.

M.R.: So, you look at how heating systems work for other people.

A.H.: Yes.

M.R.: From where do you get the information, at heating plant installation companies or from relatives?

A.H.: Yes, but also at exhibitions.

Interview_g_g

M.R.: Where do you get your information from?

G.G.: Aside from external consultancy and discussions between friends and family, surely from the media. Energy is an omnipresent topic. Even if you are not interested in it, you cannot avoid it. You read very specific things.

Interview_m_I

M.R.: Where have you got your information from, aside from the manufacturers?

M.L.: Actually, only from manufacturers. From experts at exhibitions. Well, where did I get my information from? Mainly from experts, from exhibitions. I went to exhibitions, which is where I got my information. 
Interview_c_w

C.W.: Well, I think the first information source will be the Internet. So, that you Google there and you call up pages dealing with this topic. Then, as mentioned, we have a relative who owns a heating plant construction company. I would definitely talk to him in more detail. And then, I would possibly speak with an energy consultant, too.

A complete 'package' of sources again was mentioned by the married couple below:

Interview_c_I\&e_I

M.R.: And why are you restrained with respect to pellets?

C.L.: Well, we watched some reports on television. But we are not really up to date. It also depends on the materials you use; what do they consist of. Well, do all aspects come together, so that it is a reasonable renewable technology?

M.R.: Where do you get your information from?

E.L.: Well, in that way that we went to such a company [manufacturer] and asked for advice.

C.L.: Well, today, we would probably do it differently. Maybe, we would go to an energy consultant to get some general information there.

\section{M.R.: Do you use the Internet?}

C.L.: Yes.

M.R.: Exhibitions as well?

C.L.: We did it at that time, too. So we went to an exhibition. We did it once, but, no. You are approached by many people. I find it difficult as layperson. I prefer to take a rest and sit down instead of go to an exhibition.

E.L.: Well, I must be honest. I prefer to ask an expert and sit down afterwards to see what will be okay for me. 
The next interviewee, a pensioner, commented on a change of his engaged sources from print media to the Internet in recent years:

Interview_r_b

M.R.: Where do you get your information from?

R.B.: I use different sources. In earlier days, I read STIFTUNG WARENTEST [expert magazine] and their evaluations. Nowadays, I use the Internet. A change has taken place there. So, I am now rather focused on the digital world. Therefore, a change has taken place with me.

Data show that the involved information sources can be rational or bounded rational related with respect to their relationship and to end users and their content. Rational related aspects to form a comprehensive picture may be a summary of various sources, such as the Internet or print media. Bounded rational related issues can be personal contacts to relations and their later influence on the decision-making process. The involvement of human beings has a stronger influence on the decision-making process of end users compared to the simple searching and (non-emotional) reading of data, for example, via the Internet or by reading expert magazines.

\section{b. Stages - Information:}

The code reflects on the stage of gaining information in the first part of the rational decision-making process, as explored by Mintzberg, Raisinghani \& Theoret (1976), March (1991), Lunenberg (2010), or Turpin \& Marais (2004). Compared to the code 'Sources', the stage of 'Information' considers that the decision-maker identifies activities (Mintzberg, Raisinghani \& Theorer, 1976) or is being involved with activities (Lunenberg, 2010). Therefore, knowledge of alternatives as the chronological stage after information gaining, before taking action, assumes intelligence to find occasion for making decisions (Turpin \& Marais, 2004). The expression 'finds', therefore, expresses being active to get this information and possibly to enter into a decision-making approach. 
The approach to information is realised in different ways, depending on the personality of the decision-makers.

Five different considerations of stages are analysed. The grounded research offers the exciting opportunity to develop different observations by means of a deep analysis of the interviews and text data.

\section{First stage - passive acquisition of information}

The information considered here is that which the interviewees picked up without a clear intention of evaluating a certain heating technology. The information was not canalised. The data indicates that references to others and the Internet are the main sources related to this issue. Aside from the mentioned sources, expressions, which indicate this passive stage within the decision-making process, are of interest for the data analysis.

The following interviewee was asked to what extent he was influenced in his decisionmaking process by others, own experiences, or own attitudes:

\section{Interview_c_w}

C.W.: Well, I make sure, of course, that I pick up experiences or advices from others or relations. A relation of ours owns a heating plant construction company. I would definitely ask him when we have to decide it. Funnily enough, our neighbour has just bought a new gas heating system. Obviously, renewable heating energy was no subject for him.

The term 'pick up' stands for a rather passive, gained information, compared to an active 'searching' for an answer on a question or an inquiry. However, 'pick up' stands for a sensitisation on this issue, similar to 'listening carefully'.

The answer of another interviewee is presented below, who was asked the same question:

\section{Interview_d_v}

D.V.: Influenced, rather not. But from others you can get information. And relations, too. And you believe them more than enterprises or representatives.

M.R.: That means, your relationship to enterprises or representatives is rather restrained? 
D.V.: Not restrained. I look for advice, I go to exhibitions and I have discussions. But, well, it is not the way that I ask for many quotations. It is for information.

The expression 'for information' again indicates that no concrete intention related to purchasing stands behind it.

In the following statement, this aspect is expressed by saying 'we got the information by reading... Through television', which demonstrates absorption of certain information, instead of an active demand for it:

Interview_e_s\&w_s

M.R.: And the information you read in your technical magazines. Thus, not through relations, heating constructors...

E.S.: Yes, and on television.

W.S.: And in [pause]. Where has it been?

E.S.: You mean an energy consultancy? Yes.

$\cdots$

M.R.: He then recommended to you these micro combined heat and power units?

E.S.: Actually, we got the information by reading, Mr. Reichler. Through television, too. There, some people introduced it [interrupted by W.S.]

W.S.: Stiftung Warentest [technical magazine]

E.S.: Yes, Stiftung Warentest.

In the next interview, this rather passive behaviour was represented by the term 'sometimes' in the context of gaining information:

Interview_t_a

M.R.: Do you also pay attention to other people, to other references? 
T.A.: Yes. Sometimes, I have a look at what other people are thinking. I was also on the Internet. There, you can gain a lot of information about pellet heating. There, I sometimes have a look at what the people, what the forums say. Today, the Internet is a great thing. With such diversity, an opinion crystallises. When you then read a lot of commentaries that it does not work, always breaks down or so, then, of course, you are careful.

\section{Second stage - active acquisition of information}

Information which the interviewees picked up concretely with the intention to use for the decision-making process is considered here. The data again indicates that mainly advice from others and the Internet are the main sources of information. To constrain this phenomenon, reference is made to certain expressions.

In the following interview the term 'important' underlines the awareness of what is seen as relevant for the decision-making process:

Interview_d_v

M.R.: And whom do you involve. You mentioned your heating plant constructor, your relations who are important - who is important for advice?

D.V.: Relations are very important. Especially those who have built a house already.

M.R.: Manufacturers as well?

D.V.: Yes, too [pause]. You always have to analyse the information, where does it come from and what is intended by it. You are in better hands with your relations, rather than with the municipality [laughing].

G.G. mentioned energy consultants whose meaning he evaluates by 'listening to them very carefully': 
Interview_g_g

M.R.: Which institutions, individuals, or groups do you involve in your decision-making process and how do you see their act to push, change, or accelerate your decision?

G.G.: Well, as I told you there are energy consultants. I listen to them very carefully. There is the plant heating installer I trust who will have a big influence on my final decision. There are human beings who are in the same situation as me and who have done something in that direction and can relay their experiences and [pause].Well, that's it more or less.

The next interviewees, a married couple, underlined their active information gaining process - 'asking for advice':

Interview_c_I\&e_I

M.R.: Where do you get your information from?

E.L.: Well, in that way that we went to such a company and asked for advice.

C.L.: Well, today, we would probably do it different. Maybe, we would go to an energy consultant to get some general information there.

M.R.: Do you use the Internet?

C.L.: Yes.

M.R.: Exhibitions as well?

C.L.: We did it at that time, too. So we went to an exhibition. We did it once, but, no. You are contacted by many people. I find it difficult as layperson. Then, I prefer to take a rest and sit down instead of going to an exhibition.

E.L.: Well, I must be honest. Then, I prefer to ask an expert and to sit down afterwards to see what will be okay for me. 
In the next interview, R.Z. very strongly pointed out his interest in information when he 'made some research':

Interview_r_z

R.Z.: I have made some research on the market with different constructors about what we can do in the heating area. It should definitely be in the low temperature heating area. Before, there were night-storage heaters.

\section{Third to fifth stage - early impressing information}

Other sources of information are those decision-makers pick up at a very early stage in the decision-making process, from a chronological viewpoint. At this point, it may not have an impact on the possible purchase of heating technologies, however, it may later influence the evaluation process. Three more detailed differentiations and issues are to be considered; stages three to five:

\section{Third stage - early impressing information - issue 'neutral information'}

The information has still not been evaluated by decision-makers, but may be interpreted later on in a certain direction.

R.B. expressed this point of view when he said that the 'knowledge ... does not get lost':

Interview_r_b

M.R.: In your opinion, when you look back, which aspects only took time or were a waste of time when you think about the information search and decision-making process, but had no influence on the end decision?

R.B.: It was no waste of time. I just informed and it is always worthwhile to gain knowledge. A decision had still not been reached. The knowledge is of value, however, it does not get lost. 
The next interviewees, a married couple, mentioned this issue by 'reading a lot' and not being influenced by others, both of which indicate a longer period between the decision and action:

Interview_e_s\&w_s

M.R.: To what extend have your decisions been influenced by others, your own experience, or your own personal attitudes?

E.S.: Actually not by others. We read a lot and formed our own opinion.

M.R.: And did you then tell your heating constructor what you wanted to have or did you ask him to work out a concept for you, that you want to have something new?

E.S.: Actually we knew what we wanted to have and he then submitted us proposals on how to realise it.

C.W. admits 'not to have informed himself in a deeper way' and later evaluates his (bounded) knowledge with the weak expression 'perception':

Interview_c_w

C.W.: Well, as mentioned already, I kept myself busy with wood pellet systems, which I find very interesting. But $I$ have not informed about myself about it in a deeper way - what empirical values there are, also long-term. However, I find wood pellet systems interesting. On the one hand, they are a renewable resource. On the other hand, you do not have to drill deep holes in your garden as is the case with geothermal systems [laughing]. Sometimes you read that it can cause problems. Well, that would be something, where I am interested in information. Maybe, if it works. I do not know whether it exists, in combination with a solar thermal system. That would be $\boldsymbol{m y}$ perception, but I don't know whether it is technically possible. It would be the ideal combination when you heat with wood pellets and you support it additionally with solar. 
Fourth stage - early impressing information - issue 'negative effected information for decision-making'

This is information that contributed towards a negative impression on the purchase of renewable heating technologies and, therefore, the refusal of certain renewable heating technologies.

T.A. voiced that he 'did not want' wood gasifier ovens due to his observation of neighbours before he decided to go for a wood pellet oven:

\section{Interview_t_a}

T.A.: And our neighbours, they all have these wood gasifier ovens. Once in summer, they drove to the forest, took their wood there. Today, you cannot do that anymore. But at that time, they did it for a long time, broke it up, hacked it, sawed it. There, the house still was not there. That was a big work on wood, then this neighbour and that neighbour, they used wild wood. I did not want that. I thought, I will not do that, I will not hack wood at 65. And there is pellet wood exactly the right thing and [pause]. Yes, then we decided very fast to use a pellet oven with collectors on the roof.

A.H. again reflected on watching neighbours in the past, obviously over a longer period of time, saying 'neighbours tried it before':

Interview_a_h

M.R.: And a geothermal heating system?

A.H.: The problems are the stones below the house, as I told you. Our neighbours tried it before, but had to stop it.

M.R.: What about the aspect of the flow temperature? Normally, you say that thermal heating pumps work with a very low flow temperature. Did you prove or calculate it?

A.H.: No. We did not prove it, as we also knew colleagues who had problems with that system. 
M.R.: Due to the low flow temperature?

A.H.: No, because the drainage pipes were blocked. The water did not run off.

E.L. commented on his fear of gas and the danger of explosions [mentioned before in a wider context] as a reason why he refused gas heating systems:

Interview_c_I\&e_I

M.R.: You now have an oil heating system. Could you change over to gas?

E.L.: No [laughing]. I am afraid of it. You know, I like cooking. I could cook with gas, but it is not my world.

\section{Fifth stage - early impressing information - issue 'supporting information'}

This information stands for positive impressions and, therefore, openness to deal with the corresponding renewable heating technologies it refers to.

R.B. highlighted his unwillingness to accept a gap in his energy supply as the fundamental reason for his preference of combined solutions:

Interview_r_b

M.R.: Could you imagine covering $100 \%$ of your heating consumption by means of renewable heating technologies?

R.B.: What could it be, a micro combined heating unit?

M.R.: Also a pellet heating system. Will it influence your decision if you cannot satisfy your energy needs $100 \%$ only with renewable heating technologies?

R.B.: Well, I want to have a security of supply. I do not want to have a gap in my supply.

M.R.: So, your decision would not be to just take one solution you can use completely throughout the year as renewable heating technology? 
R.B.: Not at all, maybe solar in combination with other concepts like oil, gas, electricity, pellets, or something else. At the moment, solar must get more sophisticated with respect to its roof installation.

M.R.2 worked with a gas heating system and wood stove oven. Her family wanted to invest in a new oven when the permission would run out. This should happen in a couple of years. Therefore, they were already focusing on a new oven, without concrete intention for its purchase. Their goal was to keep the rooms upstairs warm. This solution was technically limited to wood stove systems with heat exchangers for warm water:

Interview_m_r.2

M.R.: So you now have a built-in gas heating system, a wood stove. Heat, you will then use later on and combine it. Is there a reason that you want to use the wood stove and parallel the gas heating in that way?

M.R.2: Yes, we will have it parallel.

M.R.: And why do you not use the gas heating for generating warm water?

M.R.2: We do have it that way, at the moment.

M.R.: But you will not do it that way in the future?

M.R.2: No, above all we want it warm upstairs in Fabien's [son] room, which will be heated with the oven. Through the water pipe, the heating works with water.

M.R.: So you want to use the coils in the wood stove to run the radiators?

M.R.2: Yes.

M.R.: And the oven would be located here, downstairs?

M.R.2: Yes, it would be located downstairs, yes.

M.R.: Okay. So it is not for warm water, but for the room heating.

M.R.2: Exactly, for the room heating. 
M.L. strongly emphasised eco-friendly thought as the main driver for his decision to install a thermal heating pump supplied with electricity from a photovoltaic system in his house:

Interview_m_I

M.L.: We must get away from systems, which consume oxygen.

M.R.: And there, the heating pump is the only solution?

M.L.: Yes. It is the only system which I can feed with photovoltaic energy into the heating pump. With wind electricity, I can feed the heating pump and we have sufficient electricity. Waterpower and so on, there are already providers of electricity who sell ecoelectricity.

C.W. again appreciated the sustainable thinking regarding wood pellet systems and was curious to gather more information. He looked for further information to clarify some sceptical thinking about pollution aspects related to photovoltaic and solar panels:

Interview_c_w

M.R.: Which renewable heating technologies do you know and what is your opinion on them?

C.W.: I know pellets, it is a renewable heating technology. I have a positive opinion on it. That is why I could imagine going for it. Solar thermal, but I am not sure whether it is economical for us. The sun doesn't really shine so much. And I am not sure about the solar panels. They do not work forever. They break down or have to be renewed as they do not keep up their performance they were originally designed for. I am still not sure, whether it will be profitable with respect to eco balance. On the one hand, you save renewable energy. On the other hand, you have panels, which might have to be depolluted extensively sometimes. Therefore, I am a little bit sceptical about photovoltaic and solar heat, because I do not know how to handle them when they do not work anymore. Does anybody know how to do it? 
Based on the above, it is evident that the choice of the different information sources to get more details about renewable heating concepts is grounded in different sources, forming a comprehensive picture or focusing on certain more personal communicated information. Other stakeholders may be involved as influencing factors. They are, therefore, rational or bounded related, but not generally focused on one decision-making approach.

\section{c. Stages - Alternatives and evaluation:}

The two stages of the rational decision-making process - 'Looking for alternatives' and their 'Evaluation' - as one code, are summarised in this chapter. The stages are combined, not separated. This came about by means of the interviews and the decisionmakers' short, related statements in connection with this issue.

The phase within the stepwise decision-making approach, after gaining the information and before undertaking the action, or, in other words, purchase of renewable heating technologies, will be considered. The open coding process to find initial phrases did not involve as many references and statements from the interviews as the code 'Information'. However, the aspect of whether it is justified to separate them or combine them needs to be examined.

Essential questions: which issues are involved in reaching a final decision and how will they affect the approach to a decision as a decision-making cycle? Is it better to combine or separate the two stages of the decision-making approach: 'Looking for alternatives' and 'Evaluation of alternatives'?

Beresford \& Sloper (2008) define choice as an outcome of a process, which involves assessment and judgment. In their opinion, the process is the evaluation of different options and making a decision about which option to choose. In a strict sense, they mention that two or more alternatives are needed. It involves all cognition, and psychological theories concentrated on how choices are made by people. Bounded rationality bounds humans by constraints in the environment, like information costs, and in the mind, for example, limited memory. These constraints shape people's behaviours. Decisions are not only affected by cognitive efforts and decision accuracy, but also by emotions.

An interesting question will then be, how strongly and how quickly can single aspects influence the decision-making approach: 
As an expression for the achievement of goals, Daellenbach \& McNickle (2005) mention efficiency and effectiveness. Efficiency is viewed from the perspective of how well resources are used in a given activity. Effectiveness is considered as how well the goals or objectives of the entity or activity are achieved. True efficiency also considers the overriding objectives, as this enhances the effectiveness of decisions taken by the decision-maker. Effectiveness deals with doing the right thing, efficiency with doing things right. People viewing the same situation with the same purpose in mind may form different opinions on the matter. Conceptualisations are dependent upon the individuals' personal factors, of which they may not even be aware. All human beings construct perceptions of an unknown reality, which are reconstructed through an increase in knowledge and experience. Bennet \& Bennet (2008) explore the complexity of decisionmaking processes and differentiate between diverse connections, which form part of relationships, during the decision-making process. Emergence is a global or local property of complexity that results from the interactions and relationships of people. These characteristics represent stable or quasi-stable patterns in the form of culture, trust, and attitudes. Organisational learning requires individuals to work together and combine their own knowledge during interactions:

The butterfly effect occurs when small changes in a complex system result in significant disruptions. A tipping point occurs when complex systems change slowly until a threshold is suddenly reached, which creates large changes in the system (crash). Feedback loops can be self-reinforcing or damping, improving a situation or making it worse.

Dynamic factors also influence the decision-making process in a number of ways. Mintzberg, Raisinghani \& Theoret (1976) define six dynamic factors in the managerial context: (1) interruptions (may cycle back or bargain until blocking forces disappear), scheduling (time) delays; (2) timing delays; (3) speedups; (4) feedback delays (decisionmaker waiting for result); (5) comprehension cycles (cycling back to earlier phases to recognise the issue or to understand consequences and alternatives); and (6) failure recycles (waiting for an acceptable solution as a new path).

If an end user just asks for one quotation for his renewable heating concept from a trustful heating plant installer and then places the order there, no alternatives will have been evaluated and the action will take place. A strong focus on one reference as a 
direction in thoughts at a very early stage in the decision-making process before the stage of evaluation may then be interpreted as bounded.

The above-mentioned time to decision ratio, therefore, stands for the quality of decisionmaking processes and their outcomes.

The following parts related to searching for alternative solutions and their evaluation demonstrate whether rational or bounded rational aspects are in the centre of this matter.

The statements of interviewee R.Z. were as follows:

Interview_r_z

R.Z.: I have then conducted some research in the market with different installers about what we can do in the heating area. It should definitely be in the low temperature heating area. Before, there were night-storage heaters.

R.Z.: Yes, you then evaluate. You gain information. You read the Internet, you find some professional journals and you talk to enterprises about how to realise your ideas with plants of different types.

He indicated looking for alternatives as a rational issue. However, the stepwise approach towards their evaluation is not expressed very clearly.

D.V. again pointed out very clearly that he selected between different options to acquire information:

Interview_d_v

M.R.: How have you developed your opinion, by reading, or your own attitudes?

D.V.: By gaining information or inquiries.

M.R.: Where do you get your information from?

D.V.: When I moved in, five years ago, I used the Internet. Then, a heating plant constructor. Now, my relations who built their own house. 
M.R.: Have you also thought about a contact to an energy consultant or public services?

D.V.: No, I didn't [laughing].

M.R.: Is there a reason why you did not contact them?

D.V.: Well, I treated my information as sufficient. I also did not invest a lot of money. If you invest a lot of money, you will also spend more money for a consultancy.

M.L. explained the decision-making process in a more comprehensive way and reconfirmed the stepwise approach, but also pointed out 'personalised attitudes'. At that point, it is highlighted that the evaluation criteria is not explained in detail, but may be answered with respect to the research later in this work, when analysing personal and character related issues; in other words, bounded influencing factors:

Interview_m_I

M.R.: Well, then we come to the next question. To what extent have you been influenced by others and experiences, or have your attitudes influenced you?

M.L.: Well, on the one hand, by my personal attitudes, because I was interested in this topic. On the other hand, of course, I gathered information, I weighted them and then I took my decision.

M.R.: Where have you got your information from, besides the manufacturers?

M.L.: Actually, only from manufacturers. From experts at exhibitions. Well, where did I get my information from? Mainly from experts, from exhibitions. I went to exhibitions, from where I got my information.

M.R.: Experts mainly means manufacturers?

M.L.: Manufacturers, yes.

M.R.: Not energy consultants?

M.L.: No, no. Energy consultants, I did not involve. 
M.R.: Was there a reason, why you did not involve them. Because, they are promoted as well?

M.L.: Well, at that time, they were not promoted. And actually, I did not know any.

R.B. confirmed once more the involvement of different sources and choices, however, he did not reflect on a chronological decision-making approach. The heating plant installer is again involved in the decision-making process:

Interview_r_b

M.R.: Are there topics which you consider important and others which are less important for you?

R.B.: I am very open. Therefore, I cannot tell you whether it will be pellets. a combined solution, or rather gas.

M.R.: And how will you put together your information, with the Internet and then evaluating?

R.B.: Yeah, those will probably be the steps. That's the way in which I will probably do it. Additionally, my heating technician is important for me. To see what life expectation my existing heating system is going to have. That is a point on which it will also depend. The existing system, as I know it, has very good values.

R.Z discussed the factors in more detail, which he evaluated for his decisions. Later on, he also indicated his interest in more quantitative data about key figures related to thermal heating pumps. Once more, this interviewee also mentions feelings as bounded rational issues:

Interview_r_z

R.Z.: You have to pay attention to it, because every company, of course, tries to offer from what is their core business. But of course, that is not only in the heating business, in the energy business it's also like that, it's like that everywhere. You then have to 
check, and mainly to conduct some Internet research and to form a picture about what other users of these technologies, who have already installed something like that, talk about.

$\cdots$

M.R.: How do you differentiate between whether information is neutral, or whether somebody wants to take you in?

R.Z.: That is sometimes a gut feeling. When it is mentioned that the VIESSMANN HPL 736 [manufacturer] is the best heating pump, because of its COP [coefficient of performance], when half a data sheet is presented, where a private citizen would say the heating pump is wonderfully suitable, there you notice what it will rather be a promotional statement or a private statement. Of course, you never can, when you do not know the person, be $100 \%$ right, even if you do a detailed check. Maybe, you then also characterise a private citizen and you assume he makes a promotional statement, but he does not and sometimes you may not identify a promotional statement.

M.R.: Did you also pay attention to references, for instance? Did you see the technologies in person?

R.Z.: I did not have a look at these things. There, I received at least at three different quotations for each subsection from performing companies and required guarantees that they had not erected such a plant for the first time and had erected plants of the same type already several times.

By contrast, E.S. and W.S., as a married and retired couple, were only focused on a single heating installer who worked out a distribution concept [solar heating] and then carried out the installation:

Interview_e_s\&w_s

You said that the oil heating was not the optimal solution anymore, so you asked for something else.

E.S.: Yes. 
M.R.: Who consulted you? Did you take the decision on your own?

E.S.: No, we have a plumber, Schlichting [name] in Detmold. They did all of it here. We have been working with him in recent years.

M.R.: So you mean a heating installer.

E.S.: Yes, heating installer.

M.R.2 only considered very close relations. She intended to purchase a new wood stove when the permission for the old one expired:

Interview_m_r.2

M.R.: Well, when we talk about alternatives. The reason, why you have chosen that technology, you mentioned it already. Do you also read expert magazines?

M.R.2: No.

M.R.: Do you go to exhibitions?

M.R.2: No, there is nothing going on, right now.

M.R.: And the Internet, do you use it or forums in conjunction with the Internet?

M.R.2: No, we don't.

M.R.: So, you use the information from your relation because he is an expert. Further, as I picked up, information by the chimney sweeper?

M.R.2: Yes, exactly.

The above interviews point out that a more comprehensive decision-making process is undertaken in order to involve a huge range of information. In the end, the awareness of not being able to get a $100 \%$ clear picture of what is best, or the statements of certain people involved, indicate a combination of rational and bounded rational aspects involved in the search for alternatives and their evaluation. Rational aspects are expressed through the procedural approach and looking for alternative information 
sources. Bounded rational issues reflect on influences of others, when and how to take the decision, possibly by focusing only on one information source in an early decisionmaking stage, which might be the heating plant installer for the purchase of a heating concept.

\section{Findings - Sources and stages:}

Sources of information can either be the written and rather rational data of print media or the Internet, or the rather bounded rational related data from involved stakeholders and their relationship to end users as decision-makers. For example, friends in the personal environment or heating plant installers in the B2C context are mentioned.

Sources can have weak or strong influences on the decision-making process, as they have an active and undertaking, or passive and just-registering involvement. Sources of information related to the timeline before the initiation of the stepwise (rational) decision-making process, and equivalent to active gaining of information, may also influence decisions due to their excluding or supporting effects.

The first step of the rational side of the decision-making process, gaining 'Information', and the goal of reaching a decision, is a more comprehensive process with different involved sources in comparison to the later followed part 'Looking for alternatives' and the 'Evaluation of alternatives'. Therefore, decisions are already influenced and focused very early, even before the decision-making process, towards forming a picture of a possible purchase of renewable heating technologies.

A structural involvement with other stakeholders can be confirmed, which also indicates a longer period instead of a short-term characterisation of the decision-making process.

Delays, loops or interruptions cannot be confirmed as time-critical in the purchase of renewable heating technologies by end users. In this context, looking for alternative solutions is not regarded as a time-critical factor as it strengthens and focuses the (quality of the) decision-making process of end users towards an outcome. The outcome may then be decisions for or against a solution.

During the interviews, it became clear that all of the decisions, bar one, were not taken spontaneously. The spontaneous characterisation was only mentioned by one interviewee who still had not purchased a new heating technology concept. However, she pointed out that she already knew which heating concept she would be purchasing in her house once 
she had availability of capital resources (she first prioritised insulation measurements). Therefore, the decision-making process to purchase a certain technology was already in process and almost finished before the last stage, 'Action'. A common characteristic was that all end users took or will take their decisions on the purchase of renewable heating technologies in a non-pressurised manner.

Based on the terms about rational decision-making processes as a stepwise decisionmaking approach, the stages 'Looking for alternatives' and the 'Evaluation of alternatives' follow on from each other in a short timeframe. Nevertheless, the whole process also considers bounded rational influences, such as the involvement of meanings from friends and manufacturers or consultants. Thus, the rational decision-making approach is influenced by bounded rational decision-making factors.

\subsubsection{PERSONAL CHARACTERISTICS}

This category and the following three categories consider affecting personal factors of end users for renewable heating technologies, especially during the decision-making process, which has already been undertaken or may arise in the future. The approach is related to decision outcomes in the form of action or - more specifically with respect to this research work - the purchase of renewable heating technologies. Action can also mean to confirm the existing heating technology on-site and not to adopt a new heating system.

Mintzberg, Raisinghani \& Theoret (1976) define action in a general way, stating that it just stands for the end of the decision-making process and specific commitments to action.

In this context, Franz \& Kramer (2010) call this phase decision outcome and Wilson (2004) refers to it as the endpoint of the decision-making process.

\section{a. Cost-effectiveness thinking:}

This code reflects on the same theoretical background as the code with the same name within the category on motivational aspects. The code is, therefore, also focused on figures and terms such as profitability and efficiency. 
Eisenhardt \& Zbaracki (1992) classify rationality, in the context of procedural features, as the systematic collection and interpretation of information with actors who gather appropriate information, develop alternatives and then select the optimal solution.

By contrast, bounded rational processes are contextualised by personal insights and values, or different statements with intuition or advice from others, and creative thoughts (Turpin \& Marais, 2004; Lunenberg, 2010).

As already remarked, in the context of motivational aspects, the answers presented by all interviewees for this code are very strict and clear.

\section{Pure commercial related statements}

A.H. reflected on price comparisons between his thermal pump system and gas boilers:

Interview_a_h

A.H.: I am a chemical engineer. Thirty-five years ago, I started to realise energy saving projects. Therefore, I have some technical background and can calculate some issues. As I told you, as a simple sample, electricity is six times the price of gas. It must be profitable for me, somehow. Already in the 90s, I kept myself informed about the topic of calorific value technology and spoke to various plant heating installers, but there was not even one, who was attuned to it in a positive way.

D.V. owned a split log oven in combination with an oil boiler and just mentioned the term 'cost' more generally:

Interview_d_v

M.R.: Can you please tell me something about your thoughts and attitudes when you hear about renewable heating technologies, also compared to classical distribution concepts with oil, gas or coal?

D.V.: Well, to be honest. Above all, I keep an eye on the cost. 
G.G. also reflected on cost advantages as a priority for a new heating technology, both renewable and non-renewable:

\section{Interview_g_g}

G.G.: Yes, I can tell you that I am completely free of ideology. I comply with the cost, which is associated with the usage of these technologies. It happened by random that we now use fuel oil, which has proven to be a very convenient heating method. I have just read in the newspaper that people who use fuel oil, pay $40 \%$ for heating than those who use gas. I found it especially interesting, as you normally think that gas follows the price of fuel oil.

No different statement related to cost aspects was given by R.Z. who again argued in a more general way, instead of focusing on any given technology:

\section{Interview_r_z}

M.R.: Are you driven more by figures or emotion?

R.Z.: Finally, profitability is a switch, which must be suitable. I am not prepared to burn my money for things which are nice, innovative or fantastic, but which are finally a disaster. Then I rather go on holiday. Well, then the money is also gone, but I have experienced something wonderful.

\section{Commercial related statements in a 'greater context' with other aspects}

The following statements are again focused on quantitative and profitability aspects. However, they also involve other issues, such as technical or ecological topics.

A.H. emphasised economic issues. Nevertheless, he also reflected on the eco-aspects and technical matters:

\section{Interview_a_h}

M.R.: What is the reason for your decision to use non-renewable technologies again? 
A.H.: First, due to commercial reasons. But I also see gas as an interesting solution, when we talk about distribution. Well, it cannot be seen as exuberance. But, it is rather unlimited resource. I think oil is a different issue. There, the resources are limited. And the forecasts are out-dated. It is also not a clean technology. I think gas is cleaner, when we talk about the environmental aspect, it is friendlier. I do not have to take care about the distribution. It definitely burns cleaner compared to fuel oil. Well, there was not much of an alternative. You have the old building and a low temperature system is surely difficult, you have to adapt it. We have very high ceilings and the wood floor, so a floor heating system would also not have been simple for rebuilding measurements.

D.V. again is focused on commercial aspects, but also commented that the evaluation for a heating technology adoption should not be reduced only on that matter:

Interview_d_v

M.R.: Are you focused on economic or figure related issues, on sensitivities, emotions? There are a lot of things to consider when taking a decision that is suitable for you now.

D.V.: Financially and economically, stability. I am also interested in technical issues, I want to understand them. A lot of people only compare the figures.

T.A. also prioritised cost aspects. Earlier in the interview he talked about watching oil prices and their expected increase. Below, he explained that he bought a wood pellet oven and combined it with a solar power system, even though the amortisation was not high. He argued, in this context, for the ecological aspect:

Interview_t_a

T.A.: Well, of course, I compared it, what will be the benefit of the collector. I also found it out. When you burn fuel oil, the benefit of the collector is big. However, pellets are much cheaper. There, the amortisation is not that high, but due to the environmental awareness, I thought that I will realise the collectors on the roof. $\cdots$

M.R.: Which topic do you regard as important or less important when you look at it? 
T.A.: Well, first the financial aspect is very important. It cannot be doubly expensive when you rebuild it. Well, and now, the situation is that it is only half as expensive, the operating costs. Below the line, it must be worthwhile and of course the environmental thought that it is quiet nice for the environment.

The above data show remarks on the figure and rational related statements, 'Costeffectiveness thinking', indicate the rational decision-making aspect of this issue in the same context as the one with the same name related to the category 'Motivation for the purchase', which is considered as code. Other bounded factors, like sustainable thinking issues, may be additional aspects.

\section{b. Eco-sensitivity:}

This coding property has also already been considered with the same name and same meaning in the category on motivational aspects. Therefore, this code stands for openness to technologies, as an attitude which is pro making use of renewable energy due to its sustainable criteria (Armstrong \& Ryan, 2009; Brohmann et al., 2009) with the relevant renewable resources defined behind it (BMVBS, 2011), as mentioned in Chapter 4.5.1.

As already mentioned in the code before, regarding the economic issues, no interviewees are focused exclusively on the ecological factor. Some interviewees subordinate or strongly combine this issue with commercial factors. Some statements especially related to ecological aspects are mentioned below:

C.W. had not adopted a renewable system and was still using an oil boiler, due to the already high level of investments he had made in his house (new windows, insulation):

Interview_c_w

C.W.: Well, I am open to renewable energies. I think it is not news that the fossil energies will be over, at some point. At that point at the latest, you will have to think about them. I could image, for example, as we have an oil heating system and a big cellar room where we have the oil tank, I could imagine a wood pellet system or maybe another renewable system. I am open and engaged positively for it. 
The next interviewee, R. B., built his house in 1988 and was using his second gas heating system. Due to his thinking about a 'ten to twelve years write-off amortisation' he was open to something new. He had not yet reached a final decision on a certain technology. Therefore, he still answered in a more general way, but pointed out his sustainable thinking:

Interview_r $b$

M.R.: Would district heating then be interesting for you?

R.B.: Basically, I would be open to it. There is even one supplier here in this town not too far from here. I would be open to it, yes.

M.R.: Why would you be open to it, when you say that you do not want to be dependent on somebody?

R.B.: Because, district heating is ecologically more useful compared to a hundred thousand single heating systems. I have not investigated it in detail, but I have such a feeling, but it is only a feeling, nothing more.

M.R.: Still an introducing question. Can you please tell me something about your thoughts and attitudes when you hear about renewable heating technologies, also compared to classical distribution concepts with oil, gas or coal?

R.B.: Well, the important aspect for me is sustainability, not to waste limited resources. It plays a role in renewable energy concepts.

D.V. still owned an old house but wanted to build a new one. He mentioned economic aspects, but conceded that he 'finally' based his thinking on ecological considerations:

Interview_d_v

M.R.: Is your position more eco-passive or eco-driven?

D.V.: More active, when I have to consider the decision on the adoption of a heating plant. I am prepared to invest something, when it allows me to heat more cheaply overall. 
Ecological aspects may also prevent investing in energy saving technologies as well as renewable heating technologies. A greater issue is indicated below, which was often mentioned as a reflection on the deposition of pollutant insulation material:

\section{Interview_a_h}

A.H.: But it was the statement of the energy consultant that there was no urgent action required. Well, you work on this issue from the ideological side. But on the other hand, all the insulation, I see it very critically.

M.R.: Why.

A.H.: Well, as there are big problems expected. First, with this styrol. It is not good with respect to fire protection, when their steam rises in the sky in case of domestic fuel. And then, there are field reports about people who insulated very expensively, but did not notice any advantages.

The same direction of thought on this issue was picked up by D.V.:

\section{Interview_d_v}

M.R.: How far is the improvement of the house insulation part of your investment and what is the level of priority, which you ascribe to it in comparison to new heating technologies?

D.V.: As the house is very old [pause]. When you know that you want to keep your house it will be more interesting. The wall insulation, I think when you want to get rid of it, it is special waste. Then, I heard that you have to plaster the insulation. On television I saw a report where birds put holes in the insulation and built a nest.

As already pointed out in the allocation of the code 'Eco-sensitivity' to motivational aspects reflects on views and attitudes about environmental protection and is, therefore, a bounded rational part of the decision-making process. 


\section{c. Gut feeling:}

Bernard et al. (2005) mention gut feeling in the context of if-then images. They are related to behavioural strategies for motives and trigger emotional responses in stable consciousness by searching memories. These emotional responses are related to experiences as gut feelings. They focus attention on positive and negative outcomes.

Khatri \& Ng (2000) express the use of gut feeling as a strong feeling about decisions, finally made without any basis. It is founded on a deep and intimate knowledge of the experience of the situation faced by the decision-makers. In a greater analysis, they mention gut feeling as an indicator for the role of intuition in strategic decision-making, in addition to reliance, lacking rational reasoning. Reliance is seen as judgment rather than a computational routine for non-analysable work. It is required, when the decision is to be made quickly in the absence of adequate information and without precedent. Reliance is also associated with experience as knowledge of the issues related to a specific problem and the solving of the problem. The authors conclude that decisionmaking is related to rational as well as intuitive processes.

In contrast, Turin \& Marais (2004) relate rational, in the context of rational decisionmaking models, to a completely informed decision-maker. Franz \& Kramer (2010) mention that decision-makers attempt to optimise, assuming clear goals. All these rational related decision-making models assume certain requirements, whereas, in reality, external factors during the decision-making process or personal behaviours may influence these procedures.

March (1994) already mentions that rational and stepwise related decisions assume that all issues are known. In contrast, this decision-making cycle has to be re-interpreted when the model does not fit. Uncertainty, ambiguity, risk-taking, and conflicts among actors are reasons, which cause these deviations.

Therefore, we talk about personal and individual related factors connected with information, which may have influence on the decision outcomes.

With respect to bounded rational activities, Turpin \& Marais (2004) just state that the search is terminated when the alternative satisfies the needs.

Lunenberg (2010) argues that decision-makers decide based on their intuition, experience, advice from others, or even creative thoughts, and he considers in his 
argumentation that decision-makers are limited in time to search for all possible solutions.

Antithetically to rational decision-making processes, bounded rational decisions assume that decisions do not take place under these idealised circumstances. Eisenhardt \& Zbaracki (1992) relate assumptions that decisions emerge from a process, but that they are based on different perspectives of the decision-maker at a particular time.

Emotional aspects and more enlarged personal insights are a central aspect of gut feeling. Decision-makers may have such a good feeling or, otherwise, may have a lesser or no good feeling in the form of a 'bad' gut feeling when they make or reject a decision. Situations related to these upcoming emotional aspects are mentioned below.

As a concluding remark, it can be pointed out that influencing factors, like experience, feelings, and intimate knowledge, indicate personalised characteristics. Gut feeling is, therefore, related to the bounded awareness of decision-makers and thus bounded rational decision-making factors.

\section{'Bad' gut feeling}

K.V. reflected on bad feelings from his experience with heating pumps. Obviously, these feelings are based on the high cost of heating pumps in comparison to other technologies, since he pointed out the importance of economic aspects:

Interview_k_v

M.R.: When you say a dream of the future, do you expect a sophisticated technology?

K.V.: Yes, right.

M.R.: What do you understand as being sophisticated?

K.V.: It should be an economic thing. I see it mainly under the economic aspect. Therefore, I do not want to invest in something, where I have to expect future problems. I already had a bad experience with the heating pump.

Bad feelings were especially focused on new technologies where decision-makers were obviously not sure how they would work: 
Interview_k_v

M.R.: But it is then not necessary for you that the technology was already installed five years ago, to have a confirmation?

K.V.: It should be in the field at least for 5 years because I am not prepared to work as a pioneer.

In addition to the interviewee above, uncertainty about the evaluation of heating technologies was also pointed out in the following case:

Interview_a_h

M.R.: Are you generally open to newly developed renewable heating technologies or do you only consider sophisticated technologies on the market?

A.H.: Well, I am open. But whether I would invest in these technologies? I would rather not.

M.R.: Because you do not have a know whether these technologies will be established in the market?

A.H.: For example. There are many one-way streets. Some things were pushed by politics [pause]. I talked about it.

\section{'Good' gut feeling}

C.L. first associated economic matters with a new heating system, but then talked about his feeling in a positive way, focusing on environmental aspects when purchasing a renewable heating technology:

Interview_c_I

M.R.: In case you would deal with it [renewable heating technologies]. Is there a limit in yearly running cost and the amount of investment for you? 
C.L.: Well, I would depend it on what you can affect with it. Well, I can say it is fine, it doesn't matter. But you also have to consider the financial situation. It depends on other things. Basically, we are open when we are convinced by something. So, where you have the feeling that you can do something for the environment. Then, we would be prepared to pay something more.

...

Well, and probably [pause]. You cannot evaluate it perfectly. There may be the possibility that there are even better options. But I think that a good consultancy will give you at least the feeling that you took the right decision. So that you do not ask yourself later on, well, would this or that still have been better. And there [pause]. It does not have to be true, but if there is the feeling that you have been consulted in a good way, that you are not taken to the cleaners, you will keep the feeling longer, later on.

G.G. pointed out the matter already mentioned under 'bad' gut feelings, more concretely, not dealing with new technologies. However, he reversed this when talking about safe energy. In the latter context, he talked about his needs in a way, which may be interpreted as a good gut feeling:

Interviews_g_g

M.R.: By means of which indicators do you say that it [renewable heating technology] is established in the market or not?

G.G.: When I can take it from my information providing that it is well established. I do not want to take over a pioneering task to sort out its infancies. There, I do not have essential technical background. I need a safe energy source that works.

R.B. was asked why he installed a wood stove oven in addition to his gas boiler system. As others, he also mentioned safety aspects in a greater political context. Further, he pointed out economic and environmental issues: 
Interview_r_b

R.B.: Generally, there is a safety aspect behind this wood burning oven. Being dependent on gas means, if anybody uses it as a weapon, you have a cold house in winter. There should be an option that I have at least a warm house.

M.R.: Is it a system with heat exchanger for warm water?

R.B.: No, it is very old so this technology was not considered. But it has power, I think $12 \mathrm{~kW}$. The house is open and it can heat the house and act as a replacement for my gas heating system. So, I have covered my safety aspect. Well, I have no warm water, but I will not sit in the cold.

$\cdots$

M.R.: What is your gut feeling?

R.B.: [laughing]. Well, that is to trust my gut. It must be harmonious with what I expect from a heating plant today.

M.R.: Do you expect it to be economically interesting?

R.B.: Economically interesting, a modern technology, minimised environmental pollution, less than the existing plant and higher efficiency compared to the existing plant. These are issues, which always play a part, too.

E.S. and W.S. focused on comfort and economic aspects for their decision to install a solar plant and an easier handling of their gas boiler system compared to oil boiler heating:

Interview_e_s\&w_s

M.R.: And so far, you are satisfied?

E.S.: Yes [pause]. 
M.R.: What has been the reason? You mentioned the feeling of comfort and economic aspects, where you said you wanted to save some gas.

E.S.: Yes. And we expected it to be more convenient at our age. That also plays a big role, that you do not have to fill the tank and, well, the gas heating practically also runs in summer. He told us, leave it on.

M.R.2 could not really explain personal behaviour, but confirmed gut feeling very quickly. She was the only interviewee who said that she takes decisions spontaneously. All the other interviewees claimed not to do so when faced with heating technologies, due to the significant investment. However, she reflected on her experiences as she already knew which heating technology she would adopt when she had the necessary monetary resources at her disposal. Priority was first set to insulation measurements (roof, windows):

Interview_m_r.2

M.R.: And do you then consider any personal behaviour how you take your decisions? Do you consider anything? [pause] Gut feeling, for instance?

M.R.2: Gut feeling, yes.

The term 'gut feeling' mainly stands for emotional aspects and is thus related to bounded rational decision-making approaches. However, economic and rational related issues, like references to figures or economic factors, can also have an influence on gut feeling. Khatri \& Ng (2000) relate gut feeling not only to intuitive processes, but also to rational ones based on reliance, which are associated with experience as knowledge of a problem and its resolution:

'Gut feeling' is based on the decision-maker's existing knowledge and experience and, therefore, based on influencing factors chronologically situated before the decisionmaking process. 


\section{d. References:}

This code considers that end users observe other people or ask them about the meaning of what they are saying or about their experiences with renewable or, in general, heating technologies, in consideration of the high level of expected investment. Further, they inform themselves through print media or the Internet. In other words, comprehensive decisions on the purchase of renewable heating technologies commonly take time and, therefore, have to be very carefully evaluated. Other interpretations contribute towards forming an overall picture and evaluating different options. Exceptions may, however, include the technical breakdown of the heating system on-site, where a close decision is required. The code 'References' is related to human beings, their statements and relationships, and not written data as information for the decision-making process.

In a broader context, Franz \& Kramer (2010) summarise that the decision-making process consists of decision characteristics, and personal and organisational characteristics as input influences on the process, which lead to decision outcomes. Nutt \& Wilson (2010) consider strategic decision-making processes as those which are often used for important decisions in organisations. They define the term organisation as any collective social, economic, or political activity with a plurality of human effort. More detailed, separate point of views can be pointed out in a larger context with decisionmaking.

\section{Strategic related aspects}

Elbanna (2011) characterises contextual perspectives for strategic decision-making in organisations with reference to managerial issues. These perspectives can also be related to the code 'References' in a broader managerial context: end users also have to manage strategic and closely considered long-term aspects with respect to the possible purchase of renewable heating concepts, as they are expensive investments.

Elbanna connects decision-specific characteristics with the importance, motive, and uncertainty of decisions. These environmental aspects are also considered with reference to end users in the research context as decision-makers, such as relationships to customers, suppliers, and competitors.

Therefore, influences of others or concrete references play a role in the decision-making process. 


\section{Rational related aspects}

In reference to an enlarged view on rational decision-making models, March (1994) points out that these models stand for most organisational processes. Actions based on decisions can be taken for different reasons depending on the way in which organisations are structured. In this respect, the decision-making process represents a cycle of four steps:

The first step considers interpretations and responses in the environment, which is, therefore, also related to references, followed by knowledge, interests, preferences, and world views in a second step. These may then be followed by a third step of choices and, finally, as a fourth step as action, by individuals or groups.

Reflecting on March's research, knowledge, interests, preferences and worldviews consider the personal information of decision-makers and thus their references which may be considered or first be contacted to come to a decision outcome by end users. Thus, rational stands for personal related factors, however, contextualised to clear goals to take these (rational related) decisions.

\section{Bounded rational related aspects}

Evaluating bounded rational decision-making processes, Mori (2010) reduces Strategic Decision-making Processes (SDMP) to the following kind of processes: in contrast to rationality, bounded rational related factors are seen as being approximately equivalent to intelligence or success with actions as desirable outcomes. However, in most cases it is constructed as bounded rationality and comprehensiveness, which is limited by cognitive and political realities.

Turpin \& Marais (2004) characterise bounded rationality as activities of searching and satisfying. If an alternative satisfies, the search is terminated. The political view is seen as a personalised bargaining process, driven by agendas of participants rather than rational processes. The decision process never ends.

According to Lunenberg (2010), the decision-maker is not aware of bounded rationality problems, nor is he/she aware that they are limited in time to search for all possible solutions. Lunenberg concludes that decision-makers decide based on their intuition, experience, advice from others, and, perhaps, some creative thoughts. 
Therefore, references may have influences on the personal behaviour and preferences of decision-making, which may also possibly be influenced by certain societal expectations or norms.

\section{'Garbage Can' related aspects}

An interesting point of view, in relation to the influence of others on decisions, is expressed in the context of the garbage can:

Eisenhardt \& Zbaracki (1992) and Mintzberg, Raisinghani \& Theoret (1976) point out influencing factors. They describe the garbage can model as an accidental or random confluence of four streams. Hereby, choice opportunities and participants with schedules, to which attention might be paid, are influencing factors on the decision-making process. Politics is mentioned as a set of actions by which people enhance their power to influence decisions. Further, garbage can, as decision-making in settings, is called organised anarchy. The model calls attention to the importance of chance. Intuition is seen as an aspect for a more realistic view of decision-making processes. With intuition, decision-makers refer to more incremental adaptations based on a deep, intimate knowledge of the situation.

Therefore, the garbage can also reflects on influences of references of others or even on other technologies, which may affect the original goals of the decision-maker due to the emergence of new information, which must be evaluated.

Cohen, March \& Olsen (1972) term a garbage can, in their basic research, as no standard program of action. Preferences are unclear and sometimes impossible to express. People do not always know what they want to do and have to re-interpret preferences.

These aspects may be the reason that decision-makers change their original meanings or goals, or are influenced with respect to their personal interpretations.

\section{Intuitive related aspects}

In the context of intuition, Khatri \& Ng (2000) mention three indicators for the role of intuition in strategic decision-making. Gut feeling is used to imply a strong feeling about the decision, it is based on a deep and intimate knowledge of the situation faced by the decision-maker. 
To conclude, the code 'References' considers different statements of end users as homeowners, which are related to meanings of others. It also analyses whether the homeowners are part of a rational or bounded rational decision-making process, and probably, in the end, a mixed evaluation process for the possible purchase of renewable heating technologies.

Expressions are based on good or bad experiences of others. The following interviews extract focus on the information on which the interviewees relied.

The below-mentioned statement indicated bad experience, saying that this possible heating concept would not be considered in case of a purchase, which has still not taken place. The extract was related to a possible choice in the past between a thermal heating pump and a gas boiler system - the latter was chosen:

Interview_a_h

M.R.: What about the aspect of the flow temperature? Normally, you say that thermal heating pumps work with a very low flow temperature. Did you prove or calculate it?

A.H.: No. We did not prove it, as we also knew colleagues who had problems with that system.

C.L. and E.L., a married couple, mentioned a greater number of references, which indicates that they would not take such a decision spontaneously. They still worked with their old oil system:

Interview_c_I\&e_

E.L.: Are there also disadvantages? Well, for instance that you cannot order enough of this stuff again, these wood pellets. But, there you also have such an aspiration unit. However, I think that I would ask some relations whether they have experiences with it; whether they are more ahead compared to us so that we can gain further information. We would also keep an eye on the economic aspect. Well, not with respect to money. Well, oil has gone, what is going to happen now. 
E.L.: Right now, we are bounded to our house and the installations, we have. We would then need a consultation with a company or a heating installation company we trust.

M.R.: That is an interesting comment. How do you describe a trustful heating installation company?

C.L.: Recommendations. In the past we had a lot of good luck with craftsmen. We informed at our colleagues.

E.L.: Exactly. Probably, I would also get advice from two such [pause] experts or installers. And we then have received advice from them. Then, okay. So [laughing] that we both are convinced of it. Actually, we always do it like that.

M.R.: But that means that you talk to the people who would install it.

E.L.: Possibly, they should then install it.

C.L.: An energy consultancy before. That might now be something, I would like to listen neutrally. What do I want to get, actually? Then, a second step would be to look for enterprises who consult you concretely.

M.R.: You therefore have already answered the question: which institutions, individuals or groups do you involve in your decision-making process? I picked up on relations?

C.L.: Of course, relations, too. I would like to benefit from their experiences.

E.S. and W.S., another married couple, already retired, demonstrated that they were very focused on their discussion with their heating plant installer. Obviously, they formed their opinion by reading information and through discussions with each other:

Interview_e_s\&w_s

M.R.: To what extend have your decisions been influenced by others, your own experience, or your own personal attitudes?

E.S.: Actually not by others. We read a lot and formed our own opinion.

M.R.: And did you then tell your heating plant installer what you wanted to have or did you ask him to work out a concept for you, that you want to have something new? 
E.S.: Actually we knew what we wanted to have and he then submitted us proposals on how to realise it.

M.S.: When you say you have not been influenced by him, you then did not ask relations or friends or got any advice from them? You then took the decision on your own?

E.S.: Yes, yes. We did not discuss it that much with other relations. We took the decision for us, what we thought will be good for us.

Some interviewees like R.Z. reduce their considerations to certain technologies or, in this case, already established technologies in the market. Reliability, based on experience with technologies on the market, is a main argument in support of this interpretation:

Interview_r_z

M.R.: You have already mentioned what is in use. To what extend do long-term aspects exist in the consideration of a certain technology in case of interest?

R.Z.: Definitely. As I told you in the beginning, I did not want to have something which is still being tested or in an experimental stage. It is important, when I make an investment of several 10.000 EUR that it will have a certain investment reliability.

M.R.: May I ask you what is state of the art in your opinion? Where is the bias whether it is still being developed or already ready for the market?

R.Z.: Well, from the third or fourth generation of a plant technology, I assume that it has reached a certain degree of maturity.

\section{Role of social norms}

Memo: M.A. (expert, figure 4) as an energy consultant in an administrative district assumed that the fulfilment of norms may be one reason for the purchase of renewable heating technologies, aside from economic reasons. He argued that big panels on the roof of other houses act as a status symbol, representing wealth; this acts as stimulation for others to do the same with their own property. 
With respect to the literature, Mark \& Henry (2004) explore mechanisms through which evaluation may have its effects on (decision) outcomes. Related to social and behavioural sciences, different kinds of processes are classified. General influences, especially, can occur on individual, interpersonal, and collective levels.

Christie's field research projects (2007) are focused on the evaluation influence as part of the decision-making process, which results in three identified levels. In particular, interpersonal behaviours reflect on issues, such as justification, persuasion, minorities and social norms.

Ajzen (1991) explores behaviour in terms of planned behaviour. Subjective factors, as subjective norms, refer to the perceived social pressure to perform or not to perform a certain behaviour.

Rosenkranz et al. (2013) express norms as maintenance through unwanted emotions (guilt, embarrassment, shame) an individual feels when they are not complying with them. Observing others can, therefore, affect an individual's actions by influencing their behaviour in a given situation due to their perception.

During the interview stage, no single interviewee mentioned other people, and their renewable heating solutions, as a driving influence or even a status symbol in a positive or even jealous context. Instead, reference was above all made to economic and nonemotional issues. Therefore, the purchase of renewable heating technologies cannot be said to be influenced by peer pressure in the strict sense of the term.

Turpin \& Marais' (2004) research shall be considered with respect to involved references and their meaning for end users as decision-makers regarding the purchase of renewable heating technologies. They mention emotional aspects and personal views, driven by agendas, in relation to why this code is related to rational but also bounded rational decision-making factors. Influences, such as rational factors, are caused through strategic and long-term goals by end users. Bounded rational factors entail relationships to others, their influences, and gut feeling, based on experience in the past as an intuitive aspect. Therefore, the decision for or against the purchase of renewable heating technologies may already be taken before the active part of dealing with this topic, the stepwise and rational part of the decision-making process, arises. Social norms or expectations of others to fulfil requirements, such as a possible purchase of renewable heating technologies due to ecological aspects, cannot be confirmed. 


\section{e. Strategic thinking:}

Aside from the rational decision-making models, processual models are also focused on facts, further on procedures of how to evaluate contents of information. They exclude emotional aspects, as rational models do. Therefore, they are related to decision outcomes, to making something happen. They focus on the processual approach, considering procedures, which cannot be taken short-term. Therefore, these aspects are part of this code to explore, how far decision-makers consider long-term aspects, instead of spontaneous factors, for their decision:

Anderson (2002) summarises it by saying that process orientation is the notion of making a good decision, not necessarily reaching a good outcome. He identifies different steps towards processual aspects. Decision-making consists of problem structuring and evaluation. Problem structuring is defined as involving identifications, alternatives, values that distinguish the alternatives and uncertain events, which can affect the values with the alternatives. It, therefore, follows the rational and stepwise approach to decisions. Evaluation is seen as a matter of weighing the relative desirability of various outcomes and the likely impacts of various uncertain events in deciding which alternative is, on balance, preferable. Rational is a matter of direction in thought. Process orientation is then a particular way to reduce importance and uncertainty. Process orientation is redirecting from a focus on outcomes to a focus on the decision process. It all stands for a procedural context and the involvement of different factors and, therefore, for long-term and comprehensive evaluation processes.

Papadakis, Thanos \& Barwise (2010) see a process as the middle part in a chronology with context and outcomes of structured procedures. Poole \& Van de Veen (2010) explain process theory as how a sequence of events leads to an outcome. In contrast, the variance approach is defined as satisfactory with a decision based on efficient causality, related to problem analysis, number of options, and task complexity. Four theoretical groups are defined in their conclusion. They identify a so-called teleological theory with respect to goal driven issues surrounding the possible purchase of renewable heating technologies. This theory is focused on a cycle of action or goal formulation, implementation, evaluation, and modification; in other words, a stepwise approach. Other groups consider emerging conflicts between people with unclear end-points, further emerging events, influences of relationships with reinforcing (positive), damping (negative) and complex (non-linear) factors. 
With respect to the key issues of the considered literature, two main aspects shall be considered:

(1) The content of decision-making processes based on processual criteria; and

(2) Strategic issues of decision-making processes based on long-term criteria for the evaluation of the purchase of renewable heating technologies.

\section{Processual criteria for decision-making processes}

When asked how he took his decisions, C.L. specifically excluded spontaneous decisions:

Interview_c_I

M.R.: Do you rather take your decisions spontaneously, in a structured way, or are there any external influences you pay attention to?

\section{C.L.: In this field, in a structured way.}

T.A. also underlined that he does not make spontaneous decisions, and instead mentioned some economic criteria as the basis for his decision:

\section{Interview_t_a}

M.R.: How far do you feel comfortable with the volume of information and remaining time you had or have to adopt a new heating distribution concept for your house?

T.A.: Well, I took all the time I had. Yes and the information, all I had.

...

Do you rather follow spontaneous, structured, or cognitive influences in making your decision, and on which aspects have you place greater significance?

T.A.: Well, definitely, I think about it. And my wife, she must also accept such a decision. I prepare it and present it to her. However, I plan it, not in a hurry and not spontaneously. That you cannot do, it is all structured. 
R.Z. pointed out that he involved different sources in his evaluation, which again indicates a structured decision-making approach:

Interview_r_z

M.R.: Are there any routines you follow or do you take your decision spontaneously?

R.Z.: Spontaneously, not at all. I do some research and finally I also do an economic feasibility study.

M.R.: Have you been satisfied with the content of the information?

R.Z.: No, of course not. There is no single source, three sources, that is what I wanted to get and then you are well informed. By contrast, you have to put together your information.

M.R.2 emphasised that she did not relate emotional aspects to the purchase of heating technologies. Instead, she indicated preference for a structured and processual approach based on the evaluation of figures and economic data:

Interview_m_r.2

M.R.: Last question on this topic. Do you relate any emotional aspects to the topic of heating technologies, distribution or the choices?

M.R.2: No.

A.H. explained his strongly structured decision-making approach in detail:

Interview_a_h

M.R.: Are there also aspects where you say they have no relevance on your decision and you are not interested in them at all?

A.H.: No, I am interested in any information [pause]. For bigger investments, I always ask for four or five different quotations and then I decide. 
M.R.: Which procedure or chronological steps do you take when making decisions? Or do you evaluate your information and are you satisfied with the content of information? Is there a procedure you apply?

A.H.: Yes, it is always the same. Analysis, data collection, evaluation, calculation. Then, the comparison of the different options, the variations and finally the decision.

\section{Strategic (long-term) criteria for decision-making processes}

C.W., who still works with an oil boiler system, noted that a decision may take years:

Interview_c_w

M.R.: To what extent do long-term aspects play a role in your consideration of a certain technology?

C.W.: Well, as mentioned, it should be [pause]. As it is also a long-term decision, it should be a system, which works properly long-term so that you can operate it that way. Well, it is nothing if it is just planned for two years. I think that such a heating system should work maybe ten, fifteen or twenty years. Therefore, you somehow take a longterm decision.

C.W. emphasised that decisions should not be taken spontaneously. In this context, he points out the comprehensive involvement of other references and sources which represent a long-term process:

Interview_c_w

M.R.: Are there any routines you follow or do you take your decision rather spontaneously?

C.W.: Well, definitely not spontaneously, as the decision is too expensive and too comprehensive. I would rather follow a procedure, as I told you. I would probably have 
a look into the Internet, what kind of empirical values there are and what is recommended. And then with people who already have a heating system as I imagine it. And then with the relation who owns this company. That would probably be the procedure when it comes up.

More complex criteria and involvement were also confirmed by the married couple, E.L. and C.L:

Interviews_c_I\&e_I

E.L.: Are there also disadvantages? Well, yes, for instance that you cannot order enough of this stuff again, these wood pellets. But, there you also have such a aspiration unit. But I think that I would ask some relations whether they have experiences with it; whether they are more ahead compared to us, so that we will gain further information. We would also keep an eye on the economic aspect. Well, not with respect to money. Well, oil has gone, what is going to happen now. Shall we rely on sun or whatever? I would like to decide it with respect to the benefit.

M.R.: So, with use you mean long-term reliability?

E.L.: Exactly, long-term reliability. Planning of the heating or whatever it will be, electrical heating.

The huge investment related to a new heating concept was used by C.W. as a reason to define it as a long-term matter:

Interview_c_w

M.R.: Well, then I come already to the first step of decision-making processes, motives for the adoption on renewable heating technologies. How far has your opinion been focused or changed regarding renewable technologies within recent years?

C.W.: Actually, no change. We are quite open and positively related to it. Also, as the issue of climate change has been in the media for a long time. Of course, there is always 
a level of uncertainty, because you never know what will be the best when you decide something. Long-term, it is a decision, which will stay for years or decades. What is right in the long run. But otherwise, well, I am open.

Long-term aspects are very clearly mentioned by the retired couple E.S. and W.S. with respect to economic and safety factors:

Interview_e_s\&w_s

M.R.: To what extent do long-term aspects exist to consider a certain technology in case of interest? [pause]. Was it part of your thoughts at that time? Was it something longterm?

E.S.: Yes, it should. It should be profitable long-term. That it was, Mr. Reichler. We do not know how long we can stay here and will be here, given our age.

M.R.: You said that you wanted to have some facilitation in advanced years.

E.S.: Yes, it is all adapted to our age.

M.R.: May I say, also for your safety.

E.S.: Yes.

R.B. was again focused on economic aspects, but also mentioned ecological issues as an additional criterion for his decision-making approach:

Interview_r_b

M.R.: To what extent do long-term aspects play a role in your consideration of a certain technology?

R.B.: What do you mean? Do you mean the technology or the amortisation?

M.R.: Well, the adoption of a certain technology.

R.B.: Okay. Well, I don't know exactly. The life expectancy of a heating plant is about ten to twelve years, nowadays. That is a duration, which is sufficient for me. So, I 
would not consider a longer time than that. The existing technologies, they all have this life expectancy, after which, they become outdated and something new must be installed. Whether I want to consider a plant for about twenty or twenty-five years, I do not know exactly, because the technology develops during that time.

M.R.: So, you related it to economic aspects?

R.B.: Yes, to economic aspects, but also to environmental aspects with things like the exhaust levels.

Data show that the procedural aspects, the stepwise approach and long-term aspects, particularly considering other human beings to form a comprehensive picture, characterise strategic thinking as a rational decision-making approach followed by clear goals on the purchase of heating technologies. In other words, the approach is not driven by emotional factors.

\section{f. Decisiveness:}

With respect to the character of decision-makers, an important aspect is the time it takes and the volume of information that is needed for a decision to be reached. Therefore, indicators which may influence the decision and the time it takes to reach the decision are relevant. Dynamic factors, such as feedback loops, interruptions, delays, damping and accelerating effects may have an influence on the decision time (Bennet \& Bennet, 2008; Mintzberg, Raisinghani \& Theoret, 1976; Tucker et al., 2005).

\section{Rational related aspects}

Papadakis \& Barweise (1998) explore strategic decisions in their work and define them as decisions, which involve the commitment of significant resources. They have major long-term consequences and are hard to reverse. Turpin \& Marais (2004) address rational models in their work related to rational related steps, which end with the assessment of past choices. This means that the process can start again. Eisenhardt \& Zbaracki (1992) follow the definition of Mintzberg, Raisinghani \& Theoret (1976) and relate this step to the decisions cycle through the process, which frequently repeats itself or becomes more in-depth. 


\section{Bounded rational related aspects}

In contrast, Lunenberg's (2010) research concludes that the decision-maker is not aware of problems in bounded rationality or that they are limited in time to search for all possible solutions. Decision-makers, therefore, decide based on their intuition, experience, advice from others, and perhaps some creative thoughts.

Mintzberg \& Westley (2001) argue for bounded rational decision aspects as there is much more beyond conscious thought of decision-making. They argue that decisionmaking cannot just be viewed in black and white. They reflect on the rational decisionmaking process as a clearly identified process, which consists of: define, diagnose, design and decide. In contrast, they classify three related approaches to decisions: (1) 'doing first' stands for spontaneous decisions, simple relationships may help people move forward; (2) 'seeing-first' are emotional decisions with required creative solutions; (3) 'thinking first' are problem-focused decisions as in structured processes.

The situation on-site is related by Tsoukas (2010), as the Heideggerian Approach, to deep structuring of reality under consideration of practical consciousness and the conscious process of making commitments to action for various purposes, such as problem solving, motivation, or legitimacy. He mentions decisions to address problems, and problems emerge when the world reveals itself to the actor. The decisions depend on two factors: (1) the engagement with the world of the decision-maker, expressed in the type of rationality and knowledge; (2) the appearance of consciousness to the decisionmaker, immersed in or detached from a practical context. Tsoukas mentions decisions in the context of their occurrence prior to action; whereas outcomes are related, by the decision-maker, to intentions. Often, the decisions are not calculative or abductive, just spontaneous responses to the circumstances at present.

\section{Concluding thoughts of rational vs. bounded rational related aspects}

Based on these issues and related literature, the strong-willed decisions may be taken more rationally and strategically, or more boundedly and emotionally. Details have to be explored by reflecting on the interviews and discerning the overall criteria.

C.L. discussed the issue of adapting renewable heating technologies with experts in such a way that she could understand the issues as a layperson: 
M.R.: In your opinion, how could the adoption of renewable heating technologies generally be increased and what blocks the adoption?

C.L.: Sometimes, by chance, you can see reports on television. When they present in a way that you can understand them. So, it will definitely be part of a decision-making process. I also believe, when more people rely on renewable heating technologies and have good experiences, word of mouth propaganda also plays a role. Well, if a colleague tells me that he has something like that, I think it will play a role in my decision-making.

This requirement of a 'felt' transparency and possible comparison of concepts was also expressed by the following interviewee:

Interviews_a_h

M.R.: Last question. Are there any general comments you have on the topic?

A.H.: For me, it is important that new technologies are developed. Politics should develop a reasonable strategy.

$\cdots$

M.R.: In your opinion, how could people be convinced?

A.H.: For example, with facts or figures.

\section{Transparency}

An interesting point was to ask interviewees whether they accept or reject the presentation of renewable heating concepts as part of their decision-making approach to decide in favour of a certain concept. More specifically, they were asked to consider and accept or reject certain pre-prepared solutions with certain investment amounts.

The final question was then, whether there are common decision-making aspects, which can be ascertained with respect to supporters and opponents of pre-defined concepts. In 
my view, the common aspect is transparency and availability of information for decisionmakers, enabling them to form a comprehensive picture. In the end, the information is evaluated in different ways.

Transparency was appreciated by both parties. One party already evaluated the information as part of the decision-making process at a very early stage; the statements and appreciation of solutions foreclose a comparison of solutions, they were thus bounded rational related decision-making factors. The other party refers transparency to the comparison of different concepts as part of a rational related evaluation at a late stage in the decision-making process. Whether the $\mathrm{B} 2 \mathrm{C}$ concepts are viewed in a positive or negative way depends again on the personal perspective. The consideration of predefined $\mathrm{B} 2 \mathrm{C}$ concepts came up during the expert interviews:

Memo: R.D. (expert, figure 4), as a representative for thermal pumps, and K.M. (expert, figure 4), as Managing Director of an industrial energy network society, were contacted for the interviews. Their idea was to offer packages as all-in-one-solutions to end users to facilitate decisions for the purchase of renewable heating energy concepts. I picked up this issue as part of the interviews to include homeowners' response regarding this issue as possible matter for $B 2 C$ models:

M.R.: During my research, a representative of heating systems told me that this topic is very complex and decisions should be simplified. People should be offered solutions for $6.000,12.000$, or 18.000 EUR, for example. What would your opinion be, if somebody offered you such a solution as a package? In your opinion, would it facilitate your decision or are you rather sceptical of such concepts?

\section{Transparency - Positive evaluation of information}

\section{Interview_g_g}

G.G.: I think that it is a facilitation of your decision, indeed. The topic has become very complex, nowadays; that it is really difficult. Yes, you do not have the huge overview and it is a expensive topic, and due to the complexity some people are a bit frightened. If there are packages which are clear and comparable, also with respect to prices. Finally, we also talk about money, that might be a helpful orientation. I am quite sure, also with respect to the appreciation [pause]. So, everybody can say: 'Based 
on these and these characteristics, my heating is fine'. Well, the characteristics are variable as heating systems are not the same. But if there were a pre-defined package, then you could say the package in the middle for 10.000 EUR was for my environment exactly the right one, or not. Then you could say, this package was the right solution for him, I have the same situation more or less. Then, it could be suitable for me, too. Indeed, this could be a simplification for the decision on how to proceed, I think so. Interview_m_I

M.L.: Could be, if you bind heating constructors not to exceed certain prices. Then, it could certainly be helpful, it could help you to proceed. The fact is, to stay with the topic, that you can get cheap heating pumps.

Interview_k_v

K.V.: It depends on what the packages contain.

M.R.: But would you be open for it?

K.V.: Yeah. At least, I would not say that 18.000 EUR is too expensive. I would definitely have a look at it.

Transparency - Negative evaluation of information

Interview_a_h

A.H.: To me, it is not a good idea. We have certain functions of a heating system. These are not fundamental decision-making processes. I must be economically convinced, not only ideologically. When it is profitable, it will result in a return at some point. So, I take the decision and it doesn't matter whether it is $6.000,12.000$, or 18.000 EUR. When I am convinced that it is reasonable and economically sound. If I can not only rescue the world or the environment, but also say that it will amortise in 8 to 10 years, then I will be prepared to spend 18.000 EUR. 
Interview_c_I

\section{C.L.: No, no, not at all. I would rather be sceptical.}

E.L.: No, no. I would not define a certain amount. I would ask how much is that when we build it in. How much is the running cost and what will be the effect for the environment. And when it works out then to $3.000,6.000$ or 9.000 EUR, then, we will consult among us. And when it will be 9.000 or 12.000 EUR in our opinion, okay, then we... [interruption].

C.L.: Either we can afford it or not. But if I cannot do it, I would not think to realise an alternative for 3.000 EUR. No.

Interview_c_w

C.W.: So that I say, I am prepared to spend $6.000,12.000$ or 18.000 EUR and you tell me what I can get for it?

M.R.: Yes, in that way.

C.W.: No, I don't think so. I rather think the opposite. Then I would probably have the feeling that I have to pay more for the package than what I would pay normally for the single components. I would rather not.

M.R.: Is there a limit in yearly running cost and the amount of investment for you? [pause] Maybe an amount or a target where you say that you do not want to exceed it?

C.W.: So, it does not have to be an amount?

M.R.: No. Maybe, it should not be more than your existing plant, whatever the cost is.

Interview_d_v

D.V.: There is a good example. Some time ago, as I wanted to buy a kitchen, I also went to a shop. And the salesman asked me how much I was willing to spend, so that he could then put together a kitchen. The discussion was then over.

M.R.: And why not? 
D.V.: Actually, I first want to decide. Then I can make a better plan, if it is too much money, on where can I spend my money. So, to find out what I want [pause]. When I just take the cheapest solution, I might be left dissatisfied afterwards.

The question now is: what do both interpretations - negative and positive - for the business model of all-in-one-solutions with different types of technology and prices have in common?

An evaluation of the content and interpretation of sufficient data can be summarised as follows: open-minded interviewees consider the packages helpful for their decision; whereas sceptical interviewees do not consider that the packages provide them with the right information for their possible renewable heating concept choice.

A solution may be to give a high amount of transparent economic and technical information, so that both 'parties' can form their own picture and feel well-informed.

Decisiveness is related to an evaluation of which information and volume of information is used to reach a decision. This evaluation depends on the insights of the decisionmakers and their personal worldviews. Thus, these influencing factors are related to bounded rational related issues within the decision-making process.

In this context, transparency can be interpreted as having an inverted correlation to trust. The less trustful and reliable the data seems to end users, the more information is required for them to form their own opinion. Trust might be acquired through information from 'References', as a subordinated property of the code 'Affecting factor: Character'.

\section{Findings - Personal characteristics}

Personal and character based decision-making factors cannot be entirely related to either rational or bounded rational aspects.

The concluding thoughts on the codes 'Cost-effectiveness thinking' and 'Strategic thinking' are based on clear and comparable data and a stepwise decision-making approach without emotional criteria; thus, rational related.

Either rational or bounded rational aspects stay behind the matter 'References'. 
Bounded rational factors stand for personal agendas, experiences and evaluations of statements from other people. 'Gut feeling', 'Decisiveness' and 'Eco-sensitivity' are based on bounded rational matters.

Missing trustful data may be compensated by comprehensive data and transparency with respect to the purchase of renewable heating technologies. Experiences or information about certain heating technologies in a period before the decision-making process begins, with active gaining of information, may affect intuition as a bounded rational influencing factor and, therefore, the decision outcome.

\subsubsection{AFFECTING FACTOR: TECHNICAL ISSUES}

This code considers similar aspects to the sub category 'Gut feeling', which belongs to the main category 'Personal characteristics'. Therefore, the aspects are focused on bounded rational factors during the decision-making process, in the enlarged context of decision-making processes in relation to the descriptive data of the code 'Specifics of the technology'.

In contrast to the sub category 'Gut feeling' as character-affecting related aspects, the elements of the heating concept in the broader context of the evaluation or financing of certain renewable heating technologies will not be considered. However, the close operational involvement of the end users with technical issues will be taken into consideration. These aspects may later be addressed in relation to the requirements on the involved technologies and manufacturers as part of the response to the research questions.

Eisenhardt \& Zbaracki (1992) consider bounded rational decision-making processes; assumptions are made that decisions emerge from a process, but with decisions based on different perspectives of the decision-maker at a particular time.

Khatri \& Ng (2000) define gut feeling as one aspect of decisions. Gut feeling is considered as a strong feeling about the decision, made without any basis, other than a deep and intimate knowledge of the decision faced by the decision-maker.

Bernard et al. (2006) mention gut feeling in the context of if-then images, which are related to behavioural strategies for motives, and trigger emotional responses in stable consciousness through searching memories. 


\section{a. Personal handling of the technology:}

This issue considers aspects regarding the integration and involved operation of heating technologies, and, more specifically, renewable heating technologies, with respect to noticed advantages or disadvantages on-site. These aspects facilitate end users to reach a final decision on the adoption or refusal of certain heating concepts.

One aspect strictly considers how far end users want to involve heating technologies and their operation in their daily routines:

\section{Interview_c_w}

M.R.: Are there topics which you consider important and others which are less important for you?

C.W.: Profitability and reliability throughout the entire duration are important factors. Definitely, usability as well. There are still a lot of coal-fired houses in this area. When I spoke with a relation, he told me that you have to remove the soot from the oven on a daily basis and reload the wood again. Well, in that case I would not be in the mood for it. These are the most important points, to have profitability, so you can enjoy it for a long time, because it cost a lot of money, and that it is useable with respect to its operation.

Too much involvement was viewed critically by C.W.

Following this argumentation, minimal involvement was also appreciated by K.V.:

Interview_k_v

M.R.: Handling and practical issues, is this also a topic for you?

K.V.: Okay, when the handling gets easier. As I told you, I do only deal with electricity right now and the heating system is easy to handle. The oil heating had to be cleaned once a year and the chimney sweeped. There was a separate chimney, which had to be cleaned. Now, it is gone. 
C.L. and E.L. reflected critically on the handling process with respect to a possible fire in their house, and environmental protection through necessary removal and pollution of solar heating systems:

Interview_c_I\&e_I

E.L.: Yes, for instance. Well a safety aspect is always [interruption]. Well, as for solar, when it burns in your house, they have to take care with current, with these things. They have to discharge it in a special way.

G.G. not only took minimal daily involvement into consideration, but also the effort it would take to replace his old heating system with a completely new one. Therefore, he stayed with his oil boiler system:

Interview_g_g

M.R.: Did you also think about a change to gas when you had to renew your heating system?

G.G.: I could have done it and I kept myself busy on that issue as we are connected to gas. However, I have the infrastructure for a fuel oil heating system in my house; I have a flat storage room and so on, because we could not have used it for other issues. And so on and so on. Due to this background, I decided to go for fuel oil. $\cdots$

M.R.: What is your opinion about wood pellets?

G.G.: Okay, yeah [pause] the wood pellets heating system. I am not sure about the cost situation because I picked up that wood as energy source has increased significantly within recent years to cover raw material. Definitely, you must have the possibility of a fire place, not only to fuel it, but also to remove the soot. I think it will not be insignificant. And even though I know that a certain automation is possible with store rooms that feed in automatically into the fire room, I would be afraid that it was related to a certain physical operation, which I shy away from, to say it frankly. I do not want to transport wood or wood pellets from A to B, store them, bring them 
intermediately to the fire place, and remove the soot, finally. To be honest, I am too lazy for it.

In contrast, T.A. is the only interviewee that showed strong enthusiasm for certain involvement, when talking about his own experiences with an adapted wood pellet and solar heating system:

Interview_t_a

The heat exchanger of the roof, it causes the heat in the bottom of the boiler, in the storage. There, it brings in the heat. The storage, it works fantastically. The wood boiler heats the upper part and in the bottom it stays cold. And when something comes in from the roof, the rest is heated. And when you then have a look at it the next day, you see that the lower temperature goes down.

M.R.: Are there any emotional aspects you combine with this subject? [pause] That you are worried or happy about?

\section{T.A.: Yes, I enjoy it every day.}

The aspect of daily operation is viewed differently by end users. However, the majority of interviewees view daily operation needs more negatively, preferring less involvement. In a broader context, with respect to selective coding considerations, interpretations of involvement in heating technologies - renewable or non-renewable ones - are based on experiences, emotions, and attitudes. 'Personal handling of the technology' is thus related to bounded rational decision-making criteria.

\section{b. On-site integration of the technology:}

This code stands strongly for gut feeling. It is characterised by a deep and intimate knowledge of the decision, addressed by the decision-maker (Khatri \& Ng, 2000). In this context, Bernard et al. (2006) regard gut feeling as experiences which are related to behavioural strategies for motives. They trigger emotional responses in stable consciousness through searching memories.

Therefore, gut feeling is linked to bounded related issues. 
Bounded related factors are indicated through assumptions, which the decision-maker makes regarding different perspectives at a particular time (Eisenhardt \& Zbaracki, 1992).

This code stands for the openness to integrate heating technologies in the existing environment with a particular consideration of the technical situation 'on-site'.

C.L. and E.L. mentioned that they were restricted in their choice due to expected problems associated with mounting panels on their roof. They did not focus solely on commercial issues when saying that they did not want to tear up the garden [in reference to air / air thermal heating pumps]. This can be interpreted as antipathy towards the destruction and alteration of familiar environment:

Interview_c_I\&e_I

E.L.: Yes, yes. He would also have built in a heating plant.

C.L.: Yes, and they gave as advice and they told us that due to the shape of our roof a solar plant is not suitable. The reason is the inclination of the roof. And we have such a, how do you call it, hipped roof? It has many slants and borders. They told us that it would only work to cover a part of the energy demand.

$\cdots$

M.R.: Which information do you require and which do you leave out to form a picture?

C.L.: On the one hand, it is a reasonable consultancy, related to the house you have and what kind of possibilities there are. How much effort do I have to put in it?

M.R.: So, by saying effort you mean cost?

C.L.: No, effort also means whether I have to tear up the garden or alter the roof in order to install something...

Restrictions on-site, in this case to terminate a planned adoption of a photovoltaic, were also referred to by M.L. as a central theme, focusing on 'feelings' as emotional, not rational, issues: 
Interview_m_I

M.R.: Have there been any emotional aspects you combine with your concept? Have you been satisfied or did you have a bad feeling?

M.L.: Well, the feeling was okay. It would have been better had I owned a monovalent plant, which is only based on electricity. I would have favoured a photovoltaic plant to produce electricity on my own.

M.R.: And why did you not realise it?

M.L.: I had not proceeded that much. First, the roof had to be reconstructed, before putting a photovoltaic plant on it. The rafters had to be fortified, the house was constructed in 1937.

G.G. cited economic reasons, more specifically, the high investment, for their decision to replace their oil boiler system with another oil boiler system. However, in the previous chapter, when discussing his opinion-making on the handling of heating technologies, he also mentioned the existing infrastructure for a fuel oil heating system in his house and the required easy handling, which stands against wood pellet systems:

\section{Interview_g_g}

M.R.: Well, how far an investment in renewable heating technologies has taken place, you have mentioned. So, you have got a fuel oil heating system, further a solar system with heating support for warm water and the heating system and floor heating with radiators.

G.G.: Yes.

M.R.: What was the reason for your decision?

G.G.: A replacement had to be realised as the old plant, well, it was broken. And, as I told you, we decided to go for oil again due to economic reasons [installation cost].

In contrast, E.S. and W.S. were very much bounded by their observations of their neighbours' experiences, stating that a thermal heating pump would be too expensive: 
Interview_e_s\&w_s

M.R.: Well, and renewable energy, was it an issue coming up in the past, so that you said we want to get away from gas, oil or coal?

E.S.: Yes, it was an issue in recent days. But, here, our neighbour, he had a circulation pump and then we also thought about it, but it is not worthwhile to go. Heating pumps are still not fully developed and they need a lot of electricity. So, you do not economise anything, but we still considered it. And then, we got solar panels on our roof. When we got the gas heating, we also adopted the solar panels, at the same time.

The interviews point out that the close technical related issues consider emotional, rather than commercial aspects. End users do not refuse renewable heating technologies, in general. However, they may be focused on certain technologies and associate circumstances or experiences with their integration. In the end, people want to have a gut feeling that the system functions properly, that it is reliable, and that it does not turn their house 'upside-down' when integrated into their environment. With respect to the points presented by Eisenhardt \& Zbaracki (1992), the technical and commercial arguments against heating technologies are bounded through assumptions, which the decision-maker makes on different perspectives at a particular time.

\section{c. Coverage of the heating demand:}

An interesting issue as part of the questionnaire was how far people knew or were prepared to choose renewable heating concepts to completely cover their heating demands. Based on this technical aspect, it will be of interest to discern the kind of information that end users rely on to form their opinion.

From a technical point of view, nowadays a $100 \%$ coverage of heating demands through renewable heating technologies on-site only works with a wood pellet system, or with an additional solar system, or, respectively, a photovoltaic system, combined with a heating pump. Alternatively, wood may be replaced with oil or gas fired heating systems and solar and photovoltaic systems as a combined solution of both non-renewable and renewable systems. 
K.V. referred to his choice to connect a thermal heating pump with ground heating. In winter, he has to use an additional heating element supplied with electricity. However, nowadays, he would prefer a photovoltaic system to partially cover consumption due to lower expected cost:

Interview_k_v

M.R.: To what extent can you imagine covering $100 \%$ of your heating needs by means of renewable heating technologies?...I think, you mainly work like this, but you still use this heating element when it gets too cold?

K.V.: Yeah.

M.R.: Do you think you could cover your entire heating needs throughout the year with only renewable heating technologies?

K.V.: What do you mean? I work with the heating pump, but it is not sufficient. If I did not have the $9 \mathrm{KW}$ heating element, I could not get the house warm.

M.R.: You said you will not use photovoltaic cells as you are sceptical about whether they would be compatible with your roof.

K.V.: Yes, exactly...It would be possible with respect to location, but I am not in the mood to renew the complete roof [pause]. If it had been around in the 90s, when I renewed the roof, I would probably have done it, especially as it was more subsidised than it is today.

Another interviewee was open for a combined solution with solar systems. In his opinion, this technology still had to be more sophisticated to be prepared for an installation on the roof:

Interview_r_b

M.R.: To what extent can you imagine covering $100 \%$ of your heating needs by means of renewable heating technologies?

R.B.: What could it be, a micro combined heating unit? 
M.R.: Also pellet heating. Will it influence your decision if you cannot use $100 \%$ renewable heating technologies?

R.B.: Well, I want to have a security of supply. I do not want to have a gap in my supply.

M.R.: So, it would not be your decision to just adopt one renewable heating technology solution, which you can use throughout the year?

R.B.: Not at all, maybe solar in combination with other concepts like oil, gas, electricity, pellets, or something else. At the moment, solar must get more sophisticated with respect to its roof installation.

C.W. was up-front about considering a pellet system in combination with solar panels. He still used an oil boiler system, but had previously mentioned that he was not prepared financially for it at that time:

Interview_c.w.

M.R.: To what extent can you imagine covering $100 \%$ of your heating needs by means of renewable heating technologies?

C.W.: Well, when I get back to pellets. Okay, there I assume that I can cover my complete heat consumption. That is how I imagine that. I must have enough pellets and then I can heat and have warm water. As I told you, I do not think that you can satisfy your heating needs completely only using solar energy. Therefore, I already had the idea that the combination of solar and pellets could be an interesting thing.

M.L. relied on a thermal heating pump as a central power unit. However, he considered the capacity limits to its heating performance in winter, when an additional system was required. At an earlier stage, he refused anything related to wood due to the decomposition of forests: 
M.L.: A so-called bivalent plant.

M.R.: What is the meaning of bivalent?

M.L.: Bivalent means that you have two systems. When it gets very cold and the heating pump cannot keep up its performance anymore, the oil heating, gas heating, or a second heating generator acts as a supporting mechanism. Depending on what you have, it can also be a wood boiler or something like that. In other words, a second heating generator supports the heating pump. An air, water, thermal heating pump will never be designed for $100 \%$ performance, it would be much too big. In the area of transition, when the temperatures is like it is now, between five and seven degrees, then the air water heating pump is sufficient to heat the house. When there are temperatures of minus twenty degrees or even less, then it is not sufficient on its own.

R.Z. considered a focused, even limited, approach in his evaluation of his thermal heating pump. He pointed out that this technology cannot cover his heating demand throughout the year. In a broader sense he considered his additional and, with respect to performance, limited photovoltaic system when reflecting on the fed in tariffs he could benefit from during the summer season:

Interview_r_z

R.Z.: What you earn with your photovoltaic plant will be much more compared to another pump, a buffer storage to generate your tap water. If after 20 years the guaranteed buyback price is gone, you can produce your own electricity to keep your heating pump running to produce your warm water.

$\cdots$

R.Z.: I do not know of any technology, which will guarantee your heating needs by $100 \%$ guaranteed solely through renewable energy. So-called peaks then, too. It is always heat, wind, solar power, when it is there. And, at least, I have to combine different renewable technologies. The only exception is when I have a heating pump as a 
renewable technology. However, at the start I have to use primary energy to use it, I need electricity.

The interviews highlighted that commercial aspects are not considered as a main factor with respect to 'Coverage of the heating demand'. Instead, the political or practical aspect in the attitude of the end users determines the kind of heating concept to be purchased. Combined solutions, focused on sophisticated technologies and on-site limitations for the integration, were considered important. The statements indicate that wood pellet systems were not mentioned. As a simple quantitative expression, $100 \%$ coverage of heating demand, stands for qualitative and personal attitudes of end users. They might also be bounded by particular knowledge or attitudes and are, therefore, affected by bounded rational related influencing factors.

\section{Findings - Affecting factor: Technical issues}

Technical issues with respect to the appreciation of heating technologies by homeowners are, surprisingly, closely related to bounded rational aspects of end users and not to functional and rational issues.

In this context, 'Personal handling of the technology' is a contrasting code in terms of pros and cons, but is very closely connected to a lack of desired involvement with respect to the heating technologies.

The 'On-site integration of the technology' considers emotional, rather than commercial, aspects. End users do not refuse renewable heating technologies, in general. However, they may be focused on certain technologies and connected circumstances or experiences with their integration. Integration of renewable heating systems may also be limited by other non-thermal cycle related investments and issues, such as expected built-in problems (e.g. mounting on the roof) or priority given to insulation (overall statements not only related to this code) .

Both issues - personal handling and on-site integration - reflect on the desired gut feeling of end users that the system functions properly and is reliable.

'Coverage of the heating demand' is not strongly focused on commercial aspects. The main focus of end users' attitudes is on political or practical aspects. Combined sophisticated solutions are considered important. Wood fired systems are not considered 
a possible stand-alone solution by end-users. The lack of acceptance of this $100 \%$ coverage is based on different aspects: either in political points of view to combine certain technologies or to ignore wood fired systems due to the greenhouse effect (carbon foot print). Other reasons may also include lack of knowledge regarding possible opportunities. A motivating economical aspect can be using photovoltaic systems that cover their electricity demand and enable them to benefit from feed-in tariffs into the public network, which are paid to the end users.

\subsubsection{AFFECTING FACTOR: B2C ISSUES}

This code considers the involved stakeholders who may be or are in a B2C relationship with end users in the heating market.

B2C aspects involve different active or passive commercial related participants in the market, which need to be clarified, especially for end users with respect to possible purchase of renewable heating technologies. The interviews pointed out that, in particular, consultants, heating plant installers and providers, such as municipalities, are the relevant individuals or individual groups involved in business with end users.

In the theoretical context, these market members are contextualised as stakeholders. In his seminal work, Freeman (1994) provides a classical definition of the term stakeholder. He states that a stakeholder in an organisation represents any group or individual who can affect or is affected by the achievement of the organisation's objectives.

Mitchell, Agle \& Wood (1997) qualify persons, groups, neighbourhoods, organisations, institutions, societies, and even the natural environment as actual or potential stakeholders. They regard stake as an area of argument, because it is upon this basis that 'what counts' is ultimately decided.

Both works of Freeman and Mitchell et al., therefore, point out that organisations and individuals play a role in the engagement of individuals, which is related in this work to the market of renewable heating technologies for end users.

The connections of the engaged parties are mentioned by Daellenbach \& McNickle (2005) in a very abstract way as operations within systems. An important aspect, which is identified, is the behaviour or activities within the relationship of systems. Complex relationships may cause conflicts, due to the people involved, their world views, goals, 
aims, physical relationships, structures and processes, behaviour, and control over actions. Social aspects may, therefore, play a greater role.

The effective interaction and communication, with reference to barriers, has been investigated by Castellani, Piazzalungs \& Sala (2013). They propose effective ways to overcome barriers between scientific inquiry and decision-making. Based on research conducted by the European Environmental Agency (1999), they consider that different influences should be used for the assessment and management of environmental problems. Different roles of influencers are identified; namely, drivers and pressures.

More specifically, Gachet \& Brézillon (2002) identify four possible roles for an organisational structure in the decision support context: (1) sensors mainly detect a change in context; (2) processors are able to proceduralise the contextual knowledge according to the problem to be fixed and to turn it into some meaningful knowledge; (3) satisfiers satisfy an abstract requirement, which can lead to change in context; and (4) decision-makers use the knowledge in the proceduralised context to formulate the requirements to solve the problem of what has to be done.

With respect to the a priori conceptual framework, the work of Bryson (2004) has already been considered as one essential part. He explores and defines the role of stakeholders, identifying both weak and strong supporters, and weak and strong opponents.

\section{a. Consultants}

Consultants are seen as influencers in the exploration. They can advise end users, but, in the end, they have no power to force decisions a certain way. Nowadays, the assignment of consultants is also part of public incentive programs (ENEV, KFW), as their fee can be paid back to the end user as homeowner, up to a certain amount, when he/she engages them for a consultancy as part of a possible new heating plant installation.

'Energy Consultant' is not a protected term and their qualification is not accredited to unique standards.

The four interviewees listed below present different opinions on consultants, both sceptical and positive. In general, end users appreciate their role, when there is the conviction that consultants are independent people and not acting in the interest of others, such as distributors, public services for energy, or manufacturers of heating technologies. 
G.G. appreciated the role of consultants and assumes their independence:

\section{Interview_g_g}

M.R.: May I conclude that insulation was also an important aspect for you?

G.G.: Yes, yes. In my opinion the prevention of heating waste is as important as the generation of heating energy. You have to work on both issues. It is not useful when you have a generator for heating, but the windows are not insulated properly. I think then it will not work. Therefore, I think that you have to watch both issues. I think, it is done, actually. The energy consultants always say that the best energy is the one for which deflagration is prevented.

C.L. also underlined the statement of consultants, and again, assumed that they were independent in their evaluation:

Interview_c_I\&e_

M.R.: Would you also get information from energy consultants?

C.L.: Well, they would be independent people. That would be very important. When I go straight to a company, it can work in different directions. We are total laypersons and then you can have bad luck that it goes the wrong way.

In contrast, M.L. had a limited view of energy consultants, highlighting that they may not present an independent and neutral position:

Interview_m_I

M.R.: How far do you criticise the energy consultants of the energy supply companies, that they follow their own interests?

M.L.: That they follow their own interests and they are not responsible for what they say. They are not liable. 
A.H. reflected very critically on the quality of the advice, which consultants may give. The question was asked - whether different consultants provide the same recommendations:

Interview_a_h

M.R.: What is your opinion about energy consultants?

A.H.: I view them rather critically.

M.R.: Why?

A.H.: I have already spoken to some of them. I do not always feel that I am taken seriously. I always get the impression that they sometimes have their own preferences. One talks about insulation, the other about the heating system. The next one says that something has to be modified on the roof. As an engineer, I see it in this way: I carry out an analysis, I have my facts, so I should achieve similar results as others. I then ask questions and am not satisfied with the answers [pause]. Energy consultants are very often architects [pause]. They may possibly also come from another side. I had some discussions with them about my cost, yes...

The relationship between consultants and the service they provide is based on attitude. If consultants can present themselves as independent people, providing the best solution for end users, they are or can be accepted as involved stakeholders in the market. Therefore, this issue is a bounded rational one.

\section{b. Heating plant installers:}

Heating plant installers are a second and important group within the stakeholder context. They are normally in close contact with end users as homeowners; they also consult and represent certain manufacturers of heating technologies whose products they build-in within the properties.

Therefore, with respect to the coding term, they do not only represent their own profession, but also, in a broader context, they represent the face of installation and consultancy to the customer, the contractual manufacturer partners, and the wholesalers of heating technologies ('three-stage channel'). Thus, the following statements reflect on 
the broader three-stage channel context, and not only on the heating plant installers themselves.

M.L. did not only refer to the role played by heating plant installers, but also articulated a position addressed to a possible $\mathrm{B} 2 \mathrm{C}$ concept as a whole:

\section{Interview_c_w}

C.W.: I think, the topic could be accelerated if it were more present in the media. In my opinion, it is not addressed much in the daily news, on television, on the radio or in the newspapers. I think it could also be accelerated by means of public promotions, a concept, think again about the RWE campaign, heating for 0 EUR. Something like that to be published. That it also might accelerate such a development which I have also mentioned. What I actually should not mention is the cost for fossil fuels. As I told you, I think I am not the only one who says that it still works more or less with cost for oil heating. When it increases extremely, you will think about it more quickly. However, I hope that you are not bounded by the oil lobby to increase the prices [laughing].

In his opinion, renewable heating technologies should gain more media coverage. Although he did not expect renewable heating concepts to become cheaper, he foresaw that an increase in price in non-renewable heating technologies would render the latter less attractive.

M.L. pointed out that end users should be charged for heating consumption and not for the product price of consumed heating energy or the heating product itself:

\section{Interview_m_I}

M.R.: Are there any comments you would like to give on that topic?

M.L.: Well, I would be interested how you can convince a customer to invest in this technology, especially within the field of heating pumps. Especially for old houses, where there are a lot of old people who do not invest anymore. Whether it would make sense to tell them that we install the plant and we charge you for the heating price. Therefore, that might be an opportunity to get this eco-friendly technology onto the market very quickly. 
M.R.: So, this is a question you will then address to the suppliers?

M.L.: Yes, exactly.

M.R.: Have you talked about it with suppliers?

M.L.: Yes, but they will not invest. Therefore, the next step would be to debate with the manufacturers, whether they are interested in working with rental-price models. That means the supplier has to invest, the manufacturer delivers the plant, I build it in or contract somebody else to do it. I then have a certain cost frame, which I pay off, but I get paid a certain heating price. It will definitely be profitable for the energy supply company.

M.R.: But energy supply companies, they are commercial enterprises. It is the question which cost will arise over which period of time?

M.L.: Well, you do not want to take over 18.000 or 20.000 EUR times 10 plants. Therefore take over 18.000 to 20.000 EUR. But when I work with a rental-price model, then I first displace the cost, the investment, to the manufacturer. The manufacturer gives me, by assuming that he gets a certain monthly amount over 10 years. He will give me the plant. Well, and due to the heating price, it will be profitable in any way. I do not have to provide own money.

M.R.: Who is 'I'? You as a consumer or the public service?

M.L.: The municipality, the public service or whoever. Well, in earlier days, the public services used to be municipal enterprises. You always had to prove whether there was a hidden raising of credit. That would be a hidden raising of credit.

C.W., who still worked with his oil burner system, had still not reached a decision as he was also undertaking other investment in his house. But he was already very sensitive to the idea of a positive eco-balance. In this case he referred to the production and disposal of solar panels: 
Interview_c_w

M.R.: Well, I have heard these comments already quiet often. It is an interesting question, also considering the production of these panels.

C.W.: Yes, yes, that is one aspect. There, you consume raw materials and energy and so on. And then you have to depollute them. So, I am not sure whether this will result in a positive or negative eco balance. Geo thermal heat, I still know about, but only a bit. You drill a hole somehow and then you pump water into the depth, I believe, and then it comes up again hotter than it was when it was pumped in.

M.R.: There are still air heating circulation pumps. Sometimes, you see it on the walls with the ventilation systems. The air is then sucked in and compressed and finally heat is generated with a heat exchanger. A lot of people combine it with photovoltaic systems to feed the circulation pump with the generated electricity.

C.W.: That, I heard already. Then, you have electricity derived from the sun and the heat from the ground or the air. It sounds plausible. But the question remains, what are you going to do with the panels and how do you depollute them.

R.B. considered information about renewable heating technologies to be more important than the product. This issue was addressed to the advertisement of manufacturers of heating technologies, but also politics and political programs, which are part of the next chapter:

Interview_r_b

M.R.: Last question. Are there any general comments you have about that topic?

R.B.: For me, it is important that renewable energy is made public, to put it one way. Money is not the end of it. We have certain political requirements, such as the reduction of carbon dioxide. If we want to succeed, we have to work in a way which contributes towards the reduction of carbon dioxide emissions. 
M.L. confirmed the role of heating plant installers due to their recommendations on future heating concepts. For this reason, he pointed out that several companies should be contacted in order to form an overall picture without relying on only one statement:

Interview_m_I

M.R.: I have the impression that the heating plant installer is very important [pause]

M.L.: He is very important for the end customer. Then, he goes to the next heating constructor and he then says: 'Oh, my god'. So, he breaks everything down.

M.R.: But then, it is up to him to get two or three other opinions from other heating constructors [interrupted by M.L.].

M.L.: But he will not do so.

The relationship with heating plant installers is based on attitudes. Their relationship with end users can be assumed to be stronger compared to the relationship between end users and consultants as they are involved in counselling interviews, in regular on-site maintenance work relating to existing heating systems, or in case of break downs in extraordinary maintenance activities. In a wider context, they represent the face of heating plant manufacturers to customers as performing contractual partners. Their involvement is a bounded rational aspect.

\section{c. Providers:}

Providers mainly stand for municipalities or distributors, above all related to nonrenewable heating concepts, using gas or oil. However, more and more municipalities work on self-distributing concepts, such as biogas, to cover heating demand with renewable heating concepts or even district heating generated with biomass.

The following proposition of an end user was, again, as in the former part, addressed to either manufacturers or providers. It focused on a monthly rate as an allocation to minimise the amount of the cost purchase price of a new heating concept: 
Interview_c_w

C.W.: Well, the heating plant was already built in when we moved in. So, the plant is for free, with the exception of the oil we use. But, of course, when we build in a new plant, it should be much cheaper, there should be less consumption compared to the system we have right now. Definitely, that would be a goal. What the investment of a system should be, we have not thought about it so far. But it should not be in the upper five digit part. It would be nice, if it still would be in the area of four digits [laughing]. RWE [provider] did some campaigns on it. Then you pay 0 EUR, I think. You pay a flat monthly rate. It is not a renewable system, it is a gas system. They build in a gas heating system for you. Then you pay the flat monthly rate for the heating and the service and these things.

In the following interview, D.V. was asked how he could be influenced in a positive way, as owner of an old house, to invest more. In his opinion, the municipalities could play an active role, as with thermography campaigns, in sensitising end users. He ascribed responsibility to get more information on regulations within the heating market to manufacturers:

Interview_d_v

D.V.: For instance, by means of a thermography from the municipality. Actually, there should be more advertisement for it. A lot of people probably do not know that it exists.

$\cdots$

M.R.: Would you also inform yourself about the latest regulations? Because so far, we have talked about issues you can decide on your own, like ENEV, regulations on renewable heating energy, or a building passport, in order to motivate or even force people to do something?

D.V.: Actually, I see it as the manufacturers' responsibility. I tell them what I want, that it is especially designed to fit my requirements and they tell me then, how much promotion I can get. When they would force me, I would be against it [laughing]. 
In terms of financing issues, M.L. considered campaigns and the cost of heating consumption, instead of the investment in a new heating technology:

\section{Interview_m_I}

M.R.: Factoring?

M.L.: Well... we went for new ways with respect of financing those things. In the past, my heating pump was more expensive than today.

M.R.: And how do the public services arrange it, today?

M.L.: The only public service with arrangements is the RWE [electricity supply company] with their heating pump weekly campaigns. That means to renew the heating plant at initial tariffs. That means I get a new heating system, I go for a new heating system, and pay for it with a certain amount at the end of the month. But so far, I have not asked for calculations, how much it is and for the attached conditions. My suggestion would be, not to pay a certain amount on a monthly basis, but to charge through the heating price. That means you have got a heat meter. So, the more heat I consume, the more I have to pay.

In a broader context, aside from possible financing programs, R.B. emphasised his expectations regarding information he required with respect to renewable heating technologies:

Interview_r_b

R.B.: Well, first, there are economical aspects, which are important to me, like the investment amount or the running cost, then the life expectancy and maybe even the possible modification of the system involved with changing to another kind of gas. These might be aspects in the future, which did not play a part in the past.

The engagement of providers in the interviews is mainly reduced to campaigns and information to monitor heating consumption and minimise energy. This aspect is seen as a stage of the rational decision-making process, namely gaining information in order to compare and evaluate the information later on. Personal relationships are not as strong or 
just as weak as those with heating plant installers. Therefore, the engagement of providers is rather a rational decision-making factor.

\section{Findings: Affecting factors: B2C}

Consultants, manufacturers and providers are very involved in the decision-making process of end users as stakeholders, following the expression of Freeman (1984) on stakeholders which may be organisations, any group or individual who can effect or is affected by the achievement of the organisation's objectives.

Processes of their engagement are socially constructed (Mitchell, Agle \& Wood, 1997) and, therefore, depend on the relationship between end users and these experts.

Consultants are viewed in one of two ways, either as independent from or dependent on ( 'bounded' to) interests of other engaged market players, such as manufacturers or public services. However, this view of end users is malleable; consultants may be able to convince the end user that they provide independent advice and that they have an accredited qualification.

Heating plant installers are in very close contact with end users, in a bounded rational related sense, and are a given fact. There is no discussion about whether or not they are needed. They are part of maintenance measurements at heating plants in households, and act as consultants and representatives for heating plant manufacturers. Their meaning is important. Therefore, one crucial, yet challenging, factor is that they should all present a consistent opinion and way of thinking regarding the purchase of renewable heating technologies.

Providers mainly represent municipalities or distributors of gas and oil as part of existing heating concepts, normally with these fuels as carbonised and non-renewable solutions. As they form part of the information process of end users within the stepwise rational approach, with less personal contact compared to heating plant installers, their significance is comparative to other suppliers of heating solutions, such as heating plant installers who have a stronger personal relationship with end users. Therefore, if figures and economic aspects can present renewable heating concepts in a favourable light and end users are made more aware of these options, they may play an important role in the choice of renewable heating technologies. 
Various end users reflect on minimising prices for the investment through cost allocation concepts, such as charging a surplus for the energy consumption rather than for a new heating technology.

With respect to further theoretical aspects about stakeholders, no single interviewee admitted to taking decisions on the purchase of renewable heating technologies under the pressure of time constraints, as mentioned by Bryson (2004) and other academics (Bennet \& Bennet, 2008; Mintzberg, Raisinghani \& Theoret, 1976; Tucker et al., 2005) in the context of pushing or damping factors. Decision-makers take their time and do not decide spontaneously. They also did not mention at any stage in the interviews that their decision had been thwarted during the decision-making process. However, another classification by Bryson is interesting in considering the way in which certain stakeholders may influence end users to purchase renewable heating technologies.

\subsubsection{AFFECTING FACTOR: POLITICS}

In the context of this work, politics is related to political instruments to push the purchase of renewable heating technologies. Therefore, the term is not associated with political views of end users, which Turpin \& Marais (2004) characterise as personalised bargaining processes. However, as Turpin \& Marais also mention, the goals, values, and relevance of information differs between involved people. This may influence the instruments appreciated by end users.

Furthermore, the term politics is not related to behaviour, which may be interpreted, in more detail, as empowerment and tactics among decision-makers, as Child, Elbanna \& Rodrigues (2010) point out in their study. In contrast, reference is made to financial instruments with which the decision-maker is faced.

Nevertheless, the authors mention an interesting point of view; transparency is considered essential for good corporate governance. In their review, they reflect on political studies as one aspect to inform corporate governance policies. From there, in a broader context, transparency as comprehensive information for well-informed end users may encourage the purchase of renewable heating technologies, if advantages in their purchase are seen by end users. 
Mark \& Henry (2004), and Christie (2007) focus their research on mechanisms through which evaluation may affect the behaviour of decision-makers and, therefore, decision outcomes. Influences can occur on individual, interpersonal and collective levels, and may ultimately affect the decision outcome.

\section{a. Authorities:}

Authorities, as empowered governmental agencies and legislator, can enforce the direction and instruments of energy policy.

C.L. pointed out the power of governance, above all, through a clear and comprehensive information policy, which is addressed to authorities as frame conditions:

Interview_c_I\&e_I

M.R.: In your opinion, how could the adoption of renewable heating technologies generally be increased and what blocks the adoption?

C.L.: Sometimes, by chance, you can see reports on television. When they present in a way that you can understand them. So, it will definitely be part of a decision-making process. I also believe, when more people rely on renewable heating technologies and have good experiences, word of mouth propaganda also plays a role. Well, if a colleague tells me that he has something like that, I think it will play a role in my decision-making.

Frame conditions by political authorities were also mentioned by R.B.:

Interview_r_b

M.R.: Still a general question on this topic. In your opinion, how could the adoption of renewable heating technologies generally be improved and what blocks the adoption?

R.B.: Well, I think that there have to be frame conditions by politics on how to handle renewable energy. Or a political goal to say that they are focused to a certain degree on renewable energy and want to promote it. And you also have to advertise it, I think. Otherwise, it will not work socially as a tusk. 
D.V. only considered cheaper renewable heating technologies in relation to an increase in price of other energy distribution solutions:

Interview_d_v

D.V.: No. In my opinion, it should be handled with higher gas prices or an electricity tariff, as they do now.

M.R.: A higher electricity tariff means that you want to do cover your electricity production by your own photovoltaic?

D.V.: Well, a higher oil or gas price.

M.R.: So that there is a motivation that you look for cheaper renewable energies?

D.V.: Well, that renewable energy will become cheaper than oil, at some point.

The recommendations about political instruments reflect very much on financial and regulating issues and are, therefore, very much figure orientated and focused on rational decision-making factors. Emotional issues are not mentioned, instead of this, transparent, comparable and regulating information is required to set frame conditions.

\section{b. Incentive models:}

One governmental instrument is incentive models, through which the end user will receive a certain amount in pay-back when he decides to purchase a certain concept. Based on the interviews, interest rates for investments are generally considered too low compared to opportunities of other banks; therefore, at least they are not seen as fostering an advantage.

End users, like R.B., referred to these unattractive financing opportunities for investment in new technologies in the following manner:

Interview_r_b

M.R.: One question about promotions. There are different options nowadays. Either to get a cheap loan or to get some grants. Is this also a topic, which might influence your decision? 
R.B.: Not right now, because the level of credit rates is too low. Therefore, no. Of course, if I can get a grant, I would use it.

M.R.: But to make use of it, you would not go for it?

R.B.: No.

Some end users concluded that incentive models are more interesting than public loans. However, again, as a stand-alone factor, they do not motivate homeowners to invest, as expressed by C.W. with the conjunctive term 'would'. In a broader context, they referred to other investments in their house:

Interview_c_w

C.W.: Well, I do not think that we will keep ourselves busy on that just because of promotions or loans. I rather think not. Well, I think we would inform ourselves on these promotion possibilities when the heating system does not work properly anymore, when we expect it to breakdown or to consume more and more oil, or the values justify it. When it becomes more concrete, then we would definitely inform ourselves about these opportunities. However, I do not think that we will push it due to a promotion programme.

M.R.: Because, the bottom line is that it costs money?

C.W.: Yes, right. Because, as far as I am concerned you do not get it financed completely [laughing]. Therefore, you still have to pay a lot on your own. So, I do not think that we would push the decision.

The large investment and only relatively small, related incentives were again mentioned by R.Z.:

Interview_r_z

M.R.: Is there a limit in yearly running cost and the amount of investment to adopt renewable heating technologies and how do you evaluate this amount? 
R.Z.: Yes, of course, as for the investment, it is what I can afford. I would never make an investment, which I will have to refinance for the next fifty-two years. That's logic at the age of forty. It has to be a clear investment, where I can say I will amortise sometime in order to handle it. Otherwise, it will be a technology, which will not be at my disposal, sometime. Because it is too expensive, because I cannot afford it. Just to choose something, the most renewable available, is one extreme. The other extreme is to choose something which will amortise very fast.

Thermography campaigns are an example of a B2C concept about incentives, which are appreciated by end customers. End users get this service for free, or strongly supported by public institutions, such as municipalities. The thermography can only point out a badly insulated house with the objective of motivating end users to make further investments:

Interview_c_w

C.W.: There were financial reasons. Later on, we got an offer from our municipality, for a small amount money, to take these photographs. How do you call it?

M.R.: Thermography.

C.W.: Right. A thermography campaign. Thereafter, there was also a consultancy, quite well done. A good presentation, what could you do. But the house already cost some money.

In contrast, T.A. used an incentive model but added that, in general, he had the money for the investment. Therefore, the incentive model was not the initial reason for purchase:

Interview t a

From a financial point of view, it would have been cheaper to install smaller storage and also to install a smaller collector and to burn more wood. However, I decided to do more; it was also promoted at the time. 
$\cdots$

T.A.: No, no one else. I do not think that I spoke to the tax adviser, because it is not fiscally noticeable, it is not renting or so. Definitely, I inquired at the KFW [Credit Institute for Reconstruction] what kind of advantages you have or that you can apply for a promotion. Well, there you can do something.

M.R.: But you did not make use of it?

T.A.: I did. But not KFW instruments, but it is still the same. A promotion. The things are promoted by the BAFA [Federal Office of Economics and Export Controls]. 2.500 EUR.

Incentive models are only focused on figure-orientated decision-making factors. Therefore, they are grounded in rational decision-making issues, without emotional influencing values. They were not valued by the interviewees with respect to their decision regarding the purchase of renewable heating technologies.

\section{c. Laws:}

Aside from institutions and incentives, laws contain more enforcing instruments and greater direction of governmental policies.

R.B. pointed out that transparency of information would be important to make end users aware of opportunities for renewable heating concepts. People would then decide which way to go when it interests them:

Interview_r_b

M.R.: Last question. Are there any general comments you have on the topic?

R.B.: For me, it is important that new technologies are developed. Politics should develop a reasonable strategy. There are numerous actions made without proper planning. A lot has been done for publicity, like 1 Million electric vehicles. You must convince people that electric vehicles represent technical progress. 
A.H. mentioned that new technologies should be developed, and that politics were responsible for the creation of a reasonable strategy. With reference to the purchase of electric vehicles, people have to be convinced by figure related information. He was then asked for details:

\section{Interview_a $\mathrm{h}$}

M.R.: In your opinion, how could people be convinced?

A.H.: For example, with facts or figures. You cannot say then, electric vehicles produce no emissions. It is wrong. And they do not take you seriously. When you produce electricity, with an efficiency rate of 40 or $50 \%$ in power stations [interruption]. You must transport the electricity, with motor cars. You must move them, they weight 100 or 200 kilograms. Physicists say mass times acceleration or energy. I need energy. Further, I must consider the production of these batteries. Which substances do they use, how do they extract these substances? What do you do with old batteries, also in terms of safety? These questions have to be answered reasonably. It cannot be excluded, when they say that no emission gets out there. How much energy do they need to produce these batteries, what is their efficiency rate?

M.R.: Do you assume that other people reflect on economic or figure-related aspects?

A.H.: I would like to think so. When I talk about electricity, I also have to talk about emissions. How much emissions are released when you generate electricity? When they have shut down the nuclear power stations? We talk about carbon dioxide reduction.

Transparency is indirectly also referred to by G.G., suggesting that enforcing instruments will only change things which are explicitly required due to missing conviction:

Interview_g_g

G.G.: But nowadays, building plans are only approved when, related to the basic structure of the building, you have considered that for your energy generation. In my opinion, it is remarkable, because I did not know that I am actually forced to carry out certain investments. To be honest, when I am forced to certain things, I find it 
suboptimal. Even though it is required politically, it will not be done voluntarily so will only be realised a little.

M.L. focuses on governmental instruments, arguing that they should be more socially balanced and combined with smaller concepts in order to minimise investments:

\section{Interview_m_}

M.L.: I think it has not changed. It is necessary more and more that we have to do something. It is a shame that politics is not doing more. It is a shame that politics has mulcted photovoltaic systems with penalty taxes. Well, you plant apples in your garden and when you want to eat them, you must pay taxes. Actually, it is a no go, but this was expected to happen. As the big energy supply companies expect their business to go down, the private consumer is the cow whose milk you want to drink and the industry does not earn money with it, because you have to provide electricity very cheap. In most cases, the big customers do not have to pay the EEG contribution and, well, the private citizen pays all of it. It is politically volitional to keep these technologies on a low level. Normally, it would be fair, we have invested billions in aid money in nuclear power. Coal gets billions in aid money, but the renewable technologies must be financed with the EEG contribution, which is paid by the customer. Actually, that is not right.

M.R.: There are favourable loans through the KfW or grants.

M.L.: Yes, but so far, it has been like this that you had to realise a complete package of measurements. I had to put in new windows, a new heating system, and insulate my roof. Therefore, a complete package. I got favourable loans. It is not very helpful, homeowners should be granted favourable loans for single measurements. That means, very often the customer is not able to finance such big packages, but he only wants to get a new heating system without changing his windows or something like that. So, he should fulfil his desire. When he is forced to change the windows, it works out to be without limits.

Figure related issues, but also demand for transparent information stand for the conjunction of 'laws'. Instead of focusing on emotional aspects, people consider 
regulations in their decision on whether to purchase renewable heating technologies. Therefore, the purchase of renewable heating technologies indicates a rational related decision-making process on this topic.

\section{Findings - Affecting factor: policy}

End users as decision-makers for the purchase of renewable heating technologies reflect very strongly on figure related aspects. Clear and transparent information is required to deal with these large investments. Politically associated regulations by authorities mainly contain this kind of data.

Franz \& Kramer (2010) mention that decision-makers attempt optimisation, assuming clear goals. In contrast, as the interviews show, there seems to be no room for emotional matters.

Therefore, 'Authorities', 'Incentive models' and 'Laws' are limited to comparable and prescribing data, and, accordingly, rational related decision-making factors.

\subsection{SUMMARY}

Different aspects of the data analysis about decision-making related to renewable heating technologies in detached and semi-detached houses are concluded through the interviews with end users as homeowners. The data has been systematically gathered and interpreted using the grounded research approach identified by Strauss \& Corbin (1998), referred to in Chapter 3.6.1:

\section{Findings - Specifics of the technology:}

Part of this chapter addresses technical related issues about the description of renewable heating technologies to identify technical key data. Enlarged bounded rational and rational related issues will be contextualised to influencing decision-making factors in Chapter 10.4.5 on the evaluation of affecting technical issues.

In order to express it in terms of the exclusion principle: renewable heating technologies are not related to one specific technology in the end user context. Even the limited number of interviews indicates that each case has to be seen as a single and individual case with respect to general summaries. 
In relation to the present chapter, wood pellet systems and solar systems were best known among interviewees. Further, participants were also aware of thermal heating pump systems, mainly combined with photovoltaic systems to feed in electricity from the photovoltaic panel system into the public network and / or to cover the electricity demand of the heating pump and domestic demand of the house.

In general, with respect to decision-making processes, the arguments are particularly contradictory between participants in terms of technical and commercial evaluations. The arguments are, therefore, also grounded and thus bounded in different backgrounds about the interpretation and availability of information.

The opinion of end users is also related to other prioritisations or to measurements relating to their chosen heating energy, which have already been carried out. Aside from other investment, insulation is one important aspect; not only is it often considered expensive, it also gives rise to concern in the context of environmental protection with respect to the materials used and the removal of waste. Further, photovoltaic energy as a form of renewable electricity supply is regarded as a power supply covering own energy demand. This system may then be an alternative to solar heating systems, also in combination with thermal heating pumps.

In general, participants either did not appreciate or were not aware of the possibility to cover 100\% of their heating demands using renewable energy; this is possible with a wood pellet system. Renewable heating technologies, such as solar and photovoltaic systems, are often considered in combination with other heating options, both renewable and non-renewable, such as gas and oil.

A possibility for a different perspective on technologies is limited not only due to the technical aspects, but also due to the nature of available information. Therefore, one solid renewable technology is not foreseeable, neither through the technical and on-site situation, nor through the interpretation and characterisation of end users. Further, $a$ purchase has to be considered in the context of other prioritisations of investments in domestic homes, such as insulation, furnishing or other replacements.

\section{Findings - Motivation for the purchase:}

Cost-effectiveness thinking is always an essential rational motive for the investment decision. 
Eco-sensitivity is an additional factor, but the question is, to what extent is it combined with economic issues. The bounded views differ between the individual aspect, with respect to the single purchase, and the broader political aspect, with respect to political views on a macro-economic or political level, such as climate change.

The evaluation of the necessity of the purchase of renewable heating technologies represents a comprehensive decision-making process, long-term and rather complex. Different aspects like priority over other investments, or the choice to first just observe the development of fuel prices for non-renewable technologies influence the decision in the long-run. The availability of adequate financial resources is very important in the decision-making process.

\section{Findings - Sources and stages:}

The information gathering stage, assessed during the interviews, is a more comprehensive process with different involved sources in comparison with the looking for alternatives or the evaluation of alternatives stages, which take place later during the decision-making process. A limited form of evaluation and choice often takes place at an early stage of the decision-making process, before the comparison of different options. The involvement considers active and passive recognition of information, which may later influence the phase of the motivation. A comprehensive structural approach due to the involvement of others can be attested. Delays, loops or interruptions cannot be confirmed.

Interviewees confirmed that decisions were, with only one exception, not taken spontaneously. However, this interviewee was already aware of further decisions due to prior consideration of already evaluated long-term aspects. In a broader sense, no interviewee confirmed making pressurised decisions.

Mainly experts (manufacturers, installers, consultants), relations, and written data from print media or the Internet were the main sources of information.

Considering rational decision-making processes, the stages looking for alternatives and their evaluation take place within a short space of time. Looking for alternatives is interpreted as the consideration of various choices; in other words, alternatives are rational related decision-making factors, which form part of the process stage. Nevertheless, the whole process also considers bounded rational influences, such as involved friends and relations. 


\section{Findings - Personal characteristics:}

Personal and character based decision-making factors cannot be related to either rational or bounded rational aspects.

Rational related issues are based on economic issues and strategic thinking; they reflect on goals as commercial benefits, and clear and comparable data without emotional criteria.

References fall within the category of rational or bounded rational aspects, depending on whether they derive from print media or bounded evaluated statements from personal relationships, respectively.

Eco-sensitive issues fall within the category of bounded rational factors. Personal agendas are expressed in decisions based on gut feeling of end users, involving experiences and evaluations of statements from other people. Decisiveness, in the end user context, reflects on feelings of being well-informed, and is related to bounded rational issues.

\section{Findings - Affecting factor: technical issues}

The evaluation of technical issues associated with the technology is related to bounded rational aspects of the end users.

Personal handling is a contrasting code, either related to daily involvement as passion and satisfaction, or the opposite. Both points of view are connected to gut feeling, as an important personal background for decision-making.

On-site integration is another bounded related characteristic. The bounded rational aspect can be explained with the fact that the system shall be reliable and cause no problems. Therefore, rational or financial aspects, especially as a criterion for exclusion, are not a high priority. However, the integration of renewable heating systems may be limited by or put aside in favour of other non-thermal cycle related issues, such as the insulation of a house, or mechanical problems with solar or photovoltaic panels on the roof. A stronger meaning may also include the usage of photovoltaic to benefit from feed in tariffs into the public network or to cover own electricity demand.

The 100\% coverage is founded on different aspects from a political and bounded rational point of view, either to combine certain technologies, or to ignore wood fired systems 
due to the greenhouse effect (carbon foot printing). The possible lack of knowledge on the available and possible opportunities may be another reason. Furthermore, photovoltaic technology is used to cover the domestic electricity demand or to benefit from feed in tariffs when providing electricity for the public network.

\section{Findings: Affecting factors: B2C}

As Freeman (1984) argues, consultants and installers, with their connection to manufacturers, and providers are very much involved in the decision-making process as stakeholders, following the engagement of people. Processes of their engagement are socially constructed (Mitchell, Agle \& Wood, 1997) and, therefore, depend on the relationship between themselves as experts and end users.

Consultants are viewed in one of two ways, either as independent from or dependent on ('bounded' to) interests of other engaged market players, such as manufacturers or public services. However, this view of end users is malleable; consultants may be able to convince the end user that they provide independent advice and that they have an accredited qualification.

Heating plant installers are in very close contact with end users, in a bounded rational related sense, and are a given fact. There is no discussion about whether or not they are needed. They are part of maintenance measurements at heating plants in households, and act as consultants and representatives for heating plant manufacturers. Their meaning is important. Therefore, one crucial, yet challenging, factor is that they should all present a consistent opinion and way of thinking regarding the purchase of renewable heating technologies.

Providers mainly represent municipalities or distributors of gas and oil as part of existing heating concepts, normally with these fuels as carbonised and non-renewable solutions. As they form part of the information process of end users within the stepwise rational approach, with less personal contact compared to heating plant installers, the meaning of providers for the decision-making process of end users is comparative and rational focused. Their lack of personal contact with the customer can be contrasted with heating plant installers, who are involved in the end users' heating concepts and house maintenance works. Therefore, if figures and economic aspects can present renewable heating concepts in a favourable light and end users are made more aware of these 
options, they may play a more important role with respect to the choice of renewable heating technologies.

Various end users reflect on minimising prices for the investment through cost allocation concepts, such as charging a surplus for energy consumption instead of for a new heating technology. Different B2C concepts may thereby be deduced.

With respect to further theoretical aspects about stakeholders, no single interviewee admitted to taking decisions on the purchase of renewable heating technologies under the pressure of time constraints, as mentioned by Bryson (2004) and other academics (Bennet \& Bennet, 2008; Mintzberg, Raisinghani \& Theoret, 1976; Tucker et al., 2005) in the context of pushing or damping factors. Decision-makers take their time and do not decide spontaneously. They also did not mention at any stage during the interviews that their decision was thwarted during the decision-making process. However, another classification by Bryson is interesting in considering the way in which certain stakeholders may influence end users to purchase renewable heating technologies.

\section{Findings - Affecting factor: policy}

End users as decision-makers for the purchase of renewable heating technologies reflect very strongly on figure related aspects. Clear and transparent information regarding incentive programs and authorities is required in order to validate these large investments. The alternative would be strong rules and restrictions.

In this context, Franz \& Kramer (2010) mention that rational decision-makers attempt optimisation, assuming clear goals. In contrast, as the interviews show, there seems to be no room for emotional matters. Rules, laws and economically based incentive programs are rational related issues.

\section{Rational vs. bounded rational decision-making factors}

With respect to the data discussion in Chapter 6, the key point to consider is, which parts of the decision-making process are rational ones (Mintzberg, Raisinghani \& Theoret, 1976; Eisenhardt \& Zbaracki, 1992; March, 1991; Franz \& Kramer, 2010) and which ones are bounded rational ones (Turpin \& Marais, 2004; Bennet \& Bennet, 2008; Simon, 1978).

These two cornerstones have been used as a basis to analyse and evaluate influencing factors, and to identify which factors slow down or even stop the decision-making 
process for the purchase of renewable heating technologies, and to ascertain which ones support the purchase or have no influence.

The following codes can be assigned (properties with greater categories in brackets):

\section{Rational related codes}

Cost-effectiveness thinking (motivation for the purchase and personal characteristics)

Necessity (motivation for the purchase)

Strategic thinking (personal characteristics)

Providers (influencing factor: B2C issues)

Authorities (influencing factor: politics)

Incentives (influencing factor: politics)

Rules (influencing factor: politics).

\section{Bounded rational related codes}

Eco-sensitivity (motivation for the purchase and personal characteristics)

Gut feeling (personal characteristics)

Personal handling of the technology (influencing factor: technical issues)

On-site integration of the technology (influencing factor: technical issues)

Coverage of the heating demand (influencing factor: technical issues)

Consultants (influencing factor: B2C issues)

Heating plant installers (influencing factor: B2C issues)

Decisiveness (personal characteristics).

\section{Rational and bounded rational related codes}

(more detailed analysed by means of the coded data and line-by-line analysis)

Sources (sources and stages)

Stages - information (sources and stages) 
Stages - alternatives and evaluation (sources and stages)

References (personal characteristics).

\subsection{FINAL CONCEPTUAL FRAMEWORK}

In Chapter 2.5, the a priori conceptual framework was based on three columns (Figure 1).

First, decision-making steps according to the rational decision-making approach.

Second, a decision-making procedure with different possible cycles and chronologies of the decision-making process.

Third, influencing factors impacting the decision-maker. Knowledge of and relation to renewable heating technologies, and relationships and connections to other involved people and organisations with respect of the term stakeholders (Freeman, 1994) are all mentioned.

The interviews indicated two issues, which have to now be considered within the final conceptual framework (Figure 8).

Motives are contextualised to motivation as an activating process (Edelmann, 2003). Within the structurally complex and long-term related decision-making process, they are referred to personal factors such as intentions for behavioural achievement, goals and inspirations. Information is added by influencing factors, such as experience, knowledge or networks with other stakeholders (Ajzen,1991; Mark \& Henry, 2004; Anderson, 2002; Lunenberg, 2010, Mintzberg, Raisinghani \& Theoret, 1976). Motives form part of the opinion-making, before the classical decision-making process begins with the active gathering of information as part of the stepwise rational decision-making process (Mintzberg, Raisinghani \& Theoret, 1976; Eisenhardt \& Zbaracki, 1992; March, 1991; Franz \& Kramer, 2010). In contrast, motives are linked to greater motivation as a form of powerful behaviour (Bernard et. al, 2006; Heckhausen \& Heckhausen, 2010). They are purposes, which a person has taken and follows. Therefore, by means of motives, decision-makers enter into the (classical and stepwise) decision-making process.

Cycles within the decision-making process are not relevant as the involved stakeholders are considered very carefully before a possible purchase or rejection of renewable 
heating technologies takes place. The interviews indicate that the decisions about renewable heating concepts and their purchase are strategic, long-term decisions (Mintzberg, Raisinghani \& Theoret, 1976). The decisions related to large investments are not taken under pressure by end users.

Nevertheless, character-specific factors of the decision-makers determine which step is taken, and whether any step is taken at all, towards or against renewable heating concepts. They are either rational or bounded rational, or a combination of both.

Compared to the a priori conceptual framework, the final conceptual framework considers motives as an additional step before entering into the stepwise and rational related decision-making process. The final conceptual framework will regard the decision-making procedure as an involvement of rational and/or bounded rational factors instead of a cycle process. 


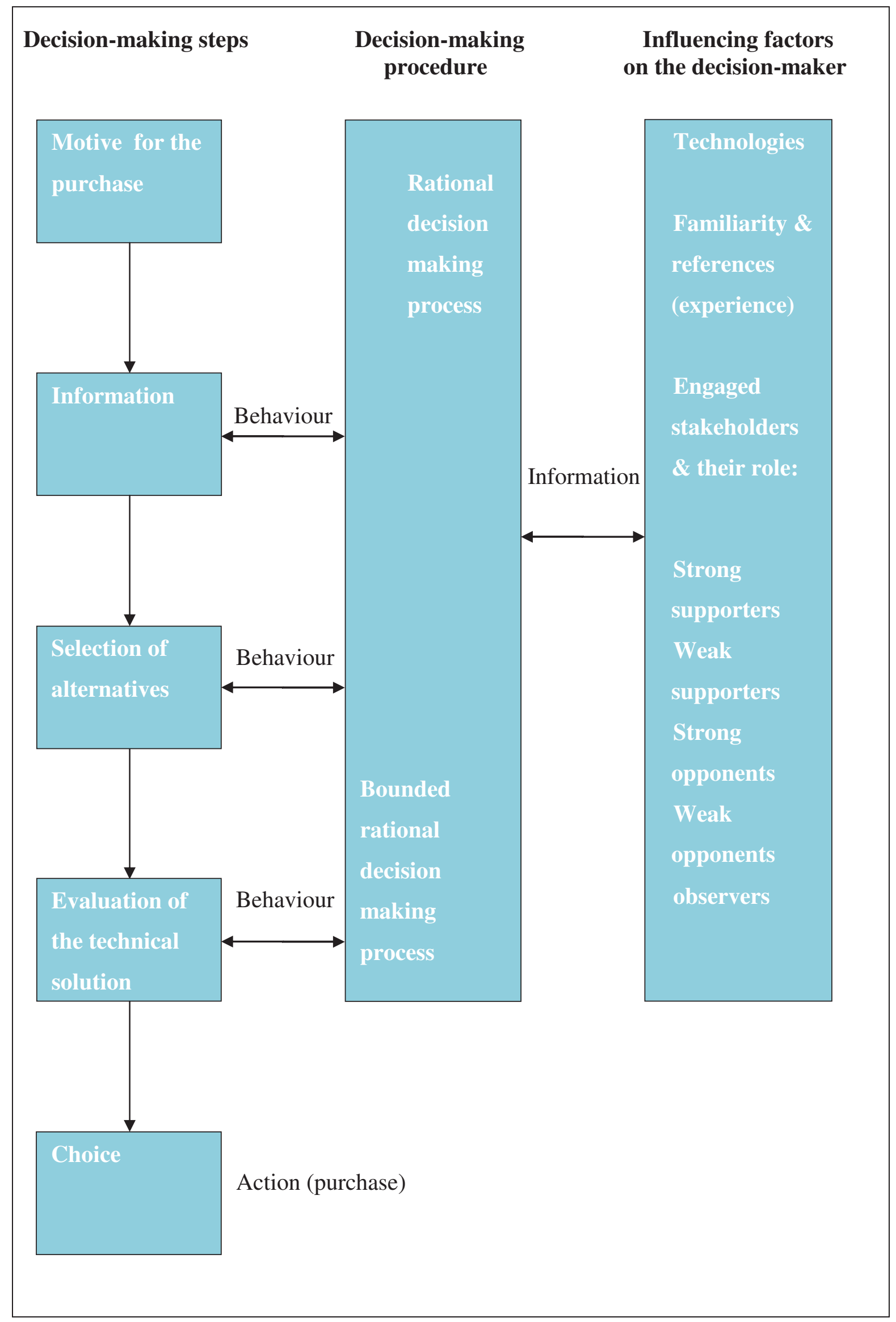

Figure 8: Final conceptual framework: decision-making process of end users 


\subsection{RATIONAL VS. BOUNDED RATIONAL DECISION-MAKING FACTORS}

The consideration of rational and bounded rational decision-making factors and their relation to decision-makers are the corner stone of this work. With respect to the purchase of renewable heating technologies, their meaning and possible influences will be of particular interest. Influencing factors derived from the data analysis are indicated in Figure 9.

\section{Rational decision-making factors}

Literature points out that rational stands for going through different stages of acquiring information, looking for alternatives, evaluating them and finally making a decision (Turpin \& Marais, 2004; March, 2004). Further, investigations relate to rational decisionmaking processes, which are based on the decision-makers' worldviews (Eisenhardt \& Zbaracki, 1992) and their optimisation, assuming clear goals (Franz \& Kramer, 2010). Another argumentation for the strict direction is expressed in a logical conclusion derived from a direction in thoughts (Anderson, 2002). They begin with facts, then value options and proceed to a logical conclusion to choose a certain option.

\section{Bounded rational decision-making factors}

The term 'bounded' points out activities for searching and satisfying, which are driven by agendas of participants rather than rational processes (Turpin \& Marais, 2004). In bounded rationality, the decision-maker is either unaware of a problem, or limited in time to search for all possible solutions.

Decisions based on intuition, experience, advice from others, and perhaps some creative thoughts represent another characteristic present in the literature (Lunenberg, 2010). Research connects bounded issues with relationship networks and cognitive insights (Bennet \& Bennet, 2008). One statement just concludes that bounded means not knowing all the alternatives (Simon, 1978).

Within the data analysis on decision-making processes about the purchase of renewable heating technologies, rational related factors stand for technical (functional) and economic issues. Bounded rational criteria can be summarised as follows: 'Ecosensitivity' and 'Personal handling' represent openness or not to ecological issues and willingness to deal with heating technologies on a daily basis. 


\section{DM factors on the purchase of renewable heating technologies by homeowners}

\section{Rational}

Rational and bounded rational (depending on content of information)

Cost-effectiveness thinking

- Profitability

Return on investment

Running cost

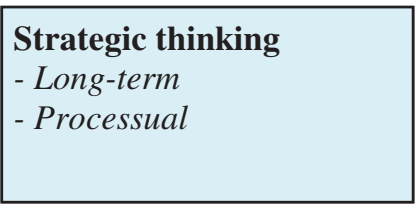

Necessity of decision

- Effectiveness of

system

- Breakdown

- Financial resources

\section{Providers}

Authorities

Incentive Models

Laws (Rules)

- Rational statements

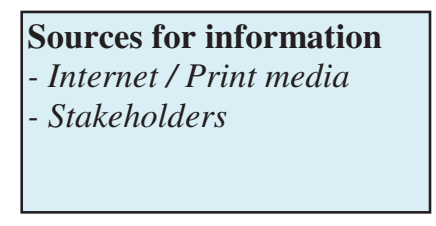

\section{Information searched}

- Passive

- Active

- Factors before DMP

- Neutral

- Negative

- Supporting

Searching alternatives and their evaluation

- Sources

- Information searched

References (statements) Context to information may be

- Personal evaluated \& socially constructed by DM (bounded rational) or

Comparative data (rational)

\section{Bounded rational}

Eco-sensitivity

- Social context

- Sustainable thinking

Personal handling of

technology

- Involvement

- Passion

\begin{tabular}{|l|}
\hline On-site integration \\
- Expenditures \\
- Sophistication \\
\hline
\end{tabular}

Coverage of heating demand

- Insulation

- Knowledge

- Prioritisation

\section{Gut feeling}

Convenience

Reliability

Availability long-term

Sophistication

Trust

Personal Background

Decisiveness

- Transparency

- Easy language

- Comparable

information

\begin{tabular}{|l|}
\hline References (humans) \\
Consultants \\
Heating plant installers \\
(statements) \\
- Personal evaluation \\
- Socially constructed \\
by DM \\
- Relationship \\
\hline
\end{tabular}

Figure 9: Influencing rational and bounded rational decision-making factors (own study) 
'On-site integration' and 'Coverage of the heating demand' depend on the content of information and the individual evaluation of these influencing factors.

'Gut feeling' and 'Decisiveness' play a major role in the decision-making process for B2C concepts, as their content can be formed with transparent and trustful data. Gut feeling strongly reflects on individual issues in the context of personal experiences (Khatri \& Ng, 2000) and the acknowledged reliability for the purchase of heating technologies. Personal agendas are important influencing factors for decisions. Decisiveness assumes transparent and sufficient data in order to motivate end users to make a decision.

'References' (humans), 'Consultants', 'Providers', 'Heating plant installers', manufacturers and interest groups which stand behind the process are the addressees of this information for B2C related aspects and concepts. Authorities and the design and monitoring of laws, regulations and incentive programmes are addressed to politics and governmental responsibilities in a wider context.

\section{Rational and bounded rational decision-making factors}

With respect to the structural context, the contents as contextualised information of the involved 'Sources for information', 'Information searched', 'Searching alternatives and their evaluation' and 'References' can be rational or bounded rational factors.

To sum up, the rational and rather processual decision-making process is not only related to rational matters, such as a strong direction in thoughts, but also involves bounded rational and personalised influences, like intuition and experience. This research follows the approach of Eisenhardt \& Zbaracki (1992), who discuss boundedly rational decisionmakers in organisations due to cognitive limits within the phase of the rational stepwise approach. Decision-makers satisfy rather than optimise their goals and may go through different cycles with different paths with stops and starts. They may often shape the decision paths as a result of the complexity of the problem.

There is no absolute truth, as Easterby-Smith, Thorpe \& Jackson (2012) point out, with respect to theorising qualitative and socially constructed data. 


\subsection{THEORETICAL KEY CONCEPTS}

Data is contextualised and interpreted in the context of the research questions (RQ).

\section{a. Influencing factors on decision-making for the purchase of renewable heating technologies in the same local area}

The starting point is that on-site technical matters for homeowners are given. They depend on each individual on-site situation. In contrast, personalised and bounded related factors can be defined as influencing factors, with respect to their content, which affect the purchase of renewable heating technologies in either a positive or negative way.

Bigby \& Douglas (2015) characterise experiences, knowledge, available information, personal values or cultural norms with a person's will and preferences about the decision.

Therefore, if the level of knowledge on the matter were to improve or to enlarge, a better evaluation could take place regarding the comparison between possible renewable heating technologies, resulting in the side-lining of non-renewable systems.

Functional and rather rational related technical issues can thus involve bounded rational factors to form an overall picture due to the limited data which can be used to form perceptions. These bounded rational factors include stakeholders and their statements, as well as reflection on the personal background of homeowners and their attitudes on renewable heating technologies.

Nikolova \& Arsic (2017) express concerns on integrating groups of people with a stake in the corporation into decision-making processes as stakeholder management. It is an approach towards people who affect or are affected by corporate policies and practices. Stakeholder management is regarded as an opportunity for managers to listen to stakeholders, understand their viewpoints and engage in dialogues and action.

Stewart et al. (2017) take on the information policy with stakeholders as evidenceinformed decision-making. It encourages the use of rigorous evidence for better decisions. Multiple sources of information are consulted before reaching a decision.

On the one hand, stakeholder aspects shall thus be strongly related to B2C concepts and the content of their information to homeowners, addressed by providers, manufacturers, heating installers, manufacturers and relevant interest groups. On the other hand, (more) effective political frame conditions (regulations, laws, incentives) are necessary and 
depend on implementation by governmental authorities (Table 10). Stakeholder related information about references and reliable heating technologies in use are mentioned. Further, messages and terms which reflect on the eco-sensitivity of homeowners with

\begin{tabular}{|c|c|c|c|}
\hline $\begin{array}{l}\text { Technical matters } \\
\text { (given) }\end{array}$ & $\begin{array}{l}\rightarrow \text { bounded rational } \\
\text { related }\end{array}$ & $\Rightarrow$ & $\begin{array}{l}\text { B2C concepts and } \\
\text { governmental public } \\
\text { relations addressed to } \\
\text { DM (contents) } \\
\rightarrow \text { samples for } \\
\quad \text { information }\end{array}$ \\
\hline \multirow{7}{*}{$\begin{array}{l}\text { Existing heating system } \\
\text { (to be connected) } \\
\text { Space on-site } \\
\text { (e. g. cellar for pellet } \\
\text { heating) } \\
\text { Installation situation } \\
\text { (e. g. roof for solar or } \\
\text { photovoltaic system, } \\
\text { garden renovation for } \\
\text { thermal heating pumps) } \\
\text { Sophistication of } \\
\text { technology } \\
\text { 100 \% coverage of heating } \\
\text { demand (single or } \\
\text { combined solutions) } \\
\text { Necessity for replacement } \\
\text { (pay back tariffs / } \\
\text { electricity supply) } \\
\text { Efficiency } \\
\text { (e. g. electricity supply for } \\
\text { thermal heating pump) } \\
\text { Protection of supply } \\
\text { Prioritisation based on } \\
\text { financial resources, prices } \\
\text { and running cost } \\
\text { (to be influenced by B2C } \\
\text { concepts) }\end{array}$} & $\begin{array}{l}\text { Stakeholders } \\
\text { (e.g. installers, providers, } \\
\text { manufacturers) }\end{array}$ & $\Rightarrow$ & $\begin{array}{l}\text { References with } \\
\text { statements of reliable } \\
\text { solutions } \\
\text { (renewable heating } \\
\text { technologies in use) }\end{array}$ \\
\hline & Eco-sensitivity & $\Rightarrow$ & $\begin{array}{l}\text { - Eco balance } \\
\text { - Depollution of systems } \\
\text { (e. g. minimising } \\
\text { reservations against } \\
\text { solar panels) }\end{array}$ \\
\hline & $\begin{array}{l}\text { Social construction of } \\
\text { statements } \\
\text { (opinion making) }\end{array}$ & $\Rightarrow$ & $\begin{array}{l}\text { Reflection on trusted } \\
\text { data for acceptance } \\
\text { (e.g. established } \\
\text { technologies, easy } \\
\text { language, experiences) }\end{array}$ \\
\hline & $\begin{array}{l}\text { Personal experience } \\
\text { (personal agenda, gut } \\
\text { feeling) }\end{array}$ & $\Rightarrow$ & $\begin{array}{l}\text { Reflection on overall } \\
\text { feeling of safety for } \\
\text { technology }\end{array}$ \\
\hline & & & \\
\hline & Decisiveness & $\Rightarrow$ & $\begin{array}{l}\text { Volume and } \\
\text { transparency of } \\
\text { information }\end{array}$ \\
\hline & Passion for technology & $\Rightarrow$ & $\begin{array}{l}\text { Appreciated desire for } \\
\text { personal handling and } \\
\text { involvement }\end{array}$ \\
\hline
\end{tabular}

Table 10: Influencing factors on new heating technologies (own study) 
trustability by homeowners and matching personal experiences which meet the demand on safety aspects of heating technologies are important. In addition, decisiveness founded in transparent information and passion for being involved in the handling of these technologies may be influencing factors.

\section{b. Dependency of economic and ecological decision-making factors}

As already pointed out within the data analysis in Chapter 5.4, economic data is the main aspect on which end users focus, regarding their choice on whether to purchase renewable heating technologies. Ecological data may also influence the decision-making process.

Pearce \& Seccombe-Hett (2000) research on the economic valuation for environmental decision-making emphasises the assignment of monetary values to changes in environmental services and functions, such as in the context of environmental protection.

In a wider national and political context, they identify pricing policy as behaviour of consumers as willingness to pay for the asset. Environmental gains and losses are defined in terms of increments or decrements of human well-being. To policy makers, they recommend establishing acceptable procedures for making decisions.

With respect to the research context of this work, one way to sensitise end users on the subject of renewable heating technologies may be to link ecological data with economic data, with the economic data acting as an amplifier. Therefore, the decision-making process will not only be limited to directly related economic data, but would also include consideration of additional matters which can also be contextualised with economic aspects (Table 11).

For instance, eco-sensitivity as ecological sensibility of homeowners may be related to commercial issues from $\mathrm{B} 2 \mathrm{C}$ concepts and public regulations, such as tax advantages, buy-back tariffs or incentives in case of purchase of renewable heating technologies (first row). References (humans) as a further issue can be used to inform end users about their experience on low operating costs, profitability and protection of supply, such as for solar panels during the summer season, in comparison with oil fired heating systems, as a commercial factor. Other important factors for 'quantifying influencing factors in economical benefits' are the eco life cycle of products, the advancement of renewable heating technologies and the scope of information about renewable heating plants. 
The relevant economic data for the transformation could then be linked 'as amplifier' to the dominating rational part of the decision-making process with respect to the stepwise approach and inspire B2C concepts.

Politics and B2C related stakeholders, such as authorities, heating plant installers and providers (manufacturers and interest groups being behind), may thus be required to develop new or additional strategies and concepts to enlarge and address relevant information to end users.

\begin{tabular}{|c|c|c|c|}
\hline $\begin{array}{l}\text { Economic data } \\
\text { (renewable vs. non- } \\
\text { renewable heating } \\
\text { technologies }\end{array}$ & Ecological aspects & $\Rightarrow$ & $\begin{array}{l}\text { Transformation to economic data } \\
\text { for B2C concepts (samples) }\end{array}$ \\
\hline $\begin{array}{l}\text { Efficiency rate } \\
\text { Reliability of the } \\
\text { system }\end{array}$ & $\begin{array}{l}\text { Eco-sensitivity } \\
\text { (greater social } \\
\text { context, depollution, } \\
\text { carbon foot print) }\end{array}$ & $\Rightarrow$ & $\begin{array}{l}\text { - Tax advantages } \\
\text { - Buy back tariffs } \\
\text { (photovoltaics) } \\
\text { - Incentives }\end{array}$ \\
\hline \multirow{4}{*}{$\begin{array}{l}\text { Breakdown (lifetime) } \\
\text { of the system } \\
\text { Oil and gas prices } \\
\text { Amount of investment } \\
\text { Financial resources } \\
\text { (prioritisation) } \\
\text { Long-term availability } \\
\text { (protection of supply) } \\
\text { B2C } \\
\text { (financing, payback } \\
\text { tariffs) }\end{array}$} & References & $\Rightarrow$ & $\begin{array}{l}\text { Statements about economic data } \\
\text { (e. g. experiences, operating costs, } \\
\text { profitability, protection of supply) }\end{array}$ \\
\hline & $\begin{array}{l}\text { Eco life cycle of } \\
\text { products } \\
(\text { e.g. panels })\end{array}$ & $\Rightarrow$ & $\begin{array}{l}\text { Transparent information } \\
\text { (cost for disposal of wastes, } \\
\text { what is real, what are rumours) }\end{array}$ \\
\hline & $\begin{array}{l}\text { Sophistication of } \\
\text { technology (location } \\
\text { context on-site, } \\
\text { handling objects for } \\
\text { new technologies) }\end{array}$ & $\Rightarrow$ & $\begin{array}{l}\text { - References } \\
\text { - Consultancy } \\
\text { (e.g. cost and tax advantages) } \\
\text { - Long-term aspects } \\
\text { (e.g. amortisation, operating costs) }\end{array}$ \\
\hline & $\begin{array}{l}\text { Scope of information } \\
\text { on optional } \\
\text { renewable heating } \\
\text { plants }\end{array}$ & $\Rightarrow$ & $\begin{array}{l}\text { - Transparency and comparability of } \\
\text { the data } \\
\text { - Cost allocation for the purchase of } \\
\text { technologies } \\
\text { (B2C concepts) } \\
\text { - Prioritisation with other greater } \\
\text { investments } \\
\text { (e.g. house insulation) }\end{array}$ \\
\hline
\end{tabular}

Table 11: Economic vs. ecological data on decision-making processes (own study) 


\section{c. Influence of early impressing information on the decision-making process}

The following three coding structure properties have been considered: (1) 'Information sources'; (2) 'Gut feeling'; and (3) 'Decisiveness'.

\section{(1) Information sources}

In Chapter 5.4.3, on information sources, the interviews highlighted that some interviewees had been influenced by positive or negative information. In case of negative experiences related to certain renewable heating technologies, these technologies were then 'faded out' in end users' further consideration of a possible purchase. Another aspect related to the consideration and importance of information was that all information is not the same. There is passive information which does not channel a clear intention regarding its evaluation; there is also active and concretely acquisitioned information. Finally early impressing information, which occurs chronologically before the classical decision-making process, begins with active gaining information. Therefore, this early information may affect motivation to deal with renewable heating technologies. Bernard et al. (2006) and Heckhausen \& Heckhausen (2010) mention motivation in the context of a powerful behaviour; in other words, it is goal driven. Motives, therefore, represent guide behaviours and interests in social domains.

The exploration of motives expressed during the interviews demonstrated that decisions on heating technologies (whether renewable or not) are planned in the long-term and are very much focused on economic issues. Perceptions are, therefore, already commonly formed before the classical information acquiring process starts, as part of the stepwise and rational approach. In some cases, influencers, such as consultants or heating plant installers, may have an effect on the approach taken as bounded rational influences. Economic aspects in the form of decision-making criteria are stable until the end of the decision-making process. Individual concepts may change depending on the personal engagement of end users with certain concepts, and depending on the stage of information.

\section{(2) Gut feeling}

The factor 'gut feeling' is also important when considering already received information. Bernard et al. (2006) mention gut feeling in the context of behavioural strategies for motives and trigger emotional responses in stable consciousness through searching memories. These emotional responses are related to experience as gut feelings. They 
focus attention on positive or negative outcomes. Khatri \& $\mathrm{Ng}$ (2000) express gut feeling as a strong feeling about the decisions, which is finally made without any base other than a deep and intimate knowledge related to the decision-maker's experience of the situation.

Therefore, past experience and events may influence the evaluation process by with respect to whether or not to consider certain criteria for the purchase of renewable heating technologies. For example, decision-makers have mentioned observing their neighbours' negative experiences with certain heating technologies (e.g. the reconstruction of the garden to extract water for thermal pumps, work to stack wood blocking).

\section{(3) Decisiveness}

Another influencing factor is decisiveness. Bearing in mind the character of decisionmakers, an important aspect to consider is the amount of information which they use in order to reach their decision. Transparency means comprehensive and comparable data, which enables decision-makers to form an opinion on whether or not to purchase renewable heating technologies. End users miss or appreciate a certain level of data volume. However, they commonly desire transparent information during the decisionmaking process.

Thus, additional information may be used to re-evaluate existing and older information, which has not yet been considered. This information may, therefore, serve to re-evaluate possible former positions of homeowners against the purchase of renewable heating technologies (Figure 10). Stakeholders apart from homeowners, as involved participants in the heating market, are required to provide transparent information, political frame conditions, and B2C models to support this purchase. Data arguing for renewable heating technologies in order to design relating concepts are the responsibility of managerial stakeholders, such as manufacturers, providers and authorities (governmental laws).

\section{Enlarged context of transparency and trust}

In different interviews, and especially in Chapter 5.4.4 on 'Decisiveness', transparency was mentioned in the context of available information as part of the decision-making process. In contrast, trust and significant information from references (humans) were individual factors, influencing decision-making. 


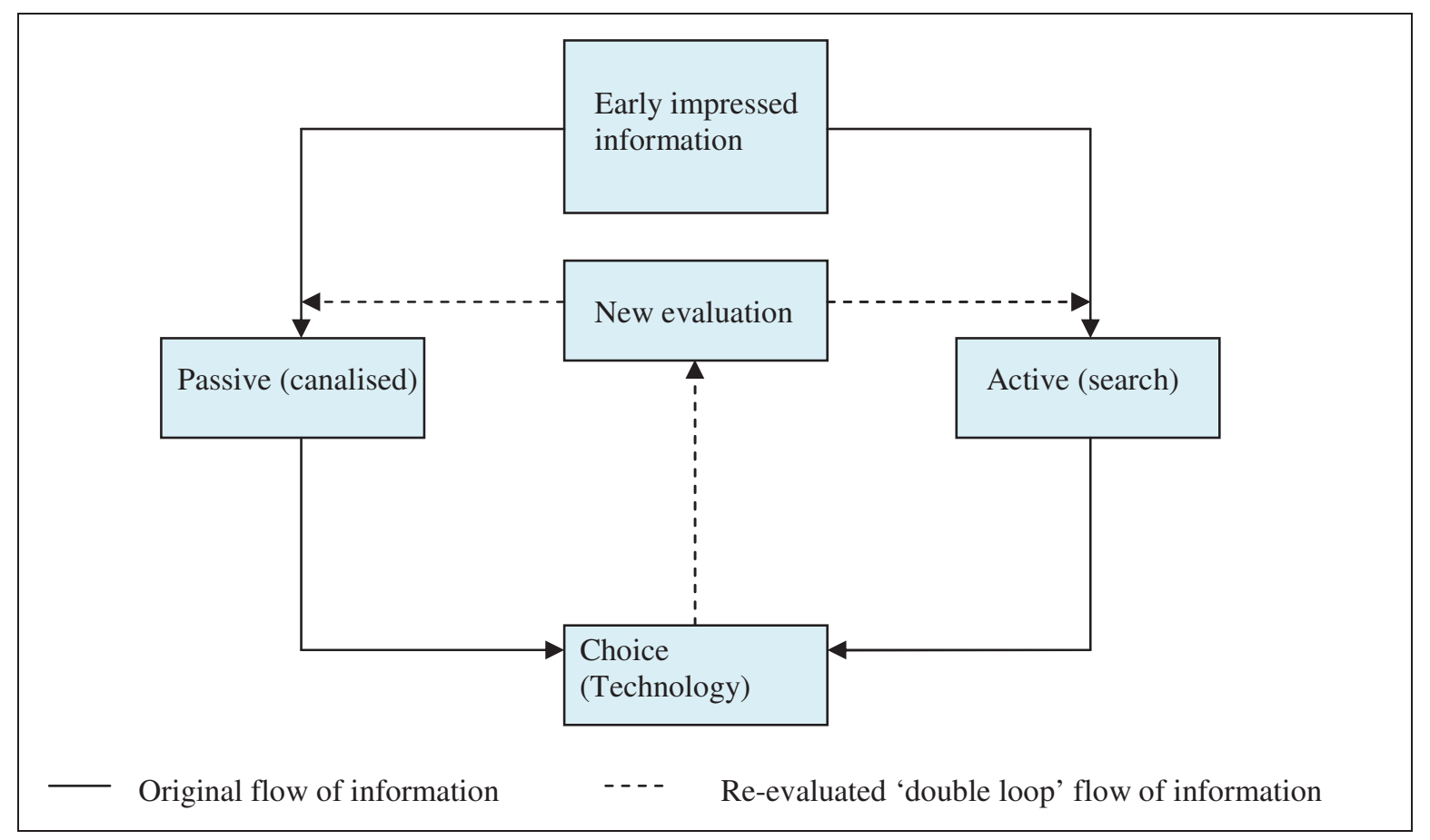

Figure 10: Influencing stages on the decision-making process

Source: The author, based on Bennet \& Bennet (2008), Mintzberg, Raisinghani \& Theoret (1976)

Lousberg \& Noorderhaven (2014) links transparency with a perception of clarity, disclosure and accuracy. His research is focused on an organisational exploration of public private partnerships (PPP) and their development, e.g. on contractors in urban development projects. This exploration also indicates a close connection with other B2C aspects, as does this research work.

Palanski, Kahai \& Yammarino (2011) examine transparency in their consideration of cooperating teams as information and explanations, which have to be shared. They enable their members to carry out their responsibilities. With respect to $\mathrm{B} 2 \mathrm{C}$ aspects and renewable heating technologies, transparency can be viewed as contributing towards the purchase of these technologies; it is the responsibility of B2C related stakeholders, such as manufacturers, authorities, and providers, to make relevant information available.

In contrast, with reference to trust, Rousseau et al. (1998) conclude their literature review by indicating that trust is related to dispositions, decisions, behaviours, social networks, and institutions. They define trust as follows (p. 395):

'Trust is a psychological state comprising the intention to accept vulnerability based upon positive expectations of the intentions or behavior of another.' 
They connect trust with risk-taking and reliance. It is not a behaviour, but a psychological condition. Trust is seen as a substitute for control, reflecting a positive attitude about another's motives. However, trust can take different forms in relationships, from a calculated weighing of perceived gains and losses, to relational trust, based on relationships and emotions which reflect on reliability and dependability.

Glyn et al. (2017) focus on shared decision-making in the context of healthcare decisions. Their research on wider engagement of relevant stakeholders requires their consultation to achieve shared decision-making. It demands shifts in the power and control of interactions. Trustworthy information is required in the decision-making process.

It can thus be summarised that transparency represents circumstances which enable decision-makers to have comprehensive data for decision-making, while trust stands for a behaviour related influencing factor, reflecting on calculative (rational) and relational (bounded rational) issues. With respect to this work, they shall not be considered as separate theoretical indicators. The weighting of their influence on behavioural aspects depends on character related aspects of decision-makers and is already considered, in the codes 'Gut feeling' and 'Decisiveness', as a bounded rational influencing factor on decision-making.

In order to re-evaluate information by means of causes, conditions, and consequences, early obtained and influencing information has to be provided again and to be enriched for end users as decision-makers. A context is given to feedback loops. Bennet \& Bennet (2008) consider feedback loops as self-reinforcing or damping, improving a situation or making it worse. Mintzberg, Raisinghani \& Theoret (1976) call them comprehension cycles. They cycle back to earlier phases to recognise the issue or to understand consequences and alternatives.

Therefore, the positive information must reach the decision-makers, and stakeholders in the B2C market and politics are required to 'provide' the information with arguments and concepts. Transparency is required to make information available at an early stage in the decision-making process or before it, in the motivational stage as opinion-forming.

The Government Office for Science (2015) mentions artificial intelligence by governments to make decisions more transparent, e.g. by capturing digital records and visualising data. More data will help officials to inform decisions. However, they 
confirm that a 'human in the loop' must be involved in autonomous decision-making when using algorithmic processes.

\section{d. Accelerating factors on decision-making}

The analysis in Chapter 5.4.2 and 5.4.4, about motivation and character related decisionmaking aspects, pointed out that the decisions on heating technologies are taken longterm. The evaluation of options which are expected to contain large investments takes time.

All interviewed decision-makers commented that they do not make decisions under pressure. The decision-making process was thus very structured; it did not involve damping factors as decision-making stages, nor did it include the review of elements that were considered to have been completely wrong. However, interviewees strongly emphasised the importance of economic factors. Their motivation was driven by availability of monetary resources and the degree of priority in relation to other investments in the home. Therefore, decisions will likely be accelerated when heating solutions are regarded as being cheaper in comparison to other solutions or in the context of the availability of homeowners' financial resources.

The decision-making process may thus be shortened, if relevant economic information about heating concepts is made available to end users. In relation to regulating aspects, consultants can play a major role in prioritising certain concepts over others at an early stage in the decision-making process (Figure 11):

Nowadays, consultants are optionally involved. Their honorary cost can then be covered by governmental supported incentives (reference: KfW, ENEV in Chapter 4.5.2). Two factors, which may strengthen their position, are identified below:

(1) Soft aspects: to encourage end users to accept them as independent and non-bounded to the interests of providers and manufacturers. Campaigns on this issue and accredited standards on their role and training will be necessary.

(2) Hard aspects: an instructive regulatory involvement may support knowledge of different renewable heating technologies and their purchase.

This involvement of consultants should take place before the comprehensive and longterm information gaining stage by end users. Thereafter, a stronger follow up and more directive realisation with engaged installers and other authorities may take place. 


\section{Stage}

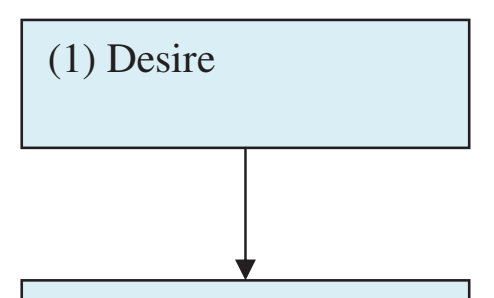

(2) Priorities

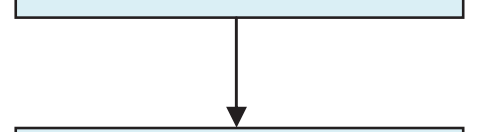

(3) On-site Situation

(4) Secondary data (aware)

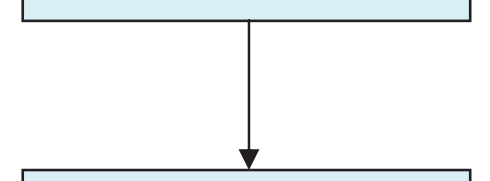

(5) Installers involved

(6) Other stakeholders

optional

(7) Energy consulters

(8) Decision

\section{Influences / Requirements (monetary)}

$\rightarrow \quad$ transparency of information about benefits

$\rightarrow \quad$ time to decision

$\rightarrow \quad$ motivation to proceed

$\rightarrow \quad$ availability of money (running cost, invest)

$\rightarrow \quad$ volume of invest (information $\rightarrow$ motivation)

$\rightarrow \quad$ future: early involvement of consultants

$\rightarrow \quad$ transparency of information about all options

$\rightarrow \quad$ statements about technical concept

$\rightarrow$ relations, providers... (campaigns)

$\rightarrow$ today: voluntary involvement of consultants

$\rightarrow \quad$ so far only particularly involved

$\rightarrow$ evaluation

$\rightarrow \quad$ (possible) purchase of technology

--- shortcut (early involvement of consultants)

Figure 11: Accelerating decision-making factors for end users (own study) 
BSR (2016) argues that stakeholder engagement must integrate stakeholder feedback and input to become more collaborative, inclusive and strategic. A deep understanding of stakeholders and a proactive response to their needs is required.

This observation is therefore related to structural issues in the political context and addressed to governmental authorities. The obligatory involvement and valorising of consultants may improve transparency at a very early stage in the decision-making process for decision-makers and contribute to the shortening of decision-making stages.

\section{e. Age as a decision-making factor}

The question is grounded in the fact that houses with old heating technologies are commonly old houses and are expected to be mainly owned by middle aged or elderly people, when not sold to younger people. Nevertheless, the purchase of old houses by new (young) owners requires certain investments in insulation and heating standards, as indicated in Chapter 4.5.2.

The interviewees did not confirm any differences in dealing with renewable heating concepts based on their age. However, age is expected to indirectly influence the motivation for a purchase due to the importance end users attribute to economic factors. As the decision-maker's interest in return on investment is inversely proportional to age; the effect is that the older the end user, the less willing they will be to purchase new expensive heating technologies.

\section{f. Role of stakeholders in the purchase of renewable heating technologies}

With respect to renewable heating technologies, authorities, manufacturers, and providers are identified as stakeholders from the end users' viewpoint in the heating market (Chapter 5.4.6 and 5.4.7).

Freemann (1994) defines stakeholders as any group or individual that can effect or is affected by the achievement of a corporation's purpose. More concretely, Mitchell, Agle \& Wood (1997) qualify persons, groups, neighbourhoods, organisations, institutions, societies, and even the natural environment as actual or potential stakeholders.

Mitchell, Agle \& Wood's (1997) statement, that stakeholders' attributes are variable and not steady, is important. These attributes are socially constructed and do not contain an objective reality. Thus, the authors indicate personalised criteria. 
The role of stakeholders has been pointed out by Bryson (2004) who differentiates between weak and strong supporters as well as weak and strong opponents to find winning coalitions. Explanations and consideration of this categorisation have already been given as part of the conceptual framework (Chapter 5.6). In addition, the following criteria are mentioned, by means of the data analysis, in relation to the purchase of renewable heating technologies:

(1) Strong supporters definitely support the DMP on renewable heating technologies.

(2) Weak supporters may, but do not necessarily, support the DMP on renewable heating technologies.

(3) Strong opponents definitely prevent DMP on renewable heating technologies.

(4) Weak opponents may but do not necessarily the DMP on renewable heating technologies.

(5) Question marks may exert influence for or against the purchase of renewable heating technologies (new term separate from the term 'neutral' stakeholders, which was derived from the conceptual framework and associated with no influence).

In this context, 'support' stands for encouraging the purchase of renewable heating technologies within the stepwise decision-making process. Relevant stakeholders in the renewable heating market are as follows (Figure 12):

(1) 'Strong supporters' represent sophisticated technologies by manufacturers, cheap technologies, suitable on-site integration, (economic) buy-back tariffs (photovoltaics), and, in general, clear (comparable) and transparent data by stakeholders arguing for renewable heating technologies. Their data is rational-related.

(2) 'Weak supporters' represent promotions / incentives by authorities, (absent awareness of) concepts of municipalities, personalised references, ecological aspects and laws (noninstructive guidelines). They are rational and bounded rational related influencing factors. However, they are only optional aspects as they are not appreciated strongly enough by end users or the corresponding messages behind them are not convincing enough for homeowners (e.g. amount of incentives). Above all, B2C concepts and modified rules are required to change the role of weak supporters to strong ones.

(3) 'Strong opponents' represent non-renewable and cheaper heating technologies by manufacturers, compared to renewable heating technologies. This factor is rational related; due to weaker ecological thinking, but stronger cost-effectiveness thinking, 
single end users are prevented from purchasing renewable technologies. Unsophisticated technologies reflect more on bounded rational criteria. They stand against gut feeling and decisiveness due to missing information and experience in relation to certain new renewable heating technologies.

(4) 'Weak opponents' stand for aspects which do not prevent end users from dealing with and purchasing renewable heating technologies: insulation standards are also high domestic investments, as are heating technologies. However, their prioritisation in relation to new (renewable) heating technologies is defined by the necessity of these investments (above all reliability of old heating system). Both types of investment insulation and heating technologies - are related to rational and economic data. Insulation can be purchased, however, non-reliable heating systems must be exchanged. Social norms, as a bounded rational issue linked to peer pressure, e.g. to regard renewable heating technologies as a status symbol, cannot be confirmed as a pressurising factor.

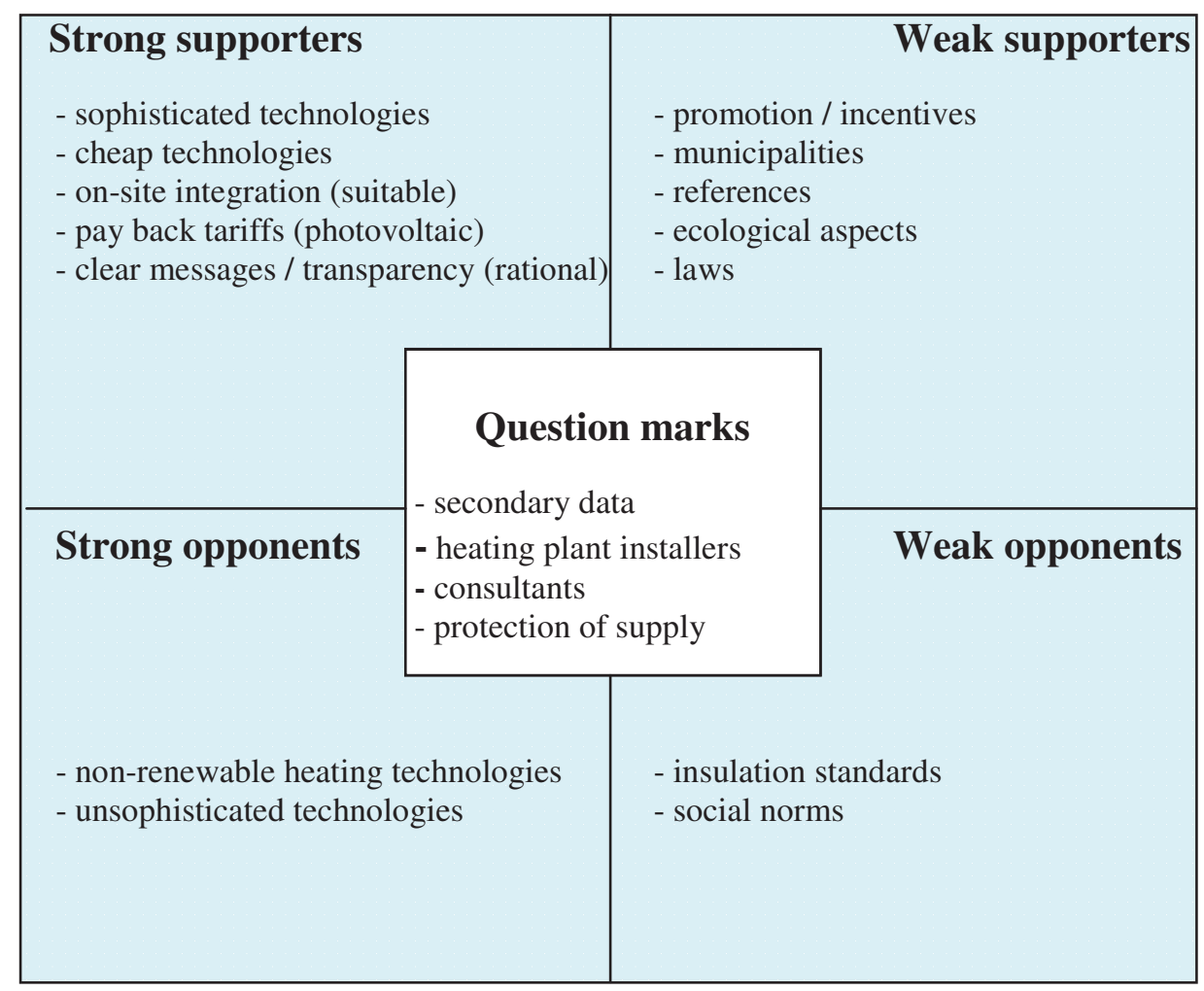

Figure 12: Meaning of involved decision-making factors (own study in the style of Bryson, 2004) 
(5) 'Question marks' representing statements and positions in secondary data and by heating plant installers and consultants may argue for different (renewable) heating concepts. Protection of supply stands for gut feeling and decisiveness, essential information is required for end users to form an overall picture, so that they feel wellinformed and make the 'right decision'. The way end users feel, depends on their insights and personal evaluation of heating technologies.

The final conceptual framework identifies bounded and rational bounded influencing factors and the role of different involved stakeholders. The framework identifies required statements they must make in order to influence end users as decision-makers. As personal insights of decision-makers cannot be changed, relevant information has to be provided by the stakeholders, as influencing factors, within the decision-making process of end users. These aspects mainly reflect on figure and economic related B2C concepts (addressed to heating plant manufacturers and installers, their interest groups and providers) and restricting or promoting rules from the political authorities, also involving greater involvement on the side of consultants.

However, personalised gut feeling and decisiveness, in the form of trustfulness about the situation, will affect choices related to renewable heating technologies by end users, when rational and financial aspects based on transparency of the information do not already lead to a decision output - action and purchase of renewable heating technologies.

\subsection{RESPONSE ON RESEARCH QUESTIONS}

Based on the data analysis and data discussion (Chapter 5 and 6), the research questions of Chapter 1.4 can be answered as follows, reflecting on rational and bounded rational issues, as pointed out in Chapter 6.1:

\section{RQ 1: What are the specifics of existing renewable heating technologies and their usage from the perspective of consumers?}

From a technical point of view, greater common specifics or focus on one certain renewable heating technology cannot be confirmed. Heating technologies are related to the individual on-site situation in houses. End users are not usually aware or appreciative of the possibility for $100 \%$ coverage of heating demand through renewable heating 
technologies. Combinations may include sophisticated technologies, such as thermal heating pumps with photovoltaic, or solar heating with wood pellet ovens.

As the evaluation of more significant purchases is very strongly affected by economic and goal-orientated rational aspects, combinations may also include renewable heating systems with non-renewable ones, such as oil or gas heating systems, to cover the complete demand.

However, technical solutions may influence end users due to personal and bounded related factors, as the on-site situation is considered a given. The availability of monetary resources and prioritisation of investments, expressed as a necessity, were mentioned as factors which affect end users' decisions related to the purchase of renewable heating technologies at a certain point in time. Furthermore, influences from references and their statements, as involved people in a familiar or B2C context, may be given. In addition, personal experiences or information in the environment of end users may influence the decision through, for example, gut feeling (Khatri \& Ng, 2000). The interpretation of information is limited and thus contrasts the concept of assumed rational and completely informed decision-makers in idealised circumstances.

Proposition 1: Decision-makers should not be 'bounded' by limited information. Involved managerial stakeholders are required to ensure a comprehensive and transparent information policy. Stakeholders consist of authorities with respect to political instruments, and manufacturers, heating plant installers, distributors and their interest groups with respect to renewable heating systems and involving B2C concepts.

\section{RQ 2: What are the motives of consumers for the purchase of existing renewable heating technologies?}

Core motives constitute figure related aspects, such as economic data, on whether a purchase will be profitable or not. Aside from these rational related influencing factors, bounded rational issues have to also be taken into consideration.

Ecological motivation for the purchase of renewable heating technologies plays a role for some end users; however, it is viewed more as 'nice to have'. Ecological information is above all focused on a broader social and political context (e.g. environmental protection), so it is bounded rational, rather than centring on the individual situation onsite. Ecological data may reflect on economic aspects (Table 11), such as incentives or 
buy-back tariffs related to the purchase of these technologies, but does not necessarily do so.

Security of supply, as a gut feeling, is an important influencing factor when considering new heating technologies with respect to preventing possible shortages in own distribution, or expected increases in non-renewable fuels, such as oil and gas. Motives are, therefore, focused on long-term decisions and a processual decision-making approach. They also consider the necessity of such large expected investments based on own financial resources of end users. Although motives are not directly dependent on end user age, they are indirectly related to this factor, as they will evaluate the purchase of renewable heating technologies based on their period of amortisation.

Proposition 2: The preparation of figure related and contextualised information is the most important aspect for end users in the purchase of renewable heating technologies. Transparency of information is required for end users to compare necessary data. Involved stakeholders such as responsible politics (political strategy as a whole), authorities, manufacturers, distributors, and interest groups should ensure the preparation of comprehensive information with comparable economic data. Furnishing of economically orientated ecological data can serve as an 'amplifier' for economically motivated decisions. Decision-making approaches related to technological breakdowns, which require urgent decisions, are not considered.

\section{RQ 3: How do the specifics of existing renewable heating technologies affect consumer choice of a specific technology?}

The economic data is the most important rational related factor with respect to renewable heating technologies as possible alternatives to the technology in use. However, the onsite situation related to the instalment of new technologies plays a big role as well. For example, the availability of space to integrate a storage room for a wood pellet system is mentioned as a significant point for consideration, as is the suitability of the roof whether it is well-adapted for installation of solar or photovoltaic systems. Though photovoltaic systems are not immediately related to heating technologies, they may be considered as possible options in combination with thermal heating pumps or may be used to cover own electricity demand. In this case, they may even prevent the investment in renewable heating technologies, at least at an early stage of replacements in old houses. 
Sophisticated technologies and a gut feeling about the protection of supply of already confirmed and applied technologies by references are important factors for end users. This issue falls within the category of bounded rational aspects and relates to the available information which is considered by end users when they are forming their opinion. In contrast, rational decision-making models assume transparent information for well-informed decision-makers.

Proposition 3: apart from the important economic aspects, end users have to be aware of all possible heating solutions and their combination, in addition to individual bounded related decision-making factors, such as bad or good experiences about certain technologies or the influences of references, for example, neighbours or relations. Transparent and comprehensive information is required to close the information gap.

Supply of information is the responsibility of politics through designing frame conditions, and involved stakeholders through B2C concepts.

\section{RQ 4: What are stages through which consumers go through in order to reach a final decision on the purchase of an existing renewable heating technology?}

Positive or negative experiences based on 'external' information sources, such as neighbours or friends, can have amplifying or weakening effects on end users in relation to their decision on the possible purchase of renewable heating technologies. The heating technologies in question will either be considered more closely or ignored. Therefore, a certain pre-evaluation of heating technologies, whether conscious or unconscious, means that 'opinion-making' may already take place before the decisionmaking process. This stage stands for motivation as a decision-making aspect, which occurs prior to the information gaining as an active decision-making stage that contains the classical rational and stepwise decision-making process. Bernard et al. (2006) relate motivation to human beings initiative, choice and persistence in particular behaviours and environments. Motives can then be categorised as purposeful behaviours aimed at solving problems in a particular social domain.

In this context, decision-makers do not take pressurised decisions on high investment (renewable or non-renewable) heating technologies. The process takes place over a longer period of time in the form of a process. Loops, delays or interruptions (Bennet \& Bennet, 2008) by engaged stakeholders cannot be confirmed. Therefore, the stages of searching for alternatives and their evaluation cannot be separated, as these are stages 
of interaction within a similar timeframe and may be related to personal and bounded rational aspects, like involved heating plant installers (e.g. partner of trust for maintenance of existing heating system).

The early engagement of consultants based on their independent accreditation or awareness may shorten the decision-making process when transparent data is prepared by them for end users. The engagement of additional information from heating plant installers or providers could then be reduced (Figure 11).

Proposition 4: End users' awareness of transparent information is required to support the purchase of renewable heating technologies with comprehensive data, which points out the advantages of renewable heating technologies. Instead of engaging different information sources, decision-makers can thus channel and filter the 'right' information about renewable heating technologies at a very early stage. This information can reduce evaluation time and possibly result in end users ignoring 'wrong' and misleading information. More direct and formal information may shorten the decision-making approach. Thereby, consultants could play a greater role, when they are considered as independent experts and their apprenticeship is attested. Politics and responsible authorities should be required to ensure rules and transparent data. In contrast, information from references (human beings), such as neighbours or heating plant installers represent relational and bounded rational influencing factors and their evaluation depends on the individual homeowner.

RQ 5: How do consumer-related, technology-related, and provider-related factors affect consumers in the various stages of the decision-making process for the purchase of an existing renewable heating technology?

Reference is made to the three questions as subordinated criteria for the stages.

\section{Consumer-related factors}

Consumer-related factors are very much focused on economic data and the availability of financial resources. Economic issues signify figure related and comparable data. They are evaluated with clear goals related to which technology may be most profitable. Therefore, they are focused on rational decision-making factors. The assessment of renewable heating technologies also considers long-term aspects of their application. This decision-making approach stands for processual and stepwise procedures and thus rational related decision-making approaches. 
However, bounded rational factors are involved; for example, advice from friends, own experiences, the meaning of trustful consultancy, and gut feeling all influence the end user to reach a 'right' decision. The evaluation of the decision-makers' statements reflects on personal insights. These bounded rational factors assume that there is "no absolute truth' (Easterby-Smith, Thorpe \& Jackson, 2012), when referring to constructivists' approaches of different views. End users evaluate these issues through the perspective of different personal backgrounds gut feeling and decisiveness, which again reflect on aspects like experiences or reliability of technologies.

In contrast to these bounded rational factors, dominating economic data in the $\mathrm{B} 2 \mathrm{C}$ context can be conceptually pointed out to end users by involved stakeholders, in order to make end users aware of this information. With respect to investments, the following factors are mentioned (AEE, 2016/1): consumer related cost (fuel, electricity tariffs), operating related cost (maintenance, insurance), capital related cost (life of a loan, interest rates) and investment cost (plant, connection fees).

\section{Technology-related factors}

Technology-related factors are mainly bounded rational related and are associated with whether a certain technology is accepted or not, and whether it is sophisticated and reliable. The interpretation of the security of supply as reliability or desired daily involvement may play an additional role.

Transparency and awareness of data is important, as the possible 100\% coverage of heating demand with renewable heating technologies is not usually an aim for end users. A broader political environment for or against certain technologies may influence the decision output and cause the purchase of combined solutions with non-renewable heating technologies, such as oil and gas fired systems.

Decisions may be limited due to the on-site situation, such as limitations for the installation of photovoltaic or solar systems (instability of roof) or required space for wood pellet systems. This means that this technology is most suitable for end users who are replacing existing oil fired systems in their home due to available storage room after removal of tanks.

Prioritisation of other domestic investments, such as heating insulation to reduce heat consumption, over the installation of new heating technologies may also be evaluated. 


\section{Provider-related factors}

Provider-related influences should be amplified in a positive way with respect to the purchase of renewable heating technologies by heating plant installers, manufacturers of heating technologies as an 'extended workbench', consultants and authorities with political instruments in a greater $\mathrm{B} 2 \mathrm{C}$ context. Campaigns, information policy and rules to support or prevent renewable heating technologies, or to make non-renewable heating technologies more expensive, are also important factors. Manufacturers, their interest groups, providers and politics may be required to design new financing models to make renewable heating technologies more attractive, also in the context of prioritisation of other domestic investments. These economic and stakeholder related issues reflect on rational and bounded rational influencing factors.

A leading German agency points out in its literature review of scientific reports (AEE, 2016/2) that different instruments may support the increase in purchases of renewable heating technologies. In addition to greater macro-economic aspects, they also refer to micro-economic factors in which end users shall be involved.

Economic instruments represent stronger promotion programs and even a higher price policy for non-renewable fuels.

Administrative regulations signify laws as instructions and prohibitions. Stronger regulations for the application of renewable heating technologies are mentioned, such as refitting of existing heating technologies in use, and even prohibitions of certain nonrenewable technologies, by rendering these technologies more expensive through recommendations for higher oil and gas prices.

Planning and soft instruments represent political aims and the provision of data. Information campaigns are one important instrument.

Proposition 5: In a broader context, politics should establish the field of activity and frame conditions for the renewable heating market. In a narrower context, the involved stakeholders in the B2C context (providers, manufacturers, heating plant installers and interest groups behind) should design new or modified business models. Information and financing instruments may be two aspects. Financing models involve minimising or preventing the investment as expenditure for end users, instead of allocating the amount regularly, e.g. monthly, on a certain runtime or as a supplement to the energy consumption cost. 
An overview of all aspects is given in Table 12:

\section{Influencing decision-making factors}

\begin{tabular}{|l|l|l|l|}
\hline \multicolumn{2}{|l|}{ How and Why } & \multicolumn{2}{l|}{ What } \\
\hline Rational & Bounded rational & Technology & B2C / Politics \\
\hline - step-wise & - awareness of data & - combination of & - financing models \\
approach & (transparency, point in time) & concepts to cover & - higher incentives \\
- economic data & - references (human beings) & demand & - campaigns \\
- long-term & - gut feeling & (information policy) \\
decision & (reflection on experience, & on-site & - rules \\
- own financial & reliability of technology, & - involved handling & - price policy non- \\
resources & consultancy) & renewable fuels \\
- necessity of & - decisiveness & - compulsory \\
adoption & (volume and content of data) & & consultancy \\
- volume of data & - eco-sensitivity & - accredited consultants \\
& - prioritisations & - Internet / print media \\
\hline
\end{tabular}

Table 12: Influencing factors on the purchase of renewable heating technologies (own study) 


\subsection{REFLECTION ON CONTRIBUTION TO KNOWLEDGE AND PROFESSIONAL PRACTICE}

\section{Contribution to decision-making theory:}

The research points out that decisions on the purchase of renewable heating technologies are considered using a long-term, stepwise approach. Clear goals are in focus with respect to a desired economic solution. These aspects stand for rational related decisionmaking factors. However, bounded rational related influencing factors, such as ecosensitivity and the meaning of involved stakeholders (e.g. friends, neighbours, manufacturers, heating plant installers, and distributors) form part of the processual approach. Decisions regarding renewable and non-renewable heating are not taken under pressure.

Therefore, the research indicates that the decision-making process relies chronologically on an initial rational decision-making model, with bounded rational influencing factors. In the end, the interpretation of information to reach a decision is limited; it is not in line with the idea of completely informed decision-makers, as rational decision-making models assume. Decision-makers also decide based on their intuition, experience, advice from others or creative thoughts - bounded rational related factors. Eisenhardt \& Zbaracki (1992) relate cognitive limits to boundedly rational decision-making. Wilson (2010) indicates that decisions become framed and bounded due to different connections.

More complex strategic decision-making processes are contextualised to long-term aspects (Nutt \& Wilson, 2010; Mintzberg, Raisinghani \& Theoret, 1976). Purchases of renewable heating technologies are distinguished by higher purchase prices and require longer planning periods compared to consumer products for daily requirements. Issues, such as financing, influence on the cash-flow budget of end users and the reliability of the chosen solution in the field of renewable heating technologies have to be evaluated carefully. Thus, they are related to strategic decision-making processes which are new and not related to routines (Morris, Greenwood \& Fairclough, 2010).

The involvement of participants in the B2C context, such as relations, manufacturers, heating plant installers or providers, emphasise the comprehensive decision-making process. These groups or persons are qualified as actual or potential stakeholders (Mitchell, Agle \& Wood, 1997). 
The decision-making process is not only related to rational and bounded rational factors during or at the beginning by gaining and accumulating information. Motives are closely related to the behaviour of consumers and influenced by their needs. Bernard et al. (2006) define motives in the context of wider motivation. They are purposes, which a person has taken and follows; thus, they are personalised. Edelmann (2003) mentions motivation as activating processes. Heckhausen \& Heckhausen (2010) argue that motives pursue behaviour to activity in an individual and personal context.

Some of the authors referred to in this work encompass motivational aspects in different contexts. Motivational processes are contextualised to goals, inspirations and finally changes in action as decision outcomes and part of behavioural processes (Mark \& Henry, 2004). Behavioural achievement depends jointly on motivation (Ajzen, 1991). Decision-making is characterised in the context of relationships with customers, suppliers and competitors. They are determined by the decision maker's motive (Elbanna, 2011). Deep structuring of reality under consideration of practical consciousness and the conscious process of making commitments (Heideggerian approach) is reasoned in various purposes, such as motivation (Tsoukas, 2010).

I claim to consider the decision-making process in a greater context by contextualising motivational factors to the decision-making process. More concrete motives are the starting point of the stepwise decision-making approach for the purchase of renewable heating technologies.

\section{Managerial and policy implications for the use of renewable heating technologies:}

Transparency of information to point out the economic advantages of renewable heating technologies has to be indicated to decision-makers as end users. Shared decisionmaking empowers interactions (Glyn et al., 2017). Aside from this rational related aspect, decision-making processes of end users are bounded due to their gut feeling based on experiences and decisiveness in the context of sufficient data, and the awareness of ecosensitivity. The availability of data in order to evaluate information is essential. The data and deviated consequences to stronger purchase renewable heating technologies for end users should be strongly reflected in the development of B2C models and political instruments and thus be addressed by managers of involved manufacturers, heating plant installers, distributors, their underlying interest groups and politics. 
More concretely, ecological data should be linked to economic issues, which will act as an 'amplifier' to increase the motivation for purchase. Campaigns of distributors and manufacturers, and financing models may be supporting factors applied by these stakeholders, enabling end users to spread the investment over a longer period of time. Public financing models must be more attractive due to low public interest rates, and for promotions due to the existing poor share.

Hard political instruments may result in a more expensive price policy for non-renewable fuels, or even in stronger prohibitions on corresponding technologies.

It will be important to consider concepts where combined heating technologies contain different renewable solutions to cover the complete domestic heating demand through a combination of renewable heating technologies, instead of a combination with oil or gas fired systems.

\section{Social implication:}

Although end users are strongly focused on economic facts, they are also sensitive to environmental protection in a greater social and political context, in addition to their individual situation about heating distribution in their house. Therefore, governmental policy is required to utilise this sensitivity with respect to economical renewable heating technologies. Climate change, eco-balance, environmental protection and long-term influences on the security of supply and price stability for heating distribution, stand behind these aspects. However, it has to be considered that restricting and more expensive concepts can influence the social climate in our society.

Personalised and individual aspects on-site and broader political decision-making factors have to also be considered. The statements of end users pointed out that the purchase of capital goods, like renewable heating technologies, depends on their necessity. Therefore, renewable heating technologies have to be affordable by homeowners over other investments. Political instruments and a stronger promotion may manage the purchase of renewable heating technologies by making renewable heating technologies cheaper or by making non-renewable heating technologies more expensive. A stronger involvement of consultants and more interesting promotion concepts may support the purchase. 


\subsection{LIMITATIONS AND IMPLICATIONS FOR FURTHER RESEARCH}

The research study, based on a qualitative approach, emphasises the role of rational and bounded rational decision-making factors in the purchase of renewable heating technologies. As Greener (2008) argues for qualitative research, data shall be understood and related to theory or ideas. In opposition to quantitative studies, findings and conclusions are not fixed in a set pattern and hypothetical questions.

Further investigations should consider key factors for B2C models. They should be addressed to stakeholders, focusing on the ways in which stakeholders can encourage increased purchase of renewable heating technologies by homeowners. A stronger evaluation of different heating technologies should take place and complete this social study. Case study research can investigate success factors of already realised local heat distribution on a municipal level.

Furthermore, psychological studies should investigate personal insights more closely (e.g. experiences, past influencing information, role of relations and other stakeholders) as bounded rational factors related to the reasons why certain decisions are taken or dismissed. The existing study is focused on decision outcomes.

Based on the existing methodological approach, credibility of the existing research should be strengthened by other qualitative studies examining greater overall themes (codes). Quantitative studies, taking into account key factors of qualitative studies, may confirm and enrich qualitative explorations by means of statistical data. Quantitative studies shall take into account that qualitative research assumes views and meanings sought by the researcher (Daymon \& Holloway, 2011). There is no absolute truth, therefore, qualitative studies require gathering views through different research methods (Easterby-Smith, Thorpe \& Jackson, 2012).

\subsection{CONCLUSION}

This work investigates the influencing factors for the purchase of renewable heating technologies by homeowners in older houses. This investigation of the decision-making process of end users is focused on existing heating technologies, not on possible future technologies which are not foreseeable. 
The methodology is based on a qualitative investigation by means of a grounded research approach. Semi-structured interviews ensure a discussion of the relevant key issues. Core questions, aimed at forming a theoretical concept, rely on the rational and bounded rational decision-making factors of the decision-makers.

The research identifies that rational and structural factors, very strongly related to economic benefits for end users, are the central-point of the decision-making process and motives. However, bounded rational factors also influence the decision-making approach.

Personal insights of the decision-makers cannot be exchanged and are considered a given. Bounded rational related factors, which can influence decision-makers towards a possible purchase of renewable heating technologies, are very much focused on the involved stakeholders, as well as other individual contextualisation, such as gut feeling.

Broadly speaking, responsibility is therefore placed on manufacturers, providers and consultants to design influencing B2C concepts, and on politics to ensure the "political frame'. As the decision-making process of end users is very strongly influenced by economic issues, comparable and transparent information in the $B 2 C$ context is necessary. An important question is: 'What is known?', in the consideration of information by end users in their decision-making process. Although decisions are taken over a long period of time and are not taken under pressure, awareness and substantial information may accelerate decision-making processes. Considering their weak influence from an economic point of view, stakeholders can amplify their message by connecting it with factors that are consistent with the rather rational approach of end users.

The research underlines that the motivation and willingness of end users to purchase renewable heating technologies can be enhanced through further research on business models in the $\mathrm{B} 2 \mathrm{C}$ context in order to realise the potential of these models. Other options to increase openness to renewable heating technologies will probably mainly focus on hard, regulative political instruments.

The research has highlighted interesting aspects thanks to the qualitative research approach, which shall be a motivation to continue further consumer related research on qualitative studies. Quantitative studies may confirm key questions for personalised decision-making factors of end users. In a wider social context, through awareness of these decision-making matters and influencing factors, politics and B2C concepts can 
play a role in minimising climate change and stabilising eco-balance through environmental protection. 


\section{APPENDIX I}

\begin{tabular}{|c|c|c|c|}
\hline $\begin{array}{l}\text { Context to } \\
\text { research topic }\end{array}$ & $\begin{array}{l}\text { Theoretical issues on } \\
\text { DMP }\end{array}$ & $\begin{array}{l}\text { Relevance for } \\
\text { further research }\end{array}$ & Author \\
\hline Meaning of DMP & $\begin{array}{l}\text { DMP is a set of action } \\
\text { factors with beginning \& end }\end{array}$ & $\begin{array}{l}\text { Activities are process } \\
\text { outcomes, DMP is } \\
\text { limited over period of } \\
\text { time }\end{array}$ & $\begin{array}{l}\text { Mintzberg, Raisinghani } \\
\text { \& Theoret (1976) }\end{array}$ \\
\hline Meaning of DMP & $\begin{array}{l}\text { DMP includes personal \& } \\
\text { organisational characteristics } \\
\text { with decision outcomes }\end{array}$ & $\begin{array}{l}\text { DMP in organisational } \\
\text { context with others } \\
\text { activities leads to } \\
\text { process outcomes }\end{array}$ & Franz \& Kramer (2010) \\
\hline Meaning of DMP & $\begin{array}{l}\text { DMP involves individuals } \\
\text { over period of time, } \\
\text { selection \& implementation } \\
\text { process with end point }\end{array}$ & $\begin{array}{l}\text { DMP in organisational } \\
\text { context with others, } \\
\text { stepwise approach, } \\
\text { DMP limited in access } \\
\text { to knowledge }\end{array}$ & Wilson (2004) \\
\hline SDMP & $\begin{array}{l}\text { SDMP to be seen in } \\
\text { organisational context with } \\
\text { plurality of human effort }\end{array}$ & $\begin{array}{l}\text { SDMP engages people } \\
\text { related to DMP of all } \\
\text { types of organisations }\end{array}$ & Nutt \& Wilson (2010) \\
\hline SDMP & $\begin{array}{l}\text { SDMP is related to long- } \\
\text { term consequences, } \\
\text { commitment to future action }\end{array}$ & $\begin{array}{l}\text { Decision to be reduced } \\
\text { to sub-decisions due to } \\
\text { complex situations } \\
\text { faced to DM }\end{array}$ & $\begin{array}{l}\text { Mintzberg, Raisinghani } \\
\text { \& Theoret (1976) }\end{array}$ \\
\hline SDMP & $\begin{array}{l}\text { SDMP is no routine, } \\
\text { context with organisational } \\
\text { resources }\end{array}$ & $\begin{array}{l}\text { SDMP engages people } \\
\text { and is substantial for } \\
\text { DM }\end{array}$ & $\begin{array}{l}\text { Morris, Greenwood \& } \\
\text { Fairclough (2010) }\end{array}$ \\
\hline SDMP & $\begin{array}{l}\text { SDMP is related to human } \\
\text { beings \& organisational } \\
\text { characteristics }\end{array}$ & $\begin{array}{l}\text { SDMP engages DM in a } \\
\text { structural context with } \\
\text { other people }\end{array}$ & Elbanna (2011) \\
\hline Rational DMP & $\begin{array}{l}\text { DM is completely informed, } \\
4 \text { steps as decision approach } \\
\text { to decision outcomes }\end{array}$ & $\begin{array}{l}\text { All information for } \\
\text { DMP assumed to be } \\
\text { available, } \\
\text { stepwise approach }\end{array}$ & Turpin \& Marais (2004) \\
\hline Rational DMP & $\begin{array}{l}\text { Rational DMP is perceptual } \\
\text { accuracy, organisations do } \\
\text { not fit that way }\end{array}$ & $\begin{array}{l}\text { Accurate information is } \\
\text { important, problems } \\
\text { must be solved by } \\
\text { means of experience, } \\
\text { evaluation \& } \\
\text { interpretations of } \\
\text { choices }\end{array}$ & $\begin{array}{l}\text { Weick, Sutcliffe \& } \\
\text { Obstfeld (2005) }\end{array}$ \\
\hline Rational DMP & $\begin{array}{l}\text { Rationality begins with facts, } \\
\text { values premises \& proceeds } \\
\text { to logical conclusion }\end{array}$ & $\begin{array}{l}\text { Rationality is a direction } \\
\text { in thoughts }\end{array}$ & Anderson (2002) \\
\hline Rational DMP & $\begin{array}{l}\text { DMP consists of different } \\
\text { steps until final action }\end{array}$ & $\begin{array}{l}\text { Stepwise approach, } \\
\text { cognitive limits require } \\
\text { process cycles \& going } \\
\text { deeper }\end{array}$ & $\begin{array}{l}\text { Eisenhardt \& Zbaracki } \\
\text { (1992) }\end{array}$ \\
\hline Rational DMP & $\begin{array}{l}\text { Rationality is simple, } \\
\text { bounded rationality is less } \\
\text { simple }\end{array}$ & $\begin{array}{l}\text { Assumptions of } \\
\text { rationality determine } \\
\text { behaviour, but bounded } \\
\text { rationality demands } \\
\text { knowledge \& human } \\
\text { abilities }\end{array}$ & Simon (1978) \\
\hline Rational DMP & $\begin{array}{l}\text { Rationality is action related } \\
\text { to desirable outcomes }\end{array}$ & $\begin{array}{l}\text { DMP constructed as } \\
\text { bounded rationality with } \\
\text { cognitive \& political } \\
\text { limits }\end{array}$ & Mori (2010) \\
\hline
\end{tabular}




\begin{tabular}{|c|c|c|c|}
\hline Rational DMP & $\begin{array}{l}\text { Objectivity is interpretation } \\
\text { of facts or conditions as } \\
\text { perceived without distortion } \\
\text { by personal feelings \& } \\
\text { prejudices }\end{array}$ & $\begin{array}{l}\text { Objectivity depends on } \\
\text { the observer's bounded } \\
\text { rational mind }\end{array}$ & $\begin{array}{l}\text { Daellenbach \& } \\
\text { McNickle (2005) }\end{array}$ \\
\hline Rational DMP & $\begin{array}{l}\text { DMP is decision under } \\
\text { certainty }\end{array}$ & $\begin{array}{l}\text { All information for } \\
\text { DMP assumed to be } \\
\text { available, } \\
\text { stepwise approach }\end{array}$ & Lunenberg (2010) \\
\hline Rational DMP & $\begin{array}{l}\text { DMP consists of different } \\
\text { steps until final action }\end{array}$ & $\begin{array}{l}\text { DMP is stepwise } \\
\text { approach }\end{array}$ & Turban (1990) \\
\hline Processual DMP & $\begin{array}{l}\text { Process orientation in DMP } \\
\text { is the way to reduce } \\
\text { importance \& uncertainty, } \\
\text { reflecting from outcomes to } \\
\text { the DMP }\end{array}$ & $\begin{array}{l}\text { Weighing preferable } \\
\text { alternatives }\end{array}$ & Anderson (2002) \\
\hline Processual DMP & $\begin{array}{l}\text { DMP related to context \& } \\
\text { process \& outcomes }\end{array}$ & $\begin{array}{l}\text { Research process } \\
\text { related to 'how' \& } \\
\text { 'what' to decide }\end{array}$ & $\begin{array}{l}\text { Papadakis, Thanos \& } \\
\text { Barwise (2010) }\end{array}$ \\
\hline Processual DMP & DMP is sequence of events & $\begin{array}{l}\text { Goal driven approach } \\
\text { focused on a cycle of } \\
\text { goal formulation, } \\
\text { implementation, } \\
\text { evaluation \& } \\
\text { modification of actions } \\
\text { or goals }\end{array}$ & $\begin{array}{l}\text { Poole \& Van de Veen } \\
(2010)\end{array}$ \\
\hline Processual DMP & $\begin{array}{l}\text { No assumptions about the } \\
\text { possible system structure are } \\
\text { made, observed processes \& } \\
\text { relationships are relevant }\end{array}$ & $\begin{array}{l}\text { All information for } \\
\text { DMP assumed to be } \\
\text { available, } \\
\text { stepwise approach, } \\
\text { worldview dictates } \\
\text { observed process \& } \\
\text { relationships }\end{array}$ & $\begin{array}{l}\text { Daellenbach \& } \\
\text { McNickle (2005) }\end{array}$ \\
\hline $\begin{array}{l}\text { Bounded Rational } \\
\text { DMP }\end{array}$ & $\begin{array}{l}\text { Activities of searching \& } \\
\text { satisfying, political view as } \\
\text { personal bargaining process, } \\
\text { values differ between the } \\
\text { involved people }\end{array}$ & $\begin{array}{l}\text { Perceptions of the DM } \\
\text { are part of the DMP, } \\
\text { they differ between the } \\
\text { involved people } \& \text { are } \\
\text { not unique }\end{array}$ & Turpin \& Marais (2004) \\
\hline $\begin{array}{l}\text { Bounded Rational } \\
\text { DMP }\end{array}$ & $\begin{array}{l}\text { DM is not aware of problems } \\
\text { or is limited in time to } \\
\text { search, DMP based on } \\
\text { intuition, experience \& other } \\
\text { thoughts }\end{array}$ & $\begin{array}{l}\text { Not all information is } \\
\text { available to take a } \\
\text { decision, perceptions of } \\
\text { the DM are part of the } \\
\text { DMP }\end{array}$ & Lunenburg (2010) \\
\hline $\begin{array}{l}\text { Bounded Rational } \\
\text { DMP }\end{array}$ & $\begin{array}{l}\text { Bounding through political } \\
\text { conflicts of DM }\end{array}$ & $\begin{array}{l}\text { Decisions differ } \\
\text { between the involved } \\
\text { people \& are not unique }\end{array}$ & Wilson (2004) \\
\hline $\begin{array}{l}\text { Bounded Rational } \\
\text { DMP }\end{array}$ & $\begin{array}{l}\text { Informed DM requires \& } \\
\text { includes experience \& } \\
\text { education \& other personal } \\
\text { insights }\end{array}$ & $\begin{array}{l}\text { Not all information is } \\
\text { available to take a } \\
\text { decision, perceptions of } \\
\text { the DM are part of the } \\
\text { DMP }\end{array}$ & Bennet \& Bennet (2008) \\
\hline $\begin{array}{l}\text { Bounded Rational } \\
\text { DMP }\end{array}$ & $\begin{array}{l}\text { Evaluation for DMP takes } \\
\text { place through different } \\
\text { processes with cognitive \& } \\
\text { motivational processes }\end{array}$ & $\begin{array}{l}\text { Not all information is } \\
\text { available to take a } \\
\text { decision, perceptions of } \\
\text { the DM are part of the } \\
\text { DMP }\end{array}$ & Mark \& Henry (2004) \\
\hline $\begin{array}{l}\text { Bounded Rational } \\
\text { DMP }\end{array}$ & $\begin{array}{l}\text { Boundaries are failures of } \\
\text { knowing all alternatives \& } \\
\text { uncertainty about events }\end{array}$ & $\begin{array}{l}\text { Consequences cannot be } \\
\text { calculated }\end{array}$ & Simon (1978) \\
\hline
\end{tabular}




\begin{tabular}{|c|c|c|c|}
\hline $\begin{array}{l}\text { Bounded Rational } \\
\text { DMP }\end{array}$ & $\begin{array}{l}\text { Focus on three levels as } \\
\text { evaluation influence on the } \\
\text { DMP }\end{array}$ & $\begin{array}{l}\text { Individual attitudes, } \\
\text { interpersonal behaviours } \\
\& \text { collective action are } \\
\text { important for decision } \\
\text { outcome }\end{array}$ & Christie (2007) \\
\hline $\begin{array}{l}\text { Bounded Rational } \\
\text { DMP }\end{array}$ & $\begin{array}{l}\text { Rational \& bounded rational } \\
\text { choices in context with } \\
\text { organisational aspects seen } \\
\text { as 'critical system thinking' }\end{array}$ & $\begin{array}{l}\text { Human beings interpret } \\
\text { a real world through } \\
\text { their perceptions, } \\
\text { associated boundary } \\
\text { choices involve } \\
\text { subjectivity }\end{array}$ & $\begin{array}{l}\text { Daellenbach \& } \\
\text { McNickle (2005) }\end{array}$ \\
\hline $\begin{array}{l}\text { Bounded Rational } \\
\text { DMP - Garbage } \\
\text { Can }\end{array}$ & $\begin{array}{l}\text { DMP is based on random } \\
\text { confluence }\end{array}$ & $\begin{array}{l}\text { People engaged in an } \\
\text { organisational context } \\
\text { gain knowledge by } \\
\text { learning of trial \& error, } \\
\text { without a clear } \\
\text { understanding of } \\
\text { underlying causes as not } \\
\text { all information is } \\
\text { available }\end{array}$ & $\begin{array}{l}\text { Eisenhardt \& Zbaracki } \\
\text { (1992) }\end{array}$ \\
\hline $\begin{array}{l}\text { Bounded Rational } \\
\text { DMP - Garbage } \\
\text { Can }\end{array}$ & $\begin{array}{l}\text { Participation \& preferences } \\
\text { are uncertain \& changing }\end{array}$ & $\begin{array}{l}\text { Decision-making occurs } \\
\text { in case of an arising } \\
\text { problem \& the decision- } \\
\text { maker come together in } \\
\text { a choice opportunity, } \\
\text { not all information is } \\
\text { available }\end{array}$ & $\begin{array}{l}\text { Rainey, Ronquillo \& } \\
\text { Avellaneda (2010) }\end{array}$ \\
\hline $\begin{array}{l}\text { Bounded Rational } \\
\text { DMP - Garbage } \\
\text { Can }\end{array}$ & $\begin{array}{l}\text { DM has no standard program } \\
\text { of action, preferences by DM } \\
\text { are sometimes impossible to } \\
\text { impress, DMP takes place in } \\
\text { organised hierarchy }\end{array}$ & $\begin{array}{l}\text { Not all information is } \\
\text { available to take a } \\
\text { decision, perceptions of } \\
\text { the DM are part of the } \\
\text { DMP }\end{array}$ & $\begin{array}{l}\text { Cohen, March \& Olsen } \\
\text { (1972) }\end{array}$ \\
\hline $\begin{array}{l}\text { Action \& } \\
\text { Behaviour }\end{array}$ & $\begin{array}{l}\text { Three related approaches } \\
\text { stand for action based DMP: } \\
\text { doing first, seeing first \& } \\
\text { thinking first }\end{array}$ & $\begin{array}{l}\text { DMP depends on the } \\
\text { way how to approach, } \\
\text { in opposition to rational } \\
\text { DMP }\end{array}$ & $\begin{array}{l}\text { Mintzberg \& Westley } \\
\text { (2010) }\end{array}$ \\
\hline $\begin{array}{l}\text { Action \& } \\
\text { Behaviour - } \\
\text { Heideggerian } \\
\text { Approach }\end{array}$ & $\begin{array}{l}\text { Approach to deep structuring } \\
\text { of reality under } \\
\text { consideration of practical } \\
\text { consciousness and the } \\
\text { conscious process of making } \\
\text { commitments to action }\end{array}$ & $\begin{array}{l}\text { Problems emerge when } \\
\text { the world appears to the } \\
\text { actor in his type of } \\
\text { rationality \& knowledge } \\
\& \text { his appearance of } \\
\text { consciousness, } \\
\text { decisions are not always } \\
\text { calculative or abductive } \\
\text { but spontaneous }\end{array}$ & Tsoukas (2010) \\
\hline $\begin{array}{l}\text { Action \& } \\
\text { Behaviour }\end{array}$ & $\begin{array}{l}\text { Behaviour is contextualised } \\
\text { to evaluate influence on } \\
\text { outcomes }\end{array}$ & $\begin{array}{l}\text { Changes in action are } \\
\text { behavioural processes } \\
\text { with long-term } \\
\text { outcomes of interest }\end{array}$ & Mark \& Henry (2004) \\
\hline $\begin{array}{l}\text { Action \& } \\
\text { Behaviour }\end{array}$ & $\begin{array}{l}\text { Behaviour as doing related } \\
\text { in organisations by means of } \\
\text { observations }\end{array}$ & $\begin{array}{l}\text { Decision-making } \\
\text { behaviour is related to } \\
\text { rational processes which } \\
\text { may follow routines }\end{array}$ & March (1991) \\
\hline $\begin{array}{l}\text { Action \& } \\
\text { Behaviour }\end{array}$ & $\begin{array}{l}\text { Decisions are derived from } \\
\text { behaviour and perceived } \\
\text { social norms }\end{array}$ & $\begin{array}{l}\text { DMP of DM depends } \\
\text { on personal views \& } \\
\text { associated norms }\end{array}$ & Ajzen (1991) \\
\hline $\begin{array}{l}\text { Action \& } \\
\text { Behaviour }\end{array}$ & $\begin{array}{l}\text { Behaviour is driven by } \\
\text { individual, collective \& } \\
\text { material context to the DM }\end{array}$ & $\begin{array}{l}\text { DM depends on } \\
\text { personal views of DM } \\
\& \text { history in obtaining } \\
\text { perception of } \\
\text { knowledge }\end{array}$ & $\begin{array}{l}\text { Department of Energy } \\
\text { \& Climate Change } \\
(2012)\end{array}$ \\
\hline
\end{tabular}




\begin{tabular}{|c|c|c|c|}
\hline $\begin{array}{l}\text { Action \& } \\
\text { Behaviour }\end{array}$ & $\begin{array}{l}\text { Norms are maintenance by } \\
\text { unwanted emotions (guilt, } \\
\text { embarrassment, shame) an } \\
\text { individual feels when he/she } \\
\text { is not complying with them }\end{array}$ & $\begin{array}{l}\text { Observing others can } \\
\text { affect individuals' } \\
\text { action by influencing } \\
\text { their behaviour in a } \\
\text { given situation due to } \\
\text { their perception }\end{array}$ & Rosenkranz et. al (2013) \\
\hline $\begin{array}{l}\text { Action \& } \\
\text { Behaviour }\end{array}$ & $\begin{array}{l}\text { Heuristics are as a set of } \\
\text { heuristics to guide decisions }\end{array}$ & $\begin{array}{l}\text { Heuristics help simplify } \\
\text { complex decision- } \\
\text { making situations }\end{array}$ & Lunenberg (2010) \\
\hline $\begin{array}{l}\text { Action \& } \\
\text { Behaviour }\end{array}$ & $\begin{array}{l}\text { Heuristic models describe } \\
\text { the actual process of } \\
\text { decision-making and specify } \\
\text { a process rule }\end{array}$ & $\begin{array}{l}\text { DM do not know the } \\
\text { optimal solution to } \\
\text { problems but can use } \\
\text { heuristics to find a good } \\
\text { enough solution }\end{array}$ & $\begin{array}{l}\text { Beresford \& Sloper } \\
\text { (2008) }\end{array}$ \\
\hline $\begin{array}{l}\text { Action \& } \\
\text { Behaviour }\end{array}$ & $\begin{array}{l}\text { Political behaviour is related } \\
\text { to different power \& } \\
\text { conflicts of interests of DM }\end{array}$ & $\begin{array}{l}\text { Conflicts minimise by } \\
\text { shared visions between } \\
\text { stakeholders }\end{array}$ & Mori (2010) \\
\hline $\begin{array}{l}\text { Action \& } \\
\text { Behaviour }\end{array}$ & $\begin{array}{l}\text { Political behaviour is action } \\
\text { to serve own interest of DM, } \\
\text { conflicts to other } \\
\text { stakeholders are possible, } \\
\text { transparency helps for good } \\
\text { performance }\end{array}$ & $\begin{array}{l}\text { DM may be influenced } \\
\text { by others, transparency } \\
\text { is an essential } \\
\text { requirement for good } \\
\text { corporate governance }\end{array}$ & $\begin{array}{l}\text { Child, Elbanna \& } \\
\text { Rodrigues (2010) }\end{array}$ \\
\hline $\begin{array}{l}\text { Action \& } \\
\text { Behaviour }\end{array}$ & $\begin{array}{l}\text { Differences exist between } \\
\text { bounded rational and } \\
\text { political decision-making } \\
\text { models, bounded related } \\
\text { models are a reaction to } \\
\text { cognitive assumptions about } \\
\text { individuals, political models } \\
\text { are expressed as reaction to } \\
\text { groups and their social } \\
\text { assumptions, they are } \\
\text { individually rational, but not } \\
\text { collectively so }\end{array}$ & $\begin{array}{l}\text { Conflicts may arise } \\
\text { between coalitions with } \\
\text { people and competing } \\
\text { interests }\end{array}$ & $\begin{array}{l}\text { Eisenhardt \& Zbaracki } \\
\text { (1992) }\end{array}$ \\
\hline $\begin{array}{l}\text { Action \& } \\
\text { Behaviour }\end{array}$ & $\begin{array}{l}\text { Politics is seen in an } \\
\text { organisational context with } \\
\text { different tasks, authorities } \\
\text { and power to groups or } \\
\text { interests which }\end{array}$ & $\begin{array}{l}\text { Members of the } \\
\text { organisation do not } \\
\text { always share the same } \\
\text { goals, they may lead to } \\
\text { conflicts and contention }\end{array}$ & Miller (2010) \\
\hline Intuition & $\begin{array}{l}\text { Intuition are strategic } \\
\text { decisions based on deep \& } \\
\text { intimate knowledge of the } \\
\text { situation }\end{array}$ & $\begin{array}{l}\text { Personal judgment, gut } \\
\text { feeling \& past } \\
\text { experience are criteria }\end{array}$ & Mori (2010) \\
\hline Intuition & $\begin{array}{l}\text { Intuition is assumption } \\
\text { related to different } \\
\text { perspectives of DM with } \\
\text { incremental adaptations }\end{array}$ & $\begin{array}{l}\text { Assumption for } \\
\text { decisions emerge from a } \\
\text { process in which } \\
\text { decisions are based on } \\
\text { different perspectives of } \\
\text { DM at that particular } \\
\text { time }\end{array}$ & $\begin{array}{l}\text { Eisenhardt \& Zbaracki } \\
\text { (1992) }\end{array}$ \\
\hline Intuition & $\begin{array}{l}\text { Reliance is seen as indicator } \\
\text { for intuition, related to } \\
\text { experience \& judgment \& } \\
\text { strong feelings about } \\
\text { decision }\end{array}$ & $\begin{array}{l}\text { DMP socially } \\
\text { constructed, rational and } \\
\text { bounded rational } \\
\text { process }\end{array}$ & Khatri \& Ng (2000) \\
\hline
\end{tabular}




\begin{tabular}{|c|c|c|c|}
\hline Intuition & $\begin{array}{l}\text { Sense-making of DM is } \\
\text { development of plausible } \\
\text { images, action is then an } \\
\text { ongoing process }\end{array}$ & $\begin{array}{l}\text { Decision outcome } \\
\text { between actors \& their } \\
\text { environment is } \\
\text { meaningful \& } \\
\text { preserved, settling for } \\
\text { plausibility }\end{array}$ & $\begin{array}{l}\text { Weick, Sutcliffe \& } \\
\text { Obstfield (2005) }\end{array}$ \\
\hline Intuition & $\begin{array}{l}\text { Sense-making of DM is } \\
\text { social process and linked to } \\
\text { experience }\end{array}$ & $\begin{array}{l}\text { DMP is socially } \\
\text { constructed \& not } \\
\text { rational }\end{array}$ & Wright (2004) \\
\hline $\begin{array}{l}\text { Stakeholder } \\
\text { context }\end{array}$ & $\begin{array}{l}\text { Stakeholder is group or } \\
\text { individual in an } \\
\text { organisational context }\end{array}$ & $\begin{array}{l}\text { DM interacts with } \\
\text { others }\end{array}$ & Freeman (1984) \\
\hline $\begin{array}{l}\text { Stakeholder } \\
\text { context }\end{array}$ & $\begin{array}{l}\text { Stakeholders are human } \\
\text { beings from different } \\
\text { background, such as } \\
\text { institutions or neighbours }\end{array}$ & $\begin{array}{l}\text { Consciousness and } \\
\text { wilful exercise may or } \\
\text { may not be present }\end{array}$ & $\begin{array}{l}\text { Mitchell, Agle \& Wood } \\
\text { (1997) }\end{array}$ \\
\hline $\begin{array}{l}\text { Stakeholder } \\
\text { context }\end{array}$ & $\begin{array}{l}\text { Stakeholders defined in an } \\
\text { abstract context as } \\
\text { components in systems, } \\
\text { boundaries separate system } \\
\text { \& environment }\end{array}$ & $\begin{array}{l}\text { Complex relationships } \\
\text { may cause conflicts, due } \\
\text { to the people involved, } \\
\text { their world views \& } \\
\text { personal character }\end{array}$ & $\begin{array}{l}\text { Daellenbach \& } \\
\text { McNickle (2005) }\end{array}$ \\
\hline Stakeholder roles & $\begin{array}{l}\text { Decisions classified as } \\
\text { (1) right-based decisions } \\
\text { (2) value-based decisions } \\
\text { (3) interest-based decisions } \\
\text { (4) power-based decisions }\end{array}$ & $\begin{array}{l}\text { Transparency in } \\
\text { stakeholder processes } \\
\text { ensures openness \& } \\
\text { accountability of all } \\
\text { participants }\end{array}$ & Yosie \& Herbst (1998) \\
\hline Stakeholder roles & $\begin{array}{l}\text { Classified are: } \\
\text { (1) problem owners } \\
\text { (2) problem user } \\
\text { (3) problem customers } \\
\text { (4) problem analysts }\end{array}$ & $\begin{array}{l}\text { Stakeholders addressed } \\
\text { to active or passive } \\
\text { roles in their } \\
\text { relationships }\end{array}$ & $\begin{array}{l}\text { Daellenbach \& } \\
\text { McNickle (2005) }\end{array}$ \\
\hline Stakeholder roles & $\begin{array}{l}\text { Different influences to be } \\
\text { used for the assessment \& } \\
\text { management as drivers \& } \\
\text { pressures, related to positive } \\
\text { and negative effects }\end{array}$ & $\begin{array}{l}\text { Bidirectional } \\
\text { relationships are } \\
\text { important to exchange } \\
\text { understandable } \\
\text { information }\end{array}$ & $\begin{array}{l}\text { Castellani, Piazzalungs } \\
\& \text { Sala (2013) }\end{array}$ \\
\hline Stakeholder roles & $\begin{array}{l}\text { Classified are in an } \\
\text { organizational context: } \\
\text { (1) sensors } \\
\text { (2) processors } \\
\text { (3) DM } \\
\text { (4) satisfiers }\end{array}$ & $\begin{array}{l}\text { Influences in social } \\
\text { networks, enterprises, } \\
\text { communities and task } \\
\text { forces in a DMP }\end{array}$ & $\begin{array}{l}\text { Gachet \& Brézillon } \\
\text { (2002) }\end{array}$ \\
\hline Stakeholder roles & $\begin{array}{l}\text { Related to power-interest } \\
\text { grids: } \\
\text { (1) players } \\
\text { (2) subjects (little power) } \\
\text { (3) context (high power but } \\
\text { little interests) } \\
\text { (4) crowd (rather potential } \\
\text { stakeholders) }\end{array}$ & $\begin{array}{l}\text { Some stakeholders are } \\
\text { more or less powerful } \\
\text { than originally } \\
\text { supposed, discovering } \\
\text { the networks can often } \\
\text { reveal new stakeholders }\end{array}$ & $\begin{array}{l}\text { Ackermann \& Eden } \\
\text { (2011) }\end{array}$ \\
\hline Stakeholder roles & $\begin{array}{l}\text { Identified are weak \& strong } \\
\text { supporters as well as weak \& } \\
\text { strong opponents }\end{array}$ & $\begin{array}{l}\text { 'Problem-frame } \\
\text { stakeholder map' may } \\
\text { find winning coalitions }\end{array}$ & Bryson (2004) \\
\hline
\end{tabular}




\begin{tabular}{|c|c|c|c|}
\hline $\begin{array}{l}\text { Decision-making } \\
\text { cycle }\end{array}$ & $\begin{array}{l}\text { 'Doing right things' is the } \\
\text { enhanced consideration of } \\
\text { achieving goals compared to } \\
\text { 'doing things right', system } \\
\text { context required instead of } \\
\text { reduced cause-and-effect } \\
\text { thinking }\end{array}$ & $\begin{array}{l}\text { Situations have to be } \\
\text { seen through other } \\
\text { people's eyes as } \\
\text { observers, people } \\
\text { viewing the same } \\
\text { situation with the same } \\
\text { purpose in mind may } \\
\text { form different } \\
\text { conceptualisations }\end{array}$ & $\begin{array}{l}\text { Daellenbach \& } \\
\text { McNickle (2005) }\end{array}$ \\
\hline $\begin{array}{l}\text { Decision-making } \\
\text { cycle }\end{array}$ & $\begin{array}{l}\text { DMPs differ between } \\
\text { relationships, with occurred } \\
\text { influences among its people, } \\
\text { they represent stable or quasi } \\
\text { stable patters, like culture, } \\
\text { trust and attitudes. Butterfly } \\
\text { effects may have huge } \\
\text { disruptions, feedback loops } \\
\text { can reinforce, damp or } \\
\text { improve the situation }\end{array}$ & $\begin{array}{l}\text { DM must rely on their } \\
\text { intuition and judgment }\end{array}$ & Bennet \& Bennet (2008) \\
\hline $\begin{array}{l}\text { Decision-making } \\
\text { cycle }\end{array}$ & $\begin{array}{l}\text { Dynamic factors influence } \\
\text { DMP, like interrupts, delays } \\
\text { \& feedback loops }\end{array}$ & $\begin{array}{l}\text { DM affect the time to } \\
\text { decision depending on } \\
\text { their decision-making } \\
\text { approach }\end{array}$ & $\begin{array}{l}\text { Mintzberg, Raisinghani } \\
\text { \& Theoret (1976) }\end{array}$ \\
\hline $\begin{array}{l}\text { Decision-making } \\
\text { cycle }\end{array}$ & $\begin{array}{l}\text { DMPs differ between single- } \\
\text { loop learning and double- } \\
\text { loop learning processes, } \\
\text { double-loop learning re- } \\
\text { evaluates the governing } \\
\text { mechanisms, the process } \\
\text { then often leads to new } \\
\text { decision strategies }\end{array}$ & $\begin{array}{l}\text { DMPs are interaction } \\
\text { based on cause-effect } \\
\text { chain to learn from } \\
\text { experience of the } \\
\text { engaged participants, } \\
\text { the process often leads } \\
\text { to new decision } \\
\text { strategies }\end{array}$ & Tucker et al. (2005) \\
\hline
\end{tabular}

Table 2: Literature review: decision-making models and influencing factors (own study) 


\section{APPENDIX II}

\begin{tabular}{|c|c|c|}
\hline Heating technology & Advantage & Disadvantage \\
\hline $\begin{array}{l}\text { Solar heat } \\
\text { Systems consists of solar collectors to collect } \\
\text { heat on the roof, a solar station and a } \\
\text { regulation unit with a water puffer storage. } \\
\text { Systems are available for warm water heating } \\
\text { and optional heating system support }\end{array}$ & $\begin{array}{l}\text { Usage during summer } \\
\text { season without additional } \\
\text { heating boiler and further } \\
\text { primary energy }\end{array}$ & $\begin{array}{l}\text { Usage during wintertime } \\
\text { limited due to poor } \\
\text { availability of solar energy }\end{array}$ \\
\hline $\begin{array}{l}\text { Bio mass } \\
\text { Systems are available with pellet ovens, split } \\
\text { log ovens, woodchip ovens and wood gasifier } \\
\text { technology. Wood pellets, split logs and wood } \\
\text { chips have to be stored }\end{array}$ & $\begin{array}{l}\text { System can work } \\
\text { permanently throughout } \\
\text { the year }\end{array}$ & $\begin{array}{l}\text { High investment compared } \\
\text { to classical oil boilers, } \\
\text { necessary storage place }\end{array}$ \\
\hline $\begin{array}{l}\text { Thermal heating pump } \\
\text { Circulation pumps driven with electricity. } \\
\text { Differences are made between thermal } \\
\text { heating pumps, which use ground water to } \\
\text { increase temperature of air, thermal heating } \\
\text { pumps, which fall back on ambient air, and } \\
\text { systems working with ground collectors, } \\
\text { which are installed in the ground and absorb } \\
\text { the heat by means of a thermal fluid } \\
\text { Characteristics of these systems are that they } \\
\text { remove natural heat from the air, water or soil } \\
\text { to use for heating. In simplified terms, in most } \\
\text { cases the temperature is increased by means } \\
\text { of a compressor powered with electricity, and } \\
\text { is then fed into the heating system } \\
\text { Heating pumps operate with electrical power. } \\
\text { However, in combination with photovoltaic } \\
\text { panel systems mounted on the roof, they can } \\
\text { generate heat using renewable energy; } \\
\text { nowadays also referred to as power-to-heat }\end{array}$ & $\begin{array}{l}\text { Low operating cost } \\
\text { compared to oil or gas } \\
\text { burners in case of } \\
\text { optimised integration }\end{array}$ & $\begin{array}{l}\text { High investment compared } \\
\text { to oil and gas boilers, } \\
\text { especially due to hole } \\
\text { drilling for water reliant } \\
\text { systems. As they commonly } \\
\text { work with low temperature, } \\
\text { they are rather less suitable } \\
\text { in their economic } \\
\text { application for old houses } \\
\text { with bad insulation }\end{array}$ \\
\hline $\begin{array}{l}\text { Micro CHP } \\
\text { Plant to generate heat and electricity } \\
\text { (combined heat and power). Waste heat of the } \\
\text { motor is used for room and water heating. } \\
\text { Electricity can be used for own consumption } \\
\text { or fed into the public network. It can be } \\
\text { applied with combustion engines, gas motors } \\
\text { or fuel cells. With respect to renewable } \\
\text { energy requirements, they can be operated } \\
\text { with biomass (e.g. bio diesel) or biogas }\end{array}$ & $\begin{array}{l}\text { Usage of electricity and } \\
\text { heat }\end{array}$ & $\begin{array}{l}\text { Limited efficiency in case of } \\
\text { inconstant and poor energy } \\
\text { consumption. Therefore, } \\
\text { they are more suitable for } \\
\text { multi-family houses }\end{array}$ \\
\hline
\end{tabular}

Table 9: Overview of renewable heating technologies

Source: The author, based on BMWI (2016/2), AEE (2015), BMVBS (2013) and expert interview data 


\section{Questionnaire for semi-structured interviews with end users as decision-makers} (homeowners) for the purchase of renewable heating technologies

\section{[Attunement to the topic and the interview:]}

I am interested in getting more information on the topic of renewable energy in combination with heating technologies. I am looking to converse with owners of detached or semi-detached houses who decide what kind of heating technologies to use. It is important for me to learn more about the decision-making process: to what extent do homeowners of older houses with oil, gas or coal heating decide to adopt renewable technologies or have already decided to do so?

Please consider the interview as an open guided interview where you give a comprehensive statement on this topic. Therefore, the questions are only a guideline. For the purposes of the interview, behavioural aspects should be interpreted as ethical principles I have explained to you before the interview.

\section{[Introducing questions:]}

Please describe, in general, which designing or rebuilding measurements have played a part in your house in recent years?

Can you please tell me something about your thoughts and attitudes when you hear about renewable heating technologies, also compared to classical distribution concepts with oil, gas or coal?

\section{[Motivation for the purchase of renewable heating technologies:]}

How far has your opinion been focused or changed within recent years with respect to renewable technologies?

How far has an investment or decision on renewable heating technologies taken place?

What is the reason for your decision?

In case an adaption has taken place or has been decided: is the motivation for the decision the replacement of non-renewable technology or the necessary replacement of the technology in use so far?

What kind of heating technology is in use or has been in use so far?

To what extent do long-term aspects affect the consideration of a certain technology in case of interest?

To what extent have your decisions been influenced by others, your own experience, or your own personal attitudes? 


\section{[Choice of alternatives:]}

Have you considered any renewable heating technologies?

If yes, why have you chosen that technology?

If not, which aspects may influence your decision?

Which information do you require and which one do you prefer not to consider in your decision-making?

Are there any routines or criteria you follow or do you take your decision spontaneously?

To what extent is the improvement of the house insulation part of your investment and which level of priority does this have in comparison to new heating technologies?

\section{[Evaluation of the technical solution:]}

Which renewable heating technologies do you know and what meaning do you ascribe to them?

So far, have you been reminded of any personal positive or negative experiences in relation to this topic?

To what extent do you feel comfortable with the volume of information and the remaining time you had or you have to adopt a new heating concept?

Is there a limit for you with respect to investment amount and yearly running cost? Which components are included in your consideration?

How far can you imagine covering $100 \%$ of your heating consumption with exclusively renewable heating technologies?

Which institutions, individuals or groups are involved and how do you see their role in pushing or blocking the decision-making process?

Are there any key issues with respect to this topic, which you remember?

Which topics do you regard as important and which ones are less important?

How far has your opinion changed on decisions you have taken in the past?

\section{[Action for technical solution:]}

Which technology do you favour in case of a decision? 
Are there aspects, which have accelerated, interrupted or postponed your decision process?

In your opinion, which aspects only take time but do not have any influence on the adoption?

Is there a certain sequence regarding your decision-making - how you proceed and the extent to which you are usually satisfied with the grade of information?

In your opinion, how could the adoption of renewable heating technologies in domestic households be influenced in a positive way and what blocks the adoption?

Are there any emotional aspects you relate to this topic?

\section{[Personal characteristics:]}

Do you prefer to follow spontaneous, structured or cognitive influences, like consultancy, when making your decision?

How would you describe your personal character and behaviour with respect to your decision-making process?

Is your position more eco-passive or eco-driven in relation to renewable technologies?

Are your decisions mainly figure-orientated or are there other factors or attitudes on which you base your decision?

What is your professional background?

May I ask you for your age?

Finally, are there any comments from your side on the topic of renewable energy?

Figure 3: Questionnaire for semi-structured interviews (final version after 2 pre-tests) 


\section{APPENDIX IV}

\section{Interviewees - end users}

\begin{tabular}{|c|c|c|c|c|c|c|c|c|c|c|c|}
\hline \multirow[t]{3}{*}{ No. } & \multirow[t]{3}{*}{ Initials } & \multirow[t]{3}{*}{ Age } & \multirow[t]{3}{*}{ Profession } & \multicolumn{8}{|c|}{ Heating system in use } \\
\hline & & & & \multicolumn{6}{|c|}{ Renewable } & \multicolumn{2}{|c|}{$\begin{array}{c}\text { Non- } \\
\text { renewable }\end{array}$} \\
\hline & & & & THP & PV & PS & SH & SLO & $\mathrm{GC}$ & GB & $\mathrm{OB}$ \\
\hline 1 & R.Z. & 40 & Businessman & $\bullet$ & $\bullet$ & & & & & & - \\
\hline 2 & T.A. & 59 & Engineer & & & - & - & & & & \\
\hline 3 & $\begin{array}{l}\text { E.S. \& } \\
\text { W.S. }\end{array}$ & $\begin{array}{l}76 / \\
77 \\
\end{array}$ & $\begin{array}{l}\text { Teachers (married } \\
\text { couple, retired) }\end{array}$ & & & & - & & & - & \\
\hline 4 & M.R. & 46 & Business woman & & & & & - & & & - \\
\hline 5 & M.L. & 61 & Energy Consulter & - & - & & & & & & - \\
\hline 6 & D.V. & 36 & Technician & & & & & $\bullet$ & & & $\bullet$ \\
\hline 7 & C.W. & 41 & $\begin{array}{l}\text { Assurancy } \\
\text { Consulter }\end{array}$ & & & & & & & & • \\
\hline 8 & $\begin{array}{l}\text { C.L. \& } \\
\text { E.L. }\end{array}$ & $\begin{array}{l}53 / \\
61\end{array}$ & $\begin{array}{l}\text { Civil servants in } \\
\text { an administrative } \\
\text { district (married } \\
\text { couple) }\end{array}$ & & & & & & & & - \\
\hline 9 & K.V. & 74 & Engineer (retired) & - & & & & & - & & \\
\hline 10 & R.B. & 60 & $\begin{array}{l}\text { Employee in a } \\
\text { municipality }\end{array}$ & & & & & - & & - & \\
\hline 11 & G.G. & 52 & Entrepreneur & & & & $\bullet$ & & & & $\bullet$ \\
\hline 12 & A.H. & 63 & Engineer (retired) & & & & & - & & - & \\
\hline $\begin{array}{l}\text { THP: } \\
\text { PV: }\end{array}$ & $\begin{array}{l}\text { ermal heati } \\
\text { tovoltaics }\end{array}$ & Imp & $\begin{array}{l}\text { PS: Pellet syst } \\
\text { SH: Solar heat }\end{array}$ & & & $\begin{array}{l}\mathrm{O}: \mathrm{Sp} \\
\mathrm{Gro}\end{array}$ & $\begin{array}{l}\log o \\
d \text { coll }\end{array}$ & & & $\begin{array}{l}\text { Gas } \\
\text { Oil b }\end{array}$ & $\begin{array}{l}\text { iler } \\
\text { ler }\end{array}$ \\
\hline
\end{tabular}

Interviewees - experts

\begin{tabular}{|l|l|l|}
\hline No. & Initials & Profession \\
\hline 1 & T.R. & Heating plant installer \\
\hline 2 & K.M. & Managing Director of an industrial energy network society \\
\hline 3 & R.D. & Sales Agent for thermal pumps \\
\hline 4 & A.C. & Trainer of a manufacturer for fuel cells \\
\hline 5 & S.F. & Sales Director of a public service \\
\hline 6 & M.A. & Energy Consultant in an administrative district \\
\hline
\end{tabular}

Figure 4: List of interviewees 


\section{CONFIDENTIALITY UNDERTAKING \\ VERTRAULICHKEITSERKLÄRUNG}

Reference: Doctoral research with involvement of end users as house owners of detached or semi-detached houses.

Bezug: Promotionserstellung unter Einbindung von Endkunden als Hausbesitzer von Ein- oder Zweifamilienhäusern.

Title of work: Decision-making process for the adoption of renewable heating technologies: a consumer perspective.

Thema der Arbeit: Entscheidungsprozesse zur Übernahme erneuerbarer Heizungstechnologien: eine Verbraucherperspektive.

Registered at The University of Gloucestershire in accordance with the requirements of the degree of Doctor of Business Administration in the Faculty of Business, Computing and Applied Sciences.

Angemeldet an der Universität von Gloucestershire in Übereinstimmung mit dem Grad eines ,Doctor of Business Administration“ in der Fakultät für „Business, Computing and Applied Sciences “.

The aim of the study is to investigate the decision-making process of end consumers by means of semi-structured interviews. The expected duration will be 1 to $1 \frac{1 / 2}{2}$ hours. The promise of anonymity and confidentiality is guaranteed.

Das Ziel der Studie ist die Untersuchung von Entscheidungsprozessen von Endkunden im Rahmen sogenannter halb-strukturierter Interviews. Die erwartete Dauer liegt bei 1 bis 1 1/2 Stunden. Die Zusage zur anonymisierten und vertraulichen Behandlung wird garantiert.

A general introduction on the research topic and the research procedure will be given at the beginning of the interview. If interviewees wish to speak on related issues, they will have the freedom to do so. In that sense, the semi-structured questionnaire will not be restrictive. 
Eine generelle Einführung in das Forschungsthema und den Forschungsablauf wird zu Beginn des Interviews gegeben. Sofern die Interviewpartner zu ähnlichen Themen sprechen möchten, wird ihnen die Möglichkeit dazu gegeben.

Audio and written recording is important for the documentation of the coding process (structure of topics). Interviewees will be able to refuse participation or switch off the tape recorder at any time. Confidentiality will be guaranteed through anonymised citing. Die Aufnahme und schriftliche Dokumentation der Daten ist von Bedeutung für den Kodierprozess (Strukturierung der Themenkomplexe). Interviewpartner haben die Möglichkeit, die Teilnahme abzusagen oder das Aufnahmegerät zu jeder Zeit auszuschalten. Die Vertraulichkeit wird durch die Wiedergabe anonymisierter Daten sichergestellt.

Participation in the research is voluntary and the interviewee can withdraw at any time from the research process. No indiscreet questions will be asked. Names of interviewees will not be published and only citied as initials.

Die Teilnahme an der Untersuchung ist freiwillig und der Interviewpartner kann sich zu jeder Zeit von der Teilnahme zurückziehen. Namen von Interviewpartnern werden nicht publiziert und nur durch die Namensinitialen zitiert.

The interviewee will be informed that he can get full information about the research goals and the research path and that he has the option to get feedback on the research results after the termination of the research study.

Der Interviewpartner wird darüber informiert, dass er alle Informationen über die Forschungsziele und Forschungsschritte erhalten kann und er die Option hat, eine Rückmeldung über die Forschungsergebnisse nach Abschluss der Studie zu erhalten.

Mario Reichler

Address, telephone number and email redacted.

Figure 5: Confidentiality agreement for structured interviews 


\section{REFERENCES}

Ackermann, F. \& Eden, C. (2011). Strategic Management of Stakeholders: Theory and Practice. Long Range Planning, Volume 44, pp. 179 - 196.

AEE, Agentur für Erneuerbare Energien (2015). Renews Kompakt. Ausgabe 28: https://www.unendlich-viel-energie.de/media/file/420.Warum_sich_Heizen_mit_ Bioenergie_lohnt_Dez15.pdf, accessed on 20 September, 2016.

AEE, Agentur für Erneuerbare Energien (2016/1). Renews Kompakt. Ausgabe 35: https://www.unendlich-viel-energie.de/media/file/521.AEE_RK_Heizkosten_ senken_mit_Erneuerbaren_Dez16.pdf, accessed on 12 March, 2017.

AEE, Agentur für Erneuerbare Energien (2016/2). Metaanalyse 2016. Instrumente und Maßnahmen für die Wärmewende: http://www.forschungsradar.de/fileadmin/content/ bilder/Vergleichsgrafiken/meta_waermeinstrumente_2016/AEE_Metaanalyse_Waermein strumente_okt16.pdf, accessed on 5 November, 2016.

AEE, Agentur für Erneuerbare Energien (2017). Metaanalyse Juli 2017. Zusammenspiel von Strom- und Wärmesystem: http://www.forschungsradar.de/fileadmin/content/ bilder/Vergleichsgrafiken/Metaanalyse_Strom-Waerme/AEE_Metaanalyse_Strom_ Waerme_Langfassung_jul17.pdf, accessed on 20 May, 2018.

AEE, Agentur für Erneuerbare Energien (2019). Renews Spezial Nr. 86: Verknüpfung von Strom, Wärme und Verkehr im Energiesystem der Zukunft - Die Rolle der Bioenergie in den Sektoren: https://www.unendlich-viel-energie.de/media/file/3081. AEE_86_Renews_Spezial_Sektorenkopplung_Jan19-web.pdf, accessed on 28 April, 2019.

Agora Energiewende (2019). European Energy Transition 2030: The Big Picture: https://www.agora-energiewende.de/fileadmin2/Projekte/2019/EU_Big_Picture/153_EUBig-Pic_WEB.pdf, accessed on 28 April, 2019.

Ajzen, I. (1991). The Theory of Planned Behavior. Organizational Behavior and Human Decision Processes, Volume 50, pp. 179-211.

Al-Tarawneh, H. A. (2012). The Main Factors beyond Decision-making. Journal of Management Research. Volume 4, Number 1. 
Anderson, B. F. (2002). The Three Secrets of Wise Decision-making. Single Reef Press: Portland, Oregon.

Armstrong, M. \& Ryan, V. (2009). Development of Renewables Framework for Decision-making. Beacon Pathway Limited and Foundation for Research, Science and Technology, New Zealand: http://www.beaconpathway.co.nz/images/uploads/Final _Report_EN6590(3)_Development_of_Renewables_Framework.pdf, accessed on 18 September, 2016.

Bennet, A. \& Bennet, D. (2008). The Decision-making Process for Complex Situations in a Complex Environment, First chapter in Burstein, F. and Holsapple, C. W. (eds). Handbook on Decision Support Systems, New York: Springer-Verlag.

Beresford, B. \& Sloper, T. (2008). Understanding the Dynamics of Decision-Making and Choice: A Scoping Study of Key Psychological Theories to Inform The Design and Analysis of the Panel Study. The University of York: http://www.york.ac.uk/inst/ spru/pubs/pdf/decisionmaking.pdf, accessed on 1 June, 2015.

Bernard, L. C., Mills, M., Swenson, L. \& Walsh, R. P. (2006). An Evolutionary Theory of Human Motivation. Genetic, Social and General Psychology Monographs, 131 (2), pp. 129-184.

Bigby, C. \& Douglas, J. (2015). Support for Decision Making - A Practice Framework: http://arrow.latrobe.edu.au/store/4/1/8/4/9/public/BIGBY_a_Practice_Framework_2016. pdf, accessed on 13 September, 2018.

Bitsch, V. (2005). Qualitative Research: A Grounded Theory Example and Evaluation Criteria. Journal of Agribusiness, 23, 1, pp. 75-91.

BMVBS (2011). Strategische Einbindung Regenerativer Energien in Regionale Energiekonzepte. BMVBS-Online-Publikation Nr. 23/2011: http://www.bbsr.bund.de/ BBSR/DE/Veroeffentlichungen/BMVBS/Online/2011/DL_ON232011.pdf?_blob=publi cationFile\&v=2, accessed on 27 May, 2015.

BMVBS (2013). Maßnahmen zur Umsetzung der Ziele des Energiekonzepts im Gebäudebereich - Zielerreichungsszenario: http://www.bbsr.bund.de/BBSR/DE/ Veroeffentlichungen/BMVBS/Online/2013/DL_ON032013.pdf?_blob=publication File \&v=5, accessed on 3 February, 2015. 
BMWI (2018). Erneuerbare Energien in Zahlen - Nationale und internationale Entwicklung im Jahr 2017: https://www.bmwi.de/Redaktion/DE/Publikationen/ Energie/ erneuerbare-energien-in-zahlen-2017.pdf?_blob=publicationFile\&v=27.

BMWI (2017). Renewable Energy Sources in Figures - National and International Development, 2016: https://www.bmwi.de/Redaktion/EN/Publikationen/renewableenergy-sources-in-figures-2016.pdf?_blob=publicationFile\&v=5, accessed on 11 May, 2018.

BMWI (2016/1). Entwicklung der erneuerbaren Energien in Deutschland im Jahr 2015: http://www.erneuerbare-energien.de/EE/Redaktion/DE/Downloads/entwicklung_der_ erneuerbaren_energien_in_deutschland_im_jahr_2015.pdf?_blob=publicationFile $\& v=13$, accessed on 19 September, 2016.

BMWI (2016/2). Zweiter Erfahrungsbericht zum Erneuerbare-Energien-Wärmegesetz: https://www.bmwi.de/BMWi/Redaktion/PDF/Publikationen/zweiter-erfahrungsberichterneuerbare-energien-waermegesetz,property=pdf,bereich=bmwi2012, sprache=de,rwb $=$ true.pdf, accessed on September 20, 2016.

Breuer, F. (2010). Reflexive Grounded Theory. Wiesbaden: VS Verlag für Sozialwissenschaften.

Brohmann, B., Heinzle, S., Nentwich, J., Offenberger, U., Rennings, K., Schleich, J., Wüstenhagen, R. (2009). Sustainable energy consumption and individual decisions of consumers - review of the literature and research needs. Working Paper No. 1 within the project: Soziale, ökologische und ökonomische Dimensionen eines nachhaltigen Energiekonsums in Wohngebäuden: file://C:/Users/mreichler/AppData/Local/ Microsoft/Windows/Temporary\%20Internet\%20Files/Content.IE5/W8PAO0CQ/00b495 28f06256abdc000000.pdf, accessed on 25 May 2015.

Brundtland, G. H. (1987). Our Common Future. Report of the World Commission on Environment and Development: our common future. Expert Group on Environmental Law: http://www.un-documents.net/our-common-future.pdf, accessed on 25 May 2015.

Bryson, J. M. (2004). What to do when stakeholders matter. Public Management Review, Volume 6, Issue 1, pp. $21-53$. 
BSR (2016). The Future of Stakeholder Engagement - Transformative Engagement for Inclusive Business: https://www.bsr.org/reports/BSR_Future_of_Stakeholder_ Engagement_Report.pdf, assessed on 13 September, 2018.

Burrel, G. ; Morgan, G. (1979). Sociological Paradigms and Organisational Analysis Elements of the Sociology of Corporate Life. New Hampshire: Heinemann Educational Books.

Castellani, V., Piazzalunga, A. \& Sala, S. (2013). Research findings and decisionmaking: the case of renewable energy. Environmental Sciences Europe, 25:22: http://www.enveurope.com/content/pdf/2190-4715-25-22.pdf, accessed on 1 June 2015.

Charmaz, K. (2006). Constructing Grounded Theory - A Practical Guide Through Qualitative Analysis. London: Sage Publications.

Child, J., Elbanna, S. \& Rodrigues, S. (2010). The Political Aspects of Strategic Decision-making. Handbook of Decision-making, West Sussex: John Wiley \& Sons, pp. 105-137.

Christie, C. A. (2007). Reported Influence of Evaluation Data on Decision-makers's Actions - An Empirical Examination. American Journal of Evaluation, Volume 28 No.1, pp. $8-25$.

Cohen, M.D., March, J.P. \& Olsen, J.P. (1972). A garbage can model of organizational choice. Administrative Science Quarterly, 17, pp. 1-25.

Daellenbach, H.G. \& McNickle, D.C. (2005). Management science - Decision-making through systems thinking. New York: Palgrave MacMillan.

Daymon, C. \& Holloway, I. (2011). Qualitative Research Methods in Public Relations and Marketing Communications. Abingdon: Taylor \& Francis Group.

Denzin, K. N.; Lincoln, Y. S. (2003). Handbook of Qualitative Research. Handbook of Qualitative Research. Thousand Oaks, London and New Delhi: Sage Publications.

Department of Energy \& Climate Change (2012). What are the Factors influencing Energy Behaviours and Decision-making in the Non-Domestic Sector? Centre for Sustainable Energy (CSE) and the Environmental Change Institute, University of Oxford, URN 12D/426. 
Easterby-Smith, M.; Thorpe, R. \& Jackson, P. (2012). Management Research, $4^{\text {th }}$ edition, London: Sage Publications.

Edelmann, W. (2003). Intrinsische und extrinsische Motivation. Grundschule. Issue 4/2003. Braunschweig: Bildungshaus Schulbuchverlage Westermann Schroedel Diesterweg Schöningh Winklers.

Eisenhardt, K., \& Zbaracki, M.J. (1992). Strategic Decision-making. Strategic Management Journal, Volume 13, pp. 17-37.

Elbanna, S. (2011). Multi-Theoretic Perspectives of Strategy Processes: http://www.academia.edu/994007/Elbanna_S._2011._Multi-theoretic_perspectives_of_ strategy_processes_UAEU-FBE-Working_Paper_Series_Number_2011-09, accessed on 7 February 2015.

Erasmus, A. C., Boshoff, E. \& Rousseau, G. G. (2001). Consumer decision-making models within the discipline of consumer science: a critical approach. Journal of Family Ecology and Consumer Sciences, Vol 29.

Finlay, L. (2008). Reflecting on 'Reflective practice'. Practice-based Professional Learning Centre (PBPL), The Open University, paper 52: http://www.open.ac.uk/ opencetl/files/opencetl/file/ecms/web-content/Finlay-(2008)-Reflecting-on-reflectivepractice-PBPL-paper-52.pdf, accessed on 2 June 2015.

Franz, L. S. \& Kramer, M. W. (2010), The Dimensions of Decisions: A Conceptual and Empirical Investigation. Handbook of Decision-making, West Sussex: John Wiley \& Sons, pp. $517-540$.

Freeman, R. E. (1984). Strategic management: A stakeholder approach. Boston: Pitman.

Freeman, R. E. (1994). The Stakeholder Approach Revisited. Journal for Business, St. Gallen: Economics \& Ethics (Zeitschrift für Wirtschafts- und Unternehmensethik, zfwu), 2004.

Gachet, A. \& Brézillon P. (2002). Organizational Structures and Decision-making Processes: A Multi-Level Model: http://www-desir.lip6.fr/publications/pub_344_1_ JDS_Gachet_BrezillonVF.pdf, accessed on 1 September 2014. 
Gentles, S. J., Charles, C., Ploeg, J. \& McKibbon, K. A. (2015). Sampling in Qualitative Research: Insights from an Overview of the Methods Literature: http://www.miguelangelmartinez.net/IMG/pdf/2015_Gentles_Sampling_Qualitative_Res earch_TQR.pdf, accessed on May 11, 2018.

Glaser, B. \& Strauss, S. (1978). Theoretical Sensitivity. Mill Valley, California: Sociological Press.

Glaser, B. G. (1992). Basics of Grounded Theory Analysis: Emergence vs Forcing. Mill Valley, California: Sociological Press.

Glaser, B. G. \& Strauss, A. L. (1965). Discovery of Substantive Theory: A Basic Strategy Underlying Qualitative Research. The American Behavioral Scientist, Volume 8, Number 6, February 1986.

Glaser, B. \& Strauss, S. (1967). The Discovery of Grounded Theory: strategies for qualitative research. New Brunswick: Aldine Transaction.

Glyn, E., Durand, M. A., Song, J., Aarts, J., Barr, P. J., Berger, Z., Cochran, N., Frosch, G., Galasinski, D., Gulbrandsen, P., Han, P. K. J., Härter, M., Kinnersley, P., Lloyd, A., Mishra, M., Perestelo-Perez, L., Scholl, I., Tomori, K., Trevena, L., Wittemann, H. O., \& Weyden, T. V. D (2017). A three-talk model for shared decision making: multistage consulting process: https://www.bmj.com/content/bmj/359/bmj.j4891.full.pdf, accessed on 13 September, 2018.

Government Office for Science (2015). Artificial intelligence: opportunities and implications for the future of decision making: https://assets.publishing.service. gov.uk/ government/uploads/system/uploads/attachment_data/file/566075/gs-16-19-artificialintelligence-ai-report.pdf, accessed on May 11, 2018.

Greener, S. (2008). Business Research Methods. bookboon.com: http://irfanlal. yolasite.com/resources/introduction-to-research-methods.pdf, accessed on 1 September, 2014.

Guba, E. G.; Lincoln, Y. S. (1994). Competing Paradigms in Qualitative Research. Handbook of qualitative research, pp. 105-117. Thousand Oaks, California: Sage Publications. 
Harrison, J. S., Freeman, R. E. \& Cavalcanti Sá de Abreu (2015). Stakeholder Theory As an Ethical Approach to Effective Management: applying the theory to multiple contexts: http://www.scielo.br/pdf/rbgn/v17n55/1806-4892-rbgn-17-55-00858.pdf, accessed on May 11, 2018.

Heath, H. \& Cowley, S. (2004). Developing a grounded theory approach: a comparison of Glaser and Strauss. International Journal of Nursing Studies, 2004, Volume 41, pp. 141-150.

Heckhausen, J. \& Heckhausen, H. (2010). Motivation und Handeln. Heidelberg: Springer.

Herr, K. \& Anderson, G. L. (2005). The Action Research Dissertation - A Guide for Students and Faculty. California: Sage Publications.

Jones, M. \& Alony, I. (2011). Guiding the Use of Grounded Theory in Doctoral Studies An Example from the Australian Film Industry. International Journal of Doctoral Studies, Volume 6: http://ijds.org/Volume6/IJDSv6p095-114Jones322.pdf, accessed on 1 September 2014.

Khatri, N. \& Ng, A.H. (2000). The role of intuition in strategic decision-making. Human Relations, Volume 53 (1), pp. 57-86. London: Sage Publications.

Koshy, V. (2005). Action Research for Improving Practice. London: Sage Publications.

Kuittinen, H. \& Velte, D. (2018). Case Study Report: Energiewende: http://jiip.eu/Case\%20studies\%20on\%20Mission\%20Orientation\%20-\%20

Energiewende.pdf, accessed on May 11, 2018.

Kura, S. Y. B. (2012). Qualitative and Quantitative Approaches to the Study of Poverty: Taming the Tensions and Appreciating the Complementarities. The Qualitative Report, Volume 17, Article 34, pp. 1 - 19.

Leech, B. L. (2002). Asking Questions: Techniques for Semistructured Interviews. Political Science and Politics, Volume 35, Number 4, pp. 665-668.

Locke, K. D. (2001)). Grounded Theory in Management Research. London: Sage Publications. 
Lousberg, L. \& Noorderhaven, N. (2014). Trust Transparency and PPP. Conference paper: $\quad$ https://www.researchgate.net/publication/272670212_Trust_Transparency_ and_PPP, accessed on 26 June 2017.

Lunenburg, F. C. (2010). The Decision-making Process. National Forum of Educational Administration and Supervision Journal, Volume 27, Number 4: http://www. nationalforum.com/Electronic\%20Journal\%20Volumes/Lunenburg,\%20Fred\%20C.\% 20The\%20Decision\%20Making\%20Process\%20NFEASJ\%20V27\%20N4\%202010.pdf, accessed on 1 September 2014.

Mantere, S., Schildt, H. A. \& Sillince, J. A. A. (2012). Reversal of Strategic Change. Academy of Management Journal, Volume 55, Number 1, pp. 172-196.

March, J. G. (1991). How decisions happen in organizations. Human-Computer Interaction. Volume 6, Lawrence Erlbaum Associates, pp. 95-117.

Mark, M.M. \& Henry, G.T. (2004). The Mechanisms and Outcomes of Evaluation Influence. Volume 10, Issue 1, pp. 35-57. London: Sage Publications.

McNiff, J. \& Whitehead, J. (2009). Doing and Writing Action Research. London: Sage Publications.

Miller, S. (2010), The Bradford Studies: Decision-making and Implementation Processes and Performance. Handbook of Decision-making, West Sussex: John Wiley \& Sons, pp. $433-448$.

Mintzberg, H. \& Westley, F. (2001). Decision-making: It's not what you think. Handbook of Decision-making (2010), West Sussex: John Wiley \& Sons, pp. 73-81.

Mintzberg, H., Raisinghani, D., \& Theoret, A. (1976). The structure of unstructured decisions. Administrative Science Quarterly, Volume 21 (2), pp. 246-275.

Mitchell, R.K., Agle, B.R. \& Wood, D.J. (1997). Toward a Theory of Stakeholder Identification and Salience: Defining the Principle of Who and What Really Counts. The Academy of Management Review, Volume 22, Number 4, pp. 853-886.

Moon, J. A. (2006), Learning Journals - A Handbook for Reflective Practice and Professional Development, $2^{\text {nd }}$ edition, London and New York: Routledge, Taylor \& Francis Group. 
Mori, N. (2010). Roles of Stakeholders in Strategic Decision-Making of Microfinance Organizations. International Business \& Economics Research Journal, Volume 9, Number 7.

Morris, T., Greenwood, R. \& Fairclough, S. (2010), Decision-making in Professional Service Firms. Handbook of Decision-making, West Sussex: John Wiley \& Sons, pp. $275-306$.

Müller-Hansen, F., Schlüter, M., Mäs, M., Donges, J. F., Kolb, J. J., Thonicke, K. \& Heitzig, J. (2017). Towards representing human behavior and decision making in Earth system models - an overview of techniques and approaches: https://www.earth-systdynam.net/8/977/2017/esd-8-977-2017.pdf, accessed on May 11, 2018.

Nikolova, V. \& Arsic, S. (2017): The Stakeholder Approach in Corporate Social Responsibility: http://menadzment.tfbor.bg.ac.rs/english/wp-content/uploads/sites/2/ 2017/02/3_1_24-35.pdf, accessed on 11May, 2018.

Nutt, P. C.\& Wilson, D. C. (2010). Crucial Trends and Issues in Strategic Decisionmaking. Handbook of Decision-making, West Sussex: John Wiley \& Sons, pp. 3 - 29.

Palanski, M., Kahai, S. \& Yammarino, F. J. (2016). Team Virtues and Performance: An Examination of Transparency, Behavioral Integrity, and Trust. Journal of Business Ethics, Volume 99 (2), pp. 201-216.

Papadakis, V., Thanos, I. \& Barweise, P. (2010). Research on Strategic Decisions: Taking Stock and Looking Ahead. Handbook of Decision-making, West Sussex: John Wiley \& Sons, pp. 31-69.

Patvardhan, S. D.; Gioia, D. A. \& Hamilton, A. L. (2015). Weathering a Metal-Level Identiy Crisis: Forging a Coherent Collective Identity for an Emerging Field. Academy of Management Journal, Volume 58, Number 2, pp. 405-435.

Pearce, D. W. \& Seccombe-Hett, T. (2000). Economic Valuation and Environmental Decision-Making in Europe: https://pubs.acs.org/doi/pdf/10.1021/es9906711, accessed on May 112018.

Poole, M. S. \& Van de Ven A. H. (2010). Empirical Methods for Research on Organizational Decision-making Processes. Handbook of Decision-making, West Sussex: John Wiley \& Sons, pp. 543-580. 
Rainey, H. G., Ronquillo, J. C. \& Avellaneda, C. N. (2010). Decision-making in Public Organizations. Handbook of Decision-making, West Sussex: John Wiley \& Sons, pp. $349-377$.

Reynolds, M. (1998). Reflection and Critical Reflection in Management Learning. Management Learning, Volume 29 (2), pp. 183-200.

Rosenkranz, S., Laan, van der, G., Donk, van der, J., Kesteren, van, E.-J., Spek, van der, H., Muehlfeld, K., Weitzel, U., Ivanova, H., Ottink, M. (2013). Sustainable DecisionMaking: Non-Monetary Incentives for Pro-Social Behavior in the Energy Sector. Tjalling C. Koopmans Research Institute, Discussion Paper Series Number: 13-16: http://dspace.library.uu.nl/bitstream/handle/1874/309762/13_16.pdf?sequence=1, accessed on September 20, 2015.

Rousseau, D. M., Sitkin, S. B., Burt, R. S. \& CAmerer, C. (1998). Not so different after all: a cross-discipline view of trust. Academy of Management Review, Volume 23, Number 3, pp. 393-404.

Simon, H. A. (1977). The new science of management decisions. $2^{\text {nd }}$ edition, Englewood Cliffs (NJ): Prentice Hall.

Simon, H. A. (1978). Rational decision-making in business organizations. Nobel Memorial Lecture, 8 December 1978: http://www.nobelprize.org/nobel_prizes/economicsciences/laureates/1978/simon-lecture.pdf, accessed on 16 August 2015.

Smith, N.-J. (2009). Achieving your Professional Doctorate. Berkshire: Open University Press.

Stewart, R., Dayal H. \& Langer, L. (2017). Terminology and tensions within evidenceinformed decision-making in South Africa over a 15-year period: http://docserver.ingentaconnect.com/deliver/connect/ioep/23998121/v1n2/s3.pdf?expires $=1526030223 \& \mathrm{id}=0000 \&$ titleid=72010652\& $\mathrm{checksum}=$ D9DA63EC968A2D64B36A33 B6668C658B, accessed on 11 May, 2018.

Strauss, A. L.; Corbin, J. M. (1998). Basics of Qualitative Research: Techniques and Procedures for Developing Grounded Theory. London: Sage Publications.

Strauss, A. L. (1987). Qualitative Analysis for Social Scientists. Cambridge: Cambridge University Press. 
Timonen, V., Foley, G. \& Conlon, C. (2018). Challenges When Using Grounded Theory: A Pragmatic Introduction to Doing GT Research: http://journals.sagepub.com/doi/pdf/ 10.1177/1609406918758086, accessed on 11 May, 2018.

Tsoukas, H. (2010). Strategic Decision-making and Knowledge: A Heideggerian Approach. Handbook of Decision-making, West Sussex: John Wiley \& Sons, pp. 379-402.

Tucker, J. S.; Cullen, J. C.; Sinclair, R. R.; Wakeland, W. W. (2005). Dynamic Systems and Organisational Decision-Making Processes in Nonprofits. The Journal of Applied Behavioural Science, Volume 41, Number 4, pp. 482-502.

Turpin, S.M. \& Marais, M.A. (2004). Decision-making: Theory and practice. Orion: South Africa, Volume 20 (2), pp. 143-160.

University of Gloucestershire (2008). Research Ethics: A Handbook of Principles and Procedures. Approved by University Research Degrees Committee: http://insight.glos. ac.uk/ResearchDevelopment/Documents/Research\%20Ethics\%20Handbook\%20final \%20Nov\%2010.pdf, accessed on 5 October 2014.

Wahyuni, D. (2012), The Research Design Maze: Understanding Paradigms, Cases, Methods and Methodologies, Journal of Applied Management Accounting Research, Volume 10, Number 1, pp. 69-80: http://dro.deakin.edu.au/eserv/DU:30057483/wahyuniresearchdesignmaze-2012.pdf, accessed on 11 April 2015.

Weick, K. E., Sutcliffe, K. M. \& Obstfeld, D. (2005). Organizing and the Process of Sensemaking. Handbook of Decision-making (2010), West Sussex: John Wiley \& Sons, pp. 83-104.

Wilson, D. C. (2004). The Bradford Studies: Issues Raised by These and Other Studies for the Understanding of Decision-making (2010). Handbook of Decision-making, West Sussex: John Wiley \& Sons, pp. 619 - 642.

Wright, A. (2004). Enhancing inductive strategizing through sensemaking and scenario thinking. Wolverhampton University Business School: http://www.wlv.ac.uk/media/wlv/ pdf/uwbs_04-WP002-04-Wright.pdf, accessed on 1 June 2015. 
Yin, R. K. (2012). Applications of Case Study Research. Thousand Oaks: Sage Publications.

Yosie, T. F. \& Herbst, T. D. (1998). Using Stakeholder Processes in Environmental Decision-making. An Evaluation of Lessons Learned, Key Issues, and Future Challenges. Washington: Rudder Finn: http://www.gdrc.org/decision/nr98ab01.pdf, accessed on 28 August 2016. 